\title{
Best Practices for Reducing the Potential for Progressive Collapse in Buildings
}

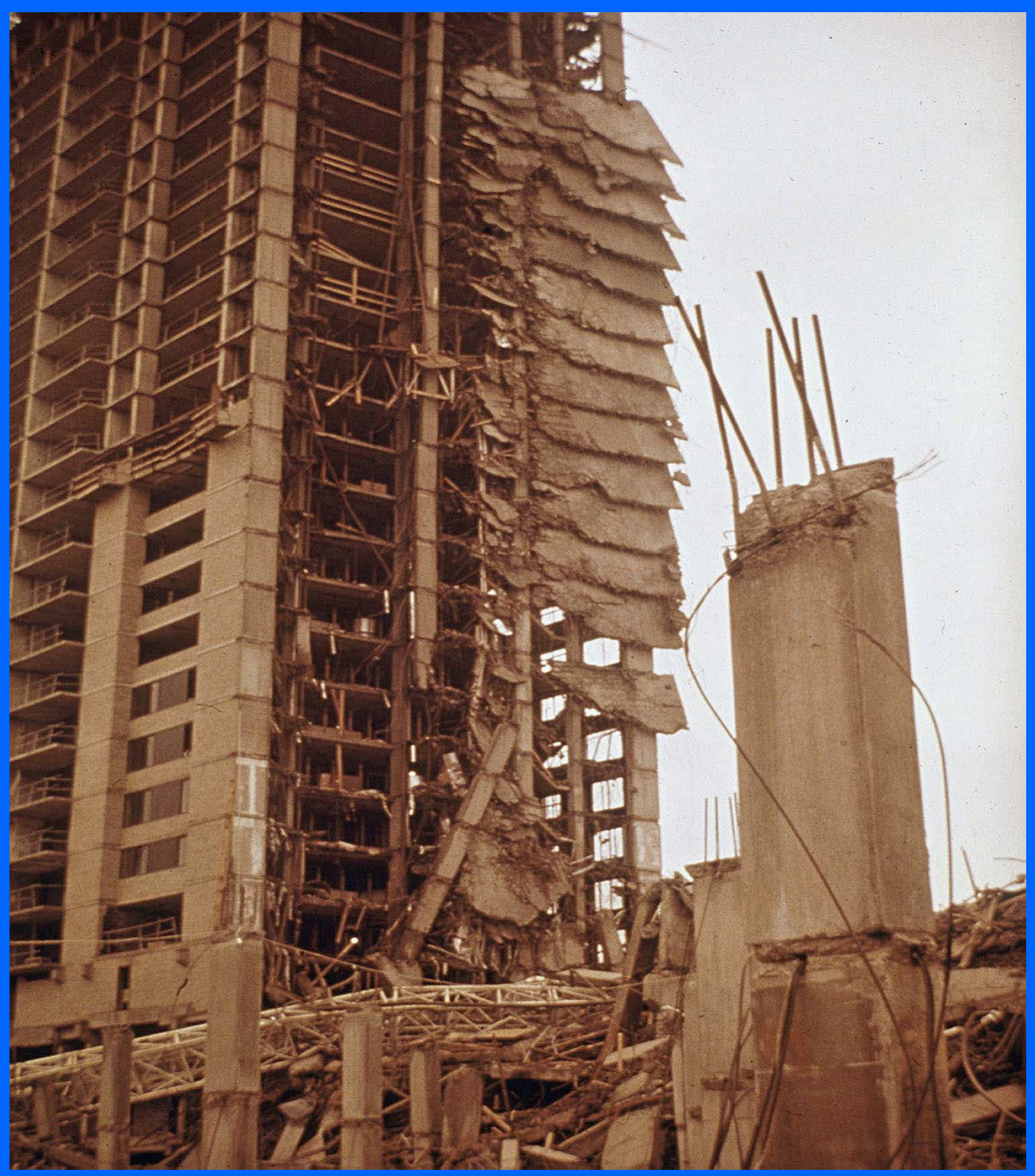





\section{Best Practices for Reducing the Potential for Progressive Collapse in Buildings}

Bruce R. Ellingwood

Georgia Institute of Technology

Robert Smilowitz

Weidlinger Associates

Donald O. Dusenberry

Simpson Gumpertz \& Heger

Dat Duthinh

H.S. Lew

National Institute of Standards and Technology

Building and Fire Research Laboratory

Nicholas J. Carino

Consultant

February 2007

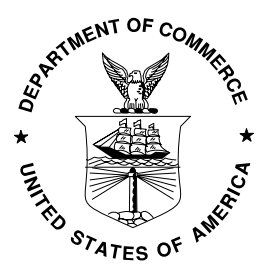

U.S. Department of Commerce

Carlos M. Gutierrez, Secretary

Technology Administration

Robert C. Cresanti, Under Secretary for Technology

National Institute of Standards and Technology

William A. Jeffrey, Director 



\section{ABSTRACT}

This document is intended to provide owners and practicing engineers with current "best practices" to reduce the likelihood of progressive collapse of buildings in the event of abnormal loading. The report includes a discussion of an acceptable risk approach to progressive collapse, which involves defining the threat, event control, and structural design to resist postulated event. Practical means for reducing risk for new and existing buildings are presented. An extensive review is provided of the design methods used to enhance a buildings resistance to progressive collapse. These include the indirect method (providing sufficient tie forces), the specific local resistance method (designing key elements to withstand abnormal loads), and the alternate load path method (allowing for redistribution of load in the event of the loss of a key member). Design considerations for different structural materials are summarized. The methodology for evaluating and mitigating progressive collapse potential in existing buildings is also discussed. Three appendices provide supporting information. Appendix A presents a worldwide review of progressive collapse provisions in various national design standards. Appendix B identifies knowledge gaps related to progressive collapse that require research. Appendix $\mathrm{C}$ provides case studies of progressive collapses. This document is not intended to provide step-by-step design guidance for practicing engineers; however, applicable design standards are referenced and summarized in Appendix A.

Keywords: alternate load path; blast loading; buildings; design standards; direct method; indirect method; progressive collapse; risk; specific local resistance. 
The policy of the National Institute of Standards and Technology is to use metric units in all its published materials. Because this report is intended for the U.S. building construction industry which uses inchpound units, it is more practical and less confusing to use inch-pound units rather than metric units within quoted text. 


\section{Preface}

This best practices document is prepared in response to one of the recommendations from the July 2002 industry workshop on prevention of progressive collapse, which was held in Chicago, Illinois. The preparation of this document was facilitated by the Multihazard Mitigation Council (MMC) of the National Institute of Building Sciences. The MMC contracted with the three principal authors to prepare an initial draft and organized a workshop in February 2004 to solicit public comments on the initial draft document.

The body of the document was prepared by three principal authors:

- Dr. Bruce R. Ellingwood (Georgia Institute of Technology),Chapter 2;

- Dr. Robert Smilowitz (Weidlinger Associates), Chapters 3, 4, and 5 and Appendix B.

- Mr. Donald O. Dusenberry (Simpson, Gumpertz \& Heger), Chapters 3, 4, and 5 and Appendix C.

Contributing authors to Chapters 3, 4, and 5 included Dr. Wilkins Aquino, Mr. John Dal Pino, and Mr.

James R. Cagely. Dr. Dat Duthinh of the National Institute of Standards and Technology (NIST)prepared Appendix A. Dr. H. S. Lew of NIST and Dr. Nicholas J. Carino of KT Consulting Inc. contributed to Chapters 1 and 6 and served as co-editors.

To aid the understanding and use of this best practices document and to provide an opportunity for technical exchange with the principal authors, NIST and the Structural Engineering Institute of the American Society of Civil Engineers organized jointly four workshops during September and October 2006. The workshops were held in Denver, New York City, San Francisco, and Chicago. In addition, the document was posted on the Web to solicit public comments. Comments received during and subsequent to the workshops have been incorporated into this final document. Individuals who submitted comments are acknowledged for their useful suggestions.

The Chicago workshop also identified a need for code provisions and design standards that will provide resistance to progressive collapse at reasonable additional design and construction costs. This need was reinforced by Recommendation 1 resulting from the NIST investigation of the collapse of the World Trade Center towers, which calls for development and adoption of code provisions and consensus standards to prevent progressive collapse in buildings. NIST is currently carrying out research in support of meeting this need.

Disclaimer: Certain trade names or company products are mentioned in the text to specify adequately certain products. In no case does identification imply recommendation or endorsement by the National Institute of Standards and Technology, nor does it imply the product is the best available for the purpose. 
This page intentionally left blank. 


\section{TABLE OF CONTENTS}

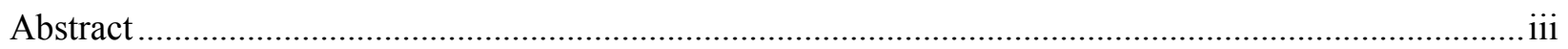

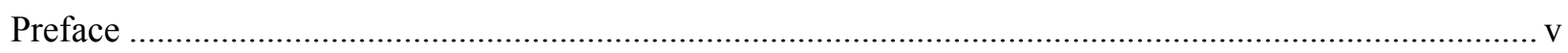

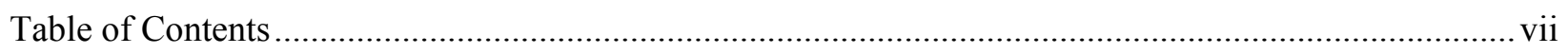

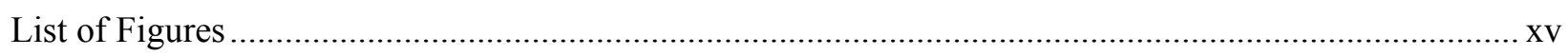

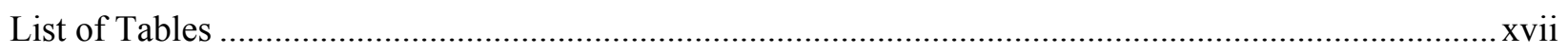

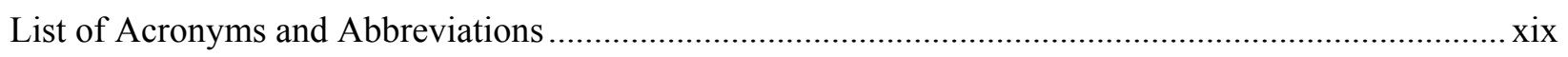

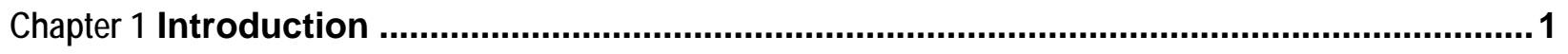

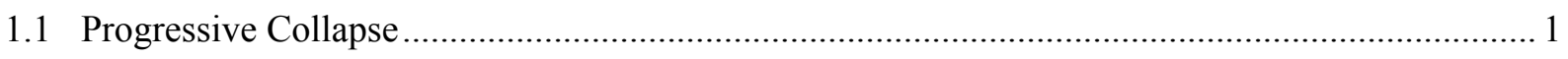

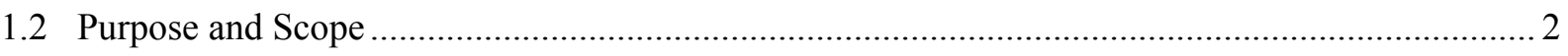

Chapter 2 Acceptable Risk Bases ................................................................................. 5

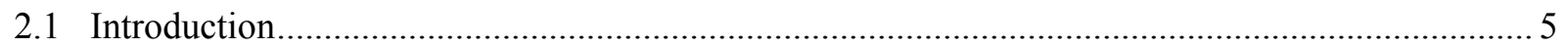

2.2 Fundamentals of Risk Assessment for Natural and Man-Made Hazards ...................................... 6

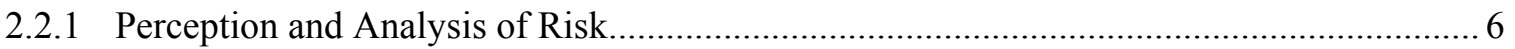

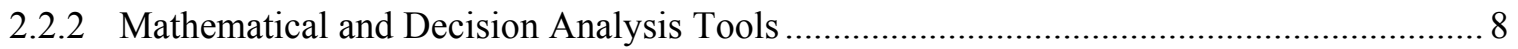

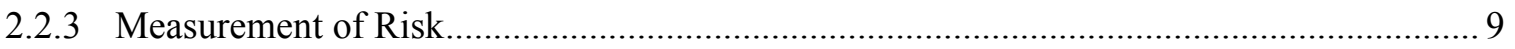

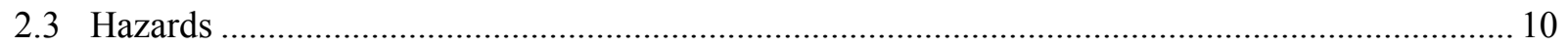

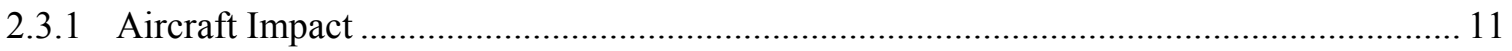

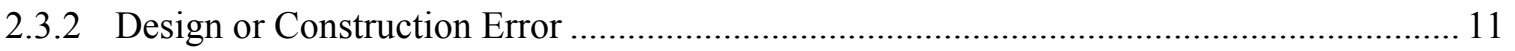

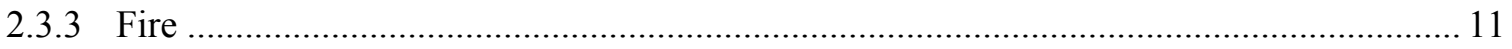

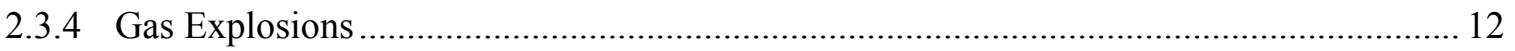

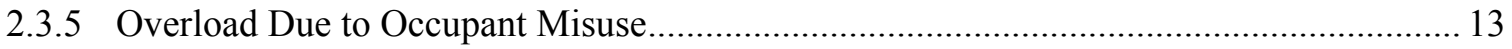

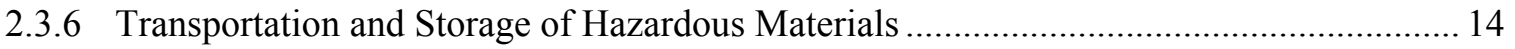

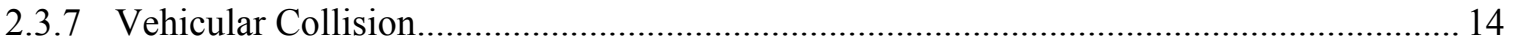

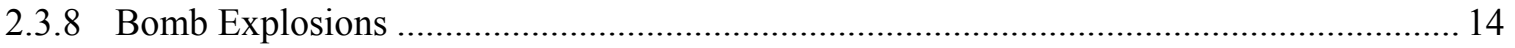

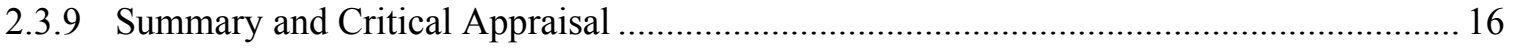

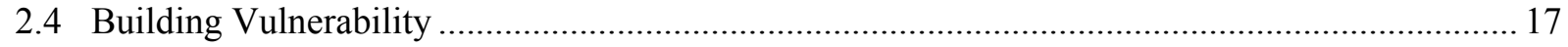

2.5 Design to Reduce Risk of Progressive Collapse …..................................................................... 18

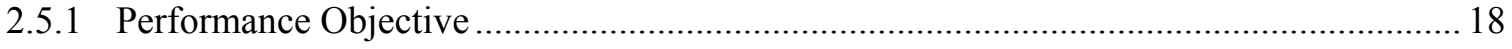

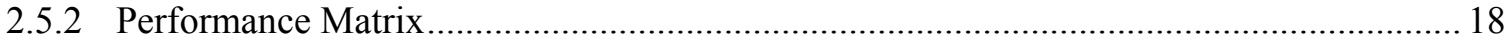

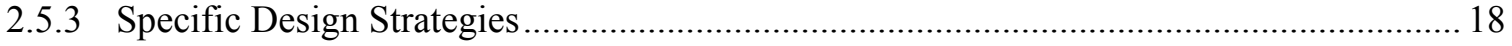




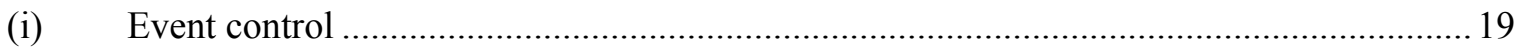

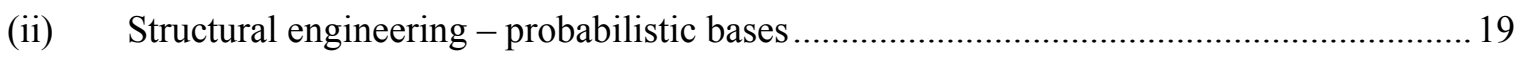

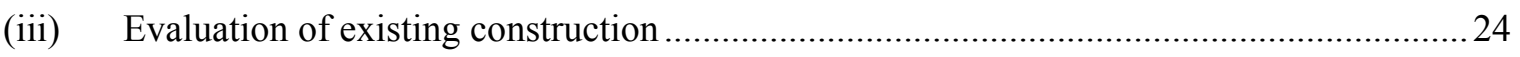

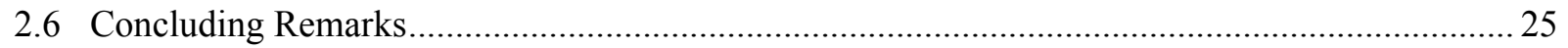

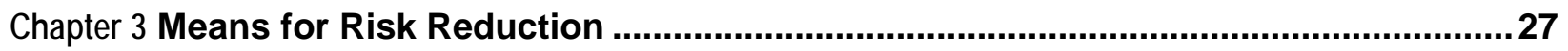

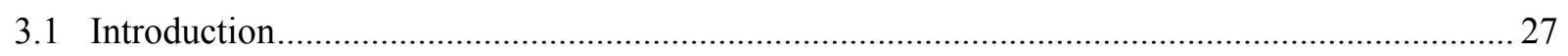

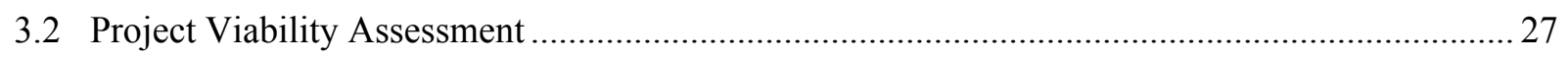

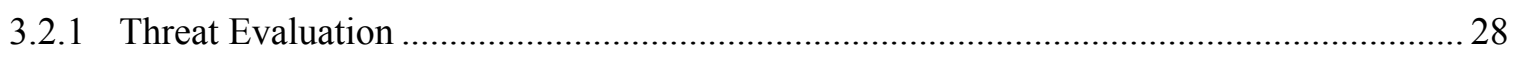

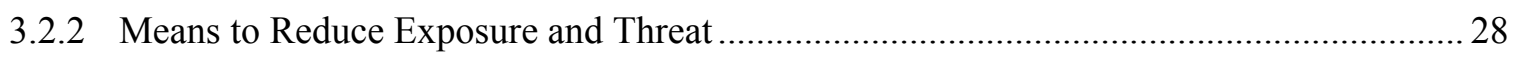

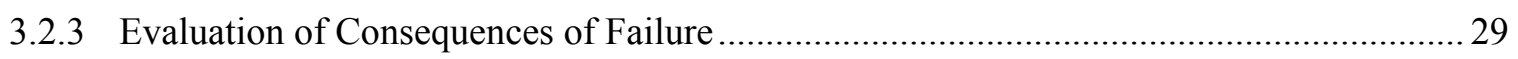

3.2.4 Evaluation of Alternative Means to Reduce Consequences .............................................. 29

3.2.5 Determination of Qualification of Structure for Upgrade Consideration........................... 30

3.3 Assessment of Potential For Progressive Collapse ................................................................... 30

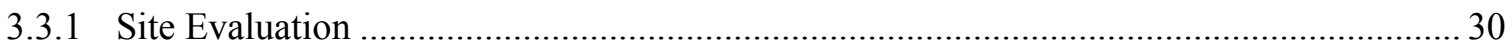

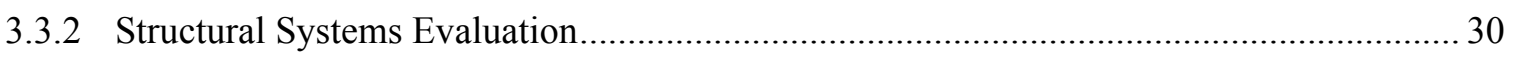

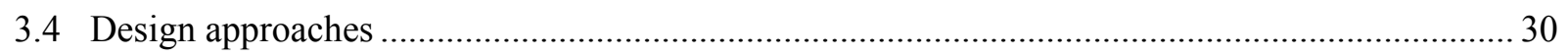

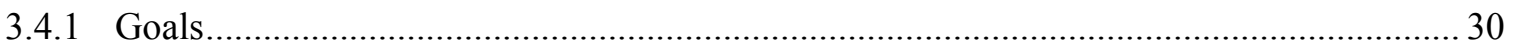

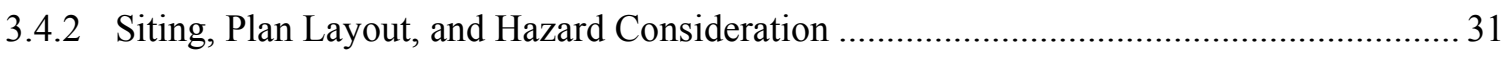

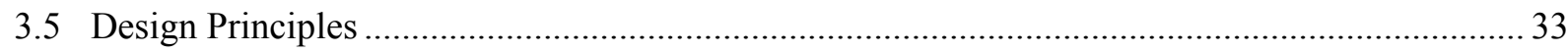

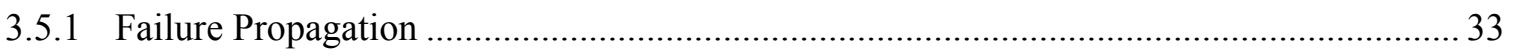

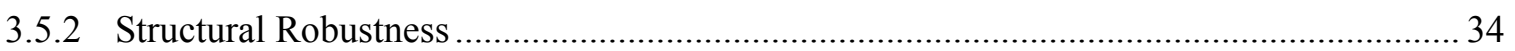

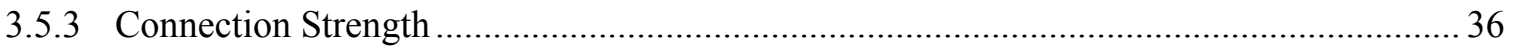

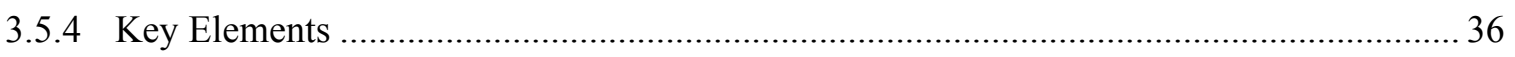

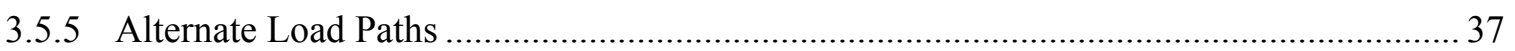

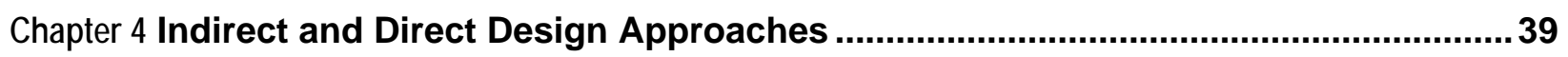

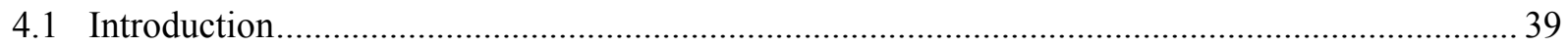

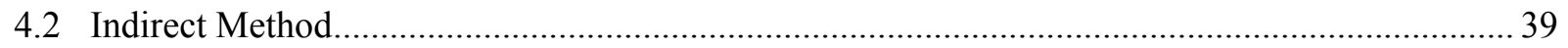

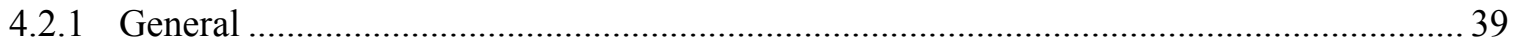

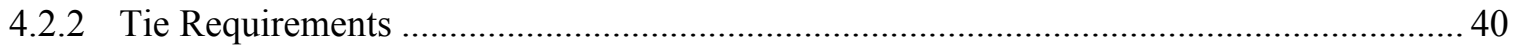

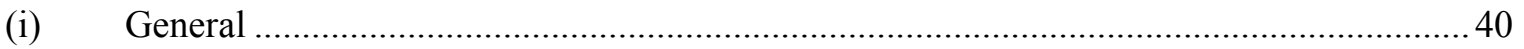

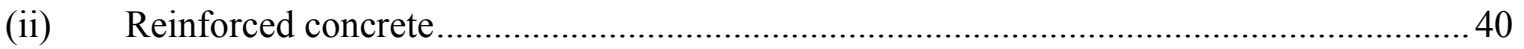

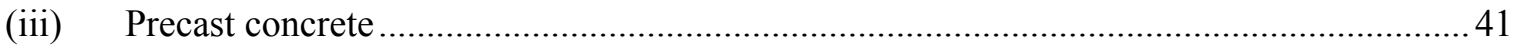

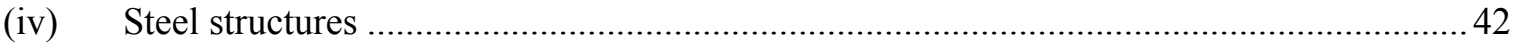




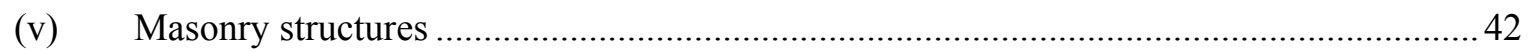

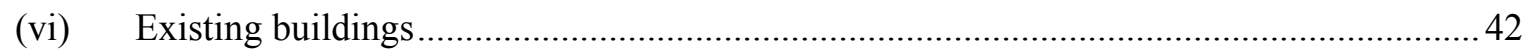

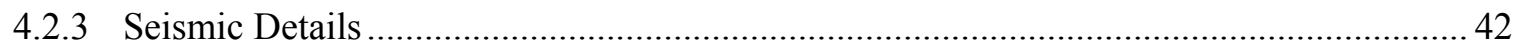

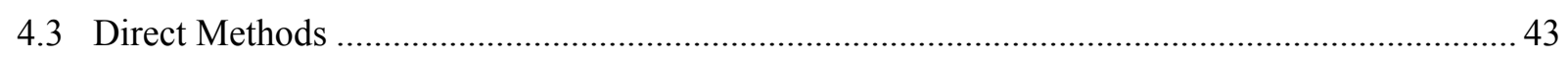

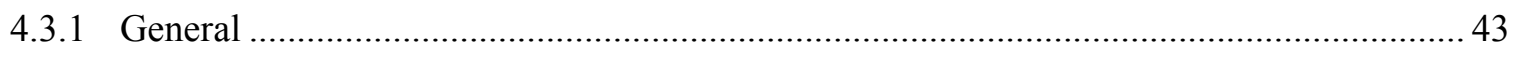

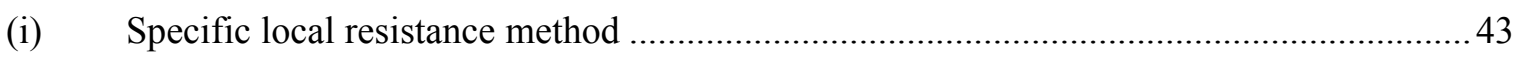

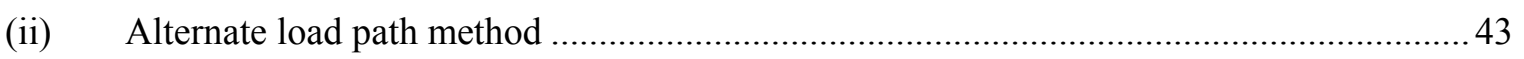

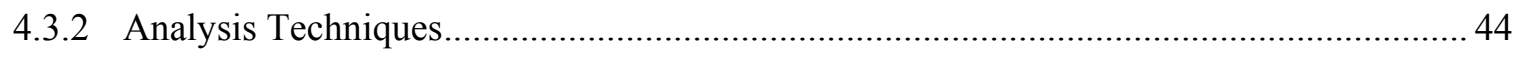

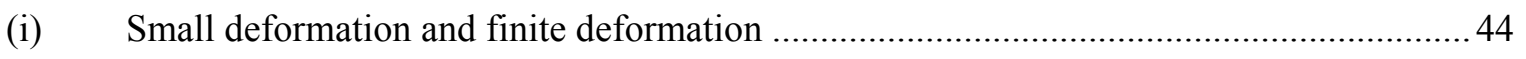

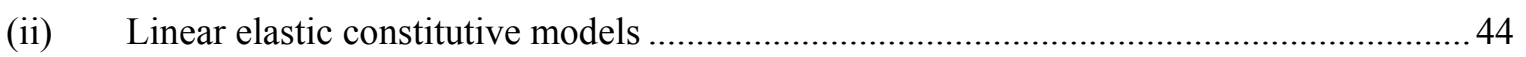

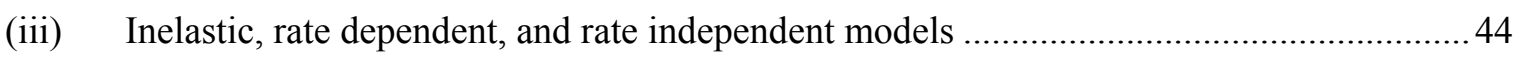

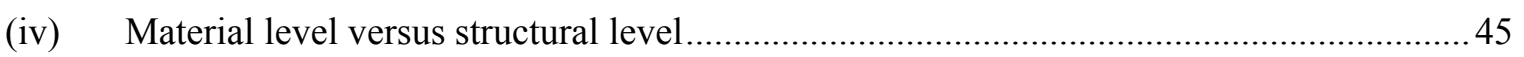

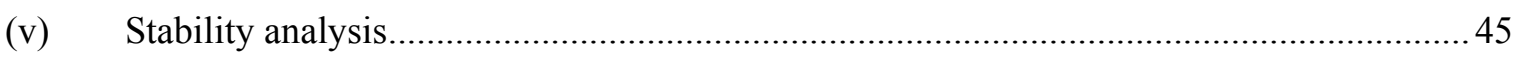

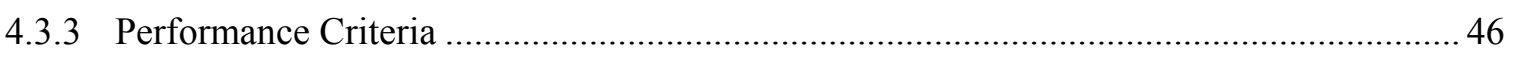

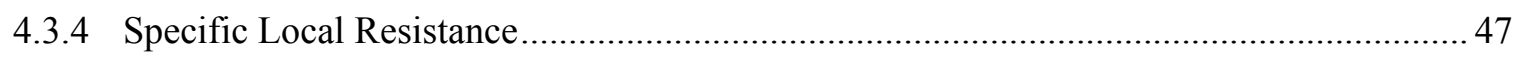

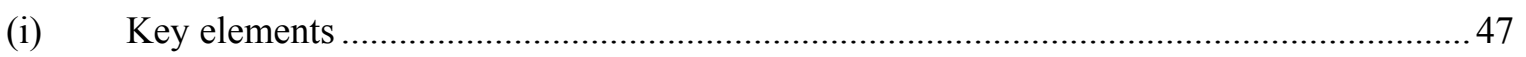

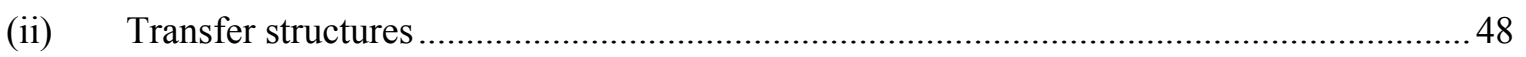

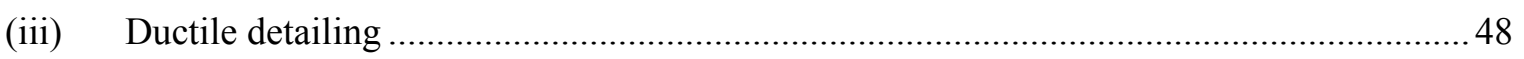

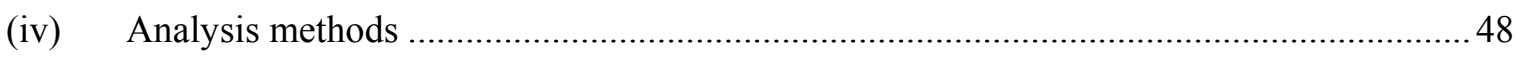

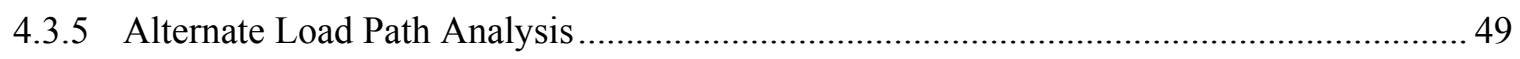

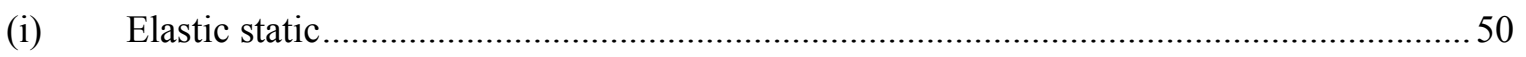

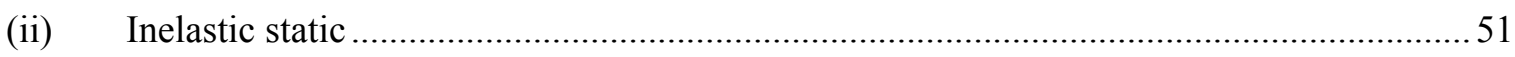

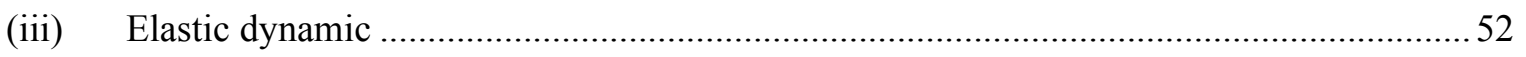

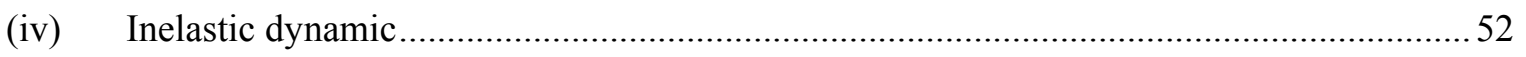

4.3.6 General Purpose Approach for Progressive Collapse Potential ....................................... 53

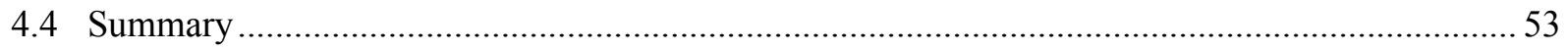

Chapter 5 Practical Design To Prevent Progressive Collapse ...........................................55

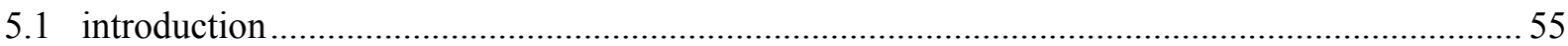

5.2 Design Guidance for Different Structural Systems...................................................................... 55

5.2.1 General Beneficial Features of Structures and Foundations .............................................55

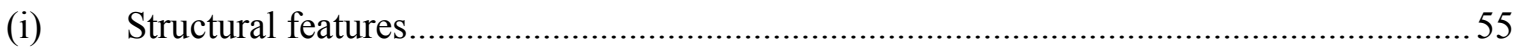

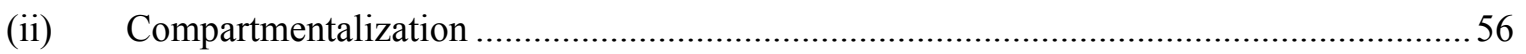

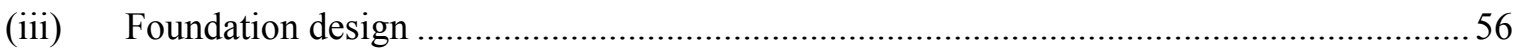

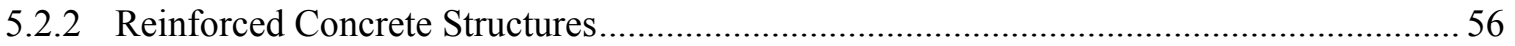




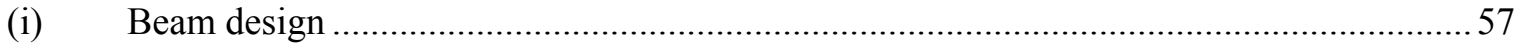

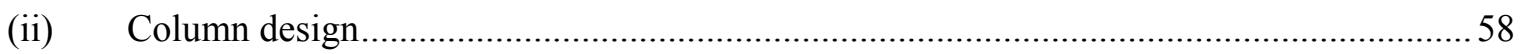

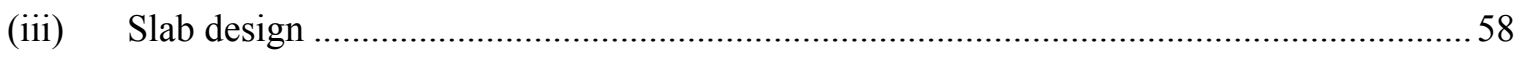

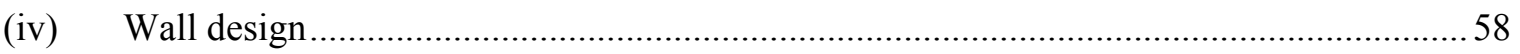

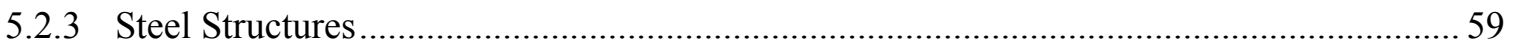

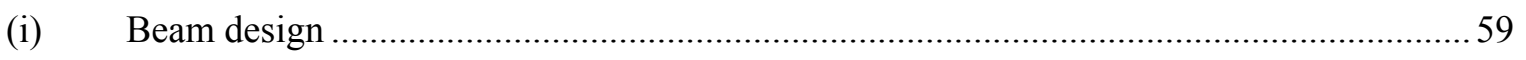

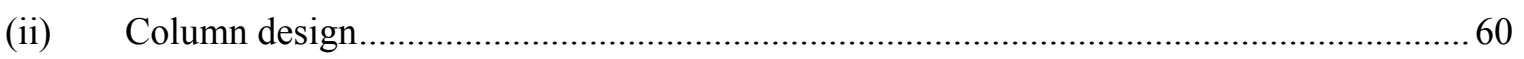

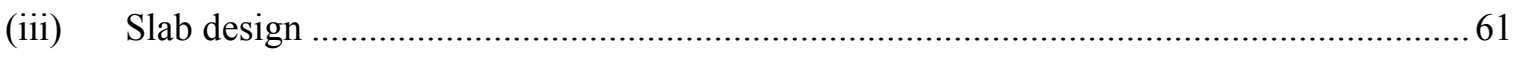

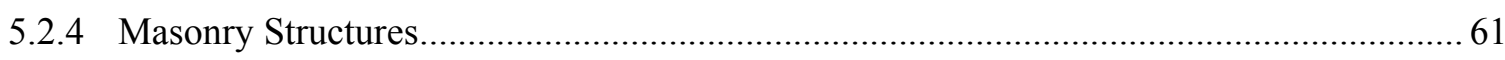

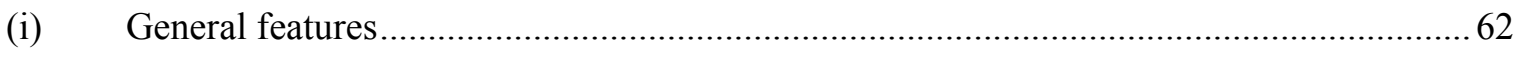

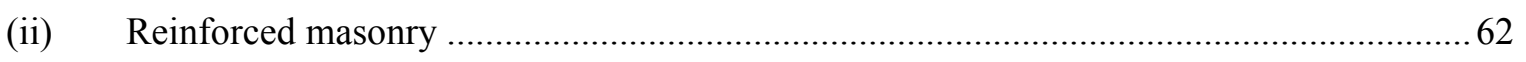

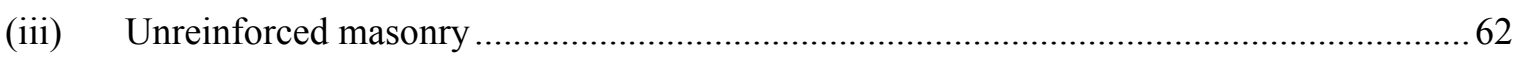

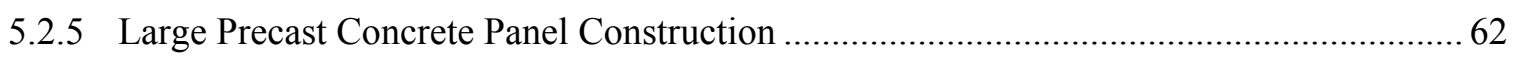

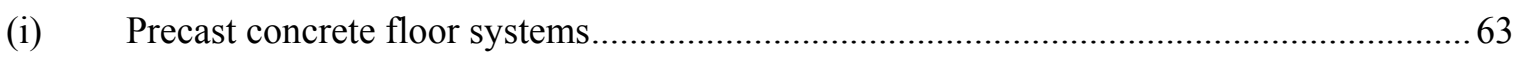

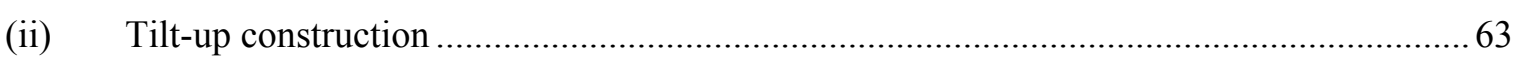

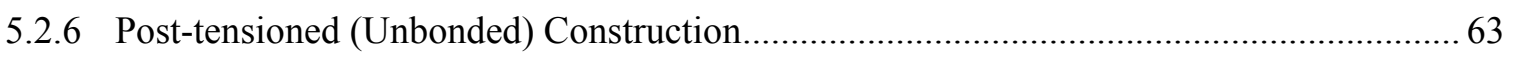

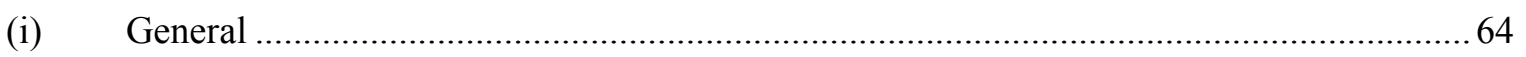

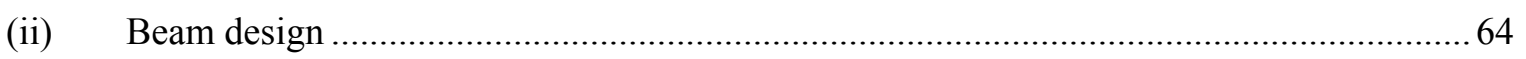

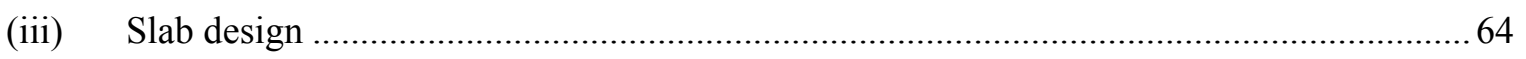

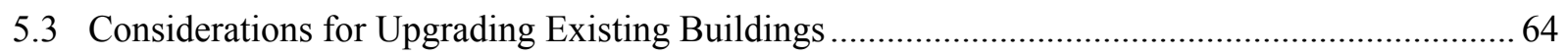

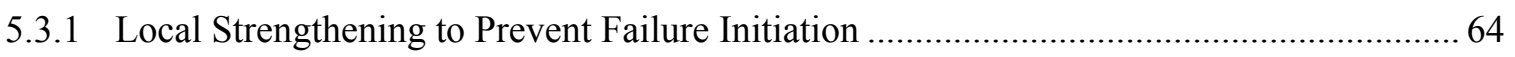

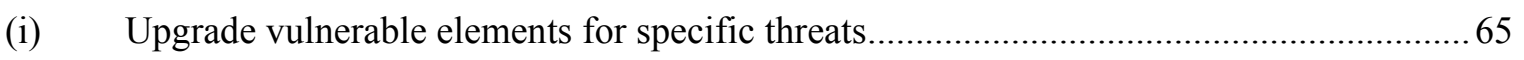

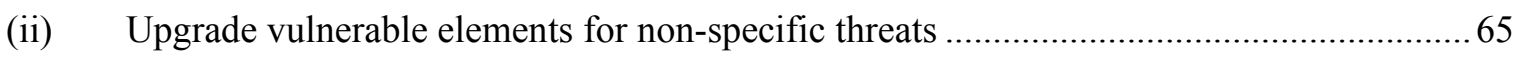

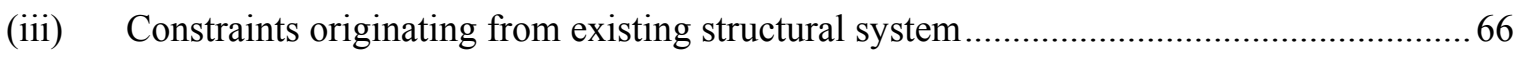

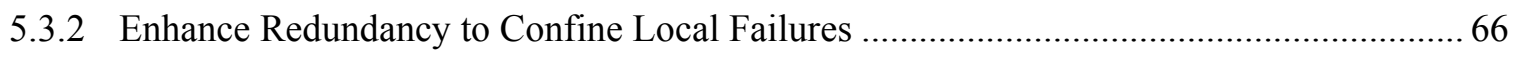

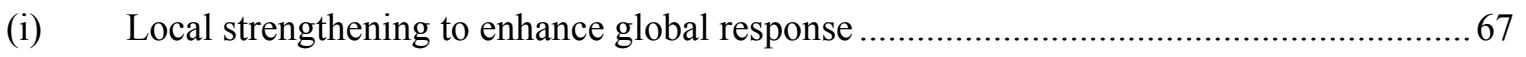

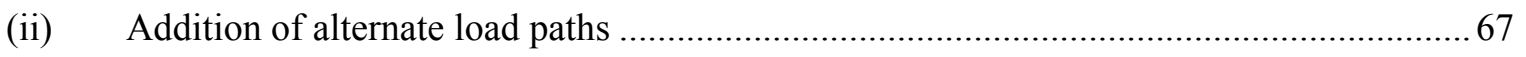

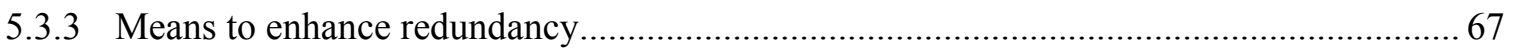

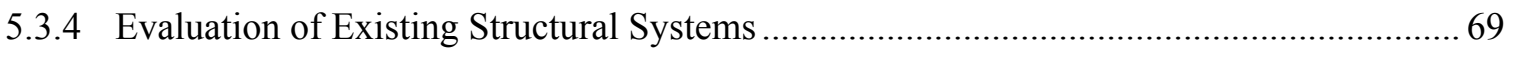

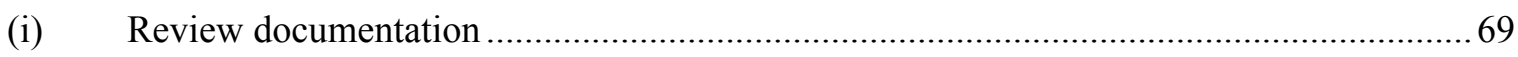

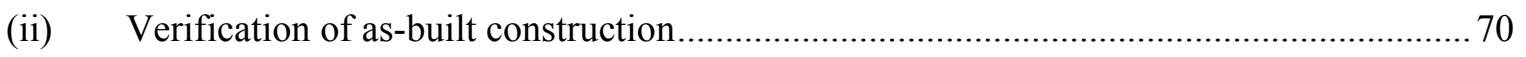

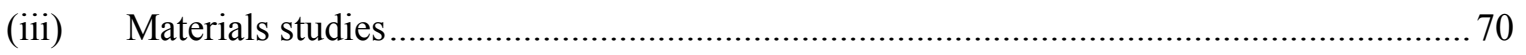

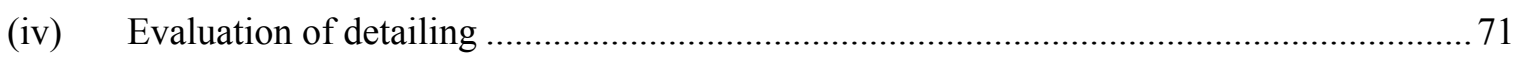

(v) Assessment of existing capacity of structural systems ................................................ 71

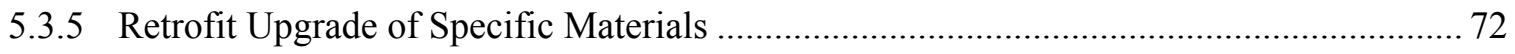




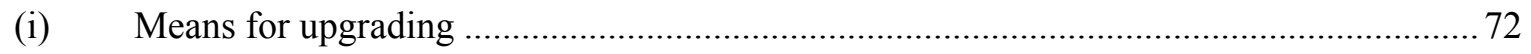

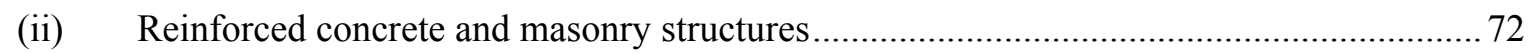

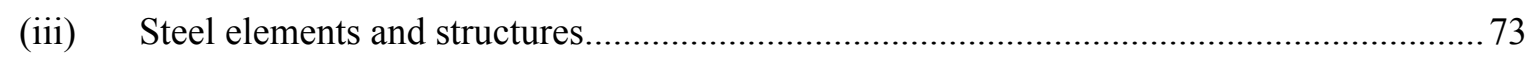

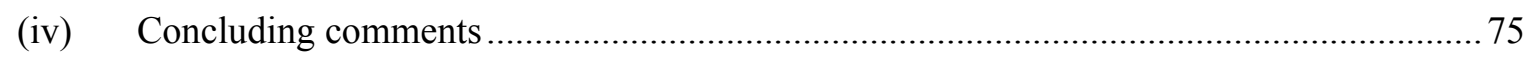

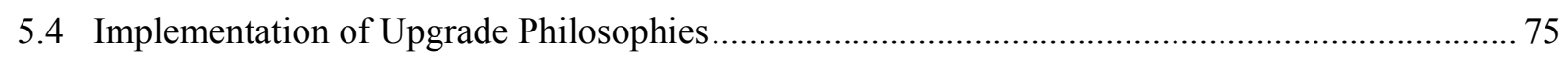

5.4.1 Comparative Analysis of Benefits Offered by Upgrade Options ……….......................... 75

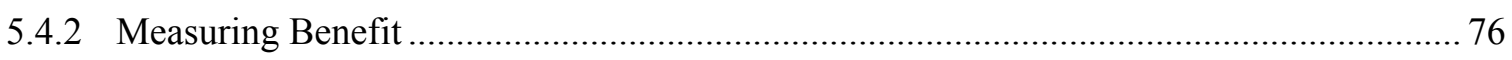

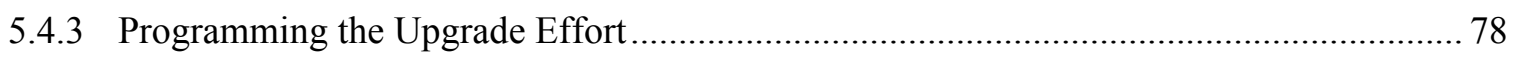

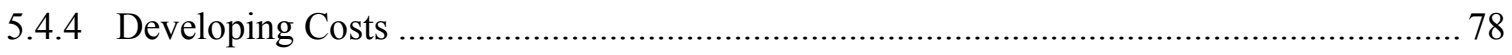

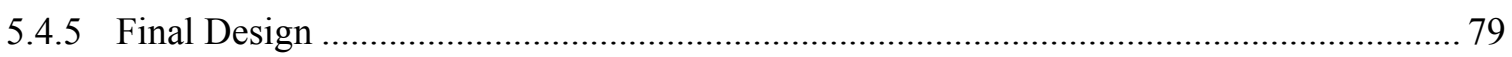

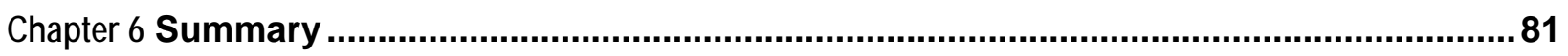

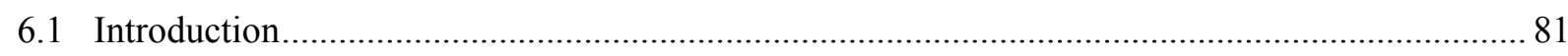

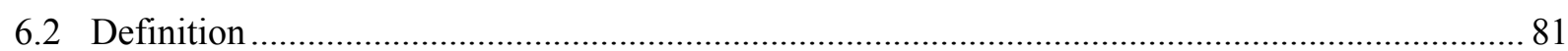

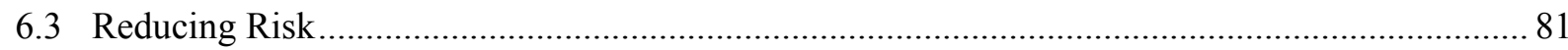

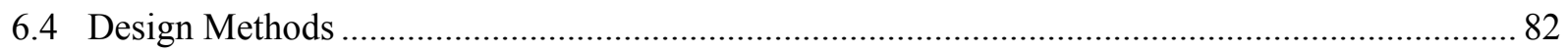

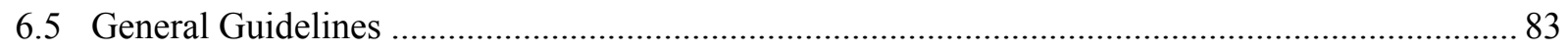

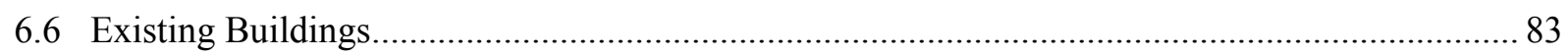

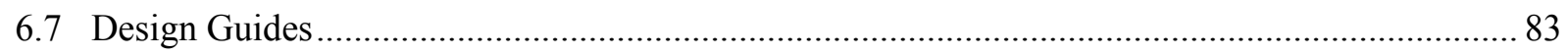

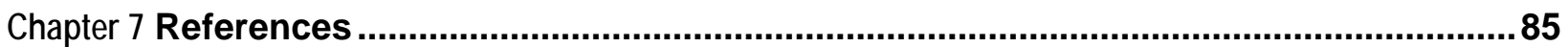

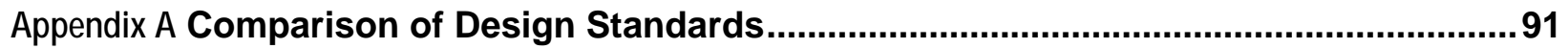

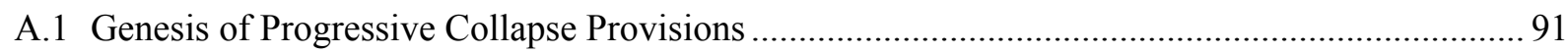

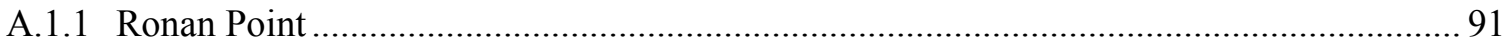

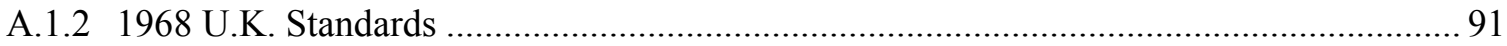

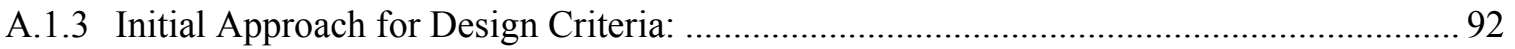

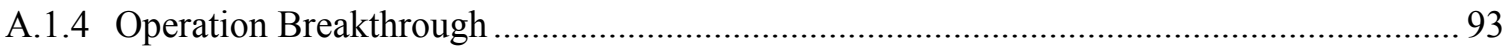

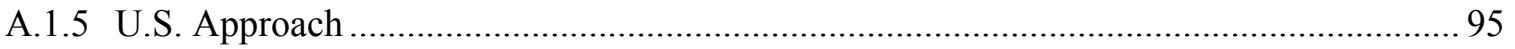

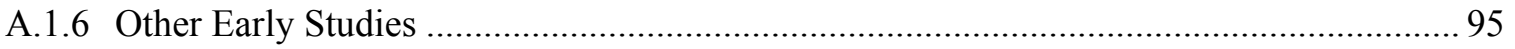

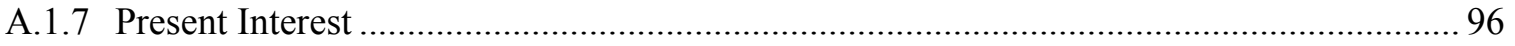

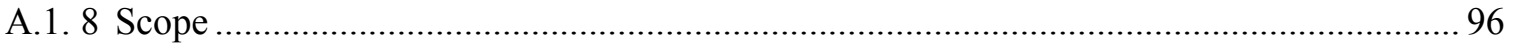

A.2. Approaches to Mitigating Progressive Collapse …….................................................................... 97

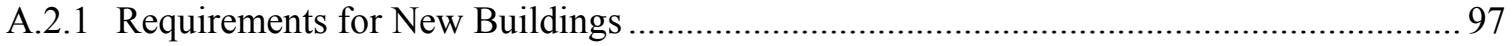

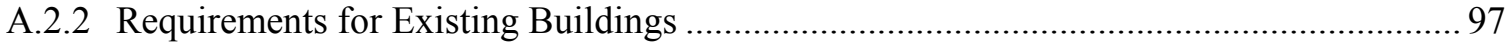

A.3 Summary of Standards on Progressive Collapse ......................................................................... 97 


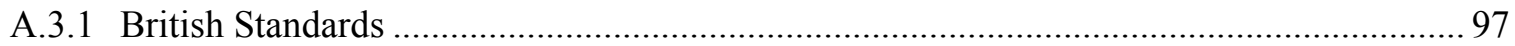

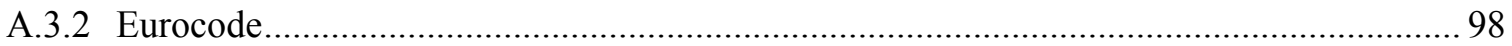

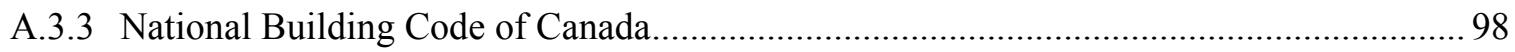

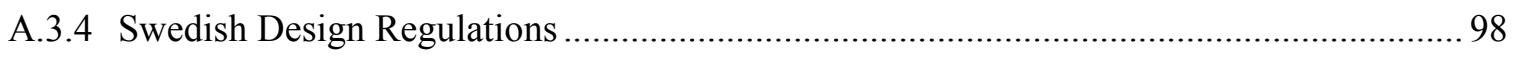

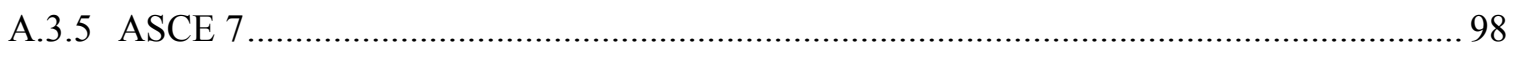

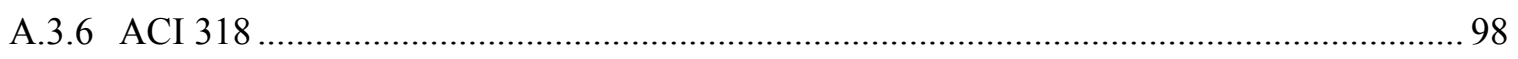

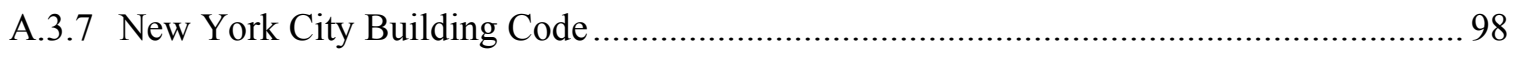

A.3.8 Department of Defense Unified Facilities Criteria ........................................................... 99

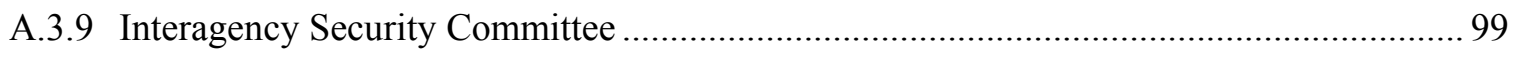

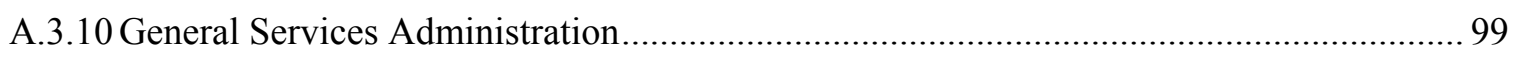

A.4 Comparison of Progressive Collapse Provisions .................................................................... 99

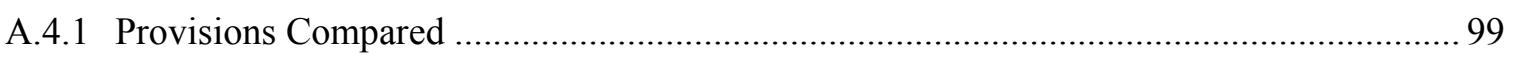

A.4.2 Definition of Progressive Collapse, Local Collapse, and Structural Integrity .................. 99

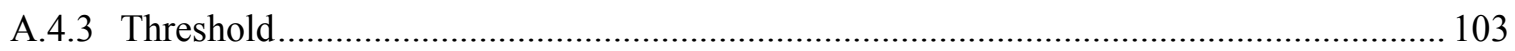

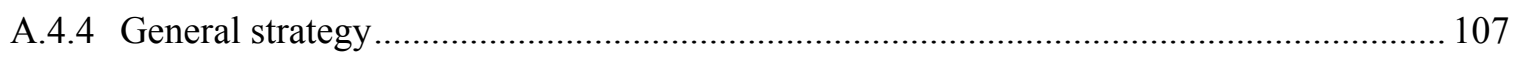

A.4.5 Loads for Design to Resist Progressive Collapse.......................................................... 128

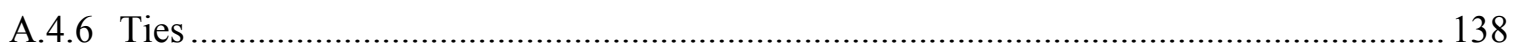

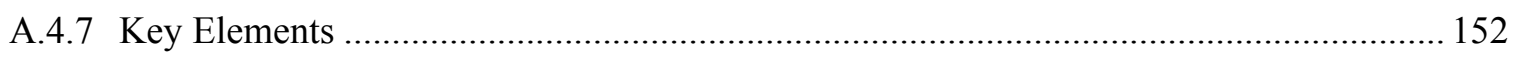

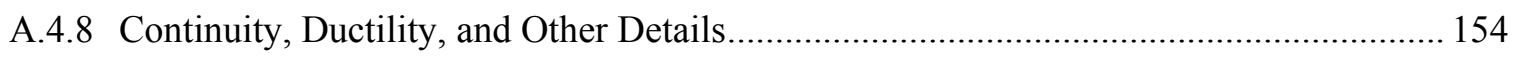

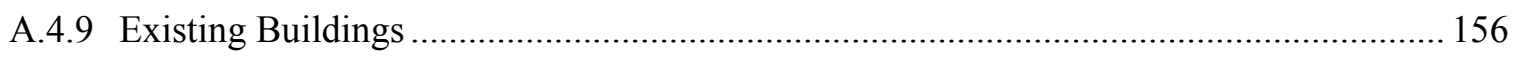

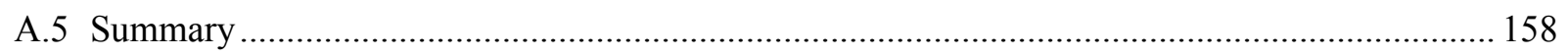

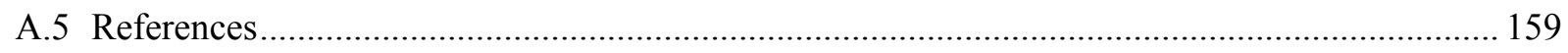

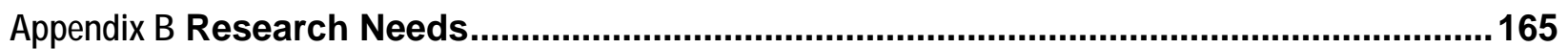

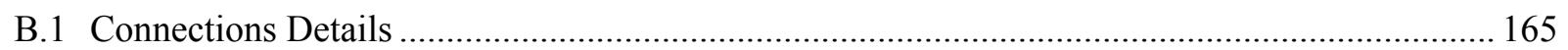

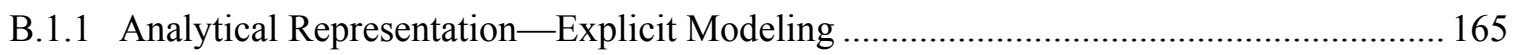

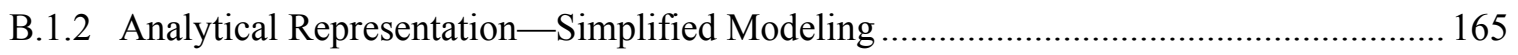

B.1.3 Investigation of Properties of Connections in Existing Buildings.................................... 166

B.1.4 Component Testing-Develop Force-Displacement and Moment-Rotation

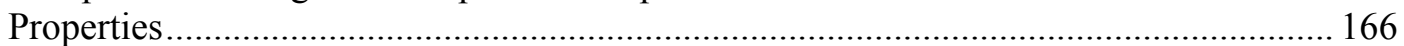

B.1.5 Evaluate Whether Seismic Connection Requirements Improve Resistance to

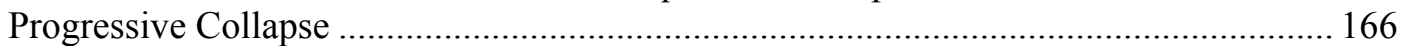

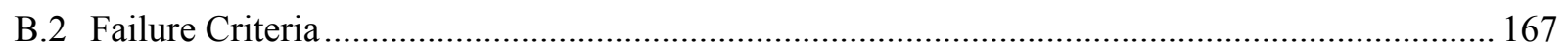

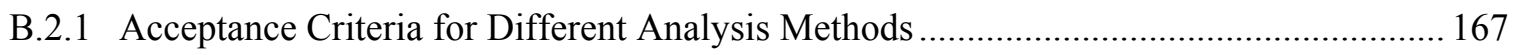

B.2.2 Applicability of Demand Capacity Ratio to Define Failure for Linear Analysis Methods 
B.2.3 Applicability of Limiting Ductility or End Rotation to Define Failure ........................... 167

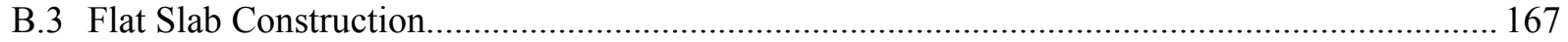

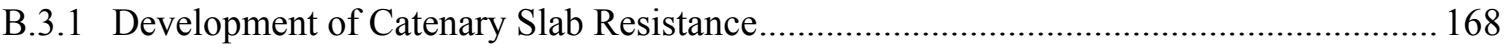

B.3.2 Testing of Full Scale Flat Slab Structure..................................................................... 168

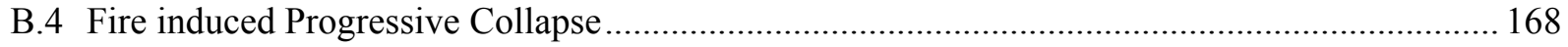

B.4.1 Coupling Thermal, Mechanical, and Structural Analysis............................................... 168

B.4.2 Material Behavior at Elevated Temperatures ............................................................... 168

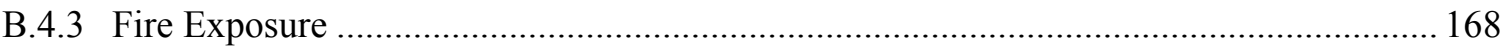

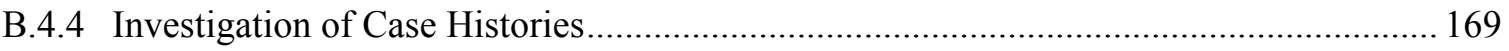

B.5 Development of Impact Factors for Slab "Pancake" Failure ..................................................... 169

B.6 Quantification of Risk Associated with Different Upgrade Approaches .................................. 169

B.7 Performance of Prescriptive Design Requirements .............................................................. 169

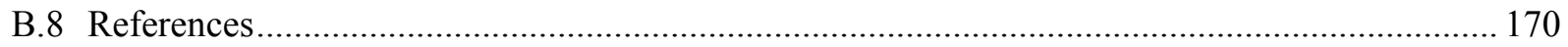

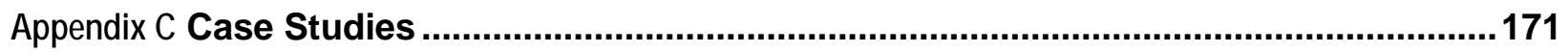

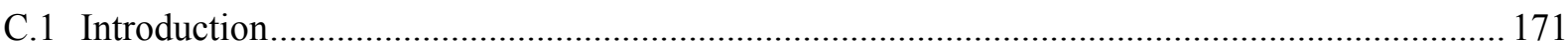

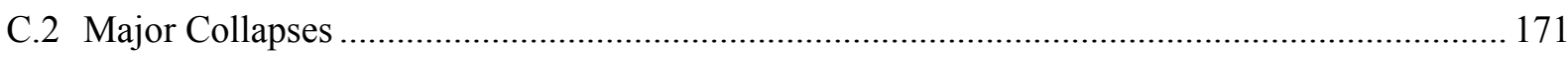

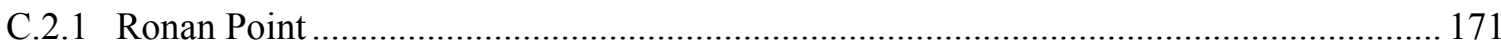

C.2.2 Kansas City Hyatt Regency Hotel Skywalks ........................................................... 173

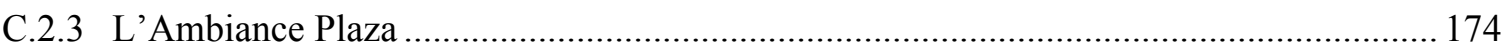

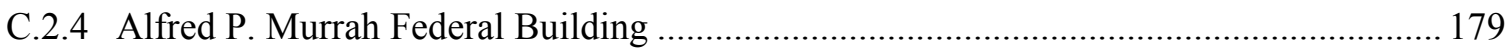

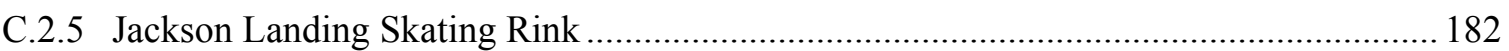

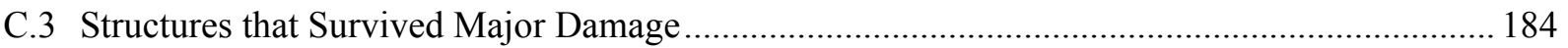

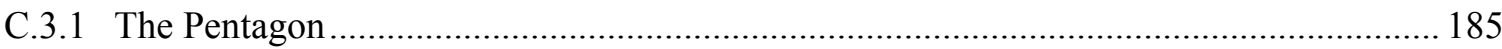

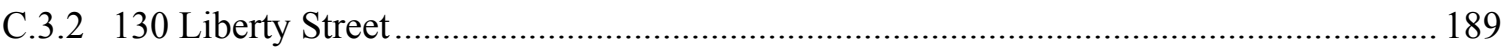

C.4 Designs to Prevent Progressive Collapse ................................................................................ 191

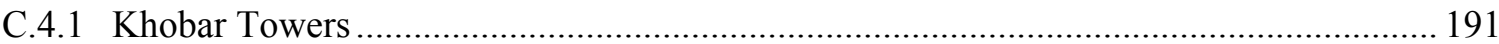


This page intentionally left blank. 


\section{LIST OF FIGURES}

Figure 1-1 Ronan Point collapse: a gas explosion on the $18^{\text {th }}$ floor resulted in a progressive collapse ....... 2

Figure 2-1 Typical pressure-time record from gas explosion (adapted from Leyendecker and

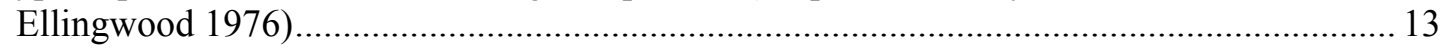

Figure 2-2 Schematic of force on column due to vehicular impact..................................................... 14

Figure 2-3 Typical pressure-time record from detonation of explosives (adapted from Mainstone

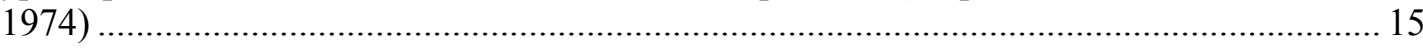

Figure 3-1 Different types of ties incorporated to provide structural integrity (DOD 2005).................. 35

Figure 4-1 Finite element representation of steel connection; (left) unloaded model and (right)

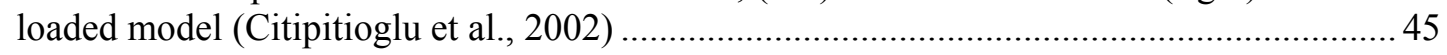

Figure 4-2 Concrete encased steel column subjected to near contact detonation ................................... 49

Figure 4-3 Phases of progressive collapse (Ettouney et al. 2004) ........................................................... 54

Figure 5-1 a) Reinforced concrete column wrapped with carbon composite; b) masonry panel reinforced with steel strips (Taghdi et al., 2000); c) sketch of a reinforced concrete

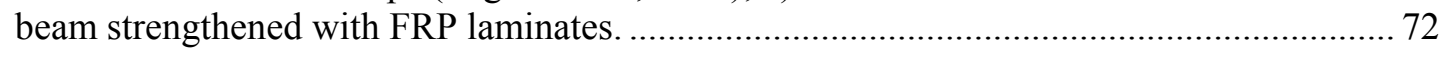

Figure 5-2 Retrofitted beam-column connection after testing (Mosallam, 2000) .................................. 73

Figure 5-3 Examples of strengthening of steel connections. Adapted from Engelhardt and Sabol

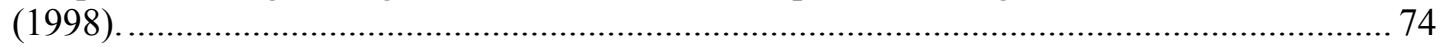

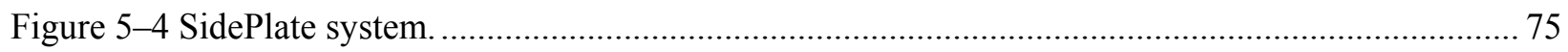


This page intentionally left blank. 


\section{LIST OF TABLES}

Table 2-1. Annual Individual Fatality Risks (Statistical, 2001) .............................................................. 7

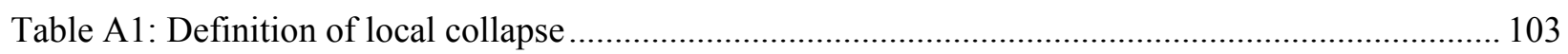

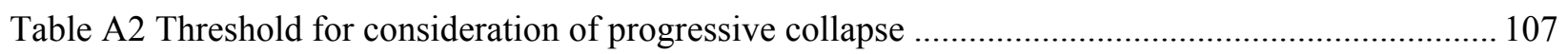

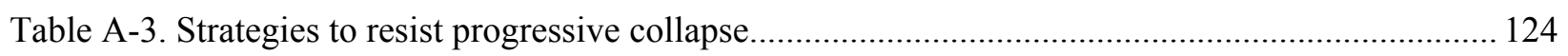

Table A-3 (Continued) Strategies to resist progressive collapse ......................................................... 125

Table A-3 (Continued) Strategies to resist progressive collapse .......................................................... 126

Table A-3 (Continued) Strategies to resist progressive collapse ........................................................ 127

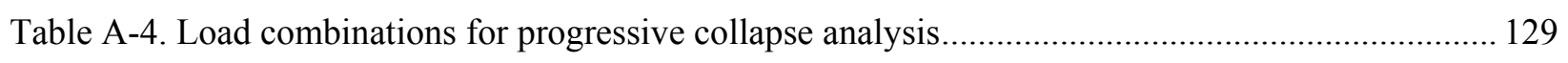

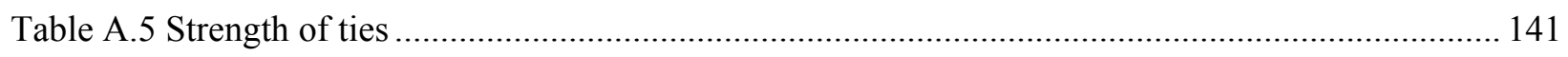


This page intentionally left blank. 


\section{LIST OF ACRONYMS AND ABBREVIATIONS}

\section{Acronyms}

ACI American Concrete Institute

AGA American Gas Association

AISC American Institute of Steel Construction

ANSI American National Standards Institute

ASCE American Society of Civil Engineers

BS British Standards

CFRP Carbon fiber-reinforced polymer

CMU Concrete masonry unit

CSA Canadian Standards Association

D Dead load

DCR Demand-Capacity Ratio

DOD Department of Defense

DTRA Defense Threat Reduction Agency

FBI Federal Bureau of Investigation

FE Finite element

FEMA Federal Emergency Management Agency

FRP Fiber-reinforced polymer

HLOP High level of protection

GSA General Services Administration

ISC Interagency Security Committee

L Live load

LLOP Low level of protection

LRFD Load and resistance factor design

MLOP Medium level of protection

NBCC National Building Code of Canada

NTSB National Transportation Safety Board

NYCDOB New York City Department of Buildings

OPSO Office of Pipeline Safety Operations 


$\begin{array}{ll}\text { PCI } & \text { Precast/Prestressed Concrete Institute } \\ \mathrm{S} & \text { Snow load } \\ \mathrm{T} & \text { Load due to temperature effects } \\ \text { UFC } & \text { Unified Facilities Criteria } \\ \text { U.K. } & \text { United Kingdom } \\ \text { U.S. } & \text { United States } \\ \text { VLLOP } & \text { Very low level of protection } \\ \mathrm{W}_{\mathrm{n}} \text { or } \mathrm{W} & \text { Wind load }\end{array}$

\section{Unit Abbreviations}

\begin{tabular}{ll}
$\mathrm{d}$ & day \\
$\mathrm{ft}$ & foot \\
$f_{y}$ & specified yield strength \\
$\mathrm{h}$ & hour \\
$\mathrm{in}$ & inch \\
$\mathrm{kg}$ & kilogram \\
$\mathrm{kip}$ & $1000 \mathrm{lb}$ \\
$\mathrm{kN}$ & kilonewton \\
$\mathrm{kPa}$ & kilopascal \\
$\mathrm{ksi}$ & 1000 psi \\
$\mathrm{lb}$ & pound \\
$\mathrm{m}$ & meter \\
$\mathrm{mi}$ & mile \\
$\mathrm{mph}$ & miles per hour \\
$\mathrm{psf}$ & pounds per square foot \\
$\mathrm{psi}$ & pounds per square inch \\
$\mathrm{s}$ & second \\
$\mathrm{yr}$ & year \\
\hline
\end{tabular}




\section{Chapter 1 \\ INTRODUCTION}

\subsection{PROGRESSIVE COLLAPSE}

The term "progressive collapse" has been used to describe the spread of an initial local failure in a manner analogous to a chain reaction that leads to partial or total collapse of a building. The underlying characteristic of progressive collapse is that the final state of failure is disproportionately greater than the failure that initiated the collapse. ASCE Standard 7-05 defines progressive collapse as "the spread of an initial local failure from element to element resulting, eventually, in the collapse of an entire structure or a disproportionately large part of it" (ASCE 2005). The disproportionality refers to the situation in which failure of one member causes a major collapse, with a magnitude disproportionate to the initial event. Thus, "progressive collapse" is an incremental type of failure wherein the total damage is out of proportion to the initial cause. In some countries, the term "disproportionate collapse" is used to describe this type of failure.

Based on the above description, it is proposed that the professional community adopt the following definition, which is based largely on ASCE 7-05:

progressive collapse - the spread of local damage, from an initiating event, from element to element resulting, eventually, in the collapse of an entire structure or a disproportionately large part of it; also known as disproportionate collapse.

The concept of progressive collapse can be illustrated by the famous 1968 collapse of the Ronan Point apartment building (Fig. 1-1). The structure was a 22-story precast concrete, bearing wall building. A gas explosion in a corner kitchen on the 18th floor blew out the exterior wall panel and failure of the corner bay of the building propagated upward to the roof and downward almost to ground level. Thus, although the entire building did not collapse, the extent of failure was disproportionate to the initial damage. Other examples of progressive collapse are provided in Appendix C. Different criteria have been developed to define acceptable spread horizontally and vertically of the initiating failure. Appendix A provides a summary of some of these criteria (see Table A1).

Generally, buildings in the U.S. are not designed for loading conditions to account for gas explosions, bomb explosions, vehicular collisions, aircraft collisions, tornados, and the like. Thus, when buildings are subjected to such abnormal loads, they may sustain extensive damage (Somes 1975; Burnett 1975a). Historically, only a limited number of buildings sustained severe damage to an extent that a total collapse occurred. However, there have been numerous cases of progressive collapse of buildings during construction. Causes of these construction failures have been traced to low material strength, construction overload, and improper construction techniques (Breen 1975). Historical data suggest that while buildings under construction have a higher probability of sustaining collapse than the same buildings after construction, construction failures are not initiated by the conditions that cause failures of buildings in use. The material presented in this document relates to only buildings in service. 


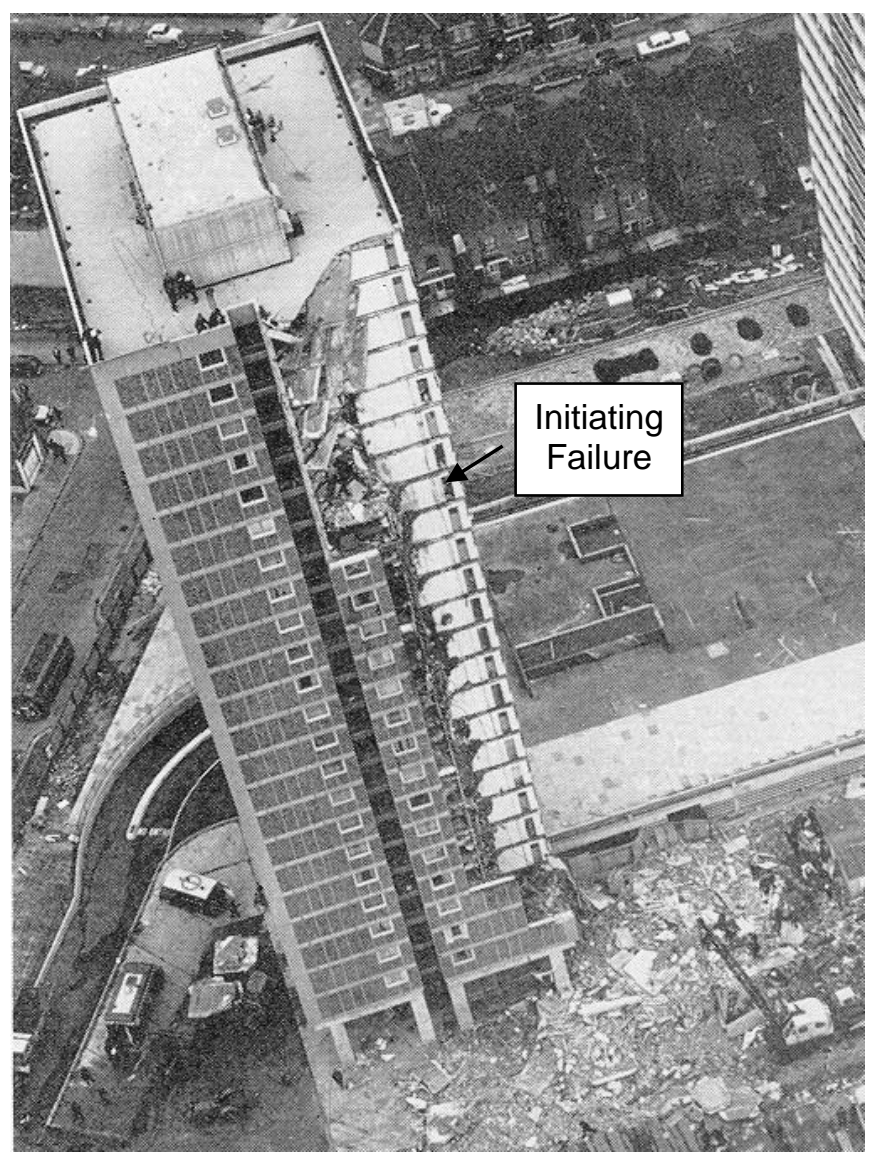

Figure 1-1 Ronan Point collapse: a gas explosion on the $18^{\text {th }}$ floor resulted in a progressive collapse

\subsection{PURPOSE AND SCOPE}

Immediately following the Ronan Point collapse, some countries, such as the U.K. and Canada adopted some form of regulatory standards to address prevention of progressive collapse. In 1976 the U.K. building regulations required that buildings not sustain collapse to an extent disproportionate to the initiating failure. The regulations required that buildings be designed to resist disproportionate failure by tying together building elements, adding redundant members, and providing sufficient strength to resist postulated abnormal loads. These requirements are considered to produce more robust structures, that is, structures that are strong, ductile, and capable of redistributing loads (refer to Section 3.5.2 for a discussion of factors that affect structural robustness).

In the 1980s, design standards in the U.S. began to incorporate requirements for "general structural integrity" to provide nominal resistance to progressive collapse (ANSI 1982). Structural integrity was to be achieved by providing continuity, redundancy and ductility in structures. At present, U.S. model building codes and standards do not include specific provisions to provide resistance against progressive collapse. Some materials design standards, however, such ACI 318 (ACI 2005) and the PCI guide for 
Precast concrete bearing wall buildings (PCI 1976), include provisions for minimum levels of structural integrity.

Although historical data indicate that the risk of progressive collapse in buildings is very low, loss of life and severe injuries would be significant when a fully occupied multi-story building sustains a large partial or total collapse. As a result of recent terrorist attacks on buildings throughout the world, particularly U.S. owned and occupied buildings, several U.S. government agencies with large construction programs have developed their own design requirements (GSA 2003; DOD 2005) to provide resistance against progressive collapse. Each agency, however, with its own mission, has adopted different performance objectives for buildings subjected to abnormal loads. Furthermore, the design approach to provide resistance to progressive collapse is not standardized among these documents. In the private sector there is, however, a diverse range of professional opinion regarding the extent and nature of changes to present practices that may be warranted to enhance the resistance of buildings to progressive collapse. A consensus has yet to be reached on the thresholds to delineate when design against progressive collapse needs to be considered and what level of resistance is acceptable.

The design of a building to resist progressive collapse may require analytical approaches that are not used in routine design. The purpose of this document is to provide the "best practices" for design professionals to reduce the likelihood of progressive collapse of buildings in the event of abnormal loading. It is not intended as a design standard. Guidance is provided that is based on existing knowledge and includes input from design professionals with a broad range of interests. This document addresses design of new buildings and upgrading of existing buildings. It does not address wood or cold-formed steel, low-rise construction.

Chapter 2 discusses an acceptable risk approach to progressive collapse, which involves defining the threat, event control, and structural design to resist a postulated event.

Chapter 3 presents practical approaches for reducing exposure to threats that could provide the initial local failure to trigger progressive collapse. It also discusses, in general terms, the design methods used to mitigate the potential for progressive collapse; these include: the indirect method (providing sufficient tie forces), the specific local resistance method (designing key elements to withstand abnormal loads), and the alternate load path method (allowing for redistribution of load in the event of the loss of a key member).

Chapter 4 provides a comprehensive discussion of the indirect and direct design approaches for mitigating progressive collapse potential. The implementation of these methods in the guidelines developed by the General Services Administration (GSA) and the Department of Defense (DOD) is also discussed. The chapter concludes with a review of analytical tools that are available for evaluating progressive collapse potential of new or existing buildings. The inherent limitations of different analytical approaches are highlighted.

Chapter 5 includes practical design guidance to mitigate the potential for progressive collapse in new and existing buildings. Included are recommended design details for different structural materials and structural systems. 
Appendix A presents a detailed worldwide review of progressive collapse provisions in various national design standards. Appendix B identifies knowledge gaps related to progressive collapse that require research. The report concludes with Appendix C, which provides case studies of progressive collapses.

This document is not intended to provide step-by-step design guidance for practicing engineers, but it is intended to acquaint engineers with considerations involved in designing buildings for resistance to progressive collapse. Applicable design procedures are available as indicated in Appendix A. 


\section{Chapter 2 \\ ACCEPTABLE RISK BASES}

\section{$2.1 \quad$ INTRODUCTION}

A progressive collapse involves a chain reaction of failures that develops into an extensive partial or total collapse of a building, where the resulting damage is disproportionate to the local damage caused by the initiating event. The notion of "disproportionality" is common to all definitions of progressive collapse but is ambiguous. Typically, damage in such a collapse would extend beyond one structural bay, $100 \mathrm{~m}^{2}$ $\left(\approx 1000 \mathrm{ft}^{2}\right)$ of floor area, or two stories. Such collapses can be initiated by many causes, including design and construction errors and load events that are beyond the design envelope or are not considered explicitly. Such events would include abnormal loads not considered routinely in design (e.g., gas explosions, vehicular collisions, and sabotage), severe fires, extreme values of environmental loads that stress the building system well beyond the design envelope, and abuse.

Customary structural design practice for combinations of dead, occupancy live, wind, snow and earthquake loads provides a degree of strength and ductility that is also available to withstand abnormal loads and provide some resistance to progressive collapse. The evolution in design practices made possible by computerized design and the use of high-performance materials has led to modern building systems that are light and flexible. In contrast, older structures were less efficient and were designed more conservatively than necessary because of limited knowledge at the time. Pressures to achieve efficiency or economy in design or versatility in occupancy may lead to systems that have little inherent energyabsorbing capacity or built-in protections against progressive collapse and may be vulnerable to load conditions outside the design envelope. Construction technologies aimed at minimizing erection costs also may lead to structures with little inherent continuity and resistance to progressive collapse. Finally, social and political factors also have led to an increase in incidents that may initiate such failures. Public awareness of building safety issues has increased markedly during the past thirty years as a result of wellpublicized natural and man-made disasters. Structural failures, whatever their cause, are thoroughly examined in the public forum. Studies in many countries have shown that the risk of structural failure due to such effects as fire, vehicular impact, explosions and other abnormal events in some instances may be comparable to the risks associated with hazards that traditionally have been addressed in structural design.

Despite advances in structural engineering that have revolutionized building design and construction during the past two decades, there are numerous sources of uncertainty in the building design process. Some of these uncertainties are inherent, such as environmental loads, structural strength, while others are knowledge-based, such as approximations in finite element models and limitations in supporting databases. The natural consequence of uncertainty is risk. Only if there is certainty is there no risk. Risk cannot be eliminated; rather, it must be managed. Risk avoidance as public policy is naïve, uneconomical and discourages innovation and new technology. Individuals and society as a whole must accept risk in order to achieve objectives, and this willingness to accept reasonable risks is a sign of progress and health. 
No building system can be engineered and constructed to be absolutely risk-free. Building codes are key tools for structural engineers to manage risk in the interest of public safety. The provisions for structural design in codes and standards for load combinations and design strength address the risks in building performance as the code and standard-writers have historically understood them. Such risks often have been managed judgmentally in the civil engineering arena. However, the aftermath of recent natural and man-made disasters has made it clear that judgmental approaches to risk management are not acceptable. Rational approaches to progressive collapse mitigation require risk-informed assessment and decisionmaking.

This chapter summarizes basic concepts of modern risk-informed decision-making and its application to developing and implementing design requirements for progressive collapse mitigation. This summary also will illuminate some of the inherent difficulties in developing such requirements for building design and construction.

\subsection{FUNDAMENTALS OF RISK ASSESSMENT FOR NATURAL AND MAN- MADE HAZARDS}

In the field of structural reliability, the term "risk" is often used more or less interchangeably with "probability" or is thought of as the complement of "reliability." But this may not be a sufficiently rich definition to be useful in engineering decision-making involving rare natural or man-made events. To stakeholders and the decision-maker, it is the consequences (e.g., deaths or serious injury; economic loss) that are most important. Low-probability events with grave consequences are inherently risky. Society takes steps to mitigate the impact of such events through education and regulatory action.

\subsubsection{Perception and Analysis of Risk}

The concept of risk involves three components: hazard, consequences, and context (Elms 1992). The hazard is a potentially harmful event, action or state of nature. To take a specific example, the potential for an explosion of natural gas supplied to a residential building is a hazard. The hazard can be quantified by its annual probability or mean rate of occurrence per dwelling unit (as described in Section 2.3.4). The occurrence of the hazard has consequences - building damage, building collapse, personal injury, loss of life, economic losses, or damage to the environment - which must be measured in terms of a value system involving some metric. Finally, there is the context, which provides a frame of reference for the risk analysis and assessment and resulting decisions. As stakeholders to a risk assessment, individuals, management groups, government agencies or other decision-makers view risk differently. Most individuals tend to be risk-averse (implying that they require a substantial increase in value or benefit in return for accepting marginal increases in risk). On the other hand, governments and large corporations, which may be self-insured, tend to be risk-neutral. Furthermore, society views incidents involving large numbers of people differently from incidents involving individuals; attitudes toward airline versus automobile accidents are a case in point. The element of dread or the unknown is a factor, e.g., public attitudes toward nuclear power. The context also is determined by the necessity for risk management, where investment in risk reduction must be balanced against available resources.

Structural codes and design practice aim at delivering buildings and systems with acceptable risks. It is unclear exactly what is "acceptable risk" in the built environment. The general absence of public outcry (except after catastrophic events such as 9/11 and Hurricane Katrina) indicates, however, that codes and 
standards and the building regulatory process are delivering building products with risks that are acceptable to the public. Acceptable risk is a relative term. Acceptable risk in buildings can be determined only in the context of what is acceptable in other activities, what investment is required to marginally reduce the risk, and what losses might be incurred if the risk were to increase. As noted above, the threshold of risk depends on one's point of view. To a building occupant, any risk below the (unknown) threshold is acceptable. To a developer, on the other hand, any risk above the threshold represents wasted cost.

It is natural to attempt to compare risks in the built environment with those that are presumably acceptable in other human endeavors. A summary of mortality statistics for several recent years in the United States is presented in Table 2-1. These are presented simply to provide context for subsequent probabilistic analysis; the associated risks are not truly comparable even in these simple categories because of differences in exposure (e.g., not everyone flies and is exposed to aircraft hazards) and consequences. Mortality from cardiovascular disease and cancer provides a psychological yardstick, of sorts, in measuring risk. People seldom undertake risky activities without an expectation of some benefit. There is a tradeoff between risk (and risk reduction) and benefits. A now-classic study by Starr (1969) revealed that acceptable risk (measured by annual frequency) may be approximately three orders of magnitude higher for activities that are undertaken voluntarily (e.g., mountain climbing, general aviation) than for those that are involuntary (commercial aviation). Starr later noted that acceptable risk is determined by an individual's perception of his/her ability to manage the situation creating the risk.

Table 2-1. Annual Individual Fatality Risks (Statistical, 2001)

\begin{tabular}{|l|c|}
\hline \multicolumn{1}{|c|}{ Source } & Fatality/yr \\
\hline Cardiovascular disease & $3.5 \times 10^{-3}$ \\
\hline Cancer (all) & $2.0 \times 10^{-3}$ \\
\hline All accidents & $3.4 \times 10^{-4}$ \\
\hline $\begin{array}{l}\text { Motor vehicle } \\
\quad \begin{array}{l}\text { Per vehicle-km } \\
\text { Per year (25,000 km) }\end{array}\end{array}$ & $6.4 \times 10^{-9}$ \\
& $1.6 \times 10^{-4}$ \\
\hline Accidents in the home & $1.1 \times 10^{-4}$ \\
\hline Fires ${ }^{1}$ & $1.2 \times 10^{-5}$ \\
\hline Homicide and legal intervention & $6.4 \times 10^{-5}$ \\
\hline Electrocution & $5.3 \times 10^{-6}$ \\
\hline Air travel & $1.6 \times 10^{-7}$ \\
$\quad \begin{array}{l}\text { Per round trip } \\
\text { Per year (25 trips) }\end{array}$ & $4.0 \times 10^{-6}$ \\
\hline Hurricanes, tornados and floods & $7.2 \times 10^{-7}$ \\
\hline Lightening strike & $3.3 \times 10^{-7}$ \\
\hline
\end{tabular}

\footnotetext{
${ }^{1}$ According to Karter (2002), in 2001 there were 3745 civilian fire fatalities, excluding those that occurred in the events of 9/11/2001. Of these, 2650 occurred in one- and two-family dwellings, 490 occurred in residential buildings (apartments, hotels, dormitories), and 80 occurred in non-residential buildings and structures.
} 
While current building codes and standards and code enforcement keep failure rates at a (fortunately) very low level, no one knows exactly what a socially acceptable failure rate might be. However, there is evidence (Pate-Cornell 1994) that the de minimis risk, that risk below which society normally does not impose any regulatory guidance, is on the order of $10^{-7} / \mathrm{yr}$. For the sake of the following discussion, we may take $10^{-7} / \mathrm{yr}$ as a target value, with the understanding that final decisions regarding acceptable building risk are outside the scope of this document.

\subsubsection{Mathematical and Decision Analysis Tools}

A basic mathematical framework for risk assessment involving a hazard is provided by the following equation:

$$
\mathrm{P}[\text { Loss }]=\Sigma_{\mathrm{H}} \Sigma_{\mathrm{LS}} \Sigma_{\mathrm{D}} \mathrm{P}[\text { Loss } \mid \mathrm{D}] \mathrm{P}[\mathrm{D} \mid \mathrm{LS}] \mathrm{P}[\mathrm{LS} \mid \mathrm{H}] \mathrm{P}[\mathrm{H}]
$$

in which $\mathrm{P}[\bullet]=$ probability of the event in the brackets. It is assumed that "Loss" is an appropriate loss metric: severe injury or death, direct damage costs, loss of opportunity costs, etc. The term $\mathrm{P}[\mathrm{H}]$ is a measure of the intensity of the hazard, $\mathrm{P}[\mathrm{LS} \mid \mathrm{H}]=$ conditional probability of a structural limit state, $\mathrm{P}[\mathrm{D} \mid \mathrm{LS}]=$ conditional probability of damage state (e.g., negligible, minor, moderate, severe), and $\mathrm{P}[\operatorname{Loss} \mid \mathrm{D}]=$ conditional probability of loss. Alternatively, if the risk is based on a stipulated scenario event, then

$$
\mathrm{P}[\text { Loss } \mid \text { Scenario }]=\Sigma_{\mathrm{LS}} \Sigma_{\mathrm{D}} \mathrm{P}[\operatorname{Loss} \mid \mathrm{D}] \mathrm{P}[\mathrm{D} \mid \mathrm{LS}] \mathrm{P}[\mathrm{LS} \mid \text { Scenario }]
$$

Equations 2.1 and 2.2 deconstruct the risk analysis into its major constituents and along disciplinary lines. The likelihood of the hazard is measured by $\mathrm{P}[\mathrm{H}]$ or, approximately, by its mean occurrence rate, $\lambda_{\mathrm{H}}$ (as described in Section 2.3). The probabilities $\mathrm{P}[\mathrm{LS} \mid \mathrm{H}]$ or $\mathrm{P}[\mathrm{LS} \mid \mathrm{Scenario}]$ are determined by structural engineering analysis. For limit states that are relevant for progressive collapse mitigation, a finite element (FE) platform with nonlinear dynamic analysis capabilities generally would be required. The P[D|LS] describes the damage state for the structural system in terms of the structural response quantities computed from the FE analysis. Finally, the conditional probability, $\mathrm{P}[\mathrm{Loss} \mid \mathrm{D}]$, describes the probability of loss, given a specific damage state. In a formal risk analysis, this probability often would be determined from insurance records.

Building failures can result from a multiplicity of hazards - occupancy loads and other demands, misuse, extreme environmental effects, fires, and other abnormal loads. If each of these distinct hazards is represented by an event, $\mathrm{H}$, and if simply local damage rather than a damage state is specified, then the total probability of structural collapse due to $\mathrm{H}$ can be simplified (compare with Eq. (2.1)) as:

$$
\mathrm{P}[\text { Collapse }]=\Sigma \mathrm{P}[\text { Collapse } \mid \mathrm{LD}] \mathrm{P}[\mathrm{LD} \mid \mathrm{H}] \mathrm{P}[\mathrm{H}]
$$

in which Collapse = structural collapse event, $\mathrm{P}[\mathrm{H}]=$ probability of hazard $\mathrm{H}, \mathrm{P}[\mathrm{LD} \mid \mathrm{H}]=$ probability of local damage (intensity not specified), given that Hoccurs, and $\mathrm{P}[$ Collapse $\mid \mathrm{LD}]=$ probability of collapse, given that hazard and local damage both occur. The term P[Collapse] must be limited to some socially acceptable value through a combination of professional practice and appropriate building regulation. Equation (2.3) is the basis for the treatment of abnormal load combinations in Commentary C2.5 of ASCE Standard 7-05. Note that while Eq. (2.3) is similar to Eqs. (2.1) and (2.2), it is more limited in its scope and implementation. First, there is a presumption that "risk" and "P[Collapse]" are identical; second, only 
"local damage" rather than a spectrum of damage states is identified. While these simplifications gloss over some issues of consequences and context, they avoid the difficulties in selecting appropriate risk (loss) metrics (discussed in Section 2.2.3) and transform the analysis of risk of progressive collapse into a problem more amenable to solution by principles of structural reliability theory. The remainder of this Chapter is developed around evaluating these terms for stipulated hazards.

Proper management of building risk involves examining each of the terms in Eq. (2.3). In this examination, it is instructive to read Eq. (2.3) from right to left. If the probability $\mathrm{P}[\mathrm{H}] \approx \lambda_{\mathrm{H}}$ is less than the de minimis threshold, the probability of damage or failure due that hazard $\mathrm{H}$ is likely to contribute little to P[Collapse]. That hazard then can safely be ignored, and attention (and risk mitigation) should focus on other potential hazards. Conversely, if $\lambda_{\mathrm{H}}$ is one or two orders of magnitude above the de minimis threshold, further investigation of that hazard is warranted. The current generation of codes and standards are focused, by tradition, on a relatively small subset of the hazards that might affect building performance — wind, earthquake, and so on — and on mitigating the risks associated with these hazards. Evolution in building practices, as well as sociopolitical events, have highlighted a group of hazards that historically either have not been recognized as significant (explosions or detonations) or have been dealt with through "deemed-to-satisfy" clauses rather than through formal structural calculations (severe fires). Consideration of these potential hazards on a consistent basis in building risk management is an essential tool for maximizing return on investment of resources and developing regulatory provisions that will enhance and improve building practices. It is not feasible, technically or economically, to consider in detail in design all hazards that might affect building performance. Potential hazards may have a different impact on risk, depending on the target risk selected. A bomb explosion hazard may have little impact on risk if the target $\mathrm{P}$ [Collapse] were $10^{-5} / \mathrm{yr}$ but may be important if the target $\mathrm{P}$ [Collapse] were $10^{-7} / \mathrm{yr}$. The time-frame considered may also be important. Risks that are annualized portray a different picture of risk exposure than those that are determined on a 50 year to 100 year basis, and may affect the decision. A competing hazard analysis allows the stakeholders and decision-makers to screen out trivial hazards, to focus on those hazards that lead to unacceptable increases in building failure rates above the de minimis level, and to devise appropriate risk mitigation strategies for those hazards.

\subsubsection{Measurement of Risk}

A key ingredient of risk management is identification of appropriate risk metrics for measuring the "Loss" term in Eqs. (2.1) and (2.2). Structural codes traditionally have been concerned first and foremost with public safety (preventing loss of life or personal injury), and in this context the collapse of a building, or a large portion of it, is a surrogate for all other metrics as it addresses that fundamental goal. It is expected that this will continue to be the primary objective of building codes as the shift toward performance-based engineering occurs over the next decade. Other performance metrics-direct economic losses from building damage, indirect losses due to interruption of function, lost business opportunities and loss of amenity - traditionally have not been addressed by the building regulatory community, but may be of concern to certain stakeholder groups for certain types of building facilities. It is important that the building design team arrives at a common understanding of how risk is to be measured, as this will determine the performance objectives for the project. This point will be addressed in Section 2.5.1. 


\section{$2.3 \quad$ HAZARDS}

A number of potential abnormal load hazards, which could trigger progressive collapse, are considered in the following paragraphs. These hazards have a low probability of occurrence and are either not considered in structural design for economic reasons or addressed indirectly through passive protective measures rather than by structural calculations. Among the reasons are: general lack of meaningful load data, difficulty in identifying possible hazard scenarios; lack of any assurance that designing for specific loads would be effective in reducing the incidence of progressive collapse. There is a consensus that strategies to manage the risk of progressive collapse from a structural engineering viewpoint should focus on methods that enable a damaged structural system to maintain its overall integrity following an abnormal load event (Breen and Siess 1979). Nevertheless, one must understand the characteristics of abnormal load events, in terms of incidence and intensity, to judge their overall significance in building construction and to predict the extent of damage that might have to be tolerated by the building structural system in specific hazard scenarios.

Abnormal loads may be grouped as pressure loads (e.g., explosions, detonations, tornado wind pressures), impact (e.g., vehicular collision, aircraft or missile impact, debris, swinging objects during construction or demolition), deformation-related (softening of steel in fire, foundation subsidence), or as faulty practice (Somes 1973; Burnett 1975b). Characteristically, the loads usually act over a relatively short period of time in comparison with ordinary design loads. The loads generally are time-varying, but may be static or dynamic in their structural action, depending on the frequency content of the load and the dynamic response characteristics of the resisting structural system (Ellingwood and Leyendecker 1978).

The Poisson occurrence model is widely used to model the random occurrence of rare events. In its simplest formulation, if the occurrences of events are statistically independent, the probability of occurrence in any interval of time, $\Delta \mathrm{t}$, is $\lambda \Delta \mathrm{t}$, and the probability of two (or more) simultaneous events is essentially zero. The number of events that occurs in time interval $(0, t)$ is a random variable, $N(t)$, and the probability that $r$ events occur in that same time interval is (Melchers 1999) as follows:

$$
\mathrm{P}[\mathrm{N}(\mathrm{t})=\mathrm{r}]=(\lambda \mathrm{t})^{\mathrm{r}} \exp (-\lambda \mathrm{t}) / \mathrm{r} ! ; \mathrm{r}=0,1,2,3 \ldots
$$

It may be shown that the expected (average) number of events in $(0, t)$ is $\lambda \mathrm{t}$; hence $\lambda=$ mean rate of occurrence of the Poisson events. Furthermore, the probability of at least one event in $(0, t)$ is

$$
\mathrm{P}[\mathrm{N}(\mathrm{t}) \geq 1]=1-\mathrm{P}[\mathrm{N}(\mathrm{t})=0]=\lambda \mathrm{t}
$$

Accordingly, if the events are very rare, then the probability of one occurrence in $(0, t)$ is approximately equal to $\lambda \mathrm{t}$, i.e., for hazard $\mathrm{H}, \mathrm{P}[\mathrm{H}] \approx \lambda_{\mathrm{H}} \mathrm{t}$. An abnormal load event normally has a short duration with respect to common gravity loads considered in structural design, measured on a time scale of seconds to minutes rather than days to years. The probability that the abnormal load is nonzero at any point in time is approximately $\lambda \tau$, in which $\tau=$ mean duration of the event. This short duration has significant implications for the development of design scenarios and load combinations involving abnormal loads. This point is addressed in detail in Section 2.5.3.

The Poisson model can be used to model the occurrence of events that can be assumed to occur randomly in time across the building inventory, i.e., hazards that are not altered systematically by deliberate human intervention. These would include fire, vehicular collisions, gas explosions, and similar effects where the 
entire building inventory (or least a significant portion of it) is exposed to the hazard. In contrast, a terrorist attack is a deliberate malevolent event directed at a specific target to maximize sociopolitical impact. The terrorist with a bomb can choose the time and target so as to maximize social disruption. Such targets are likely to include arenas and other large public assembly buildings, monumental or iconic structures, and certain governmental facilities. However, the risk to most ordinary building structures is minimal. The deliberate (non-random) nature of this hazard distinguishes it from the others identified above. Thus, in contrast to the other hazards above, the assumptions that underlie the Poisson model do not apply to incidents involving bomb explosions and similar terrorist events.

\subsubsection{Aircraft Impact}

Aircraft traffic consists of the two basic categories: civilian aviation and military aviation. The first category can be further broken down into commercial (or scheduled route) and general aviation. General aviation includes a wide variety of activities and aircraft, and accounts for approximately $80 \%$ of all civilian aviation activities. The National Transportation Safety Board (NTSB) maintains statistics on civilian aviation accidents, including those involving the built environment. The majority of accidents occur in take-off or landing operations. NTSB figures indicate that over half of all such accidents occur at airport sites and only $30 \%$ occur at distances greater than $8 \mathrm{~km}(5 \mathrm{mi})$ from the airport. The building collision rate for military aircraft is lower. Thus, for buildings some distance removed from airports, the impact probability clearly is less than the de minimis threshold. Although aircraft impact does not appear to pose a credible threat to the vast majority of buildings, certain key facilities within $10 \mathrm{~km}(6 \mathrm{mi})$ of an airport may require a site-specific analysis.

\subsubsection{Design or Construction Error}

A majority of structural failures and damage costs in ordinary buildings (some estimates range as high as $80 \%$ ) occur as a result of errors in planning, design, construction, and use rather than stochastic variability in resistance and load. Errors in concept, analysis and execution, and other unforeseen circumstances occur even when qualified personnel are involved in design and construction and when accepted methods of quality assurance and control are employed. Such errors result from human imperfections and are difficult to quantify. Modern code safety checks, such as load and resistance factor design (LRFD), are not developed with such errors in mind. Design and construction errors do not simply change the statistics in load or resistance that are used to derive probability-based design criteria; rather, they change fundamentally the load and resistance models or the relevant design limit states (Ellingwood 1987). This source of "abnormal" load or resistance is better dealt by the engineer recognizing that things can go wrong, through a consideration of hazard scenarios, and through improvements in quality assurance and control. Such performance-oriented thinking is essential to progressive collapse mitigation in general.

\subsubsection{Fire}

The fire hazard lies at an intersection between normal and abnormal loads. Traditionally, structural engineers have rarely been responsible for structural fire protection, and such protection was provided by non-structural means, such as thermal insulation. This state of affairs is changing, with the recognition that structural design for fire conditions often can add value to the building process. Fire protection traditionally has been based on component qualification testing (e.g., ASTME 119) and prescriptive 
design (ASCE/SEI/SFPE Standard 29-05), in which acceptance criteria are based on the tested component surviving a "standard" fire for a prescribed rating period. It must be understood that this test method is not intended to represent realistic conditions, but is a standard protocol for comparing relative performance of different systems. With advances in fire science and advanced structural analysis as a design tool, it is becoming possible to consider realistic fire scenarios and fire effects on the system as a whole as part of the structural design process (Kruppa 2000; Bennetts and Thomas 2002; SFPE 2002; AISC 2005a). The new approach of performance-based engineering, where there is a strong motivation to seek alternatives to design by qualification testing, will move the structural engineering profession in this direction in fire safety assurance. Structural engineering for fire conditions may become an important aspect of design for progressive collapse resistance of structural systems, especially where fire protection may have been removed by impact or other abnormal loads.

The ignition of a fire can be modeled as a Poisson event, with a mean rate of occurrence that is related to floor area. That rate is on the order of $0.2 \times 10^{-6} / \mathrm{m}^{2}$ per yr to $1.0 \times 10^{-6} / \mathrm{m}^{2}$ per yr $\left(0.2 \times 10^{-7} / \mathrm{ft}^{2}\right.$ per yr to $1.0 \times 10^{-7} / \mathrm{ft}^{2}$ per yr), the lower value tending to be for dwellings and the higher value for offices and commercial facilities (CIB W14 1983). Following ignition, the likelihood of flashover (occurrence of a fully developed compartment fire with the potential to cause significant structural damage) depends on the presence of fire detection and mitigation systems. Typical flashover probabilities (in hotels or schools) are on the order of 0.01 to 0.02 if a sprinkler system is present. Accordingly, the mean occurrence rate of a structurally significant fire, $\lambda_{\mathrm{T}}$, is on the order of $10^{-8} / \mathrm{m}^{2}$ per $\mathrm{yr}\left(10^{-9} / \mathrm{ft}^{2} \mathrm{per} \mathrm{yr}\right)$.

Fire scenarios produce temperature-time curves (fire exposure curves) that can be used in advanced structural analysis to assess the structural response during the heating phase and cooling following exhaustion of combustibles. These curves have yet to be standardized, but procedures for their determination are available. The time-temperature curve depends on the fire load, compartment ventilation, and bounding surfaces. When a building contains materials that pose a high fire hazard, involving high fuel loads, flammable liquids or explosive materials, or compartment areas greater than $1000 \mathrm{~m}^{2}\left(10000 \mathrm{ft}^{2}\right)$, a special analysis of fire hazard and fire exposure (temperature and duration) should be conducted. A structurally significant fire results in an imposed deformation on the building structure, and the forces developed in an indeterminate building frame are self-limiting in nature. Moreover, the strength and stiffness of structural materials are temperature-dependent and degrade to a fraction of the room temperature values at temperatures as high as $1000^{\circ} \mathrm{C}\left(1800^{\circ} \mathrm{F}\right)$ that may occur in a fully developed compartment fire. Results of recent full-scale building fire tests indicate that advanced structural analysis can reproduce the actual behavior of the structure with sufficient accuracy for structural design purposes (Green and Wong 2001; Bailey and Moore 2000a, 2000b).

\subsubsection{Gas Explosions}

With the extent of the network of pipelines that distribute natural gas in the United States and the number of dwellings that rely on natural gas for fundamental utility services, it is evident that gas-related explosions pose a potential hazard to building structures in most urban areas of the United States. The incidence of gas explosions can be obtained from the Office of Pipeline Safety Operations (OPSO) of the U.S. Department of Transportation and the American Gas Association (AGA). The OPSO maintains data on leaks and explosions on the distribution side (upstream) of the consumers' meter, while the AGA data include gas-related incidents on the customer side (downstream). Accordingly, the two databases are not 
consistent with one another. Moreover, the databases contain information on cost of claims but not on structurally significant damage.

An early study of the incidences of gas explosions in dwellings (Leyendecker and Burnett 1976) indicated that the mean rate of occurrence of gas explosions in dwellings was approximately $1.8 \times 10^{-5} / \mathrm{yr}$. This number since has been confirmed in two (unpublished) studies in the U.S. and the U.K., where the mean occurrence rates were found to be $2.3 \times 10^{-5} / \mathrm{yr}$ and $1.86 \times 10^{-5} / \mathrm{yr}$, respectively. Accordingly, it may be assumed that $\lambda_{\mathrm{G}} \approx 2 \times 10^{-5}$ per dwelling unit per yr. While the rate of occurrence of explosions in buildings in which a large number of units are served by natural gas is higher than in single-tenant or occupant buildings, the increase is not linear.

Following the Ronan Point collapse (discussed in Section 1.1 and Appendix C), a number of studies were conducted to determine the pressures developed in a residential compartment from an explosion of natural (building service) gas. The pressures developed in tests conducted at the optimum air/fuel mixture depended on the compartment venting and resonance of the air mass within the compartment, but seldom exceeded $17 \mathrm{kPa}$ (2.5 psi or $360 \mathrm{psf}$ ). This is a very large load when compared with ordinary design loads due to live, wind and snow load (on the order of $4.8 \mathrm{kPa}$ (100 psf) or less), but is substantially less than the $34 \mathrm{kPa}$ (5 psi) load that was mentioned frequently as the "normative" abnormal load in several regulatory documents at the time. Figure 2-1 shows a typical time history of the pressure resulting from a gas explosion. Venting limits the pressure intensity of the first pulse and the high-frequency fluctuations in pressure in the second phase are of little significance to structural response. Accordingly, the pressure effect on a structure is essentially static in nature.

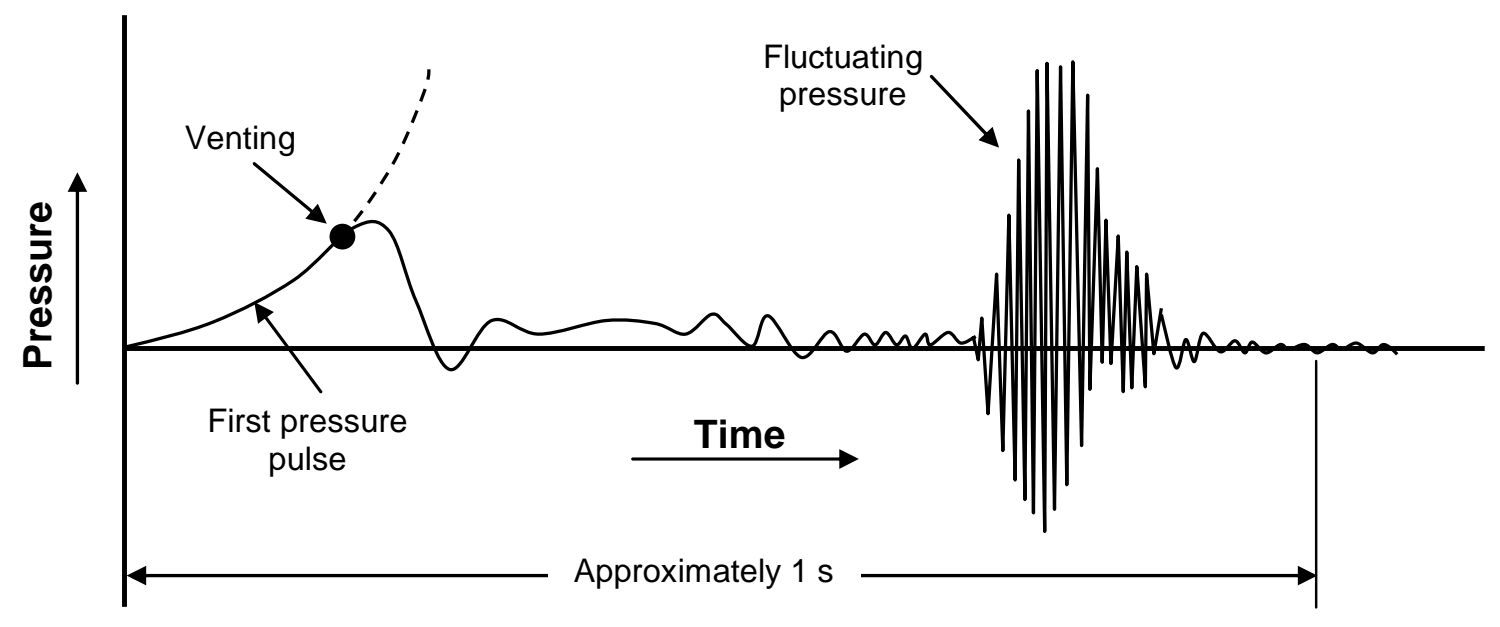

Figure 2-1 Typical pressure-time record from gas explosion (adapted from Leyendecker and Ellingwood 1976)

\subsubsection{Overload Due to Occupant Misuse}

This hazard falls in the same category as design/construction error. No information could be located to describe statistically the incidence of this hazard or its intensity. Some building owners or managers commission condition surveys aimed at determining the nature of the building occupancy and building contents. Data from such surveys are, however, practically impossible to obtain for analysis. 


\subsubsection{Transportation and Storage of Hazardous Materials}

Sources of hazardous materials include pipelines, motor vehicle transport, railway transport, water carriers and storage facilities. The potential for fire or explosion from ignition of unconfined vapors from transported liquids or gases poses a hazard to buildings that are in close proximity, one that increases in areas of high population density. There is no single national repository of data on such incidents. Although no data on the incidence or magnitude of such events could be located, the lack of media coverage suggests that the mean rate of occurrence of such events is below the de minimis threshold where they would require consideration. Further increases in population density may cause this view to change.

\subsubsection{Vehicular Collision}

Vehicular collisions with buildings occur mainly in urban areas due to single vehicles leaving the roadway. One early study (Leyendecker and Burnett, 1976) suggested that the annual frequency of impact of motor vehicles with buildings was approximately $6 \times 10^{-4}$ per dwelling unit per yr. More recent data describing the incidence of such collisions nationwide could not be located. Forces due to vehicular collision (involving trains and barges, as well as trucks) may be obtained from an analysis that relates the energy absorbed by the vehicle and the structure itself during the collision. The technology necessary to determine the impact force is available, but there are large uncertainties in the determination of the kinetic energy to be dissipated during the collision. A specific accident scenario-velocity of vehicle, distance of building from traffic-way, direction of impact, coefficient of restitution - must be postulated to estimate the impact force (Figure 2-2).

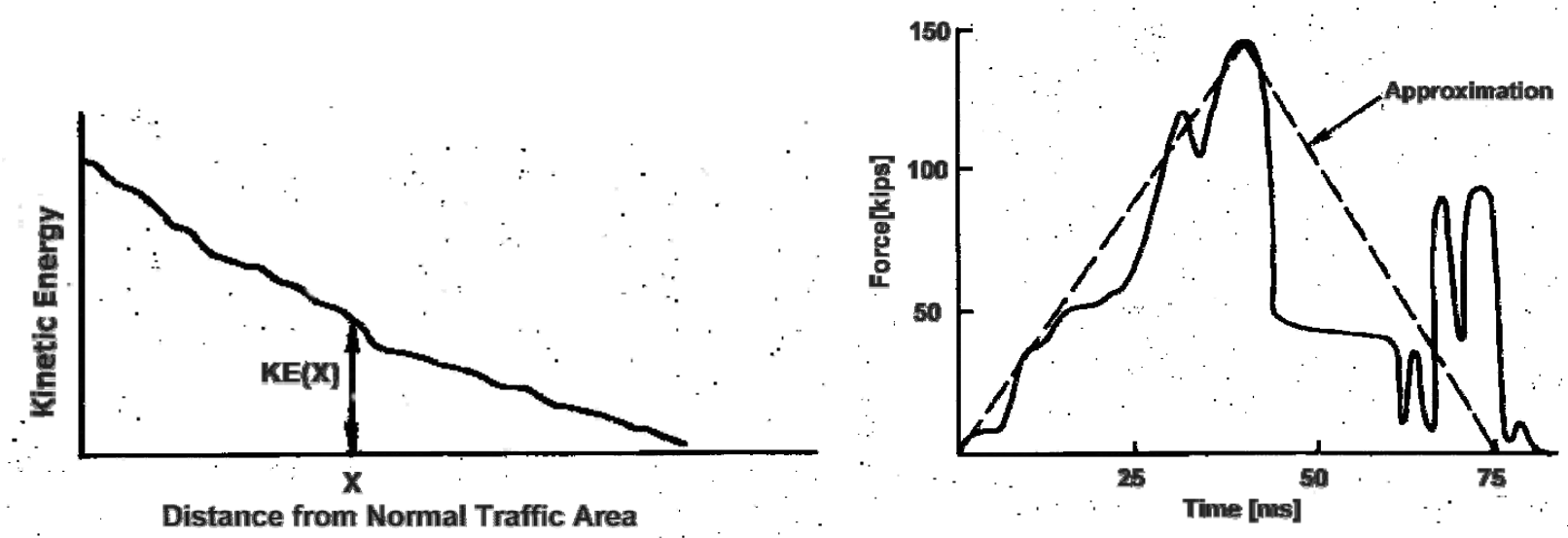

Figure 2-2 Schematic of force on column due to vehicular impact

\subsubsection{Bomb Explosions}

Records of bombings in the United States are maintained by the National Bomb Data Center, archived first by the International Association of Chiefs of Police and subsequently by the Federal Bureau of Investigation. Because bombings usually involve organized malevolent activities that are directed at a specific target for sociopolitical purposes, modeling their occurrence as Poisson events is questionable. Regrettably, the incidence of bombings and other types of sabotage is increasing in the United States and worldwide. In 1997, there were more than 250 bombing attacks against buildings in the U.S. (FBI 1998). 
This would suggest a mean occurrence rate on the order of $2 \times 10^{-6}$ per building, were these events to be truly random in occurrence (they are not, as noted above). The primary cause of occupant deaths from sabotage bombings was building collapse, while the primary cause of nonfatal injuries was flying debris (NRC 2000).

Bomb detonations create shock wave pressures that expand at a velocity on the order of $1 \mathrm{~km} / \mathrm{s}(0.6 \mathrm{mi} / \mathrm{s})$ and the dynamic pressures depend on yield and distance from the point of detonation. The initial positive pressure phase is followed by a longer and less intense negative phase; the pressure can be approximated by a triangular impulse load with essentially instantaneous rise time, linear decay, and a duration that depends on the size of the charge and distance (see Figure 2-3) but is on the order of tens of milliseconds.

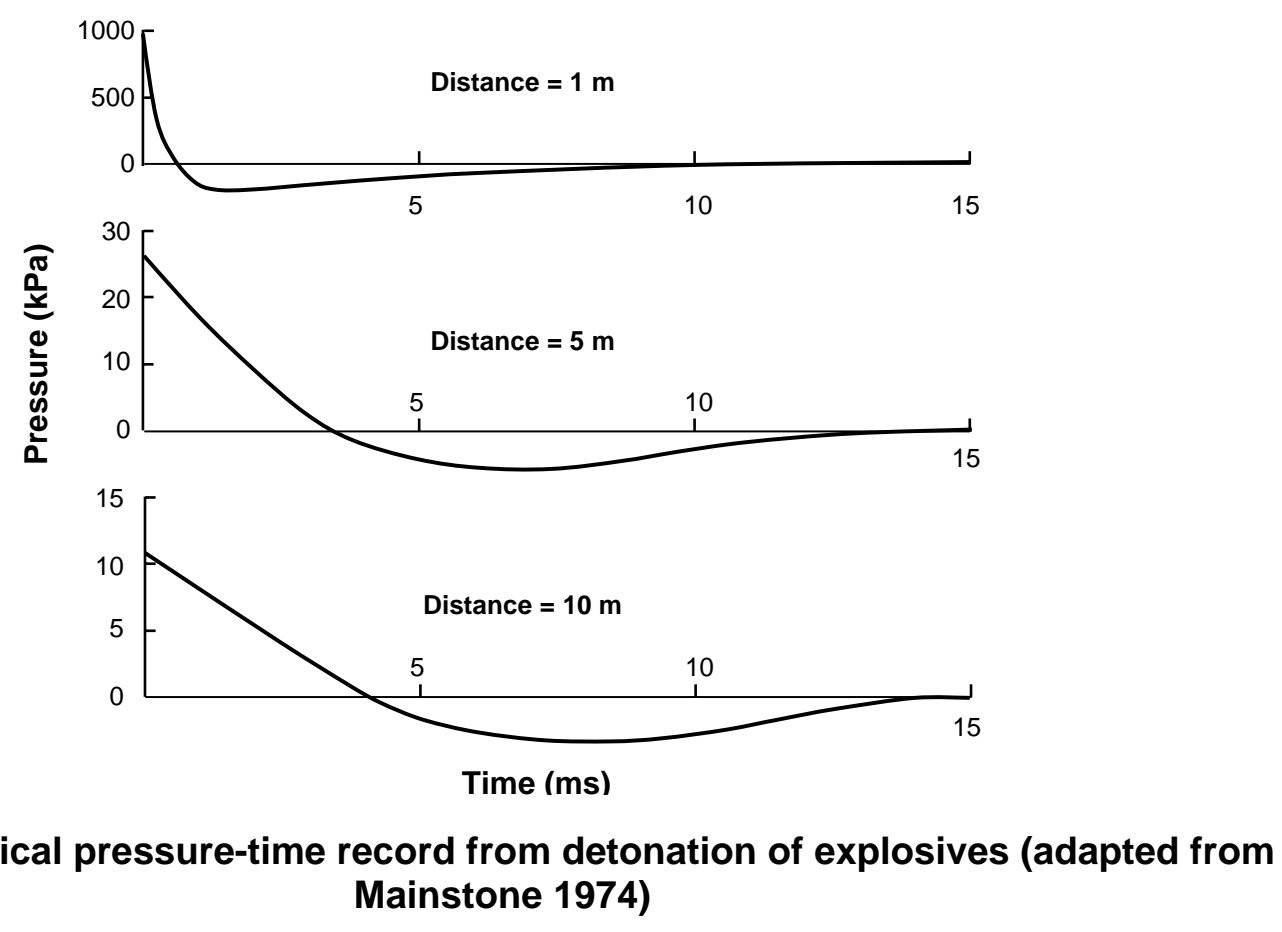

The structural effects of a large exterior explosion can be summarized as follows (FEMA 427):

- The pressure wave acts on the exterior of the building and may cause window breakage and wall or column failures;

- As the pressure wave continues to expand into the building, upward pressures are applied to the ceilings and downward pressures are applied to the floors;

- Floor failure is common due to the large surface area upon which the pressure acts; and

- Failure of floor slabs eliminates lateral support to vertical load-bearing elements, making the structure prone to progressive collapse.

For a smaller interior explosion, the type of expected damage may include (FEMA 427):

- Localized failure of the floor system below the detonation; 
- Damage and possible localized failure of the floor system above the detonation;

- Damage and possible localized failure of nearby walls (concrete or masonry); and

- Failure of non-structural elements (partitions, ductwork, windows).

While an interior charge may be smaller, the blast pressures can be large because the explosion is not able to vent, and reflections from interior surfaces will amplify the gas pressures. If the charge were to be placed strategically near a main vertical load-bearing element, more extensive damage could occur, possibly resulting in progressive collapse.

The incidence data do not distinguish exterior and interior explosions.

Most of the information on the structural impact of such detonations has been gathered by the military and is not widely available in the general structural engineering community. Providing detailed guidance to the general structural community on such effects might provide terrorists with information needed to defeat the design strategy. ASCE Standard Committee 7 has decided not to provide any information on explosive effects in ASCE Standard 7, in part for this reason. However, the recent Blast Mitigation for Structures Program, conducted by the Department of Defense, has produced new information that can be used to design more robust new buildings and to upgrade existing facilities to withstand terrorist attack (NRC 2001). The report of an ASCE task committee on structural design for physical security (1999) also contains relevant information. The SEI/ASCE Blast Protection of Buildings Standards Committee is in the process (in 2005) of developing a standard on blast protection of buildings, which should contain a section on blast loading. A primer on the design of commercial buildings to mitigate terrorist attacks also contains basic information and references on blast loading (FEMA 427, 2003).

\subsubsection{Summary and Critical Appraisal}

Statistical data exist to describe the incidence of certain abnormal load events, expressed in terms of mean rate of occurrence, $\lambda_{\mathrm{H}}$. These mean rates of occurrence appear to be reasonably independent of building construction but depend on occupancy. The data reported above for buildings in the United States compare favorably, in order of magnitude, to similar data reported in other industrialized countries. They should be considered order-of-magnitude only. Some incidences depend on building size (e.g., buildings with a large number of independent occupancies or living compartments are at higher risk for gas explosions or fire effects), accessibility or configuration (e.g.,. vehicular collisions or sabotage affect mainly ground story or basement areas). It is difficult to glean these differences from the data reported, which focus more on dollar impact than on structural behavior. There have been no attempts to examine incidences with respect to whether the building is symbolic, is a government facility, or has special occupancy characteristics. Because these factors are important for certain hazards (e.g., certain occupancies may be especially vulnerable to bombing threats), defining $\lambda_{\mathrm{H}}$ for a particular building by looking at the number of incidents with respect to the overall building population is likely to lead to an erroneous estimate of the actual hazard faced by that building. Furthermore, structural engineers have little control of tenant profile, and the design team may not be able to determine what the tenant profile will be during the period of occupancy when designing a new building. In such cases, a scenario analysis [based on Eq. (2.2)] might be a better approach to risk mitigation. Ultimately, such questions must be addressed to take full advantage of risk mitigation strategies in improving building practices. 


\section{$2.4 \quad$ BUILDING VULNERABILITY}

Most building structures are vulnerable in varying degrees to progressive collapse developing from local damage. It has been estimated that approximately $15 \%$ to $20 \%$ of building collapses develop in this manner (Leyendecker and Burnett 1976). The concern of the building regulatory community on progressive collapse as a structural engineering issue was triggered by the collapse of the Ronan Point Tower (see Section 1.1 and Appendix C). There have been other notable progressive collapse failures in the United States. To mention three, the Skyline Plaza at Bailey's Crossroads, VA, was a reinforced concrete flat plate structure which collapsed during construction in 1973; the punching shear failure at a $23^{\text {rd }}$ floor column initiated due to premature removal of formwork. The Civic Arena roof in Hartford, CT, was a steel space truss, which collapsed in January, 1978 under a combination of rain and snow load estimated at approximately $800 \mathrm{~Pa}(17 \mathrm{psf})$, which was less than $60 \%$ of the design load. The cause of failure was identified as premature buckling of compression chord members resulting from a design error. Finally, the Alfred P. Murrah Federal Building in Oklahoma City, which collapsed in 1995 as a result of a blast caused by a large truck bomb, had a reinforced concrete frame structure (see Appendix C) ${ }^{2}$.

While all buildings are at risk, certain attributes may make a building particularly vulnerable to progressive collapse. Some of these attributes are inherent to the building structural system. Others are determined by the nature of the building occupancy or the presence of the building in the community.

Perhaps the most important factor contributing to structural vulnerability is a lack of continuity within the system and lack of ductility in structural materials, members, and connections. Such systems lack "robustness" and are poorly suited to absorb or dissipate energy resulting from local damage. Large-panel or bearing wall construction and pre-cast concrete slabs or steel joist floors supported on masonry walls are inherently more vulnerable because of the difficulties in providing continuity and ductility in such systems. On the other hand, redundancy (large number of bearing walls and shorter spans) in such systems can compensate, to an extent, for reduced ductility. Flat-slab and flat-plate structures may be vulnerable to weak column/slab joints, which can be addressed by careful design. Load-bearing nonreinforced masonry walls resist poorly structural actions that are not in compression. Long-span roof structures bearing on walls require special consideration. Pre-engineered buildings are designed tightly with respect to the design envelope as a result of competition, and are sensitive to even moderate deviations from that envelope caused by unforeseen events. Many parking garages of post-tensioned construction cannot tolerate reversals in structural actions (e.g., uplift forces arising from detonation of a moderate-sized car bomb). Conversely, highly redundant frame structures or other structures designed to accommodate load reversals or changes in span if an unforeseen event occurs tend to absorb local damage reasonably well.

In the $21^{\text {st }}$ century, it should be anticipated that symbolic buildings or buildings representing or housing government, financial or corporate authority are more likely to be the object of abnormal loads from terrorist attack than the building inventory at large. Buildings associated with domestic issues that are socially or politically volatile (e.g., abortion clinics) also are at increased risk. While this vulnerability is not determined by the inherent characteristics of the building structural system, certain systems clearly are better suited to confront it.

\footnotetext{
${ }^{2}$ Some have argued that the Murrah Building collapse, stemming from the loss of three exterior columns, was not "disproportionate" for a building of its size, pointing out the difficulty in devising an unambiguous definition of progressive collapse for code implementation.
} 
Appendix C presents a number of case studies that offer insight into the causes of, and strategies for mitigating progressive collapse. Clearly, progressive collapse is an issue with many structural systems, and while some systems may be more vulnerable than others, progressive collapse provisions should be useable for any type of building construction.

\subsection{DESIGN TO REDUCE RISK OF PROGRESSIVE COLLAPSE}

Design for mitigating the risk of progressive collapse requires a different way of thinking than traditional building structural design approaches, which historically have been closely tied to prescriptive codes and standards. Perhaps most important, the design process must focus on what may go wrong. One begins by identifying the performance requirements that must be met; identifies specific hazard scenarios (threats, occurrences of abnormal loads, damage states, without regard to cause), computes the probability of not meeting the performance requirement; and finally, assesses the consequences of not meeting the requirement (Stewart and Melchers 1997). Within this general framework, the hazard scenario can be threat-specific or non threat-specific and the design approach (technical engineering response) can be indirect or direct.

\subsubsection{Performance Objective}

The performance objectives must be mutually understood and agreed upon among the stakeholders. These objectives are coupled to the way that risk is measured (see discussion in Section 2.2.3). It is clear that the objectives of life safety and rapid egress of building occupants, and life safety for fire-fighters and other first-responders must be paramount. How long the building must remain standing following local damage to allow these essential actions is an issue in determining the appropriate load combinations. Above and beyond these objectives, protection of property or minimal disruption of function or business operation so as to minimize economic losses and environmental protection may also be considered in certain circumstances.

\subsubsection{Performance Matrix}

The engineer and other members of the design team must determine which hazardous events and damage scenarios to consider and what are the acceptable probabilities and consequences. It is reasonable to expect that these would be related in some way to the building classification system in $A S C E$ Standard 7-05, Table 1-1. Such matrices have been proposed as part of the move toward performancebased earthquake engineering (e.g., FEMA 273 (1997) and FEMA 356 (2000a)). Specific recommendations would be premature at this early stage, other than that the building-design team should familiarize itself with this mode of thinking.

\subsubsection{Specific Design Strategies}

Basic progressive collapse risk mitigation strategies must be aimed at three basic levels: (i) to prevent the occurrence of intentional abnormal loads through social or political means; (ii) to prevent the occurrence of local significant structural damage that is likely to initiate a progressive collapse; and (iii) to prevent structural system collapse and loss of life through structural design, compartmentalization, development of alternate load paths, alternate exit-ways, and other active and passive measures. 
Let $\mathrm{H}$ be the event that a potentially damaging (abnormal) load occurs, let LD be the event that local damage occurs, and let $\mathrm{C}$ be the event that structural collapse ensues from this local damage. Rewriting Eq. (2.3) and making obvious abbreviations, the probability of structural collapse is,

$$
\mathrm{P}(\mathrm{C})=\mathrm{P}(\mathrm{C} \mid \mathrm{LD}) \mathrm{P}(\mathrm{LD} \mid \mathrm{H}) \lambda_{\mathrm{H}}
$$

in which the $\mathrm{P}[\mathrm{H}] \approx \lambda_{\mathrm{H}}$. How long the building must remain standing following local damage is an issue in determining the appropriate load combinations. This decomposition of the collapse probability into three components is instructive for focusing attention on appropriate strategies for hazard prevention, withstanding local damage, and absorbing local damage without progressive collapse. Reductions in $\mathrm{P}[\mathrm{C}]$ can be achieved by reducing any one, or all three, of the terms in this equation. The most cost-effective strategy for most buildings is likely to involve some combination of the three.

\section{(i) Event control}

Event control involves preventing the occurrence of the hazard (or, equivalently, taking actions to limit $\lambda_{\mathrm{H}}$ to below the de minimis threshold — see Section 2.2.2), and requires that a specific threat (or spectrum of threats) be identified. Such actions might include changes in the building site or access to it (e.g., imposing a minimum stand-off distance through placement of physical barriers and similar devices (Conrath, et al. 1999), or preventing access to certain building zones), by controlling hazardous substances within the building (e.g., limiting the use of natural gas), and by educating the building occupants on the need for caution with dangerous substances or unauthorized access. An assessment of contributors to risk based on Eq. (2.1) often shows that controlling the probability or mean rate of occurrence of the hazard is the most cost-effective route to risk reduction. Most of these measures do not require professional structural engineering services.

While it may be effective to deal with certain hazards in this manner (e.g., terrorist attack on buildings), such measures are problematic. For example, the writer is aware of one jurisdiction in which it was suggested that the use of natural gas be prohibited in certain multi-family residential buildings over four stories in height; the socio-economic impact of that ordinance, had it been implemented, would have been unacceptable.

\section{(ii) Structural engineering - probabilistic bases}

The main goal of structural engineering against the effect of abnormal loads and to mitigate progressive collapse is to obtain an acceptably low probability of a catastrophe involving loss of life, unacceptable economic or social losses, and damage to the environment. In meeting these performance objectives, a certain amount of damage to the building structure may be incurred and tolerated. Structural engineering is focused on the terms $\mathrm{P}(\mathrm{C} \mid \mathrm{LD})$ and $\mathrm{P}(\mathrm{LD} \mid \mathrm{H})$ in Eq. (2.6).

As discussed in Chapter 3 and 4, structural engineering and design options include designing the structure to withstand specific abnormal loads (specific local resistance design) or designing and detailing the structure to withstand local damage without collapse (alternate load path design). In a "specific local resistance" design strategy, the focus is on controlling $\mathrm{P}(\mathrm{C})$ by limiting $\mathrm{P}(\mathrm{LD} \mid \mathrm{H})$, that is, to minimize the likelihood of initiation of damage that may lead to progressive collapse. Generally speaking, this requires that a specific threat be identified in order to determine the demand placed on the structural member, component or subsystem. In an "alternate load path" design strategy, the focus is on controlling $\mathrm{P}(\mathrm{C})$ by limiting $\mathrm{P}(\mathrm{C} \mid \mathrm{LD})$. This may require that the design team identify a specific threat (e.g., a detonation that would remove one load-bearing element from the perimeter frame). Alternatively, the design team might 
envision certain structural damage scenarios, without regard to specific cause, and require that the system as a whole absorb such damage without progressive collapse. In any event, it is in minimizing these two probabilities that the science and art of the structural engineer becomes paramount. Structural engineering solutions might range from minimum provisions for continuity to a complete post-damage structural analysis, in which load-carrying mechanisms not normally considered in ordinary building design (e.g., membrane action of floors, large-deformations, significant nonlinear action) are mobilized.

\section{1) Reliability bases for design for conditional limit states}

As noted in Section 2.3, accidental loads occur randomly in space and in time, have uncertain magnitudes, and statistical data on their incidence, magnitude and structural effects rarely are available. "Normative" abnormal loads specified by an authority having jurisdiction for design (e.g., uniform pressure of $34 \mathrm{kPa}$ (5 psi) that found its way into some standards following the Ronan Point collapse) are arbitrary.

Similarly, the variables describing the capacity of structural members and systems and other loads that act at the time the accidental event occurs are also random. Accordingly, structural reliability principles are required to devise appropriate strategies for managing this risk.

To evaluate the terms $\mathrm{P}[\mathrm{LD} \mid \mathrm{H}]$ or $\mathrm{P}[\mathrm{C} \mid \mathrm{LD}]$, one must first postulate a mathematical model of the structural component or system, $\mathrm{G}(\mathbf{X})=0$, of load and resistance variables, expressed by vector $\mathbf{X}$, based on principles of mechanics and supplemented, where possible, with experimental data. One then determines the probability distributions of each variable, and integrates the joint density function of $\mathbf{X}$ over that region of the probability space where $G(X)<0$ to compute the conditional limit state probability. For example, in an alternate load path approach, local damage is accepted and $\mathrm{P}[\mathrm{LD} \mid \mathrm{H}] \approx 1$. In this case, $\mathrm{P}[\mathrm{C}] \approx \mathrm{P}[\mathrm{C} \mid \mathrm{LD}] \lambda_{\mathrm{H}}$, in which,

$$
P[C \mid L D]=\int F_{R}(x) f_{Q}(x) d x
$$

where $\mathrm{F}_{\mathrm{R}}(\mathrm{x})=$ cumulative distribution function $(\mathrm{CDF})$ of structural resistance in the damaged state and $\mathrm{f}_{\mathrm{Q}}(\mathrm{x})=$ probability density function $(\mathrm{PDF})$ of load, $\mathrm{Q}$. In order for $\mathrm{P}[\mathrm{C}]$ to be at the de minimis threshold, this conditional probability must be limited to,

$$
\mathrm{P}[\mathrm{C} \mid \mathrm{LD}] \approx 10^{-7} / \lambda_{\mathrm{H}}
$$

First-generation probability-based limit states design criteria (such as AISC LRFD, the Canadian CSA S16.1 (CSA 2000), and the Eurocodes) all are based, to varying degrees, on reliability of individual structural members and components (Ellingwood 2001). However, to implement practical reliabilitybased design criteria for alternate load path development, the limit state probability (or reliability index) must be evaluated for a structural system. The identification of suitable conditional limit state functions presents a significant research challenge. The limit states - formation of a mechanism, rupture, instability, loss of overall equilibrium - are not unusual. However, the structure may have already sustained a significant amount of damage. Thus, sources of load-carrying capacity that normally would not be considered in LRFD should be included in $G(\mathbf{X})$; these might include membrane or catenary action in floor systems, substantial inelastic behavior of members and connections, and other load-resisting mechanisms accompanied by large inelastic deformations. Structural analysis should allow for geometric and material nonlinearities and should model connection behavior at extreme conditions accurately.

Analysis of limit state probabilities for structural members currently designed for gravity loads, in which failures occur in a ductile fashion, suggests that these member failure probabilities (again, under gravity 
loads) are on the order of $10^{-5} / \mathrm{yr}$. The probability of structural system failure is approximately one order of magnitude less, depending on the redundancy in the system and the degree of continuity between members. If $\lambda_{\mathrm{H}}=10^{-6} / \mathrm{yr}$ to $10^{-5} / \mathrm{yr}$, then $\mathrm{P}[\mathrm{C} \mid \mathrm{LD}]$ should be limited to $0.01 / \mathrm{yr}$ to $0.10 / \mathrm{yr}$. For those readers more accustomed to thinking in terms of a reliability index, $\beta=\Phi^{-1}\left[10^{-7} / \lambda_{H}\right] \approx 1.5$, in which $\Phi^{-1}[]$ is the percent point function of a standard normal variate. This $\beta$ is substantially less than that targeted for firstgeneration LRFD because of the conditional nature of the limit state. Load and resistance criteria can be developed to be consistent with this reliability (Ellingwood 2001).

\section{2) Load combinations and resistance criteria for alternate path and specific local resistance approaches.}

Modern probabilistic analysis of load combinations has shown that the maximum combined structural action due to several randomly occurring events occurs when one of the actions achieves its maximum value while the other loads are at their frequent values. In other words, the probability that two (or more) loads attain their maximum values simultaneously is vanishingly small, provided that the events are statistically independent. Thus, a structure may be designed for a combined action that is less than the sum of the maxima of the individual actions (Ellingwood et al. 1982). This observation, which has been verified both analytically and by simulation, has given rise to the "principal action-companion action" load combination format found, in one form or another, in all modern probability-based limit states design codes, including ASCE Standard 7-05 (ASCE 2005).

If the two load events that are being combined are both intermittent in nature, with relatively small occurrence rates $\lambda_{\mathrm{i}}$ and durations $\tau_{\mathrm{i}}$, the mean rate of occurrence of a coincidence of these two events is,

$$
\lambda_{\mathrm{ij}}=\lambda_{\mathrm{i}} \lambda_{\mathrm{j}}\left(\tau_{\mathrm{i}}+\tau_{\mathrm{j}}\right)
$$

Events (or combinations of events) with very small mean rates of occurrence, $\lambda_{\mathrm{i}}$, or coincidence, $\lambda_{\mathrm{ij}}$, contribute little to overall risk. If these mean rates are below the de minimis threshold, they can be ignored in risk assessment.

As a specific example of such an event combination analysis, consider the combination of fire $(\mathrm{T})$ and occupancy live load, which is the most important load combination for designing building structures to resist severe fires. The total live load on a floor system at any time is the sum of a sustained and an extraordinary component: $\mathrm{L}=\mathrm{L}_{\mathrm{s}}+\mathrm{L}_{\mathrm{e}}$. The sustained component is the load normally present (including normal personnel load), and is typically measured during a live load survey. The mean of this sustained live load is on the order of $25 \%$ to $30 \%$ (depending on tributary loaded area) of the nominal $A S C E$ Standard 7-05 live load. The extraordinary component arises from remodeling or emergency crowding and has a short duration (on the order of hours to days). The extraordinary component is not measured during a load survey and equals zero most of the time. The total live load reaches significant intensities only infrequently, when $\mathrm{L}_{\mathrm{e}}$ is present; in fact, the nominal live load in ASCE Standard 7-05 is approximately equal to the mean of the maximum (sustained plus extraordinary) live load to occur in a period of 50 years (Chalk and Corotis 1980).

A typical mean occurrence rate and duration for $\mathrm{L}_{\mathrm{e}}$ would be $1 / \mathrm{yr}$ and $1 \mathrm{~d}(0.0027 \mathrm{yr})$, respectively. If the mean rate and duration of a structurally significant fire are $10^{-6} / \mathrm{yr}$ and $4 \mathrm{~h}(0.00046 \mathrm{yr})$, the mean rate of a coincidence of $\mathrm{L}_{\mathrm{e}}$ and $\mathrm{T}$ (approximately the annual probability) is,

$$
\lambda_{\mathrm{Le}+\mathrm{T}}=(1 / \mathrm{yr})\left(10^{-6} / \mathrm{yr}\right)(0.00046 \mathrm{yr}+0.0027 \mathrm{yr})=3.2 \times 10^{-9} / \mathrm{yr}
$$


Because this mean coincidence rate is two orders of magnitude below the de minimis threshold, there is no need to consider combinations of $\mathrm{L}_{\mathrm{e}}$ and fire. Accordingly, the appropriate combination of fire and live load for structural design should consider only the sustained component, $\mathrm{L}_{\mathrm{s}}$ (Ellingwood and Corotis 1991) which, as noted above, is likely to be substantially less than $0.5 \mathrm{~L}$.

Two basic scenarios requiring load and resistance criteria can be envisioned for progressive collapse structural design and can be identified from the fundamental performance objective in Section 2.5.1. In the first, we consider criteria for evaluating the capability of a damaged structure to bridge over or around the damaged volume or area without a progressive collapse developing. In the second, criteria are devised to check the (local) resistance to withstand a specific postulated abnormal load. Normally, only the main load-bearing structure would need to be checked using these equations.

In the first scenario, an appropriate load combination to base the reliability analysis of a building structural system with local damage would be:

Dead Load + Sustained Live Load+ (Daily Snow or Monthly Maximum Wind Load)

Using load statistics reported elsewhere (e.g., Galambos et al. 1982) and principles of reliability analysis described earlier, we find that the required strength is given by the load combination

$$
(0.9 \text { or } 1.2) \mathrm{D}+0.5 \mathrm{~L}+\left(0.2 \mathrm{~W}_{\mathrm{n}} \text { or } 0.2 \mathrm{~S}\right)
$$

This load combination has an annual probability of being exceeded of approximately 0.05 . Note that the load factors on $\mathrm{L}, \mathrm{S}$ and $\mathrm{W}_{\mathrm{n}}$ are less than unity because their means are substantially less than the nominal loads specified in ASCE Standard 7-05. The contribution of uncertainty in dead load to the reliability of a damaged structure is not especially significant and decreases with number of stories supported, suggesting that the load factor might be taken as 1.0. On the other hand, it is known (Galambos et al. 1982) that engineers tend to underestimate the dead load; indeed, the mean dead load in modern construction typically is $5 \%$ to $10 \%$ higher than the nominally specified value. Accordingly, the dead load factor is kept as 1.2 (or 0.9 when dead load stabilizes the structural system), as with other load combinations. The use of this check requires identification of postulated structural damage scenarios and the notional removal of selected (presumably damaged) load-bearing elements consistent with each scenario at the discretion of the engineer without stipulating tolerable damage.

In the second scenario, the objective is to calculate the required resistance for a postulated abnormal load. Using a similar procedure, the required strength becomes,

$$
1.2 \mathrm{D}+\mathrm{A}_{\mathrm{k}}+0.5 \mathrm{~L}+0.2 \mathrm{~W}_{\mathrm{n}}
$$

in which $A_{k}=$ structural action due to the postulated abnormal load. This structural action can be a force, as in the case of explosion or impact, or deformation-related, as in the case of fire or ground subsidence. The load factor on $A_{k}$ is 1.0; it is assumed that $A_{k}$ will be scenario-based, because statistical data are limited or non-existent.

Progressive collapse, once initiated, is driven by gravity. Building structural systems rarely are perfectly symmetric or symmetrically loaded by gravity loads; nor are columns and beams perfectly straight; nor are fabrication and erection procedures perfect. Consequently, even a "perfect" frame is subject to sway 
under gravity forces. If this sway is not accounted for, large secondary (P- $\Delta$ ) forces will develop in the frame and lead to overall instability of the frame under gravity loads. The small lateral force $0.2 \mathrm{~W}_{\mathrm{n}}$ in Eqs. (2.12) and (2.13) ensures that the lateral stability of the damaged structural system is considered in the analysis. However, the Structural Stability Research Council (1998) has recommended that the lateral stability of a building frame under gravity forces be checked by imposing a small notional lateral force equal in magnitude to $0.002 \Sigma \mathrm{P}$ at each floor level, in which the term $\Sigma \mathrm{P}$ is the cumulative gravity force due to the summation of dead and live loads acting on the story above that level. This approach to ensuring lateral stability under gravity loads is being implemented in several modern specifications and standards (AISC 2005a; NBCC). If such a practice were followed in checking general structural integrity, the force $0.2 \mathrm{~W}_{\mathrm{n}}$ in Eqs. (2.12) and (2.13) would not be necessary.

LRFD stipulates that the required strength shall not exceed the design strength, $\phi \mathrm{R}_{\mathrm{n}}$, in which $\phi$ is the resistance factor and $\mathrm{R}_{\mathrm{n}}$ is the nominal strength determined by the governing code or standard. Resistance criteria to be used for this safety check should focus on median strength ${ }^{3}$ rather than nominal strength, because the objective of the analysis should be to obtain as realistic an estimate of structural performance as possible.

Specific recommendations for designing buildings against progressive collapse and for general structural integrity are found in Chapter 5. These recommendations address beams, columns, walls, slabs and foundations in steel, concrete and masonry construction.

\section{3) Current status of code implementation}

Many structural design standards in North America and in Western Europe have acknowledged the existence and potential consequences of abnormal loads and progressive collapse for some time. Most standards contain a statement of required structural performance for new construction, to the effect that local damage to the structure shall not have catastrophic consequences. These standards are compared in Appendix A of this document. A summary of features from design standards and guidelines in the United States, Canada, Western Europe that are significant for risk-based general design requirements is presented here.

ASCE Standard 7/ANSI Standard A58 first introduced a requirement for progressive collapse due to "local failure caused by severe overloads" in ANSI Standard A58.1-1972, the first edition that followed the Ronan Point collapse. Additional commentary was provided in later editions; the requirement to check strength and stability of structural systems under low-probability events in Section 2.5 was introduced in 1995, and the load combinations described above (Eqs. (2.12) and (2.13)) were provided in a commentary to that section. The provisions in ASCE Standard 7 have remained essentially unchanged since 1995 . In Canada, Commentary C on Part 4 of the National Building Code of Canada (NBCC) requires structures to be designed for sufficient structural integrity to withstand all effects that may reasonably be expected to occur during the service life, and advises the designer to consider and take measures against severe accidents with probabilities of occurrence of $10^{-4} / \mathrm{yr}$ or more, leaving it to the designer to determine appropriate measures. The figure $10^{-4} / \mathrm{yr}$ serves as a warning to consider the consequences of lowprobability events, and distinguishes the $N B C C$ from most other standards and guidelines which have not

\footnotetext{
${ }^{3}$ The in-place median strength of properly engineered steel or reinforced concrete members is typically on the order of $10 \%$ to $20 \%$ higher than the specified strength used in design under static load conditions. Further increases in in-place strength may occur under high strain rate conditions; these increases should be determined on a case by case basis for the scenario considered.
} 
adopted a specific threshold. Finally, Eurocode No. 1 states that a structure shall be "designed in such a way that it will not be damaged by events like fire, explosions, impact or consequences of human errors, to an extent disproportionate to the original cause." The engineer is given several alternatives for achieving this performance objective, including tying the system together or designing the system to tolerate accidental removal of an element. For comparison to the load combinations presented in Eqs. (2.12) and (2.13), the Eurocode load combinations used to demonstrate compliance using a specific "accidental" action, $\mathrm{A}_{\mathrm{k}}$, in a light-occupancy building are:

$$
\begin{aligned}
& \mathrm{D}+\mathrm{A}_{\mathrm{k}}+0.5 \mathrm{~L} \\
& \mathrm{D}+\mathrm{A}_{\mathrm{k}}+0.2 \mathrm{~S}+0.3 \mathrm{~L} \\
& \mathrm{D}+\mathrm{A}_{\mathrm{k}}+0.5 \mathrm{Wn}+0.3 \mathrm{~L}
\end{aligned}
$$

In addition to the requirements above, most standards recognize the desirability for continuity between structural elements, and several specify minimum tie forces to achieve continuity. Accidental loads are acknowledged explicitly in some standards (e.g., United Kingdom and Sweden). Some specify the "notional removal" of an external load-bearing element; others specify a floor area or volume of damage that the remaining structure would be required to bridge. The applicability of provisions varies from country to country - in some, they apply to practically all buildings, while in others they apply only to certain forms of construction or buildings over a certain minimum height (typically 5 stories to 6 stories). In the United States, the most comprehensive guidelines are those issued by the General Service Administration (GSA 2003) and the Department of Defense (DOD 2003, 2005).

\section{(iii) Evaluation of existing construction}

In contrast to provisions for new construction, few standards exist to cover rehabilitation or retrofit of existing construction when a weakness, deficiency, or threat develops during the service life of the building. Strategies for mitigating progressive collapse in existing buildings are constrained by the nature of the building itself as a physical entity as well as the demands and activities of the building occupants. Options for upgrading may be governed by physical as well as economic constraints.

One of the most potentially valuable applications of risk analysis is in the evaluation of existing facilities. It often is possible to show, through a well-structured and documented risk analysis that the building system is sufficient to meet the performance objectives of the stakeholders, even though it may fail to conform to the letter of the current building code.

The first and perhaps most important step in a risk analysis of an existing facility is to ascertain the state of the structure in the as-built condition through an examination of design documents (when available) and by field inspection. Connection details are particularly important, as they are paramount in permitting load redistribution following local damage. Actual in-place mechanical properties of structural components and systems should be established, because actual material strengths typically are greater than the nominal values assumed in design. For example, the mean yield strength of ASTM A 572 steel is approximately $400 \mathrm{MPa}$ (58 ksi), or $16 \%$ higher than the nominal value of $345 \mathrm{MPa}$ (50 ksi) assumed for design. Such percentage differences are not uncommon in other types of construction materials (Galambos, et al. 1982). This information can be used with an appropriate computational platform (often involving a nonlinear dynamic analysis capability) to determine the capacity of an existing structural 
system to withstand stipulated hazards or damage scenarios or the additional margin of performance afforded by various upgrade proposals.

Specific issues related to improving the resistance of existing buildings - threat evaluation, evaluation of alternative means to reduce consequences, feasibility (both technical and economic) of upgrading solutions for specific buildings — are discussed in Chapter 5.

\subsection{CONCLUDING REMARKS}

Good design involves looking beyond the minimum design requirements in a code or standard. The existence and potential consequences of abnormal loads and the possibility of progressive collapse should be addressed explicitly in codes and standards and become an integral part of the design process. Codes of practice should stress that managing the risk of progressive collapse is a necessary component of design, regardless of whether the initiating event is an "accidental" or "normal" load, and that such effects must be accommodated from an overall structural safety viewpoint. At the same time, the building teamowner/developer, architect and engineer - must acknowledge that risk is unavoidable; that risk of progressive collapse cannot be eliminated entirely but can be managed; and that a tradeoff between risk reduction and additional cost and building amenity will be evident from different building use and design measures. The engineer must communicate to the owner and other stakeholders the limitations in what can be achieved by good engineering practice, and the uncertainty in achieving the performance goals and objectives. This task of risk communication must be a significant part of arriving at acceptable strategies for progressive collapse prevention. Its importance in arriving at both socially acceptable and technically feasible solutions cannot be overemphasized.

At the general level, the need to consider accidental loads and progressive collapse in the design of buildings should be addressed in building codes through a performance requirement that appears in a document on General Design Principles and Load Requirements. There are a number of examples of such performance requirements, including those in ASCE Standard 7-05, Section 1.4-General Structural Integrity, and the National Building Code of Canada, Section 4.1.1.3(1) and Commentary C. There should be some statement regarding the general scope of the provisions (e.g., all buildings in excess of four stories, or some other threshold) and other specific factors that might indicate a need for considering progressive collapse resistance in design. Finally, there should be loading criteria for checking the ability of the structure to resist accidental loads. These load criteria might be similar to those in Eqs. (2.12) and (2.13). Generally, only the principal load-bearing system would need to be considered in these safety checks.

In contrast to general requirements, specific prescriptive design requirements for providing general structural integrity have proven difficult to codify because of the diversity of structural systems, construction technologies and methods, and scenarios of initial damage. Perhaps the easiest type of provision to implement is one in which minimum levels of continuity and ductility are provided through requirements on force connectivity between elements (Fintel and Schultz 1979). Such requirements are relatively inexpensive to implement, avoid the need to specify tolerable damage, and do not depend on a specific threat or abnormal load. This approach, with its emphasis on continuity and ductility, is similar to current earthquake-resistant design practice in low-to-moderate seismic areas, and usually can be addressed by material specifications without difficulty. It is difficult, however, to recommend minimum tie forces without having in mind some damage that must be bridged. 
More direct structural design strategies for progressive collapse fall into two general categories: (1) providing specific local resistance for the abnormal load, and (2) developing alternate load paths. The specific local resistance approach designs "hard spots" into the structure at areas that are believed to be prone to accidental loads (e.g., exterior columns at risk from vehicular collision or sabotage) or may be required to develop alternate load paths. Such an approach provides resistance to only one hazard. There is no assurance that design for that hazard will mitigate the consequences of another. Designing the structural system to develop alternate load paths in the event of local damage is intuitively more attractive because it focuses the attention of the designer on the behavior of the structural system following the disaster. The amount of local damage that should be accommodated must be defined-two alternatives are "notional" removal of one major load-bearing element at the perimeter of the building or stipulating a certain extent of damage by floor area or by volume. Such definitions may, however, not be germane for some structural systems or common practices. Moreover, while powerful computerized structural analysis using large-deformation, nonlinear behavioral models have become available in recent years for performing the supporting structural analysis, they are not accessible to many practicing engineers and experimental data to support such analyses may not be available.

There are, of course, some common sense strategies for enhancing the overall stability of a structural system and its ability to bridge over damaged zones. Structural systems should be designed to be robust. Their performance should not be sensitive to uncertainties in occupancy or environmental loads or other influences not considered explicitly in design. The layout of walls and columns should provide stability and to limit the amount of wall that can be damaged. Floor slabs should be detailed to accommodate a change span directions if a support is lost and to transmit load to other supports, possibly by catenary action. Walls should be designed to bridge over zones of damage through beam or arch action. Slender compression elements and brittle details should be avoided in critical points of potential alternate load paths, as should details that cause yielding in confined zones. Recent suggestions to compartmentalize construction through concrete walls that are reinforced to provide structural integrity and special moment frames of the type used in high seismic zones (Corley, et al. 1998) may prove beneficial. For buildings beyond a certain threshold, it might be advisable for a peer committee to review the proposed building design and the prospects of developing alternate load paths. Some of these design practices are summarized in the Commentary of ASCE Standard 7-05, Section C1.4. Others are discussed in more detail in Chapter 5.

The risk of progressive collapse to most buildings is very low. Without financial or regulatory incentives, progressive collapse-resistant design is not likely to be readily accepted. Most building codes in the United States have not contained such provisions. Design procedures that provide resistance to a spectrum of hazards, both natural and man-made, are likely to be more readily accepted and implemented by the structural engineering profession (at least in the short term) than procedures addressed at one specific hazard. The worldwide move toward performance-based engineering will encourage structural engineers to think beyond the traditional design envelope and may require them to consider such hazards explicitly. 


\section{Chapter 3 \\ MEANS FOR RISK REDUCTION}

\section{$3.1 \quad$ INTRODUCTION}

The incorporation of specific features to mitigate progressive collapse potential for buildings is constrained by a series of circumstances that may limit flexibility for designers. Most obvious among these are the building's geometry, structural and architectural layouts, limitations on the configuration of the site, materials of construction, economic factors, and architectural expression. These factors are particularly acute for existing buildings, for which most of these features are set. In the context of these conditions, upgrading existing buildings to enhance their resistance to progressive collapse often presents challenges that are not found in new construction. Options for designing new buildings or upgrading existing buildings are as varied as the structural systems that can be employed. It is clear that each building requires a unique solution. Thus it would be unrealistic to describe in this document explicit solutions for mitigating progressive collapse potential. This chapter focuses on the general methodology for reducing the risk of progressive collapse, rather than on specific design recommendations.

\subsection{PROJECT VIABILITY ASSESSMENT}

For new buildings, the decision to provide resistance to progressive collapse is often made early in the design process. The level of effort necessary to resolve the viability of the technical and economic impacts is relatively low. Although structural detailing can become more complex for structures designed to resist progressive collapse, most conventional framing systems can be modified to provide the necessary robustness.

Decisions to upgrade existing buildings require careful consideration, because the technical and financial viabilities of the necessary remediation options often are not immediately obvious. Therefore, to minimize the potential that effort will be wasted on a project that is not viable, owners and their consultants should complete an early assessment of the remediation viability of an existing building before initiating an extensive effort to develop plans to improve resistance to progressive collapse.

Some of the basic elements of the viability assessment study include evaluations of:

- The threat;

- The means to reduce exposure and threat;

- The consequences of failure; and

- Alternative means to reduce consequences.

Each of these four elements is presented below. 


\subsubsection{Threat Evaluation}

Historically, progressive collapse of buildings has been a rare event. Among the population of buildings that have experienced progressive collapse, there has been little consistency in structural configuration, occupancy, or threat. Thus, the existing experience provides a weak basis for undocumented judgment as the justification to upgrade buildings to resist progressive collapse.

On the other hand, there are certain occupancies for which threat levels can be assumed to be reasonably high (e.g., sensitive federal buildings that attract attention of terrorists). Due to change in social and political climates in some future circumstances, decisions about the need to provide for resistance to progressive collapse in private-sector buildings might be mandated, as they are now for some publicsector buildings. For most private-sector buildings, however, it is not obvious presently that the cost to upgrade the building design will produce a commensurate increase in safety or decrease in costs in the event of failures. Hence, detailed risk analyses are needed to quantify the risks for owners that require educated and scientifically-supported decisions.

Even with uncertainty about risks, owners still might make rational decisions to upgrade building performance based on other economic and societal factors. Some owners might conclude that the ability to substantiate a robust design will allow the facility to generate increased rent that has economic benefits over the life of the facility. Other owners, faced with uncertainty in data but justified fear of the dramatic consequences of a failure, will invest for the sake of personal and professional comfort and a sense of obligation to building occupants.

In any case, the owner needs to establish postulated threats posed for the building in order to incorporate progressive collapse mitigation features in the design process. The owner needs to estimate the magnitude or extent of the threat, assess its probability of occurrence, and consider the potential for damage.

\subsubsection{Means to Reduce Exposure and Threat}

Structural modification is only one way to improve safety and reduce losses associated with progressive collapse. As a preferred alternative, owners sometimes can reduce exposure. Clearly, it is better to eliminate the events (when they can be defined reasonably) that can initiate a failure than it is to try to arrest the spread of the initial failure. For example, if a structure is vulnerable to vehicle impacts, traffic can be restricted or rerouted, or appropriate barriers can be constructed between the roadway and the structure. Such an approach can reduce the likelihood of a specific accidental initiating event and, hence, has potential to increase safety.

Buildings that attract the attention of terrorists because they house certain occupancies are more difficult to protect by elimination of the threat. Determined terrorists have been known to attack protected buildings in ways that circumvent their defenses. When analyses show that structural modifications and reasonable defense approaches can not sufficiently reduce the risk of progressive collapse, then the owner will need to accept the higher level of risk or re-examine the viability of continued occupancy of that facility.

There are several available methods to reduce potential threats without physically altering structural systems. For instance, when it is not possible to create a large stand-off distance as a defense against a bomb attack, it might be possible to construct an energy deflecting barrier to reduce the influence of an 
explosion on the structure. Barriers also can be placed close to structural elements that need protection. Bollards can prevent vehicles from impacting columns. Energy-absorbing and impulse-reflecting shields, which often are destroyed as they perform their function, can be wrapped around structural components to deflect blast impulses before they affect the structure. The design of these barriers often is essentially as complex as the design of a structural upgrade. However, these features sometimes have advantages particularly when upgrading existing buildings because their performance is not constrained by existing detailing, and they often can be installed with relatively little disruption to building operations.

In many cases, these alternative approaches to address specific threats can be more cost effective than implementation of structural upgrades. Consideration of such alternatives early in the evaluation process has potential to identify relatively inexpensive remediation measures or, conversely, to validate the need for costly construction programs.

\subsubsection{Evaluation of Consequences of Failure}

Even without comprehensive risk assessments, owners can develop working opinions about design enhancements or upgrades based on postulated failure scenarios and their impacts on occupants and operations. For instance, owners might decide that the potential consequences for human occupants are so severe that strict economic justification is not necessary to support a decision to upgrade a structure. In such cases, owners can proceed through the early stages of evaluation with confidence that exploratory costs are worthwhile.

Likewise, a manufacturer can assess economic impacts from the loss of operations at a specific manufacturing facility without fully understanding the nature of a structural failure that might cause that loss of operation. Based solely on the premise that a failure will incapacitate a facility, a manufacturer can evaluate business impacts to explore the justification for building upgrades.

Consideration of issues of consequence should focus attention on the economic commitments that must be made to upgrade existing facilities. The risk assessment study can lead to specific cost thresholds and design/construction budgets that will determine the upgrade designs that follow.

\subsubsection{Evaluation of Alternative Means to Reduce Consequences}

Some threats can be reduced by reprogramming the use of a facility. The consequences of a failure can also be reduced by such actions. It might be that the owner can postulate that a certain area of a building is vulnerable because it is exposed to a threat and the structural system is judged to have little robustness. Under these circumstances, the owner might consider using that portion of the building to non-essential functions that do not create high risk to human life. For instance, office areas near loading docks could be converted to storage uses. Then, personnel otherwise at risk if located near loading docks are isolated from the consequences of structural failures should a bomb be delivered to and detonated in the loading area. Similarly, key business operations can be located in more protected spaces, or areas with structures that have more robustness or which have greater potential for enhancement. 


\subsubsection{Determination of Qualification of Structure for Upgrade Consideration}

Given the outcome of the evaluations summarized above, an owner can reasonably conclude whether a particular facility qualifies for consideration for design and retrofit enhancements to reduce the risk of progressive collapse. The owner should determine that there is a potential hazard at the facility and that hazard can not reasonably be eliminated by alternative measures. The owner will have evaluated the consequences of a failure and alternatives to reduce those consequences. These studies will lead to conclusions about the feasibility to respond to the hazard without full analysis. The owner also will have a cost base or justified budget for designing a new building or upgrading the existing structure.

\subsection{ASSESSMENT OF POTENTIAL FOR PROGRESSIVE COLLAPSE}

The conditions that constrain a design need to be evaluated to assess the potential for progressive collapse. Generally, these conditions can be divided into two major categories: site conditions and structural systems.

\subsubsection{Site Evaluation}

The site has to be evaluated to assess the exposure of the building to potential hazards. It involves determining factors such as exposure, access, vulnerability, and constraints on protection options. The hazards include any event that can cause localized damage and trigger progressive collapse, such as vehicle impact, poor soil conditions, or bomb and gas explosions. Conditions such as the proximity of fuel storage facilities to the structure, fuel distribution lines around the site, proximity of access roads and sidewalks should be evaluated. Once the potential hazards are evaluated, mitigation measures should be considered.

\subsubsection{Structural Systems Evaluation}

The structural systems evaluation for new construction involves consideration of system features that potentially reduce robustness and alternatives to enhance performance, including assessments of the structural system vulnerability and the structural capacity of the building (i.e., strength and ductility). For existing buildings, the alternatives are constrained by existing conditions. Hence, the structural systems evaluation also involves review of available documentation related to the existing building and studies of the actual condition of the structural materials and systems. These aspects are discussed in greater detail in Section 5.3.3.

\subsection{DESIGN APPROACHES}

\subsubsection{Goals}

The scarcity of research in the field of progressive collapse prevention, including full scale laboratory tests and observations of actual failures and the difficulty for most structural engineering firms to perform advanced (nonlinear geometric and nonlinear material) structural analyses in an economical, timely and accurate manner has led to the development of broad guidelines that are open to interpretations. For example, Section 1.4 of ASCE Standard 7-05 describes protection through "an arrangement of the structural elements that provides stability to the entire structural system by transferring loads from any 
locally damaged region to adjacent regions capable of resisting these loads without collapse." For this approach, Commentary C1.4 in ASCE Standard 7-05 defines three methods to attain progressive collapse resistance: 1) Indirect Method, 2) Specific Local Resistance Method, and 3) Alternate Load Path Method. The methods are ordered by increasing levels of analytical complexity, and would be used for buildings with increasing levels of risk for the consequences of failure. The latter two methods are referred to collectively as direct methods. Chapter 4 provides more detailed discussion of these methods.

In the direct methods, the designer explicitly considers the ability of the structure to resist the effect of an abnormal load event. The designer may either explicitly design critical vertical load bearing building components to resist the design level threat or design the structure to carry loads by means of an alternative load path in the event of the loss of a primary load bearing component. In one approach, a specified threat may be explicitly considered in design by using non-linear dynamic analysis methods (see Section 4.3.4). Conversely, the alternate load path method addresses a postulated damage state without addressing the threat that produced it. This threat independent approach is specified by U.S. Government agencies including the U.S. General Services Administration (GSA 2003) and the Department of Defense (DOD 2005). Since the threat independent approaches do not consider the events that produce the damage state, this approach may be viewed as a tool to ensure redundancy in the gravity load resisting system rather than a simulation of structural response after initial damage.

The primary goals of the designer is to save lives by reducing building damage and preventing disproportionate collapse of the building, at least until it has been evacuated by occupants and firstresponder personnel. Collapse prevention begins with awareness by architects and engineers of conditions where local failure might result in disproportionately large damage consequences. Regardless of the analytical approach or structural design scheme, the structural engineer must consider the performance of the structure following local damage. By assessing the consequences of different damage mechanisms, the designer can determine whether it is more reasonable to harden the structure to resist initial damage or to design it to bridge over the damaged zone. Once the performance of the building is understood, the appropriate design features can be incorporated into common buildings at affordable cost.

\subsubsection{Siting, Plan Layout, and Hazard Consideration}

Initial local damage can result from intentional explosions, accidental explosions, vehicle impacts, fire, or other abnormal load events. For structures that are required to resist the effects of terrorist explosive threats, the location of the building on the site can have a major impact on its vulnerability to initiating events that may trigger progressive collapse. The building should be located as far from the property lines as possible with perimeter barriers. Unsecured areas such as the lobby, loading dock, mailroom, garage, and retail areas should be separated from the secured areas of the building. Exposed structural columns in unsecured areas should be minimized. Ideally, these unsecured areas are placed exterior to the main building or along the edges of the building. A separate lobby pavilion or loading dock area outside of the main footprint of the building provides enhanced protection against local damage to the main building in the event of an explosion. Similarly, placing parking areas outside the main footprint of the building can be highly effective in reducing vulnerability.

The shape of the building can have a contributing effect on the overall damage to the structure. For new buildings, a regular, uniform layout of structural elements (beams, columns, and walls) can have a significant impact on the ability of the structure to withstand progressive collapse. Regularity in design 
allows for continuity of strength, greater redundancy, and hence capacity for redistribution of load should an element fail due to blast or accident. Irregularities, such as reentrant corners and overhangs, are likely to trap the shock wave of an explosion, which may amplify the effect of the air-blast. Note that large or gradual reentrant corners have less effect than small or sharp reentrant corners and overhangs. In general, for resistance to blast loading, convex rather than concave shapes are preferred for the exterior of the building because the reflected pressure on a circular surface is less intense than on a flat or concave surface. Terraces that are treated as roof systems subject to downward loads require careful framing and detailing to limit internal damages to supporting beams.

The structural design must follow the form dictated by the architectural design. There are always trade offs between the various design disciplines, but minimizing irregularity and discontinuity in plan and elevation are good first steps for improving a structure's ability to resist progressive collapse. To the extent possible, discontinuities in load path or concentrations of load, such those resulting from the use of transfer girders, should be avoided.

An important factor in achieving integrity is the proper plan layout of walls and columns. There are a number of ways of designing for the required integrity to carry loads around damaged walls, trusses, beams, columns, and floors. In bearing-wall structures, interior longitudinal walls should be arranged to support and reduce the span of long sections of crosswall, thus enhancing the stability of individual walls and of the structures as a whole. In the case of local failure, this will also decrease the length of wall likely to be affected. Furthermore, returns on interior and exterior walls will make the walls more stable. If a floor slab is reinforced so that it can, with a low safety factor, span in the perpendicular direction if a load-bearing wall is removed, collapse of the slab will be prevented and the debris loading on other parts of the structure will be reduced. Often, shrinkage and temperature steel will be enough to enable the slab to span in the other direction. Interior walls must be capable of supporting the load associated with the change of span direction in the floor slabs. If the slab cannot change span direction, the span will increase if an intermediate supporting wall is removed. In this case, if there is enough reinforcement throughout the slab and enough continuity and restraint, the slab may be capable of carrying loads by catenary action, but large deflections will result. Finally, a wall may be capable of spanning an opening if sufficient tying steel at the top and bottom of the wall allows it to act as the web of a beam with the slabs above and below acting as flanges.

When the building contains materials that pose a high risk, such as high fuel loads, flammable liquids and gases, explosive materials, and so forth, the effects of fire must be considered by separate analysis. To protect against a reduction in strength and stiffness and differential thermal expansion that may result in progressive collapse from extended exposure to fire, the structural members and components should be designed and have a fire resistance appropriate to their designed function. These structural members and components should be appropriate for:

- The associated hazards, threats, and credible fire loads;

- The fire intensity and duration of these fire loads;

- The height and the use/occupancy of the specific building or space;

- The established goals, objectives, and level of risk acceptable to the stakeholders; 
- $\quad$ The fire and life safety features provided; and

- The proximity to adjacent structures and properties so as to avoid the spread of collapse to neighboring structures.

\subsection{DESIGN PRINCIPLES}

\subsubsection{Failure Propagation}

Because there are many potential means by which a local collapse in a specific structure may propagate from its initial extent to its final state, there is no universal approach for evaluating the potential for progressive collapse. This case specific behavior differentiates progressive collapse from other welldefined structural engineering concerns, such as design to resist gravity, wind, seismic or vibration loads. The following general statement can be made, however, of all progressive collapse scenarios: When an initiating event causes a local failure, the resulting failure front will propagate through the structure until specific structural conditions in its path arrest the progression of failure, or until the remaining structure becomes geometrically unstable and the entire structure collapses (Ettouney, 2004). Because progressive collapse is a dynamic event, the failure front divides the structure into a zone that has not yet experienced the effects of the progression of failure and the failed portion of the structure. A failure front may propagate horizontally or vertically, or both.

Because the failure front propagates away from the initial damage region, the structural properties beyond the current region of a failure front do not affect the behavior within the region. Therefore, only a small portion of the structure needs to be studied at any instant during the propagation process. Only a few key structural components are required to capture accurately the collapse of the entire system; thereby allowing a more efficient and detailed analysis at any instant in time. Because column axial stiffness is typically much greater than beam bending stiffness, vertical propagation of the failure front will be faster than horizontal propagation. Due to this difference in time scale, it might not be practical to use a single analytical model to trace the failure front propagation, and different analytical models may be considered for different stages of the failure propagation. Furthermore, because the structural response is essentially impulsive at the initial state, oscillatory at the intermediate state, and quasi-static at a later state, different numerical methods and the consideration of different analytical conditions are required for the different stages.

The propagation of the collapse is affected by the various structural components in the way of the failure front; the columns, walls, beams, slabs and connections. As the failure front propagates horizontally to a beam-column interface, the beam may form a flexural hinge, fail in shear, or experience axial failure as it develops catenary action. For structures with regular geometry, flexural yielding is not likely to propagate across a column line, and the only means to propagate failure is through column failure and/or shear failures in the connections. However, when a failure front reaches a beam-to-column or beam-to-bearing wall connection, the column or wall will be subjected to dynamic effects (shear, thrust, moment and torsion) in addition to pre-existing static effects. Because the initiating event may damage the adjoining structure and diminish its capacity, these load bearing elements must be able to accept the additional dynamic effects without precipitating failure.

The release of compressive stress, due to the failure of a column, causes an axial tensile wave to travel throughout the column line. The greater the initial axial stresses, the greater the amplitudes of the axial tension waves, which can rupture reinforced concrete columns or cause splice failure of steel columns as they propagate through the structure. Axial compressive forces are similarly amplified by the dynamic effects and a dynamic load factor cannot simply be assumed or approximated within a static pull-down analysis. 
The connection of the beams to the vertical faces of columns and the panel zones to which the beams are connected represent two potential failure zones. While failure of the connections may arrest failure propagation, failure of the panel zones may allow the failure to spread. In order to accurately represent the post-yielding behavior of reinforced concrete connections, the modeling must include the 3-D effects of the lateral reinforcement in both the beams and columns. Similarly, the accurate modeling of steel connections must account for their moment-rotation relationships and the potential for joint fracture.

Finally, the catenary forces that may develop as a result of large deformations following the removal of a structural support will be significantly larger than the vertically applied loads. Both the beam cross section and the beam-to-column connections must be capable of resisting the large axial forces that are produced while sustaining the large deformations. The remaining structure must similarly be capable of resisting the horizontal components of the catenary forces.

\subsubsection{Structural Robustness}

To reduce the risk of progressive collapse in the event of loss of structural elements, the following structural traits should be incorporated in the design. Collectively they produce "robust" structures capable of limiting the spread of damage due to an initiating event.

- Redundancy: The incorporation of redundant load paths in the vertical load carrying system helps to ensure that alternate load paths are available in the event of local failure of structural elements.

- Ties: The loss of a major structural element typically results in load redistributions and member deflections. These processes require the transfer of loads throughout the structure (vertically and horizontally) through load paths. The ability of a structure to re-distribute or transfer loads along these load paths is based in large part on the interconnectivity between adjacent members. This is often called "tying a building together" by using an integrated system of ties in three directions along the principal lines of structural framing. Figure 3-1, taken from UFC 4-023-03 (DOD 2005), illustrates the different types of ties that are typically incorporated to provide structural integrity to a building.

- Ductility: In a catastrophic event, members and their connections may have to maintain their strength through large deformations (deflections and rotations) and load redistributions associated with the loss of key structural elements. For steel structures, ductility is achieved by using steels with high toughness, maintaining overall and local structural stability and creating connections between elements that exceed the strength and toughness of the base material. For reinforced concrete and reinforced masonry structures, ductility is achieved by providing sufficient confinement of reinforcing steel, providing continuity in reinforcement through adequate lap splices or mechanical couplers, maintaining overall structural stability, and creating connections between elements that exceed the strength and toughness of the base members.

- Adequate shear strength: Structural elements in vulnerable locations, such as perimeter beams or slabs, should be designed to withstand shear load in excess of that associated with the ultimate bending moment in the event of loss of an element. Direct shear failure is a brittle mode of failure and should not be the controlling failure mechanism. Shear capacity should always exceed flexural capacity to encourage a ductile response. Typical two-way slabs without beams must be capable of providing post-failure resistance in the presence of punching shear failures and severe 
distress around the columns. Continuous top and bottom reinforcement properly anchored into the columns prevent "rip-out" after shear failure has occurred. This reduces the likelihood of progressive collapse as the slab-column connection is maintained by membrane action of the slab reinforcement (Mitchell and Cook, 1984).

- Capacity for resisting load reversals: The primary structural elements (columns, girders, roof beams, and lateral load resisting system) and secondary structural elements (floor beams and slabs) should be designed, using acceptable techniques, to resist reversals in load direction at vulnerable locations.

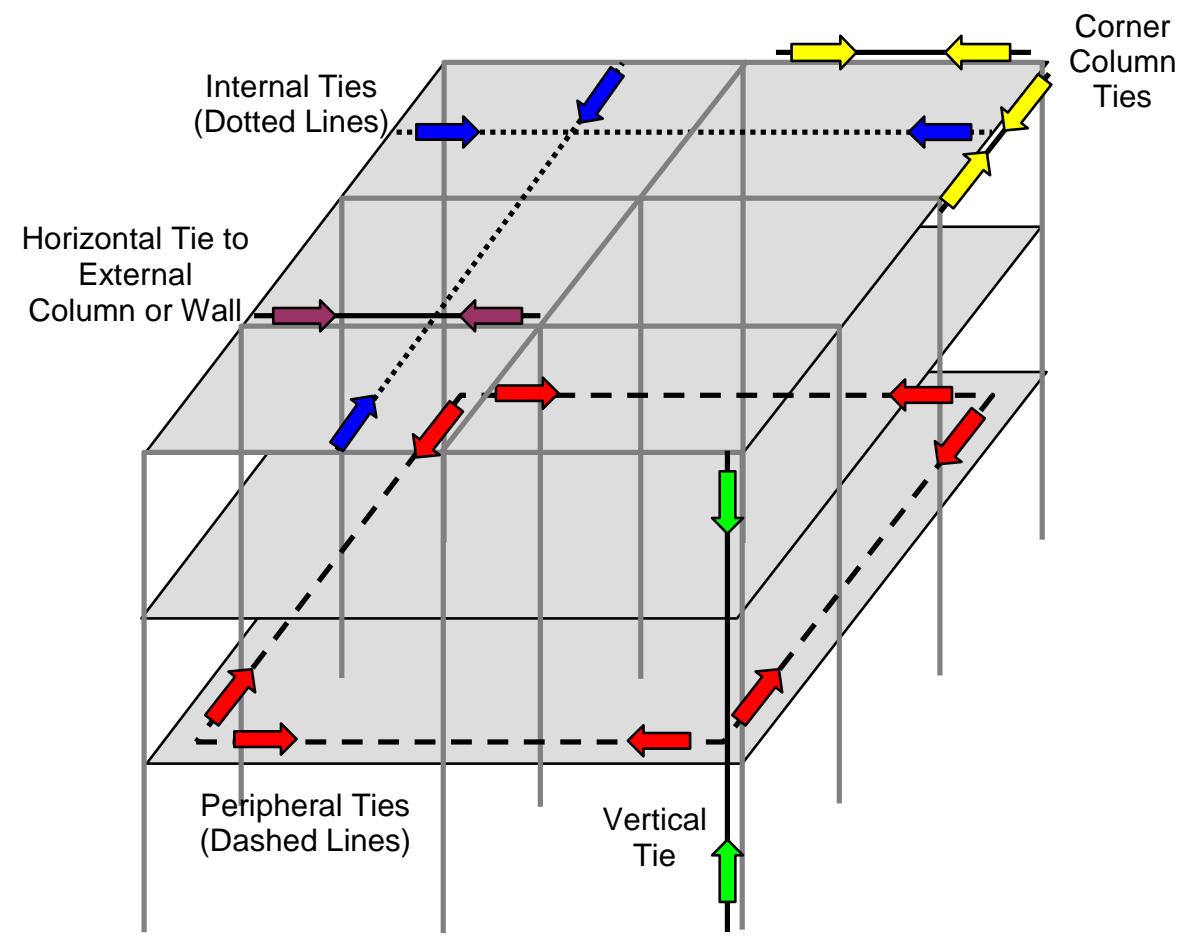

Figure 3-1 Different types of ties incorporated to provide structural integrity (DOD 2005).

In addition, the following measures are recommended to enhance the overall robustness of the structure:

- In frame structures, column spacing should be limited. Large column spacing decreases the likelihood that the structure will be able to redistribute load in the event of column failure.

- The exterior bay is most vulnerable to damage, particularly for buildings that are close to public streets. It is also less capable of redistributing loads in the event of member loss, because twoway load distribution is not possible. It is desirable to have a shallow bay adjacent to the building exterior to limit the extent of damage.

- Loss of a transfer girder or a column supporting a transfer girder can destabilize a significant area of the building. Transfer girders at the building exterior often occur to accommodate loading 
dock's large entry spaces, increasing their vulnerability to air-blast effects. It is highly desirable to avoid transfer girders or add redundant transfer systems where transfer girders are required.

- In bearing wall systems that rely primarily on interior cross-walls, interior longitudinal walls should be spaced periodically to enhance stability and control lateral progression of damage.

- In bearing wall systems that rely on exterior walls, perpendicular walls or substantial pilasters should be provided at a regular spacing to control the amount of wall that is likely to be affected.

\subsubsection{Connection Strength}

Consideration of resistance to progressive collapse during the design process will introduce additional strength to connections and will result in connections between elements that might not exist if one were designing for gravity and nominal lateral loads (wind and seismic) alone. Multiple connections will allow for more uniform, smooth load redistribution and prevent abrupt changes in strength and stiffness that result in load concentration, overstress, and early failure.

The consideration of progressive collapse in a steel frame building might involve the use of moment resisting connections in beam-column joints where only simple gravity load connections would be necessary for ordinary design. It may also involve minor modifications to standard connection details, such as increasing edge distances, or the use of continuous mild reinforcing steel in the floor slabs. These relatively low cost changes may enable the structure to withstand additional force associated with abnormal loading.

For a concrete frame building, the following design features might be incorporated to enhance resistance to progressive collapse:

- Using moment resisting connections in beam-column joints that can accommodate full load reversals where only simple, gravity load connections are necessary for routine design;

- Using continuous top and bottom reinforcing steel in beams and floor slabs (avoiding bar terminations) to permit them to span further or develop catenary action.

\subsubsection{Key Elements}

Because columns do not have much surface area, air-blast loads on columns tend to be mitigated by "clear-time effects." This refers to the pressure wave washing around these slender tall members, and consequently the entire duration of the pressure wave does not act upon them. However, if the explosive device is placed close to the column, the intensity of the blast loading will be significantly higher. For a very large weapon close to a column, shattering of the concrete due to multiple reflections of tensile stress waves within the concrete section (brisance) can destroy its integrity.

Column or wall instability may result from the loss of lateral support due to the failure of a supporting floor system. This is particularly important for buildings that are close to public streets. In this case, exterior columns or walls should be capable of spanning two or more stories without buckling. 
For a package weapon, column breach is a major consideration. To mitigate this threat, some recommendations include the following:

- Do not use exposed columns that are fully or partially accessible from the building exterior. Arcade columns should be avoided.

- Use an architectural covering that is at least six inches from the structural member. This will make it considerably more difficult to place a weapon directly against the structure. Because explosive pressures decrease rapidly with distance, every increment of additional standoff distance will help to protect the column.

Load bearing reinforced concrete wall construction can provide a considerable level of protection if adequate reinforcement is provided to achieve ductile behavior. This may be an appropriate solution for the parts of the building that are closest to the secured perimeter line.

Spandrel beams of limited depth generally do well when subject to air-blast. In general, edge beams are strongly encouraged at the perimeter of concrete slab construction to afford frame action for redistribution of vertical loads and to enhance the shear connection of floors to columns. The addition of cable reinforcement in spandrel beams may improve the outer frames resistance to progressive collapse through catenary action.

For structures where the interior is secured against explosives of moderate size, the primary concern is the exterior bay framing. For buildings that are separated from a public street only by a sidewalk, the uplift pressures may be significant enough to cause possible failure of the exterior bay floors for several levels above ground. Special concern exists in the case of vertical irregularities in the architectural system, either where the exterior wall is set back from the floor above or where the structure steps back to form terraces.

Interior columns or walls may be subject to many of the same threats as exterior columns or walls, either due to malevolent acts of terrorism or accidental effects such as gas explosions, automobile impact or fire. If accessible, the location of critical columns may be obscured or a standoff to the structural component may be imposed through the use of cladding. Methods of hardening columns include using closely spaced ties, spiral reinforcement, and architectural covering at least six inches from the structural member. Composite steel and concrete sections or steel plating of concrete columns can provide higher levels of protection. Critical columns should be designed to span two or three stories without buckling in the event one or two floor slabs providing lateral bracing are severely damaged.

Interior walls can also be effective in resisting progressive collapse if they are designed properly with load bearing capacity and tied into the floor systems below and above.

\subsubsection{Alternate Load Paths}

Once the basic design of the structure is complete, a review of the strength and ductility of key structural elements is required to determine whether the structure is able to "bridge" over the initial damage. This review process involves notionally removing key structural elements, one at a time, assessing local and overall structural stability, and modifying the design as necessary. Large rotation and ductility values are permitted when the resistance to progressive collapse is achieved by bridging over the area of immediate 
damage. This typically requires specific attention to the structure's redundancy, ductility and capacity for resisting load reversals

Depending on the type and importance of the structure, the perceived risk to the building, and the consequences of structural failure, the analysis techniques used can vary from simple linear-elastic static computations to sophisticated non-linear, dynamic computer analysis (see Section 4.3.2). In general, more complex modeling provides more realistic results, but it typically requires a greater time investment and engineering skill by the structural engineer to obtain accurate results.

As stated, the alternate load path method requires notional removal of critical load bearing elements, one at a time, and assessment of the stability of the remaining structure. These members are typically, but not exclusively, perimeter columns and/or load bearing walls between the ground and first levels. It may also include interior load bearing elements in vulnerable locations. The load carried by the lost element must find an alternate load path to the building supports without precipitating structural collapse. Large deformations are permitted before the onset of failure of an element. This method reduces the risk of progressive collapse by ensuring structural redundancy. However, it is independent of the actual threat causing loss of the element.

The alternate load path method is sometimes used after it is shown that minimum tie forces required by the indirect method can not be developed. The designer may then apply the alternate path method to determine whether the structure can bridge over the deficiency. This approach has been adopted by the DOD in UFC 4-023-03 (DOD 2005). 


\section{Chapter 4 \\ INDIRECT AND DIRECT DESIGN APPROACHES}

\subsection{INTRODUCTION}

As mentioned in Section 3.4.1, two approaches are used for providing resistance to progressive collapse, namely, the indirect method or the direct methods. This chapter provides information on these approaches. The indirect method is a prescriptive approach of providing a minimum level of connectivity between various structural components and little additional structural analysis is required by the designer. In general, in place of calculations demonstrating the effects of abnormal loads on buildings, the designer may use an implicit design approach that incorporates measures to increase the overall robustness of the structure. The direct methods, on the other hand, rely heavily on structural analysis. The designer explicitly considers the ability of the structure to resist the effects of an abnormal load event.

Analysis of a building's resistance to progressive collapse can be performed using various methods, ranging from linear elastic static analysis to sophisticated non-linear dynamic finite element analysis. The physics involved in the spread of a localized failure in a structure can be complex. Therefore, the designer should be judicious about the tools that are used to analyze a given structure. These tools should be adequate to capture the desired information. For instance, if inertia effects are to be included and energy dissipation in the form of plastic action needs to be computed, it is imperative that a non-linear dynamic analysis be performed. On the other hand, if simple parametric studies are to be performed to study redistribution of loads when certain elements of a structure are removed, simple linear elastic static analysis may suffice.

\subsection{INDIRECT METHOD}

\subsubsection{General}

In the indirect method, the designer may use a prescriptive approach to increase the overall robustness of the structure. This is accomplished by incorporating general structural integrity measures throughout the process of structural system selection, layout of walls and columns, member proportioning, and detailing of connections. Thus, the indirect method is likely to be the primary method used to enhance the robustness of the type of buildings that are the focus of this document because the risk of progressive collapse is low for most buildings.

Provisions for general structural integrity may be in the form of prescriptive requirements for minimum joint resistance, continuity and inter-member ties that will provide a robust, stable and economical design. The indirect design approach has the distinct advantage of being the easiest to apply and provides a uniformity of compliance on all projects. Although this event independent approach is not based on detailed calculations of the structural response to abnormal loading, it results in continuous tied reinforcement for concrete frame structures and stronger connections for steel frame structures to allow the structural elements to develop more of their capacity (either in flexure or membrane action) when subjected to abnormal loading conditions. Although vertical loads are not resisted efficiently by 
horizontal ties, loads that were supported initially by the damaged portions of the structure will be redistributed to undamaged elements.

The prescriptive approach has been used in the United Kingdom (see Appendix A) since the early 1970s and has been reported to be effective in protecting building occupants during extreme loading events (Moore 2002). It is generally understood that a cost/benefit tradeoff has been performed in the development of the U.K. standards, which establishes an acceptable level of protection against progressive collapse for all projects. This indirect approach is appropriate for the design of regular building layouts that do not contain significant transfer mechanisms and for structures that do not qualify for a higher importance category. The U.K. approach has been adopted, in part, by the Department of Defense (DOD) in Unified Facilities Criteria 4-023-04 (DOD 2005) (see Appendix A). In UFC 4-023, the indirect method is used exclusively for facilities that have been characterized as requiring a very low level of protection (VLLOP); for facilities requiring a low level of protection (LLOP), the indirect method may be supplemented with the alternate load path method.

\subsubsection{Tie Requirements}

\section{(i) General}

If all members are structurally connected by joints capable of transferring the specified capacity in tension, shear, or compression (as appropriate) without reliance on friction due to gravity loads or when additional tie members are provided as specified below, then the layout and configuration of the building are deemed to provide adequate protection against progressive collapse under abnormal load.

In general, structures are designed to withstand at a minimum level of horizontal load, typically defined as a percentage of each floor's weight applied simultaneously on all floors, which is checked separately from the effects of seismic or wind load. The magnitude of the horizontal load must be determined; however, this may be as low as $0.2 \%$, as recommended by the Structural Stability Research Council (SSRC 1998) for overall stability checks. To resist progressive collapse, however, key elements of a structure must be tied together so that redistribution of forces could occur due to a local failure. The ties consist of peripheral ties, internal ties, horizontal ties to columns and walls, and vertical ties (refer to Figure 3-1). The specified capacities of such ties are considered separately from the forces due to normal design loads, and should be no less than the capacities determined by the normal design loads.

\section{(ii) Reinforced concrete}

In reinforced concrete structures, the reinforcement provided to resist( normal design loads may be regarded as forming part of, or the whole of, these ties and should at a minimum conform to the requirements of ACI-318 Section 7.13 (Requirements for Structural Integrity). This reinforcement may be used to satisfy, in part, the requirements for internal ties, peripheral ties and column ties. Bars may be considered anchored to another tie at right angles if the bars extend beyond all the bars of the other tie for an effective anchorage length (based on the force of the bars). The ties must be adequately anchored where substantial changes in construction or reentrant corners interrupt the continuity of the ties.

Internal ties at each floor and roof level should be in two perpendicular directions. The ties should be effectively continuous throughout their length and should be anchored to the peripheral ties at each end. The ties may be spread evenly in the slabs or may be grouped at or in beams, walls or other appropriate structural elements. The ties should not be spaced greater than $150 \%$ of the spacing of the columns, 
frames or walls supporting any two adjacent floor spans in the direction of the tie (DOD 2005). In walls, the ties should be relatively close to the top or bottom of the floor slabs. These ties should be capable of resisting a prescribed tensile force in each direction.

An effectively continuous peripheral tie should be provided at each floor and roof level that is capable of resisting a prescribed tensile force located relatively close to the edge of the building or within the perimeter wall. Each external column and, if the peripheral tie is not located within the wall, the loadbearing external wall should be anchored or tied horizontally into the structure at each floor and roof level with a tie capable of developing a prescribed force, which should be a percentage of the total design ultimate vertical load carried by the column or wall at that level. Where the peripheral tie is located within the wall, a positive connection should be provided between the internal and peripheral ties.

Corner columns should be tied into the structure at each floor and roof level in each of two perpendicular directions with ties each capable of developing a prescribed force, which should be a percentage of the total design ultimate vertical load carried by the column or wall at that level.

Each column and each wall carrying vertical load should be tied continuously from the lowest to the highest level. The tie should be capable of resisting the largest factored vertical load, received by the column or wall from any one story due to conventional design load combinations (DOD 2005). Where a column or a wall at its lowest level is unsupported by an element other than a foundation, a general check for structural integrity should be made to ensure that there is no inherent weakness of structural layout and that adequate means exist to transmit the dead, live and wind loads safely from the highest supported level to the foundations.

\section{(iii) Precast concrete}

In precast and composite structures, the ties should be effectively continuous. The ties should conform to the minimum requirements of ACI-318 Section 16.5 governing structural integrity. The ties should be anchored effectively, such that the anchorage is capable of carrying the dead weight of the member to that part of the structure which contains the ties. For reinforced bearing, the integrity of the bearing is dependent on an overlap of reinforcement and a restraint against loss of bearing through movement. The net bearing width should be based on the design ultimate support reaction per member, the effective bearing length, and the design ultimate bearing stress.

A bar or tendon in a precast member should be lapped with a bar in cast-in-place connecting concrete bounded on two opposite sides by rough faces of the same precast member. Alternatively, a bar or tendon in a precast concrete member should be lapped with a bar in cast-in-place topping or connecting concrete anchored to the precast member by enclosing links. The ultimate resistance of the links should not be less than the ultimate tension in the tie. Bars projecting from the ends of the precast members may be joined by lapping of bars, reinforcement grouted into apertures, overlapping reinforcement loops, sleeving, threading of reinforcement or welding of bars. Alternatively, bars may be lapped with cast-in-place topping or connecting concrete to form a continuous reinforcement with projecting links from the support of the precast floor or roof members to anchor such support to the topping or connecting concrete.

Joints transmitting compression should be designed to resist all the forces and moments implicit in analyzing the structure as a whole and in designing the individual member to be joined. Joints transmitting in-plane shear may be assumed effective if the joint is grouted with a suitable concrete or mortar and should not require restraint if the design ultimate shear stress in the joint does not exceed the 
nominal capacity. Joints transmitting shear under compression in all design conditions may be assumed effective if the joint is grouted with the sides or ends of the panels forming the joint have a rough as-cast finish and the design ultimate shear stress does not exceed the nominal capacity. Joints transmitting shear may be assumed effective if the shear stress due to ultimate loads is less than the nominal capacity calculated on the minimum root area of a castellated joint. Separation of the units normal to the joints should be prevented by either steel ties across the ends of the joint or by the compressive force normal to the joint under all loading conditions. Joints transmitting shear may be assumed effective if reinforcement is provided to resist the entire shear force due to design ultimate loads. The shear force should be limited by shear friction across the joint.

\section{(iv) Steel structures}

In steel frame structures, horizontal ties should be arranged in continuous lines wherever practical, distributed throughout each floor and roof level in two perpendicular directions. Every steel member should act as a horizontal tie, and their connections should be capable of resisting a tensile force equal to its end reaction under 1.2 Dead Load plus 0.5 Live Load (or the larger end reaction if they are unequal), which need not be considered additive to other loads. The horizontal ties anchoring into columns should be capable of resisting a factored tensile load, acting horizontally in any direction, equal to the larger of the end reactions of the tie under factored loads or a nominal percentage of the maximum factored vertical dead and live loads in the column adjacent to that level. Where multiple members frame in one direction, no connection should be less than a nominal percentage of the column load. If columns are not continuous, then the frame should be detailed to provide full continuity to the columns. Each column splice should be capable of resisting a tensile force equal to the 1.2 Dead Load plus 0.5 Live Load reaction applied to the column at a specified number of floor levels located immediately below that column splice or a percentage of the column capacity. Braced bays or other systems for resisting lateral loads should be distributed throughout the building.

\section{(v) Masonry structures}

In masonry structures, peripheral horizontal ties should be provided along the whole perimeter within a nominal distance of slab edge, and anchored at reentrant corners. Interior horizontal ties should be provided both ways either uniformly or in strips at regular spacing or in walls in close proximity to the floor or roof. Exterior horizontal ties should be provided from perimeter columns and walls to floor slabs. Corner columns should be tied both ways. Walls should be tied uniformly, within a prescribed spacing and distance of wall ends. Vertical ties should be provided floor to floor at load bearing walls, which satisfy minimum thickness, strength and maximum slenderness ratios. Maximum tie spacing should be limited to prescribed values, particularly at unrestrained ends of the wall.

\section{(vi) Existing buildings}

Applying the indirect design method to the various forms of existing construction quickly becomes an enormous task. It would be a very daunting task to develop prescriptive details for every building system that might be considered and ensure that all of the systems had the same resistance to progressive collapse.

\subsubsection{Seismic Details}

Details that were developed for structures in seismic regions have the benefit of over fifty years of construction experience, research and public awareness. Much of the consideration in the development of 
these details focuses on response to multiple cycles of load reversal. The abnormal loading events that could cause localized damage that could trigger progressive collapse might not replicate the cyclic nature of strong ground motions for which seismic details were developed. Therefore, additional research is needed to determine the value of seismic detailing in effectively tying a structure together. Because ductile detailing requirements for seismic resistance is applied primarily to members of the lateral load resisting system and because the resistance to progressive collapse may extend throughout the gravity load resisting system, these seismic details may have to be applied to a greater extent throughout the structure.

\subsection{DIRECT METHODS}

\subsubsection{General}

In the direct design methods, resistance against progressive collapse is provided by enhancing the strength of key structural elements to resist failure under postulated abnormal loads or designing the structure so that it can bridge across the local failure zone. In either case, direct design methods require more sophisticated analyses compared with the usual gravity and lateral load analyses used in routine design. This section discusses the different constitutive models and analytical methods that are being used in practice.

\section{(i) Specific local resistance method}

In the specific local resistance method, the designer explicitly designs critical vertical load bearing building components to resist the design level threat, such as blast pressures. Thus it is a threat specific approach. For example, the blast pressure for a defined threat may be considered explicitly in design by using non-linear dynamic analysis methods. Unless there is a postulated internal threat or gas explosion, blast-mitigating structural design or hardening generally focuses on the structural members on the lower floor levels that are closest to defined stationary exterior vehicle-weapon threats. This method is also referred to as key element design and discussed further in Section 4.3.4.

\section{(ii) Alternate load path method}

In the alternate load path method, the designer localizes response by designing the structure to carry loads by means of an alternate path in the event of the loss of a primary load bearing component. The alternate load path method has been selected by agencies including the U.S. General Services Administration (GSA 2003) as the preferred approach for providing resistance to progressive collapse. In the DOD UFC 4-023-04 (DOD 2005), this method is used when the required vertical tie capacities cannot be obtained in low level of protection (LLOP) structures designed by the indirect method (see Appendix A). It is also used in structures designated as requiring a medium level of protection (MLOP) or high level of protection (HLOP) when design by the indirect method is not feasible. The alternate load path method provides a formal check of the capability of the structural system to resist the removal of specific elements, such as a column at the building perimeter. The method does not require characterization of the threat causing loss of the element, and is, therefore, a threat independent approach. Depending on the analytical method used to implement the alternate load path method, the results may not provide an accurate representation of actual performance in the event of a damaging event; this is discussed in greater detail in Section 4.3.5. The method may be viewed as a tool to ensure redundancy in the gravity load resisting system rather than a simulation of structural response after initial damage. 


\subsubsection{Analysis Techniques}

The accuracy of any modeling effort to assess the risk of progressive collapse of a structure depends heavily on how well the material behavior is captured. The ability of a structure to absorb and dissipate energy at the onset of localized damage is directly related to the strain energy stored and dissipated in the materials that make up the structural elements and connections. Constitutive models lie at the heart of any numerical solution of a structural problem.

There exist numerous models for common materials, such as concrete, steel, and composites, found in engineering applications. At the material or continuum level, these models range from relatively simple linear elastic isotropic models to more sophisticated plastic-damage theories. The engineer has to exercise judgment to select the most appropriate models for a given problem.

It is common to find sophisticated constitutive models integrated in commercial finite element analysis software. In addition, high-end commercial software allow users to supply user-defined material models, giving the analyst powerful tools to characterize structural systems. However, the use of constitutive models has to be handled carefully and the user must be aware of advantages and limitations of the models. For instance, it is well known that models of strain-softening materials such as concrete can lead to non-unique finite element solutions if appropriate steps are not taken such as implementing regularization techniques. It is highly advised that the designer become familiar with the basis of a constitutive model before using it in a numerical analysis.

\section{(i) Small deformation and finite deformation}

Small deformations are considered when the deformed configuration of a body or structure varies little with respect to its original shape. This is the case in most problems encountered in structural engineering design. Therefore, the conventional definitions of stress and strain apply and no further considerations have to be made. However, there are problems such as those associated with impact, fracture, and penetration where the deformed configuration can depart considerably from the original shape of the structure. In this situation, different definitions of stress and strain are needed compared with those used in conventional small deformation analysis. For instance, the definition of stress with respect to the deformed configuration (Cauchy stress) is significantly different from stress defined with respect to the undeformed configuration. It is important that the engineer in charge of modeling the phenomena assess whether the problem needs to be described using finite deformations or small deformations.

\section{(ii) Linear elastic constitutive models}

Linear elastic constitutive models are the simplest and most widely used in engineering applications, but progressive collapse of a structure invariably involves non-linear material behavior. Linear elastic models, however, can be used for preliminary studies before material non-linearity is taken into consideration. Because of the simplicity of linear elastic models, they can help to elucidate deficient structural behavior before undertaking a more complex analysis.

\section{(iii) Inelastic, rate dependent, and rate independent models}

The phenomenon of structural collapse most often will involve deformation of the structural materials into the inelastic range (i.e., permanent deformations will occur). Inelastic action is a key mechanism for a structure to dissipate energy and redistribute loads and should be taken into consideration in progressive collapse analyses. 
The inelastic response of a material can be rate dependent (i.e., response depends on the rate of loading) or rate independent. For instance, the tensile strength of concrete increases significantly for strain rates above 1/s (van Mier, 1997). The response of engineering materials such as steel, concrete, and composites can be safely considered rate independent for most analysis of progressive collapse (i.e., primarily gravity loading) where strain rates are considered slow. However, rate dependency must be taken into consideration in analyses of the direct effects of blast loads or high velocity impact.

\section{(iv) Material level versus structural level}

Constitutive relationships associate stresses and strains, at the material level, and forces and displacements at the structural level. At the material level, constitutive relationships are used when distributions of stresses and strains are needed in a continuum or when simple "strength-of-materials" concepts cannot be applied. On the other hand, constitutive relationships at the structural level, such as moment-curvature relationships, are defined at the element (macro) level, leaving aside any information about stress and strain distributions at lower scales. Examples of applications where continuum theories are needed include characterization of joint load-deformation behavior when structural tests are not available, behavior of walls, and behavior of discontinuity regions. Constitutive models at the element level can be used when the macro-structural behavior is the primary objective and beam and plate theory apply. Figure 4-1 shows an example of a finite element model of a steel connection used to determine its moment-rotation response.
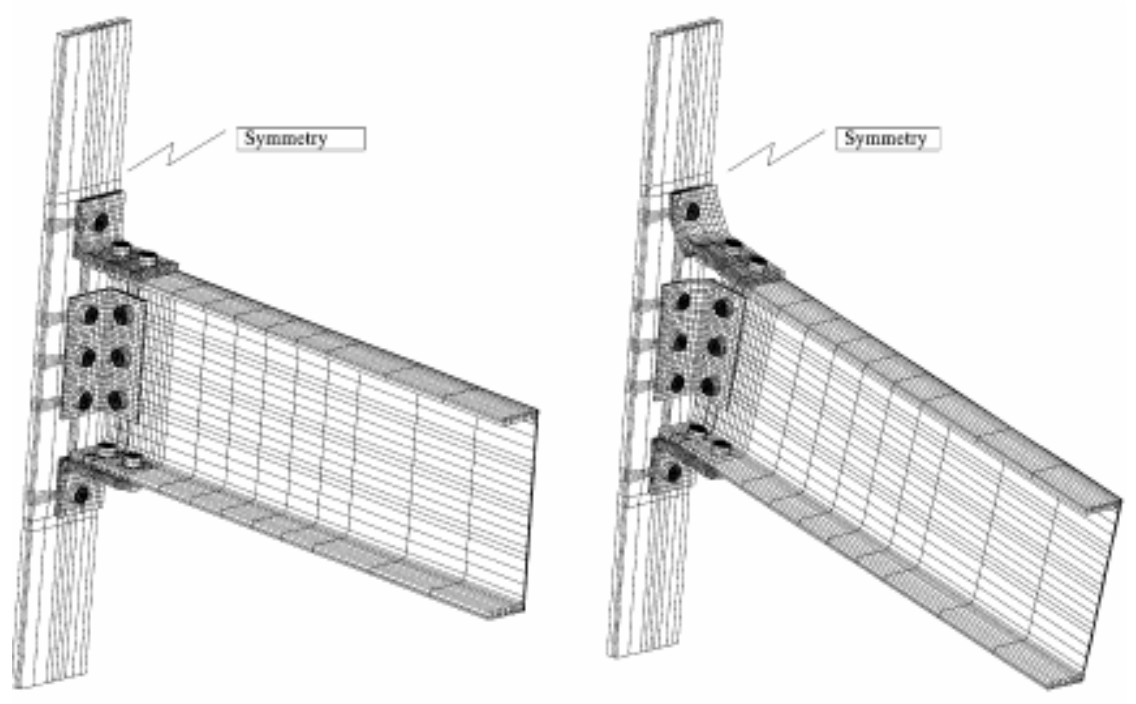

\section{Figure 4-1 Finite element representation of steel connection; (left) unloaded model and (right) loaded model (Citipitioglu et al., 2002)}

\section{(v) Stability analysis}

An important aspect in the analysis of framed structures is the stability of the system. Depending on the problem at hand, simple linear buckling analysis could help elucidate important information about critical loads. However, other problems will require that full geometric non-linear analyses be performed to determine limit loads, bifurcation loads, and secondary equilibrium paths. In the end, it is good engineering judgment that will determine the tool used and the interpretation of the results. 


\subsubsection{Performance Criteria}

A crucial and perhaps the most difficult issue when a structure is being evaluated to determine its risk to progressive collapse is establishing the analysis approach and selecting performance criteria. In other words, the engineer has to determine what scenarios to consider and what principles to use to deem the structure safe or unsafe.

Different procedures have been established in documents and codes around the world for analyzing structures and determining their susceptibility to progressive collapse (see Appendix A). In general, the approach is for the analysis to be performed for postulated initiating damage, with acceptable performance defined as the ability of the structure to confine collapse to a limited region of the building. The area of collapse must be limited generally to the bay in which the initiating damage occurred, and to one level above and below the initial damage.

Difficulties always develop when attempting to quantify the amount of damage associated with an initiating event. Uncertainties in the form of the initial damage, the understanding of structural performance at the extreme of capabilities of structural members, and the dynamics of the threedimensional collapse phenomenon cloud the precision with which such determinations can be made. As a further complication in existing buildings, engineers are uncertain about the actual construction in the building, performance of existing detailing has never been verified through comprehensive tests or analyses, and upgrades often take the form of custom designs fit to unique circumstances. Faced with these circumstances, engineers will need to set performance criteria that are measurable, and that have relevance to the specific needs of the owner and the construction of the building.

To develop criteria that are meaningful, the engineer must assess the precision with which analyses can be performed and set criteria that can be evaluated on a similar level of precision. For instance, it is not particularly useful to set a strict deformation limit when the precision of predicted deformations is unknown, or if the magnitude of predicted deformation can change significantly through minor, justifiable variations in initial assumptions.

Therefore, when using established references, the engineer needs to conduct analyses that are robust, so that it can be demonstrated that performance expectations are not sensitive to small variations of assumptions that can not be validated accurately. When special criteria are developed for a specific purpose, they need to be described in appropriate terms to allow the analysis results to be judged on their true merits.

Within these limitations, appropriate performance criteria for the evaluation of buildings include the following:

- High performance can be justified if it can be shown that collapse does not initiate, either because individual members have been hardened to the level that they survive the initial hazard or that collapse does not propagate beyond the initially damaged elements.

- Acceptable performance can be justified if the propagation of damage can be shown to be limited to the bay where initial damage is assumed to occur and does not extend more than one floor above or below the location of initial damage. 
- Acceptable performance can be justified if the amount of deformation that occurs as collapse is arrested is limited such that the life safety of individuals outside the immediate damage location is not compromised. One might consider, therefore, that deformation should be limited to a fraction of the story height.

An opinion concerning acceptability of performance can be further defended when there are authoritative references or experiential evidence that the mitigation approaches have demonstrated reliability in the subject application.

\subsubsection{Specific Local Resistance}

The method of specific local resistance is intrinsically a threat specific design approach and the design threats may be in the form of explosive, impact or fire loading. By this approach, individual members are locally hardened and detailed to withstand the specified threat or to develop the full resistance of each key structural element without failing the connections or supporting members framing into it. This balanced approach considers the load path of the structure in developing the full resistance available to the key members.

The specific local resistance direct design approach is often the only rational approach when retrofitting an existing building. The cost of bringing the building into compliance using other methods may be so great as to make the solution impractical. The specific local resistance approach might allow the owner to increase the resistance of key structural elements, such as exterior columns, to resist any reasonable threat that might otherwise compromise two adjacent columns.

\section{(i) Key elements}

In order to apply this approach, the critical elements need to be identified and strengthened to resist the identified threat without failure. Any single element essential to the stability of the structure, together with its structural connections, should not be permitted to fail under stipulated gravity loads after being subjected to a specified abnormal or extreme local loading condition. The structure should be detailed to permit load reversals and the connections must be designed to develop the capacity of the members.

If no specific threats are identified for a structure, key elements may still be designed to be more robust and resistant to abnormal loading. In this case, key elements should be designed so that they can develop their full resistance against unanticipated load without failing the connections or supporting members framing to them. This balanced approach activates the full resistance available in the key members, maximizing their ability to deal with unforeseen hazards without having to redistribute loads. As a result, this balanced approach precludes a progressive collapse that might be triggered by the limiting capacity of an individual key element. The key elements should, therefore, be detailed to develop the ultimate capacity of the materials in shear, flexure, and axial load by means of confinement and continuity of reinforcement for reinforced concrete construction and encasement or stiffeners for rolled steel construction. For a column or other compression element, the interaction between flexure and axial load must be considered when establishing the capacities. In those cases where the stability of the element depends upon the lateral support provided by the attached partitions, these partitions, or a portion of them that can provide adequate lateral support, must also satisfy requirements of this paragraph. These essential elements may respond inelastically to the abnormal or extreme local loading conditions; however it must 
be demonstrated through appropriate analytical methods that these elements can continue to carry the gravity and lateral loads they support.

\section{(ii) Transfer structures}

Transfer structures and the columns supporting transfer girders represent a particular risk due to the greater influence area they support and are particularly vulnerable to abnormal loading, including the effects of fire. Transfer girders typically concentrate the load bearing system onto fewer structural elements. This system runs contrary to the concept of redundancy that protects structures from abnormal loading conditions. Typically, the transfer girder spans a large opening, such as a loading dock, or provides the means to shift the location of column lines at a particular floor. Damage to the girder may leave several lines of columns, which terminate at the girder from above, totally unsupported. Similarly, the loss of a support column from below will create a much larger transfer span. Transfer girders therefore create critical sections whose loss may result in a progressive collapse.

If a transfer girder is required and if this girder may be vulnerable to an abnormal load, it is desirable that this girder be continuous over several supports. It is further recommended that there be substantial structure framing into the transfer girder to create a two-way redundancy and thereby an alternate load path in the event of a localized failure. The column connections that support the transfer structures should provide sustained strength despite inelastic deformations and should be designed as full moment connections. Transfer structures and the columns that support the transfer members should be hardened to the requirements of the specific local resistance. These recommendations apply also to transfer systems and to all elements that have no redundancy, such as tension hangers and tension ties in trusses. These elements should have connections that develop the full axial strength of the member. All elements of a transfer system should be designed for the lowest strength reduction factor used in the design of any supported, supporting or transfer element.

\section{(iii) Ductile detailing}

To enhance the overall performance of the structure, the specific local resistance method should be supplemented with redundant ductile detailing. For concrete structures, this detailing entails the use of continuous bottom reinforcement over supports, confinement at joints, adequate ties to allow for load transfer, peripheral ties at the spandrels, internal ties through floor slabs and beams, horizontal ties to columns and walls, vertical ties along the perimeter structure and tension ties for precast concrete construction. For steel structures, this detailing may sometimes entail the use of a moment resisting frame at the critical location and either establishing column lengths to avoid splices at critical column locations or the use of moment resisting splices at critical column locations.

\section{(iv) Analysis methods}

The analysis of a structure's response to an extreme loading that may cause damage requires advanced analytical techniques. The specific local resistance method requires numerical simulation or empirical data to demonstrate a key structural element's ability to withstand a design level threat. The successful simulation of structural response to extreme loading, when compared with results of explosive testing of columns, walls, beams and slabs, have been achieved using analytical methods that account for the nonlinear dynamic behavior of the members. These methods are generally computationally intensive, however, they need only be applied to a portion of the structural system at one time and the resulting models are relatively small and efficiently analyzed. 
As an example, the explicit finite element approach may be used to evaluate the dynamic response of perimeter building columns to specified blast environments. Finite element analyses of reinforced concrete and steel columns have been performed for the Defense Threat Reduction Agency (DTRA) to determine their capacity to resist explosive loads and to serve as pre-test predictions. Figure 4-2 depicts the performance of a concrete encased steel column in response to a near contact satchel explosive threat.

Additional finite element analyses of reinforced concrete columns have been performed for the General Services Administration (GSA) to demonstrate the ability of vulnerable columns to withstand specified explosive threats. The columns need to be modeled with three-dimensional nonlinear, explicit finite element software and analyzed to predict the damage due to the posed threat. To limit the required computational resources, an end-block boundary condition may be used to represent the connection to the rest of the structure that is not explicitly modeled. This approach was verified through explosive testing of individual columns within a full structure. The computational simulation of the event requires software that applies dynamic blast loading directly onto the column and that includes geometric nonlinearities and nonlinear, rate-dependent material properties. Similar calculations were performed to determine the increased concrete strength due to the confining effect of a steel jacket. The results of the calculations demonstrate the ability of jacketed columns to sustain a blast environment that would otherwise severely damage two adjacent unjacketed columns.

The specific local resistance direct design method may improve the resistance of a structure to a larger threat than can be achieved by other design approaches. A rational design approach that could provide the most comprehensive protection against progressive collapse may be a combination of the indirect design method for prescribing desirable details and the specific local resistance method to strengthen vulnerable structural members. This approach can be used to increase the resistance of the structure to events that would otherwise damage two or more columns and invalidate the alternate load path design approaches based on a single-element removal.
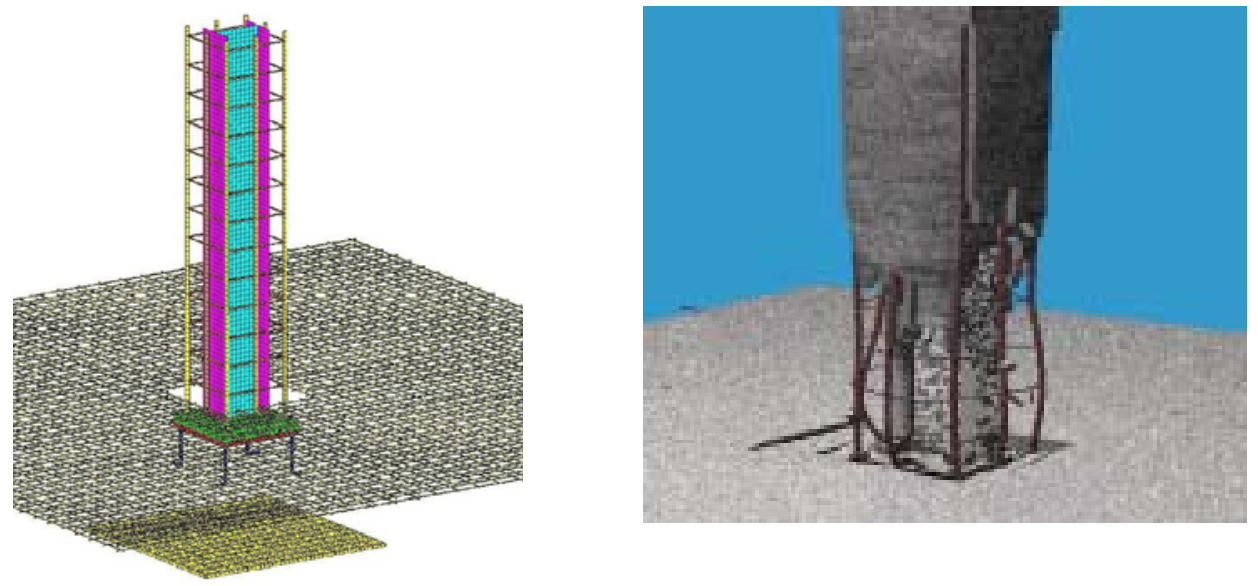

Figure 4-2 Concrete encased steel column subjected to near contact detonation

\subsubsection{Alternate Load Path Analysis}

The alternate load path direct design approach explicitly considers the resistance to progressive collapse when the level of damage is stipulated. This is often interpreted as the removal of one load bearing element, as specified in the GSA Guidelines (GSA 2003). Because this approach does not specify a threat 
or a cause for the damaged state, it limits the applicability to abnormal loading conditions that would cause the stipulated level of damage. An advantage of this approach is that it promotes structural systems with ductility, continuity, and energy absorbing properties that are desirable in preventing progressive collapse. This approach would certainly discourage the use of a large transfer girder that prevents a significant number of the columns from extending to the ground floor. This method is also consistent with the seismic design approach used in many building codes throughout the world. The seismic codes promote regular structures that are well tied together. They also require ductile details so that plastic rotations can take place.

The alternate load path approach assumes a hypothetical damage state that ignores all other damage to the structural members that may accompany the loss of critical column support in the real situation. It assumes a girder spanning a single bay is transformed into a girder spanning two bays. The transition from the original structural configuration to the damaged state is assumed to be instantaneous, exposing the structure to a dynamic effect. Dynamic effects are taken into account in different ways depending on the analytical technique used. Because it is not reasonable to require a structure to respond elastically to the effects of an instantaneous column removal, structures are permitted to develop plastic hinges and sustain significant inelastic deformations when subjected to these extreme-loading conditions. This enables the structure to dissipate significant amounts of energy that would otherwise impose much greater dynamic loadings to the individual members. The following is an overview of the analytical procedures that can be used:

\section{(i) Elastic static}

The GSA Progressive Design Guidelines (GSA 2003) were developed to provide minimum requirements for evaluating the potential for progressive collapse particularly for buildings 10-stories or less. Although a structure's response to redistributed loads following the sudden loss of a primary load-bearing member is dynamic and inelastic, these guidelines promote the use of an "equivalent" elastic static analysis method. By this approach, the characteristic load, consisting of dead load plus $25 \%$ of the live load, is amplified with a dynamic load factor of two. The GSA guidelines allow calculated demand-capacity ratios (DCR) greater than unity to account for the development of inelastic deformation. The DOD UFC (DOD 2005) document similarly considers a characteristic load consisting of $90 \%$ or $100 \%$ of the dead load, $50 \%$ of the live load, and $20 \%$ of the wind load, and also includes a dynamic load factor of 2 for static analyses. Instead of calculating demand-capacity ratios, the DOD-approach requires iterative analyses for linear elastic methods. This corresponds to the sequential removal of elements when their ultimate flexural capacities are exceeded and replacing them with fixed moments equal in magnitude to their ultimate moment capacity (see Appendix A). Total failure of a member is defined as a non-ductile failure in shear or compression.

The GSA Guidelines (GSA 2003) and the DOD UFC (DOD 2005) provide step-by-step procedures for conducting linear elastic static analyses. Although these approaches may require the least sophisticated software and expertise, they are approximations to the behavior of a buildings' performance under progressive collapse conditions. While often resulting in conservative designs, elastic static methods may sometimes mask hazardous dynamic effects. These methods should be limited to simple structures with predictable behavior (Marjanishvili 2004).

Simplified linear elastic analyses cannot account for the redistribution of forces, P-Delta instability, nonlinear material properties (including rate effects), and the development of catenary or membrane 
modes of resistance. The structure must be permitted to develop plastic hinges when subjected to the removal of the vertical load-carrying member while supporting the factored loads; however, the extent of ductility that will be permitted depends on the type and materials of construction (see GSA 2003 and DOD 2005 for recommended limits). More rigorous analysis should include the nonlinear geometric stiffening that results when membrane effects are considered as well as the inelastic stress hardening that results when materials are permitted to deform inelastically. These effects, based on the type of construction and materials, may be represented by equivalent force-displacement or moment-rotation relations that can be used to develop the permissible limits of ductility and the corresponding demand capacity ratios. This approach may be used to establish the criteria, on a structure-by-structure basis, for evaluating the potential for progressive collapse.

The linear elastic static approach attempts to address the issue by approximating the problem and using arbitrary response limits to determine adequacy. What may appear as a rational design approach is actually a fairly subjective method for defining the extent of continuity or ductility for a particular structural system. Although a considerable effort may be expended in the process, this may be no better than the indirect method for prescribing design details.

\section{(ii) Inelastic static}

The inclusion of geometric non-linearity resulting from large deformations can account for the redistribution of loads as a column is removed and the structure attempts to re-equilibrate to the larger spans through a change in behavior from a flexural response to a membrane response or combination of both. The members that originally spanned a single bay must now span two bays, and the connection or reinforcement details may have limited capacity to develop positive moments. The inclusion of geometric non-linearity will enable the designer to account for tension-membrane stiffening of slabs and spandrel beams as they sag and develop catenary resistance. These membrane forces must be compared with the tensile capacity of the members and their connections to make sure they are capable of developing the axial forces. Consideration must also be given to the relative advantages and disadvantages of a strong diaphragm that ties the floor plate together as compared with a weak diaphragm that would allow the damaged portion of the structure to break away from the remaining structure. This is particularly important for relatively narrow structures that are incapable of resisting the large lateral loads that may be imposed by floor systems that rely on catenary action to span over a missing primary support. Structural analyses that consider the geometric stiffness effects, which account for the coupling of vertical and lateral forces as large displacements are developed, are required to determine the vulnerability of the lateral load resisting system to these large diaphragm forces. Unless the structure can accept the loading patterns that result from an alternate load path analysis, the damaged portion of the structure should be isolated from the adjacent bays. Also, because catenary action is ineffective at corner bays, except for wall panel construction, corner bays require moment connections on both sides of the first inner column.

Non-linear analyses depend on an accurate representation of material behavior to represent inelastic response. Because these responses are path dependent, inaccuracies in material modeling tend to propagate errors throughout the model. Of particular importance is the actual behavior of the joints as they undergo inelastic deformation. Non-linear springs representing the behavior of the joints are required and the determination of these spring properties often entails separate studies to generate the forcedeformation and moment-curvature relations for the different connections. In order to avoid mesh dependent results, the detailed finite element models that determine the behavior of the connections require considerable experience using non-linear software and the inelastic material properties. The resulting non-linear spring properties may then be used in the frame analysis of the structure. 
The non-linear equivalent static approaches generally simulate a dynamic enhancement through a load factor and incrementally apply the gravity load reaction of the removed column to generate a "push-down curve" of the structural behavior. This load-controlled application of the gravity loads will typically engage the structural members in close proximity to the initiating damage and will represent the structural deformation as a single degree of freedom. However, even for very regular structures in which the stiffness of all the floor systems is identical, the actual dynamic response will contain many significant modes. While the inelastic static methods are preferable to the elastic static methods, significant dynamic effects may be overlooked.

The GSA Guidelines (GSA 2003) permit nonlinear static analysis as an alternative to linear static analysis. In this case, acceptance criteria are in terms of member deformation limits that are based on the 2001 DOD draft standards (DOD 2001). The DOD UFC guidelines on progressive collapse (DOD 2005) also permit nonlinear static analysis, and provide a step-by-step procedure for performing such an analysis. The DOD UFC acceptance criteria for member performance are based also on deformation limits, which are similar, but not equivalent, to those published in the 2003 GSA Guidelines.

\section{(iii) Elastic dynamic}

Linear elastic, dynamic (or time history) analyses incorporate the dynamic effects associated with the sudden removal of a structural element but do not represent the inelastic deformation or redistribution of forces in the structural elements. Although significantly easier to analyze than inelastic models of the structure, these methods require extensive judgment on the part of the analyst to determine whether PDelta effects are significant and to determine whether the calculated demand capacity ratios are acceptable.

\section{(iv) Inelastic dynamic}

A more rigorous approach for evaluating progressive collapse is through the use of inelastic finite element software. Some representative software includes LS DYNA, FLEX, ANSYS, ABAQUS, and LARSA. There are also many other nonlinear finite element software used throughout the world. These software packages have various levels of refinement that can account for the large nonlinear, time dependent behavior that occur when local damage is initiated. The use of these software packages by an experienced analyst can produce the most accurate predictions of progressive collapse. However, the additional complexity comes at a large computational expense, which can result in more expensive and longer design times on the project. This expense can often be justified in the retrofit of existing buildings where construction cost savings may greatly outweigh the cost of engineering design fees.

Computations may be performed using the three-dimensional explicit, nonlinear, large deformation, transient analysis, finite element software. These computer codes contain a library of finite elements and constitutive models that are tailored to the solution of large, transient nonlinear problems through failure. Theoretically sound constitutive models for ductile and brittle materials are required.

For large building models, beam and shell members with nonlinear, rate dependent material models can often be combined with continuum elements to give a reasonable response with increased computational efficiency. This approach is routinely used for predicting the response of explosive tests on full scale structures. The ability to make these types of modeling tradeoffs comes from the experience of the analyst who is performing the calculations. Where beam elements are used to represent the structural response, detailed three-dimensional models of structural connections, in which the steel reinforcement is explicitly 
represented for reinforced concrete frames, need to be analyzed in order to develop non-linear momentrotation properties of the joint. The more experience with predicting actual test results and building structural modeling, the better chance that the results will achieve the goal of designing a structure to prevent progressive collapse.

The GSA Guidelines (GSA 2003) permit the use of nonlinear dynamic analysis, but caution that they should be used by structural engineers with knowledge and experience in structural dynamics. The DOD UFC (DOD 2005) also permits nonlinear dynamic analysis and provides a step-by-step general procedure for this type of analysis. In both documents, acceptance criteria for the performance of structural members are in terms of deformation limits.

\subsubsection{General Purpose Approach for Progressive Collapse Potential}

A general purpose approach for evaluating the potential for a progressive collapse must include structural dynamics, nonlinear analysis, both global and local modeling and a threat dependent evaluation of the extent of the initial damage region. While the dynamic and nonlinear characteristics of the response are obvious, a global evaluation of the entire structure may be computationally exhaustive. Instead, a more efficient approach is to use higher resolution models to analyze the members and connections in the vicinity of the failure front. After analyzing the initiating event, the vertical and/or horizontal propagation of the failure front and the stability of the remaining structure (see Figure 4-3) must be analyzed. In this approach of analysis (Ettouney et al. 2004), the first step is to evaluate the performance of a column in response to a specified explosive event. This step is bypassed and the column is assumed to be removed notionally if a threat independent approach is required. The second step investigates the potential for the failure front to propagate to the interface of the adjoining beam and the adjacent column for the full height of the building. If this were to occur, the third step investigates the potential for the adjacent column to fail and whether several bays of the structure are affected. The final stage investigates the potential for a general loss of structural stability considering the failures that may have been identified in the preceding stages.

\subsection{SUMMARY}

The design of structures to be more resistant to progressive collapse requires consideration of the damaged state and the provision for multiple load paths. Best practices will start with the selection of the structural system and framing layout. It will provide ductile details that are capable of developing large inelastic deformations. For the vast majority of structures, the design requirements may be prescribed using the indirect method. This will result in a more robust structure with greater capacity to sustain abnormal loading. For special structures, iconic structures or critical facilities, direct analytical methods may be used to determine the required design details. These direct methods may be used to design key elements to resist a specified threat or to develop its full resistance against unanticipated load without failing the connections or supporting members framing to it. Alternatively, a damaged state may be postulated and the structural response may be determined using inelastic dynamic analytical methods. Damage state calculations may be performed using commercially available software; however, care must be taken to avoid numerical errors and experience is required to detect these errors should they do occur. 


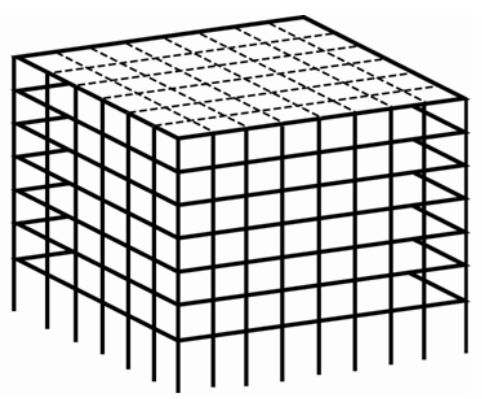

(a) Pristine Regular Framed Structure

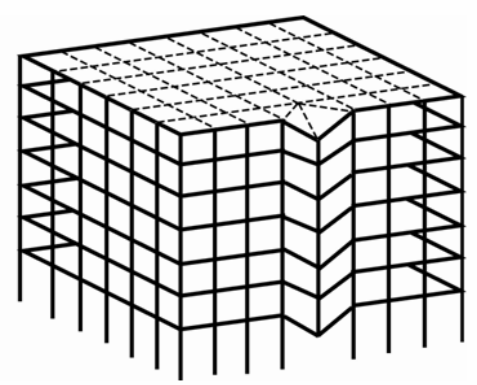

(b) Loss of Target Column, First Bay Response

General Structural Instability Phase
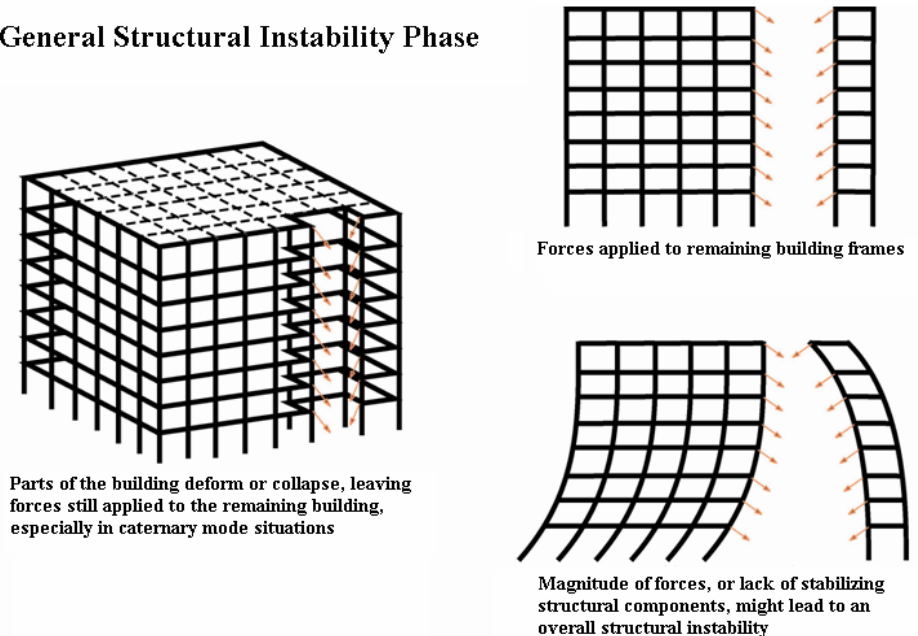

(d) Stability of Remaining Structure

Figure 4-3 Phases of progressive collapse (Ettouney et al. 2004) 


\section{Chapter 5 \\ Practical Design To Prevent Progressive Collapse}

\section{$5.1 \quad$ INTRODUCTION}

Good engineering design integrates the gravity-load resisting structural system, including the system for resisting progressive collapse, with the lateral-force resisting system required for wind and seismic loading. Current research programs are investigating the effectiveness of various conventional building systems for resisting different failure mechanisms. This chapter presents general guidelines for design of new buildings and strengthening of existing buildings for progressive collapse resistance. The guidelines are based on existing knowledge and practice. In many cases, general approaches to enhancing structural system performance for progressive collapse resistance are similar for new and existing buildings. On the other hand, design to upgrade an existing building is more challenging because of constraints of the existing structural system and site layout.

\section{$5.2 \quad$ DESIGN GUIDANCE FOR DIFFERENT STRUCTURAL SYSTEMS}

\subsubsection{General Beneficial Features of Structures and Foundations}

\section{(i) Structural features}

Beneficial features for enhancing resistance to progressive collapse that are common to different structural systems include:

- Closely spaced beams framing into a girder may improve load redistribution.

- Closely spaced columns may allow for improved load redistribution.

- Allow framing to cantilever from first bay in to the perimeter; this recesses the exterior columns relative to the façade and reduces their exposure to exterior hazards.

- Consider resistance to collapse in both directions; do not assume "plane frame" behavior.

- Avoid discontinuities that will cause load concentrations.

- A regular, symmetric building plan will allow for load sharing and redundancy.

- Multi-span beams/girders will provide greater continuity, resulting in less deflection and increased load redistribution in the event of column loss.

- Eccentricities may create large moment demand under additional load.

- A longitudinal spine of walls and stairwells may help to stabilize the structure and provide alternate load paths. 


\section{(ii) Compartmentalization}

Horizontal progression of collapse can be limited effectively by dividing the structure into independent structural systems, separated by "structural fuse planes" that will not transfer destructive forces from one portion of the structure to the next. Within each separate system, robust detailing can provide collapse resistance. In addition, the structural independence of the separate portions of the structure provides a second level of defense against catastrophic collapse by containing the collapse to one of the independent systems, in the event that robust detailing is not enough.

Fuse planes are particularly effective in large, low buildings and for certain building components, such as long cantilever balconies. In such low structures, collapse is assumed to involve perhaps the full height of the building, but is limited in horizontal extent at locations where collapse forces can not be transferred across the boundary.

The advantage is less obvious for tall buildings in which vertical progression of collapse is the major concern. Compartmentalization in tall buildings generally involves installing "strong floors"

intermittently over the height of the building, on the premise that these strong floors are designed to arrest falling debris and add stability to the surrounding structure.

\section{(iii) Foundation design}

The following features related to foundation design should be considered:

- Column connections to the foundation should be checked for additional flexure that might result from load redistribution as a consequence of the loss of a structural element.

- Loss of a column will increase loads to footings under adjacent columns as load redistributes, check to make sure ultimate bearing strength is not exceeded.

- Wider footings will reduce bearing pressure on soil.

- Thicker footings will improve resistance to punching failure at column connections.

- Tie footings together with strip footings or grade beams to improve load redistribution.

\subsubsection{Reinforced Concrete Structures}

Reinforced concrete has a number of attributes that can be used to advantage. It has significant mass, which improves response to explosions because the mass is often mobilized only after the pressure wave has diminished significantly thereby reducing deformation. This mass may become a liability, however, when assessing the progressive collapse resistance of a locally damaged frame. Members can be readily proportioned and reinforced for ductile behavior and continuity between the members. Finally the physical size of reinforced concrete columns make them less susceptible to buckling in the event of the loss of a floor system.

Confinement of concrete, using columns with closely spaced ties or spiral reinforcing, will improve shear capacity, improve the performance of lap splices in the event of loss of concrete cover, and greatly enhance column ductility. 
A preferred system is to use cast-in-place reinforced concrete with beams in two directions. If this system is used, beams should have continuous top and bottom reinforcement with tension lap splices. Use of full capacity mechanical butt splices is one means of achieving these connections. Stirrups should develop the shear capacity of the beams and be closely placed along the entire span.

Two-way floor slabs are preferred over one-way slabs, as they provide greater redundancy. Connections must be able to develop the capacity of the weaker connected element, and detailing should conform to requirements for seismic design. Top and bottom reinforcement in concrete slabs should extend into beams and columns to improve capacity to withstand load reversals. Floor slabs may carry loads through catenary action with large deflections when stressed beyond their flexural strength; however, the slab reinforcement must be able to develop its yield capacity.

In concrete flat slab or flat plate systems, the potential of shear failure at the slab-column joints should be investigated. Where flat slab or flat plate systems are employed, they should include features to enhance their punching shear resistance, such as using column capitals, drop panels, or special shear reinforcement. Continuous bottom reinforcement should be provided through columns in two directions to retain the slab in the event that punching shear failure occurs. Edge beams should be provided at the building exterior.

Concrete walls may be designed to carry loads through beam action, provided that the walls are sufficiently tied at the top and bottom to the floor slabs or edge beams.

The following sections list factors that should be considered to produce robust reinforced concrete buildings with enhanced resistance to progressive collapse.

\section{(i) Beam design}

- Ensure flexural failure (ductile) rather than shear failure (brittle); follow ACI 318 Chapter 21 (Special Provisions for Seismic Design). While no correlation currently exists between the detailing of a structure according to the provisions of Chapter 21 and the structure's resistance to progressive collapse, the ACI 318 provisions for special moment frames offer the best available recommendations for detailing connections to provide energy dissipation and toughness. These minimum requirements were developed to enable a cast-in-place or precast concrete structure to sustain a series of load cycles into the inelastic range of response without significant deterioration in strength.

- Maintain continuous positive and negative reinforcement throughout a member as recommended in Chapter 21 of ACI 318. Do not use mechanical couplers unless they can be shown to develop the tensile strength of the bar (not just $1.25 \times f_{y}$ ) and are well staggered.

- Do not splice reinforcement near joint regions or midspans.

- Provide closely spaced confining steel to improve ductility and increase shear and torsion strength.

- Use seismic hooks on all ties. Use seismic development lengths.

- Design joint regions to be stronger than incident element. 
- Larger members may provide more torsional resistance.

- For nonlinear analyses, consider maximum plastic rotation after formation of plastic hinges.

- When using plastic analysis, ensure that shear failure will not occur prior to developing full plastic moment capacity.

\section{(ii) Column design}

- Ensure plastic hinging in beams by designing columns for larger moment than beam can deliver (expected strength).

- Detail columns to have confinement.

- Splice column reinforcement at third-points, not at ends or midspan.

- Continue confining ties through joint region.

- For loss of corner column, consider possible large moments and axial loads in adjacent columns.

\section{(iii) Slab design}

- Lightweight concrete floor slabs will reduce load but the blast resistance performance can be enhanced by using normal weight concrete.

- More reinforcing steel can help tieback adjacent beam to share load in event of column loss under beam.

- Provide some amount of continuous top and bottom reinforcement in both directions. Do not splice at midspan or at ends.

- Slabs cast monolithically with beams and girders will provide more continuity and allow more load redistribution.

- Add perimeter frame for flat plate systems.

- Reinforcing steel in perpendicular directions, top and bottom may allow a slab to change span directions in the event of a support loss regardless of aspect ratio of slab plan.

- Allow for reversals of load in design.

\section{(iv) Wall design}

- Provide additional reinforcement in coupling beams and around openings to allow wall to cantilever over openings if half the wall adjacent to the opening is lost.

- Consider adding boundary elements to serve as columns if part of wall is breached.

- $\quad$ Provide sufficient tying of slab into wall. 


\subsubsection{Steel Structures}

Steel is a ductile material and provides good resistance to progressive collapse. It has a relatively high strength to weight ratio that allows for reduced weight of construction, which is advantageous for progressive collapse resistance. This lightness may become a liability, however, when assessing blast resistance. In buildings not specifically detailed for blast resistance, it is likely that the cladding and floor system will fail, leaving the steel frame intact. Steel structural systems with enhanced resistance to progressive collapse include perimeter moment frames and systems with special features such as strong floors or belt trusses.

Designing steel connections to resist progressive collapse requires special attention. Ductile steel connections should be designed to allow development of the full capacity of members. For steel columns, splices should be placed as far above grade level as practical. Although limited explosive testing of steel columns indicate typical splices generally perform well in response to air-blast loads, it is recommended that splices at exterior columns be designed to provide enhanced out of plane performance. This may entail complete penetration welded flanges as well as improved welding details and procedures for greater toughness. The connection between the column and base plate, which was demonstrated in recent explosive testing to be problematic (Lawver et al. 2003), should be encased in concrete.

When blast effects are a design consideration, special attention is needed in conventional steel beam construction with metal deck and concrete fill slab to enhance the interconnection between these elements. Although lightweight concrete floor slabs will reduce load, the performance of this system can be enhanced by use of normal weight concrete fill, increasing the gauge of welded wire fabric reinforcement, and using shear studs for the connection between the slab and beams with shear connector studs. Because it is anticipated that the slab capacity will exceed that of the supporting beams, beam end connections should be capable of developing the ultimate flexural capacity of the beams to avoid brittle failure. Beam to column connections should be capable of resisting upward as well as downward forces.

The following sections list factors that should be considered for designing steel buildings with enhanced resistance to progressive collapse (Marchand and Alfawakhiri 2004). Until more definitive tests are conducted on the performance of steel connections, including the interaction of moment and axial tension, steel connections should meet the AISC 341 standard for inelastic rotational capacity (AISC 2005b) or the AISC 358 (AISC 2005c) requirements for pre-qualified connections.

\section{(i) Beam design}

- Lateral support provided for full length of beam will prevent lateral-torsional-buckling. Loss of floor slab adjacent to a beam or change in support conditions can change the unbraced length and weaken the beam.

- Adding stiffener plates to specific beams will reduce local buckling.

- Using seismically compact sections according to AISC 341 is recommended (AISC 2005b).

- Beam should be laterally braced to reach plastic moment capacity in both positive and negative moments assuming that the slab is ineffective in lateral bracing. 
- To prevent separation of beam from slab, use shear studs as opposed to puddle welding metal deck to beam flange.

- Consider high-strength bolted connections to prevent brittle failure from concentrated stresses at weld locations. If welds are used, use notch-tough weld metal recommended for seismic design and specify the welding requirements and procedures recommended in AISC 341 (AISC 2005b).

- Design connections for two limit states: 1) developing beam plastic moment and 2) developing beam axial tension capacity. Connections should be such that they permit large plastic deformations without brittle failures.

- Size bolted connections to prevent block shear and other brittle-type rupture failures.

- Use the AISC-341 pre-qualified fully restrained (FR) connections.

- For nonlinear analyses, consider maximum plastic rotation after formation of plastic hinges.

- Use moment connections for beams in both directions from perimeter, i.e., allow beams to cantilever from one bay in from the exterior.

- If possible make all beam-column connections fully restrained.

- Size shear connections to also be capable of developing beam axial tension.

- For a composite floor system, design beams to be unshored rather than shored to provide extra strength in the beam.

- When using plastic analysis, ensure that local buckling or shear failure will not occur prior to developing full plastic moment capacity

\section{(ii) Column design}

- Check column stability for greater unbraced length due to loss of adjacent beams, increased axial load due to loss of adjacent columns, and for axial-moment interaction from beams delivering their plastic moment to the columns.

- Seismically compact columns (AISC 341) may prevent local buckling under increased flexure

- If possible, use concrete-filled tube columns or concrete-encased wide flange shapes designed and detailed in accordance with AISC 341.

- For built-up columns, use notch-tough weld metal.

- Columns should be designed stronger than beams to ensure plastic hinging of beams.

- Provide column stiffener plates (continuity plates) to prevent prying of column flanges when beams develop catenary tension. Stiffeners must be capable of transferring catenary tension from beam to beam across the column web. 
- Add doubler plates to column web. Do not weld doubler plate to column "k" region.

- For narrow columns, provide lateral flange bracing to reduce unbraced length.

- Size column splices to develop axial tension capacity of columns and permit large plastic deformations. Use either bolted splices or welded splices, with welding following AISC-341 requirements and using notch-tough weld metal.

- Thick wide flange shapes (Groups 4 and 5) should meet the special core toughness requirements in ASTM A 6 supplement S30. If they do not, such shapes may behave in a brittle manner in tension and should only be used as compression members.

\section{(iii) Slab design}

- A concrete slab on metal deck can be used to provide full lateral support to beams.

- Use shear studs as opposed to puddle welds to maintain beam-to-deck connection.

- Provide additional reinforcing steel, bars in both directions as opposed to welded wire fabric to allow slab to develop adequate membrane capacity.

- Place reinforcement in slab center or use two layers of continuous bars.

- Lap reinforcement for continuity; do not use mechanical splices unless well staggered.

- Lightweight concrete floor slabs will reduce load but the blast resistance performance can be enhanced by use of normal weight concrete.

- Reinforce slab to carry self-weight in case of column or beam loss.

\subsubsection{Masonry Structures}

Older buildings with thick walls $(\approx 500 \mathrm{~mm}$ or $18 \mathrm{in}$ ) perform well in the event of an air-blast, mostly due to the inertia of the walls. Individual masonry units, however, can become lethal flying projectiles under high pressures. Masonry infill walls fail by shear around their perimeter.

Arching action of a masonry wall may prevent localized failure from affecting a larger portion of the structure. Walls need to be well doweled at their bottom and laterally supported with steel angles or another method at their top. Concrete masonry unit walls need to be fully grouted with heavy vertical reinforcement plus regular horizontal reinforcement.

Load-bearing wall structures should be arranged with interior longitudinal walls to support and reduce the span of long sections of crosswalls. This enhances the stability of individual walls and the structure as a whole. This localized stiffening also reduces the length of wall likely to be affected. Unreinforced masonry infill walls may provide some beneficial resistance; however, this cannot be quantified or relied upon for structural stability.

The following design considerations should be considered for enhancing the robustness of masonry buildings. 


\section{(i) General features}

- Tie diaphragm to walls for out-of-plane forces.

- Strengthen diaphragms for membrane behavior if possible.

- If wood diaphragms are used, use blocked diaphragms to prevent rotation of joists or trusses.

- Provide crossties in diaphragms.

\section{(ii) Reinforced masonry}

- Provide continuous steel in both directions.

- Use lap splices or Type 2 (as described in ACI 318) mechanical couplers.

- Provide at least one horizontal bar along each course and one vertical bar in each cell so that wall has potential to span over any area that may be breached.

- Dowel wall into foundation.

- Space first bay close to wall. Allow framing to cantilever from the column if wall is lost.

\section{(iii) Unreinforced masonry}

- Limit height to one story.

- Provide separate independent gravity load supporting pilasters or columns

\subsubsection{Large Precast Concrete Panel Construction}

Precast and post-tensioned concrete systems require sufficient reinforcement and connection details that are capable of resisting load reversals generated by rebound from the direct pressure and/or the suction from the negative pressure phase of a bomb blast. Blast pressures may be applied internally or externally as a result of an accidental explosion or terrorist attack. As has been mentioned, the collapse of a portion of the Ronan Point Tower, a precast concrete structure, was due to an accidental gas explosion and was not the result of a terrorist detonation.

Large, precast-panel structures should be designed to accommodate large deformations, which will reduce reaction forces. Relatively closely spaced two-way reinforcement should be used to act as a mesh to retain fragments from crushed concrete panels.

Precast panels are problematic because of their tendency to fail at the connections. Panels should be reinforced adequately with simple connections that transfer loads directly to the supporting structure with enough concrete around the reinforcing bars to allow development of their full capacity. Connections should be designed with a minimum of welds and pieces and not introduce torsion into the precast panels. Connections should be checked for buckling. Refer also to the recommendations of the Precast Prestressed Concrete Institute (PCI 1976). 
The following provide design recommendations for enhancing the robustness of buildings with precast concrete floor systems and buildings with tilt-up walls.

\section{(i) Precast concrete floor systems}

- If used, alternate load path method cannot be relied upon and one should design explicitly for loss of one or more columns.

- Provide a topping slab to tie elements together.

- Mechanically connect members to topping slab reinforcement.

- Design topping slab as membrane and reinforce accordingly.

- Provide steel plate connections with slotted holes to accommodate volume change, but not allow members to move off supports.

- Provide mild steel top and bottom in members to prevent rupture of sections with change is support conditions.

- Interconnect adjacent members in addition to topping slab.

\section{(ii) Tilt-up construction}

- Space first line of interior columns close to panels $(\approx 4.5 \mathrm{~m}$ or $15 \mathrm{ft})$.

- Design framing to be capable of cantilevering from first interior column to support roof dead load only. Tie panels together with mechanical connections or cast-in-place pilasters.

- Consider having cast-in-place pilasters designed to act as columns if wall panel is lost.

- Tie diaphragm to walls.

- Provide membrane capacity in diaphragm.

- Allow ledge to support roof over span of one panel.

- Provide explicit connection of walls to foundation. Do not allow walls only to bear on foundation.

\subsubsection{Post-tensioned (Unbonded) Construction}

Post-tensioned systems may not be able to withstand load reversals without additional reinforcement. If post-tensioned systems are used, continuous mild steel needs to be added to the top and the bottom faces to provide the ductility needed to resist explosion loads. Because post-tensioned systems are very common for large-span parking garages, they should be avoided if explosive threats are specified and the columns should be designed to withstand accidental vehicle impact.

The following design considerations should be considered for enhancing the resistance to progressive collapse of post-tensioned structures. 


\section{(i) General}

- Should analyze for loss of column or multiple columns.

- Alternate load path not sufficient.

- Verify that change is support conditions will not rupture members.

\section{(ii) Beam design}

- Avoid large-span girders.

- Place significant amount of mild steel continuous, top and bottom.

- Do not design post-tensioning to support entire gravity load, limit to live load only.

- Provide continuous centerline tendons in addition to draped tendons. Should analyze if going to use.

- Stagger anchorage locations and splices.

\section{(iii) Slab design}

- Provide continuous mild reinforcement top and bottom.

- Do not design post-tensioning to support entire gravity load, limit to live load only.

- Provide intermediate anchorage.

- Provide perimeter frame of mild reinforced members.

- Should analyze for loss of a column.

\subsection{CONSIDERATIONS FOR UPGRADING EXISTING BUILDINGS}

\subsubsection{Local Strengthening to Prevent Failure Initiation}

Structural elements and connections in an existing structure can be strengthened to reduce the risk of initiating or spreading failure due to abnormal loading. The intent is to increase the load capacity and ductility of certain critical structural elements or connections so that they can survive the effects of specific or generalized threats. Depending on the threat and the specific detailing of the existing structural elements, this can be difficult to achieve. High-energy bombs at close range create impulses that can overwhelm even the most robust conventionally-framed systems of common building materials. It is often impractical to design specific elements of building frames for these events. When this is the type of threat for which resistance is desired, then engineers generally will need to seek alternative approaches for protection against progressive collapse.

It is often practical to impart specific resistance for less aggressive threats. Moderate-speed vehicle impacts can be resisted with cost-efficient structural upgrades. Bombs with relatively low energy-to-range ratios can be addressed reasonably with local strengthening. 
Key decisions that determine the feasibility of local strengthening are influenced by the likelihood of defining the potential threat, the effectiveness of the existing detailing in resisting the effects of the threat, and the flexibility that the existing structure offers for remediation. Nevertheless it is clear, when feasible, that the first line of defense should be to prevent the initiation of a failure, rather than trying to arrest a collapse in motion.

The strength and the ability of the structure to dissipate energy (i.e., structures with high ductility) both are essential for the resistance to most threats and for load redistribution. Therefore, any methodology that increases the capacity and ductility of existing critical elements and connections is a good candidate for consideration to upgrade a structure to prevent progressive collapse. For instance, retrofitting techniques used for seismic loads are, in some cases, viable candidates to upgrade a structure locally to prevent progressive collapse. Corley et al. (1996) recommended that techniques commonly found in earthquake retrofitting, such as column jacketing, can be used to increase ductility and load capacity. It should be pointed out that when such retrofit techniques are used for non-seismic events, potential failure modes of structural members should be considered to determine the appropriate locations for strengthening.

Elements can be upgraded following either of two perspectives: in response to specific threats and in response to non-specific threats. These two perspectives are discussed below.

\section{(i) Upgrade vulnerable elements for specific threats}

If specific threats to a building are known, it is possible to upgrade elements against the expected hazards. Although, in general, it is difficult to specify the exact nature, location, and time of a threat, there are instances when a reasonable assessment can be made. For instance, the demands caused by a vehicle crash into a bridge or columns in a building can be estimated for postulated vehicle masses and velocities. In these cases, specific demands can be defined to design remediations so that these critical elements can survive vehicle impact.

A gas explosion is another example of a specific threat for which elements can be upgraded (i.e., when the locations of gas lines and sources are known). Given the size, configuration, and volume that is assumed to contain explosive gases, one can reasonably determine the energy release and the potential influence on surrounding structural components.

\section{(ii) Upgrade vulnerable elements for non-specific threats}

Usually specific threats are not well known in advance, forcing strengthening schemes to be implemented from a general perspective to address progressive collapse vulnerability. This is accomplished by identifying and strengthening vulnerable elements and connections considering their role on the integrity of the structure but without specifying specific hazards. It is imperative, in this approach, that the engineer associates the vulnerability of the structure as a whole with the ductility and strength of individual components, disregarding the nature, location, and time of abnormal loading events.

When specific threats cannot be defined well, it often is necessary to design for conservative estimates of threat potential. It also often becomes necessary to design classes of elements, rather than specific threatened elements, for greater resistance. For instance, owners might decide, upon the advice of consultants, that there is general risk that an explosion of imprecise magnitude could occur on the first floor of a building. While the location and magnitude of the threat cannot be established with precision, this potential threat could lead to a decision to upgrade all columns on the first floor and the slab on the second floor. 
Likewise, an engineer might discover that certain structural components have particularly poor inherent resistance to abnormal loads of any reasonable character. In this case, the owner might decide that the improved general robustness gained is worth the expenditure to upgrade these vulnerable components, even though specific threats are not identified or considered.

\section{(iii) Constraints originating from existing structural system}

Existing structures present certain limitations to the implementation of upgrading schemes. Any strengthening scheme has to be selected to address, as a minimum, the existing geometry, space limitations, and aesthetics. Often it is difficult to develop details that are practical upgrades for connections in existing structures. Sometimes critical elements might be unreachable or it is impractical to install the needed upgrades due to space constraints. To the extent that upgrade components must act compositely with or transfer forces to existing components, it will be essential to be able to develop the necessary connections.

Engineers are often not certain about the actual construction of an existing building. Deviations from the available documentation and variations in strengths of materials are common in building construction. Further, there are forms of deterioration that degrade structures over time. To the extent that these conditions can not be discerned completely, the engineer is faced with a level of uncertainty that sometimes prohibits appropriate assessment of progressive collapse potential in exiting buildings.

When the constraints of the existing system are sufficiently restrictive, it will be necessary to find alternatives that do not rely on strengthening of the existing member (i.e., adding new members to create redundancy). Relatively early in the process, the engineer needs to evaluate whether the constraints established by the existing condition are technically or economically prohibitive for viable upgrade options.

\subsubsection{Enhance Redundancy to Confine Local Failures}

If a decision is made to modify the building, the solution will probably require the introduction of redundancy to the structure. Typically, this is accomplished by providing additional rotational and tensile capacity in joints or connections or by creating new alternate load paths, or both.

Sometimes the general means to establish the necessary continuity are well established. For example, previous investigations (Corley et al. 1996 and McGuire 1974) of major structural collapses have concluded that the spread of damage in those instances could have been contained if the structures had been detailed following common practice found in earthquake-resistant design. The rationale behind this assertion is that high ductility or high capacity for energy dissipation plays a fundamental role for a structure to resist both earthquake loading and impact or blast effects. Corley et al. pointed out that more than $50 \%$ of the collapsed area in the Alfred P. Murrah Building in Oklahoma City would have stood if the structure had been designed with special moment frames found in seismic regions as opposed to the ordinary moment frames used in the building.

When it is difficult technically or economically to provide the required localized resistance, or when uncertainties related to the threat, the as-built conditions, or the response are significant, then the viable alternative is to strengthen structural elements and systems to increase their ductility and capacity to redistribute and support loads once a localized failure has occurred. Enhanced redundancy, potentially 
developed in response to specific threats, additionally provides general robustness that offers protection for other, unspecific, threats that might affect the building.

\section{(i) Local strengthening to enhance global response}

For steel-framed buildings, the beam-to-column connections may have been generally designed only for shear forces while the lateral loads in the structure are carried by cross bracing in limited locations or by a few moment frames. To increase the energy dissipation and load capacity for these simply-supported beams, a designer might create moment connections to columns. While this upgrade is intended to enhance the performance of specific beams, it also can lead to improved overall performance. A program to provide enhanced moment resistance at columns also will improve the tensile capacity of structural steel connections. This could be one component of a significant increase in the level of redundancy in the structure, by allowing beams to act as catenary elements to span over a damaged area.

Precast concrete structures often need enhanced tensile capacity in the connections if they are to resist progressive collapse. Usually the connections of these structures have been designed for gravity loads only, with the only tensile capability resulting from friction. Positive connections for tension could be introduced to tie together the components of such structures.

Under these conditions, upgrades that are intended to enhance local resistance, perhaps during design for a specific threat, can add significantly to the overall robustness of a building system. If the local upgrade of connections enforces continuity that did not previously exist, then there is the possibility that the retrofitted structure has enhanced bridging action. Hence, decisions leading toward a final design for improved resistance to progressive collapse should consider the potential for cross benefits - both ways between local strengthening to prevent initial failures and overall strengthening to limit spreading of failures.

\section{(ii) Addition of alternate load paths}

Generally, the addition of an alternate load path means providing capability for the structure above the first level at grade on the exterior to "bridge over" or redistribute loads after the loss of a column at a lower level.

Also, alternate load paths can be created by introducing two-way behavior in structures that have been designed with planar systems. Such modifications force structural systems to engage the resistance of more components when one or more critical elements have been damaged. This ability to spread out the load over more existing elements reduces the demand on each element.

\subsubsection{Means to enhance redundancy}

Redundancy requires alternate load paths and elimination of critical mechanisms. The means to provide these features are as varied as the population of framing systems that exist in buildings of interest. However, in general, redundancy can be provided by creation of two-way action in the framing system, introduction of secondary trusses, relying on Vierendeel action, creation of "strong floors" in buildings, and introduction of means to hang portions of the structure from above. 


\section{1) Two-way action}

Existing structural framing systems that can span two ways have greater robustness than structures that are designed and constructed to span just one way. The inherent resilience of structures that have interwoven framing elements provides a means for the structure to distribute forces to a relatively large area of nearby structural elements, thereby reducing the demand on each of those elements. For instance, an interior column designed to support a one-way framing system typically has only two nearby columns that would be called to service if it failed. In a two-way frame, as many as eight nearby columns would be available to help share the load of an interior column. Further, for catenary action, ideal design transfers half the force in each direction.

In some instances, basic detailing such as temperature and shrinkage reinforcement in slabs provides for sufficient two-way action. For robust designs, however, the engineer can specifically consider whether such two-way features in an existing building are adequate or whether robustness can be enhanced by a specific design that provides the needed secondary support.

In general, it may be difficult to add two-way-action features to existing buildings. However, in some framing systems elements such as new beams can suffice. An example might be a floor system with open web joists spanning between beams. Joists on column lines can be augmented or replaced with robust beams that provide support for columns, should they be removed by an extreme event.

\section{2) Secondary trusses}

When the potential initiating event is the removal of certain specific columns at low levels in a building, it may be feasible to add diagonal elements at upper levels, to turn two or multiple-story column and beam systems into trusses. In this method, the trusses would be engaged if a lower level column were to be removed, with the columns above the initial damage becoming tension members.

Important considerations in such systems are the ability to connect the new diagonal members to the existing structure, the strength of adjacent existing elements to carry the new loads, and the ability of columns to act as tension members. Particular concern needs to be given to column splices (e.g., bolted or welded splices in steel members, and reinforcing steel lap lengths in concrete members) designed for compression but suddenly subjected to tension forces. Also, consideration needs to be given to the potential that addition of secondary trusses will change the distribution of lateral service loads, affecting the performance of the structure for wind and seismic loads.

An advantage of secondary truss systems is that they often can be designed to resist the applied forces with relatively little deformation, as compared with other alternatives. This could be an advantage for life safety and further could improve the prospects of rehabilitating a building after an extreme event.

\section{3) Vierendeel action}

Moment frames intended to support lateral loads can span over a location of damage through Vierendeel action. Beams experience severe double-curvature deformation, and depending on the extent of the initial damage, columns also receive severe flexural loading.

Vierendeel action often is a viable means to add robustness to some existing buildings because all the basic features already exist, in some measure. Buildings designed to resist lateral loads with moment frames have the essential members and connections in place. Consideration needs to be given to the 
proximity of the existing moment frames with respect to the locations where initiating events are likely to occur, and to the forces that occur when Vierendeel behavior is activated. However, if beams and columns - and their connections - can be reinforced to support the applied loads, this method to add robustness can be relatively unobtrusive.

In order to develop Vierendeel action for resistance to progressive collapse, it often is necessary to upgrade a large portion of the structure. It is usually insufficient to upgrade only a few floors and achieve the desired result.

\section{4) Strong floors}

It is not always necessary to implement upgrades throughout a building. The engineer and the owner sometimes can identify a few floors, often distributed throughout the building, where resistance will be concentrated. Hence, if a system can be developed wherein individual floors are strengthened to support the load of several adjacent floors, then the areas where intrusive repairs are needed will be limited.

An advantage to the strong floor approach is that the floors with added robustness can be distributed throughout the height of the building. This results in enhanced performance of the building for unspecified events. It is less likely that an unforeseen or non-explicit event will lead to propagation of a failure, and it is more difficult for a malevolent attack to foil the design.

\section{5) Allow catenary action to develop}

Within this general category are means to provide catenary action within existing element of a structural frame. The concept involves engagement of tensile forces in members that are draped or that deform into configurations that allow cable action to be engaged. In catenary action, engineers generally expect that elements (e.g., beams and slabs) that are intended to support load in flexure will deform enough and have sufficiently stiff and strong anchorages that they will take on load as tension members. In this case, adjacent structure needs to be able to resist the high horizontal loads that are necessarily associated with the resolution of the forces in the flexural members that must work while deforming to relatively small angles to the horizontal.

Remedial designs can include features that are more efficient than might be extracted from existing construction. Sometimes it is possible to drape, or weave in a saw tooth pattern, cable along column lines that need robustness. Installed cable slopes often can be developed by weaving from below the framing beam at the column that is assumed to be removed to above the beam at adjacent columns. Greater efficiency can be gained if the cables are allowed to weave for full story heights.

Connections are complicated. Collapse actions cause very high forces in the cables, and these forces need to be anchored appropriately at cable ends and transferred effectively at each column. In addition, there needs to be sufficient strength and stiffness in the framing system to be able to resist the horizontal component of the cable anchorage forces.

\subsubsection{Evaluation of Existing Structural Systems}

\section{(i) Review documentation}

The first step in the evaluation of the existing structural conditions is a thorough review of the design documentation such as design and shop drawings, electrical and mechanical plans, calculations, 
geotechnical reports, etc. The structural engineer should review the documentation meticulously and identify any questionable aspects of the design. Special attention should be devoted to connection detailing because it plays a fundamental role in ductility and redistribution of forces at the onset of local failure.

The engineer should attempt to determine if significant structural or architectural alterations were made either during original construction or during the service life of the structure. It would be important to know if load paths or structural detailing were changed significantly, or if there were any modifications that significantly affected the weight of portions of the structure.

The process is substantially complicated when the owner does not have complete documentation for the structure. In that event, it might be necessary to attempt to obtain building plans and other relevant information from the original design team, the local building official, or fabricators. When these sources are unable to provide the necessary documentation, the engineer often is forced to conduct a substantial amount of field reconnaissance to determine the details of the structural system.

\section{(ii) Verification of as-built construction}

Building evaluations should include site assessments to verify as-built conditions. Often design modifications are made during construction, and sometimes errors in fabrication result in remedial construction that might not appear on project documentation. Further, it is possible that there are construction deviations from the original design, but were not sufficiently deficient to require remedial construction to satisfy the performance requirements of the original design.

Engineers should conduct sufficient inspections to develop an understanding of the as-built conditions. This often requires removing finishes to reveal hidden details, nondestructive tests to detect conditions inside structural elements, and sometimes invasive excavations of structural elements when critical details cannot be discerned by other means.

The difficulty associated with as-built verification can be a function of the materials of construction. In general, steel elements can be viewed, measured, and tested without significantly affecting residual performance. Reinforced concrete and reinforced masonry, on the other hand, contain hidden features (i.e., reinforcing or prestressing steel) that are difficult to verify in detail without intrusive measures. It is possible that engineers responsible for the evaluation of an existing building will be faced with levels of uncertainty that give relatively low confidence in the actual construction of the subject building. This potential is generally higher when dealing with concrete and masonry structures than it is with steel structures.

In some instances, photographs taken during construction can help to resolve some uncertainties. Engineers should look to this resource when attempting to resolve questions about as-built details.

\section{(iii) Materials studies}

The in-place properties of construction materials may vary from those specified in the design, creating the potential for enhanced or diminished performance depending on the deviation. It is routine for the average strength of construction materials to exceed the minimum specified strength. When there is potential that such deviations could lead to significantly simplified upgrades, there could be justification for materials studies that quantify the actual in-place strengths of materials. Furthermore, some material properties can increase significantly over time (e.g., due to cement hydration in concrete) or there can be deterioration 
due to environmental exposure (e.g., corrosion of steel). Therefore, in order to make a reliable assessment of the capacity of a structure, it is often appropriate to conduct a thorough characterization of the existing materials.

There exist numerous methods for evaluating the mechanical properties of structural materials. It is imperative that statistically meaningful sampling be performed for obtaining the mechanical properties of the materials. ASTM E 122 (Standard Practice for Calculating Sample Size to Estimate, With a Specific Tolerable Error, the Average for a Characteristic of a Lot or Process) and ASTM E 141-91 (Acceptance of Evidence Based on the Results of Probability Sampling) describe methodologies for selecting samples and processing the data for reliable estimates of mechanical properties. The methods of evaluation can range from mildly destructive measures such as extraction of concrete cores, reinforcing bars, and pieces of steel to less intrusive, but somewhat sophisticated, nondestructive techniques for reinforced concrete members such as impact-echo, impulse-response, ground penetrating radar, and others. The selection of the methodology to be used in the investigation is left to the judgment of the engineer.

\section{(iv) Evaluation of detailing}

Detailing plays a fundamental role in the ductility and ultimate strength of structural members and connections. Key structural aspects related to progressive collapse include connection detailing, splicing of reinforcement or steel members, continuity of structural reinforced concrete members, among others.

Resistance to progressive collapse usually involves activation of the ultimate strength of structural components in failure modes that are not associated with normal use. For instance, loss of a column can cause large deformations of frames on upper floors, with resistance to collapse coming from catenary action involving beams and floor slabs. For catenary action to be effective, connections between slabs, beams, and columns must be able to sustain large rotations while subjected to unusually large tensile axial loads. Often, detailing that was developed without consideration for progressive collapse resistance does not have the ductility necessary to survive the required high rotations. Also, the connections often do not have capacity for high member tension (e.g., bolted shear plate connections are designed for beam shears; they often do not provide sufficient edge distances to develop the capacity of the bolts for loads along the axis of the beams).

The engineer will need to evaluate the rotational and tensile capacity of connections that are not designed with this behavior in mind. This is a substantially more difficult task for evaluation of existing buildings than it is for design of new buildings, because new buildings can be designed to incorporate detailing that has proven performance. For existing buildings, engineers are constrained to addressing existing conditions.

\section{(v) Assessment of existing capacity of structural systems}

The assessment of structural capacity entails determining the strength and ductility of the entire system. For this purpose, structural analyses based on the estimated material properties, geometry, and connection detailing are carried out. These analyses can vary from approximate methods such as limit-state analysis (i.e., strength based) to more sophisticated numerical modeling such as non-linear finite element analysis (i.e., strength and ductility evaluation) as discussed in Chapter 4. 


\subsubsection{Retrofit Upgrade of Specific Materials}

\section{(i) Means for upgrading}

The means to upgrade existing elements are as varied as are the configurations of existing elements and structural systems. Depending on the materials of construction, specific remediations require specific designs.

Perhaps the most common method to add strength and robustness to structural elements is to add reinforcement or confinement to the outside of the element. Conventional techniques used in earthquake engineering for increasing ductility and strength of structural members and connections can be used for minimizing, in general, the risk of progressive collapse. There has been extensive work in developing cost effective techniques to upgrade structures in seismic regions that also can assist in the evaluation of means to address progressive collapse issues.

\section{(ii) Reinforced concrete and masonry structures}

Concrete and masonry elements often can be upgraded by encapsulating the existing element in a cover of additional reinforced concrete or by adding steel, carbon fiber reinforced composites, or glass fiber reinforced composites to the outside of the element. Depending on the orientation of the fibers in these wraps, the addition of the reinforced composite adds either longitudinal strength or confinement of the concrete or masonry core. In either case, the structural element gains strength and ductility. Priestley and Seible (1995) discuss different methodologies for retrofitting reinforced concrete and masonry structures. Figure 5-1 illustrates different methods for upgrading reinforced concrete and masonry elements.

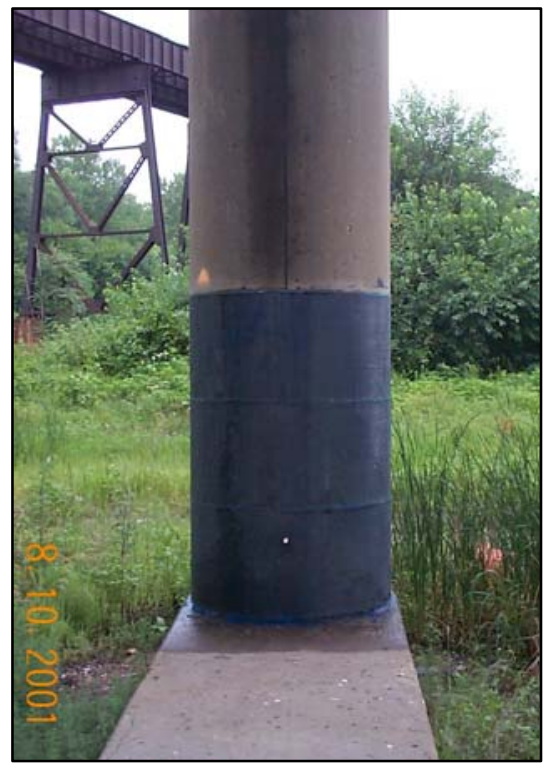

(a)

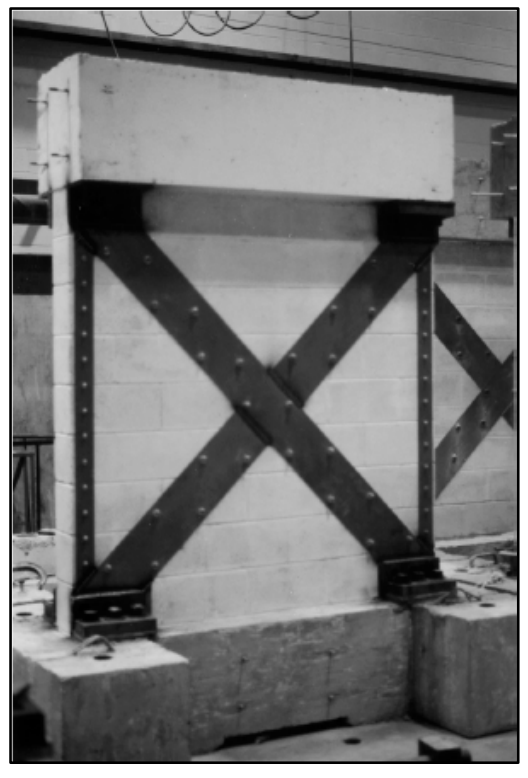

(b)

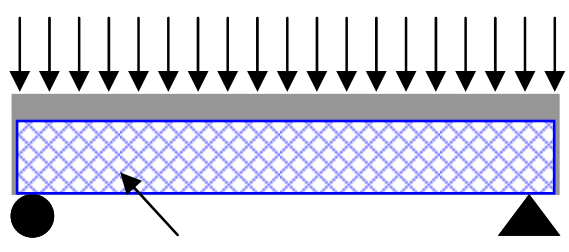

FRP Laminate

\section{Figure 5-1 a) Reinforced concrete column wrapped with carbon composite; b) masonry panel reinforced with steel strips (Taghdi et al., 2000); c) sketch of a reinforced concrete beam strengthened with FRP laminates.}

In recent years, fiber reinforced polymers (FRP) have been used increasingly for retrofitting masonry and reinforced concrete structures. Fiber reinforced polymers present certain advantages over steel for 
upgrades. These advantages, including high strength-weight ratio, ease of installation, and durability, make them very attractive for retrofitting reinforced concrete structures. In structures that may be susceptible to progressive collapse, FRP can be used to increase the ductility and strength of beams, walls, and columns, thereby increasing the ability of the structure to redistribute gravity load at the onset of a local element failure.

Reinforced concrete beam-column connections also can be upgraded using FRP. Geng et al. (1998) used carbon fiber reinforced polymers (CFRP) to repair beam-column connections with inadequate lap-splice length. They showed that the retrofitting scheme using CFRP increased significantly the ductility of the connection and more than doubled its load carrying capacity. Li et al. (1999) and Mosallam (2000) also have demonstrated the feasibility of using FRP to repair reinforced concrete beam-column connections. A beam-column connection retrofitted with advanced composites after being tested is shown in Figure 5-2.

The ductility of precast concrete structures can be increased using external cables to provide continuity (Crawford 2002). Ductility is achieved by tying precast panels together through the use of cables. The structural response of the Khobar Towers (see Appendix C) to a bomb explosion during a terrorist attack in 1996 demonstrated the feasibility of this approach.

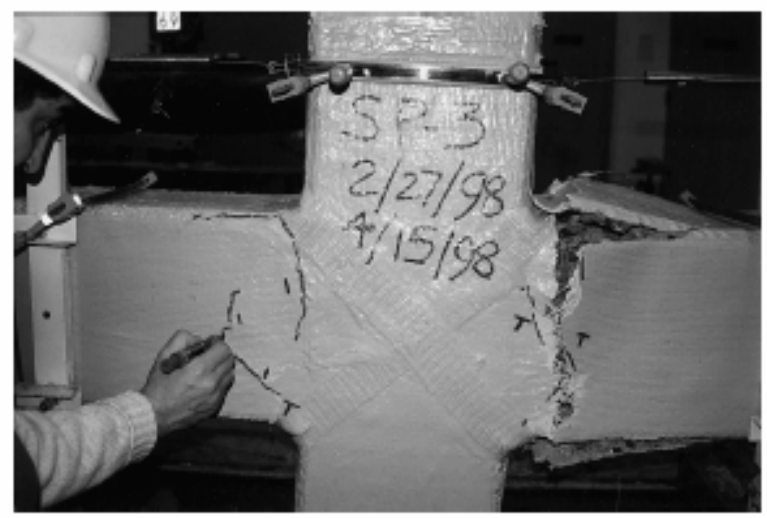

Figure 5-2 Retrofitted beam-column connection after testing (Mosallam, 2000)

There exists extensive literature on the subject of strengthening of reinforced concrete and masonry structures and the reader is directed to this work for further information (Priestley and Seible 1995). While these general approaches to upgrade structural components are applicable for increasing robustness, designers should use care to assess potential modes of failure following local damage (which often differ from those associated with earthquakes) and provide reinforcement that addresses those modes. For instance, in seismic design, maximum moments and the need for ductility often occur at connections between beams and columns in moment frames. For blast-resistant design, moments often are highest at midspan of beams and columns. Hence, concepts that are appropriate for seismic design should be adapted accordingly.

\section{(iii) Steel elements and structures}

In steel members and connections, the addition of cover plates to increase structural capacity is common practice. For instance, advantages and limitations of using welded cover plates were addressed in the work of Engelhardt and Sabol (1998), while Kasai et al. (1998) discussed the use of rigid-bolted repair methods to increase the ductility and strength of steel frames. Examples of the addition of cover plates to 
retrofit steel connections are shown in Figure 5-3. (Note that engineers need to specify connections that have been shown by test or appropriate analyses to effectively support load under severe deformation).

A similar concept for retrofitting steel moment frames is the SidePlate retrofit system (Crawford, 2002). This retrofitting scheme physically separates the face of the column flange and the end of the beam, eliminating triaxial stress concentrations, which in turn mitigates premature fracture of the connection. The SidePlate system uses parallel full- depth side plates to directly connect the beam and the column, reducing the stress transfer through panel zones. Additional information about this system and other types of upgrades can be obtained from FEMA 351 (FEMA 2000b). An illustration of the SidePlate system is shown in Figure 5-4.

It is important to realize that connection behavior can be very complex and difficult to predict. The moment-rotation response of steel connections is directly related to the distribution of stresses and strains at the material level, which can result in various failure mechanisms such as local buckling, fracture, and yielding. The distribution of stresses and strain in a connection is a direct result of the geometric configuration of the connection and its mechanisms of force transfer. Before a local retrofitting is designed, one should fully understand the mechanics underlying the connection under consideration.

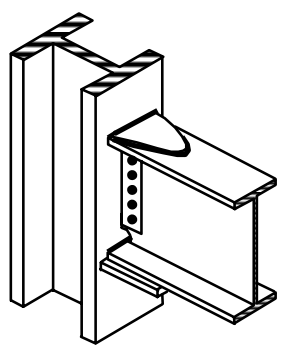

(a) Coverplate

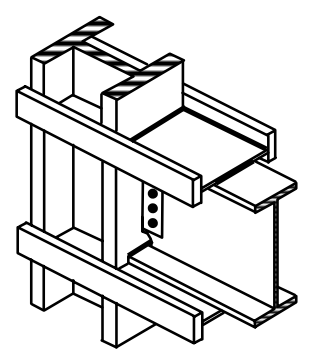

(c) Side Plate

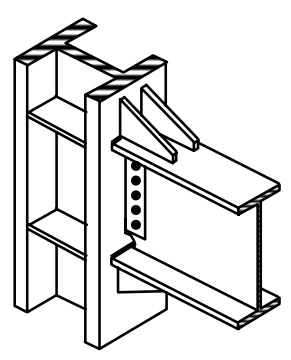

(b) Upstanding Rib

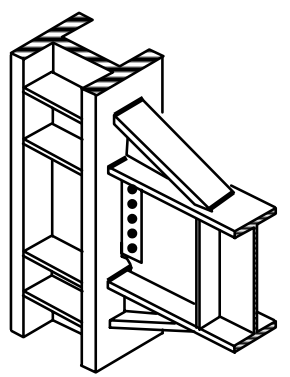

(d) Haunch

Figure 5-3 Examples of strengthening of steel connections. Adapted from Engelhardt and Sabol (1998). 


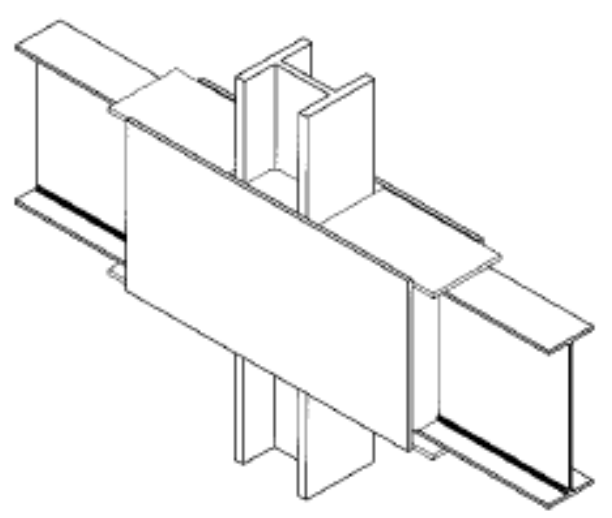

Figure 5-4 SidePlate system.

\section{(iv) Concluding comments}

When developing specific details to upgrade individual structural elements, consideration has to be given to the potential that elements with reinforcement will attract additional load because they will have increased stiffness and strength. For example, elements with enlarged dimensions will experience increased lateral loads due to blast. Also, if the relative stiffness of columns in a moment frame are changed, the distribution of forces in the frame due to other loading conditions, such as wind or earthquake, could place new demands of the reinforced element or some other elements in the frame. Hence, when designing specific elements to increase resistance to progressive collapse, due consideration has to be given to attendant influences on structural behavior during other foreseeable events.

The engineer should address the three-dimensional configuration of most building frames. Details should be developed with recognition that structural elements frame into most columns from perpendicular directions, floor slabs interfere with continuous reinforcement (and sometimes can not be penetrated without serious impact on shear strength), and such features as incompatibility among the dimensions of beams and columns that frame into a single connection prevent "clean" detailing. Remediation details should accommodate the geometric interferences that accompany these configurations, as well as other fixed architectural and mechanical components in existing buildings. Hence, some of the remediation concepts presented above are not appropriate for certain structural configurations, or they require special detailing to accommodate as-built conditions.

\subsection{IMPLEMENTATION OF UPGRADE PHILOSOPHIES}

The decision process for determining the appropriate approach to provide required resistance to progressive collapse involves several steps that inevitably consider matters, including construction costs and business interruption factors, other than structural response. A rigorous design approach will include close coordination among the owner, design team, and building users.

\subsubsection{Comparative Analysis of Benefits Offered by Upgrade Options}

Inevitably, analyses to assess means to upgrade existing buildings will lead to several concepts that have different sets of benefits and shortcomings. It will be important to assess the merits objectively and to be 
able to communicate them clearly. The owner will need clear characterizations of the value of the effort in order to make informed decisions.

There will be performance trade-offs among the viable concepts. The assessment of the concepts should evaluate the extent of the anticipated spread of the failure, both vertically and horizontally, and the end condition of the structure when failure has been arrested. For instance, consideration should be given to the relative amounts of distortion that are associated with each means of support, both for safety reasons and as distortion relates to the ability to restore the structure after the event.

Consideration needs to be given to the functional impacts on building use. Some remediation approaches will be impractical because they create untenable conditions within the building. It will not suffice to install story-high trusses on occupied floors if those trusses prevent beneficial movement around the affected floors.

In developing a comparative analysis, it is important to consider the impact on non-structural components of the building. For instance, if a proposed structural solution involves substantial remedial work in or near the plane of the exterior wall, the mechanical system may have to be modified or even redesigned and replaced.

In many cases, it is possible that construction costs will not be the dominant financial consideration. In occupied buildings, schedule and potential interruption of the use of the building can result in costs that eclipse construction costs. Hence, full programming costs and project logistics are very important and should be included in the analysis. Generally intrusive upgrades for progressive collapse remediation will be implemented in conjunction with a major remodeling required for other reasons, such as might be caused by a seismic upgrade.

Everyone who might be affected by or with a stake in the process should be involved in the selection of the upgrade option. The structural upgrade option with lowest initial cost may not be the least total cost solution or the most viable alternative, given the business needs and the protection interests of the stakeholders.

\subsubsection{Measuring Benefit}

There are few, if any, references that document actual performance of buildings with progressive collapse upgrades. Furthermore, the unique character of upgrades needed for each existing building could hinder extrapolation from known response in one case to anticipated response in another building with a similar remediation approach. Although some appreciation for performance of buildings exposed to extreme events can be gleaned from examination of buildings that have had such exposure (see Appendix C for case studies), in essentially all circumstances it will be difficult to document the structural performance of an upgraded building on the basis of test or experiential data.

Therefore, the improvement in structural performance frequently should be measured by analyses that accurately illustrate the theoretical performance before and after implementation of structural upgrades. Such demonstrations can require levels of analyses that are more sophisticated than those that are used for the upgrade design. 
Implicit (or indirect) designs, by definition, are not directed toward protection against a particular threat, nor do they provide a specific level of performance. Implicit designs are intended to add a measure of robustness that can reasonably be assumed to add resistance to progressive collapse. Some approaches for explicit designs are based on postulated and simplified initiating causes that do not necessarily have high correlation with actual initiating damage in extreme events. Furthermore, some explicit approaches rely on empirically based analysis approaches. In addition, the engineering profession has relatively few data on the actual performance of structural systems and components under the extreme demands often associated with the dynamics of the resistance to progressive collapse. While we know that all available design techniques add robustness that can reasonably be judged to improve the survivability of remediated buildings, in most circumstances owners and engineers do not gain high confidence in their understanding of the actual performance of upgraded buildings, should there be an initiating event.

To improve confidence about actual performance, engineers might need to conduct sophisticated analyses that include realistic representations of initiating damage, consider building features that might normally be discounted in practical design, and have high fidelity in the modeling of the theoretical performance of structural elements and systems.

To develop realistic representations of initiating damage, engineers will need to extend the explicit design approaches beyond the notional removal of individual isolated structural elements. While the basic assumption that a single structural element will be seriously damaged for some threats (e.g., damage to a single column is the probable initiating event when a vehicle strikes a building), it might not be representative of damage from other threats. Hence, even for explicit designs, it could be appropriate to consider a spectrum of combined initiating damages that are derived from the pursuit of theoretical element performance for specific threats, and create a statistical base for opinions about collapse resistance.

Engineers normally do not consider so-called nonstructural components when evaluating structural systems. However, features such as infill walls in frames can add significantly to the robustness of buildings. For existing buildings, where these features are part of the base system, improved assessment of collapse potential can follow from considered evaluation of the benefits provided by the associated resistance. Therefore, although engineers normally would neglect the benefit provided by nonstructural elements for conventional design, in assessments of collapse potential it sometimes is appropriate to include the secondary benefits of certain nonstructural components.

High fidelity in the analyses should come from reference to the most relevant research on the performance of structural elements and systems under extreme conditions and on detailed nonlinear modeling techniques. Simplified approaches often used for explicit designs usually will not suffice for accurate predictions of performance. The level of sophistication and the tools presently available make such analyses beyond the scope of effort normally committed for the design of most upgrades. However, as data improve and appropriate analyses tools are more broadly distributed in the profession, the opportunities to perform the required analyses will increase.

Hence, for most remediation programs benefit will be measured through rational consideration of the imperfect available data. Engineers are charged with the responsibility to apply the available information in a prudent manner, and to use appropriate judgment in the development of performance expectations. In so doing, the engineer also should remember that most owners do not have the sophistication concerning structural behavior to independently judge performance expectations. The engineer should alert the owner 
to the limitations in the state of the practice, the empirical nature of the approach used commonly in the design for progressive collapse resistance, and the uncertainty about being able to achieve the performance objectives.

\subsubsection{Programming the Upgrade Effort}

The design team should coordinate carefully with the owner. Many of the responsibilities for the collaborative success of an upgrade project fall with the owner. Therefore, the owner should be intimately involved in the design development.

Construction to upgrade an existing building most probably will be disruptive to any occupancy that might remain in the building during the work. The types of structural modifications that are necessary often require noisy and dirty work in relatively large work zones. Interior finishes and exterior cladding often must be demolished or substantially removed over large areas. Successful remediation projects include consideration to the process of construction and the impact on occupants of and neighbors to remediated buildings.

The types of upgrades likely for existing buildings sometimes involve detailing that requires contractors to install temporary shoring during installation. This also disrupts occupants during construction.

Facilities with existing buildings also often have limitations on where and how contractors can occupy the site during construction.

For these reasons, it is important to consider the complete construction process in the development of the design. At the beginning of the project, the owner and design team should evaluate the restrictions that will exist during construction. These restrictions will lead to a set of guidelines that will direct the team toward a viable design concept. The guidelines can address issues such as the fraction of the building that can be vacated at a time, the proximity relationships among vacated areas, locations for contractor storage areas, need to coordinate with neighbors to the site, and need for weather protection, to name a few.

Construction, facility use, and personnel and function relocation plans should be considered during development of the design. For some facilities with especially challenging restrictions, early in the process the owner and design team should develop specific plans that can be tested for viability during the design effort.

\subsubsection{Developing Costs}

Costs to upgrade existing buildings will include the costs for structural modifications, the demolition and restoration of architectural and mechanical systems, the logistics necessary to work in an existing building, and any business-related expenses associated with renovation of an existing, and perhaps occupied, building. Ultimately, the owner will need to make decisions based on costs, performance expectations, and other factors (e.g., incidental value associated with a general upgrade and modernization of an existing facility). Therefore, the design team should be cognizant, throughout the design process, of all costs associated with remediation and, together with the owner, maintain an appropriate estimate of the anticipated costs of each type.

While the best estimates of such costs are binding bids from qualified contractors, it clearly is impossible to have such estimates until the construction documents and project plans are complete. Therefore, one 
approach for maintaining estimates for construction costs is to have a qualified cost consultant or a contractor on the design team at the beginning of the project. These experts can provide valid cost information on which owners can rely. Additionally, contractors as design team members can play key roles in the determination of the design, especially for remediations for existing buildings. When contractors are consulted throughout the process, they can contribute to the determination of the most cost-efficient solution by offering opinions on constructability of various upgrade options as they are developed.

\subsubsection{Final Design}

The final design can be developed once the owner and the design team achieve an understanding about the performance expectations, level of performance verification that will be achieved, project logistics, and anticipated costs. It is a complicated process that necessarily involves managing and understanding uncertainties and competing demands for funds and functional characteristics.

Ultimately, the design pursued by the owner and the project consultants should have documented reliability while providing the best balance between cost and improvement in function. 
This page intentionally left blank. 


\section{Chapter 6 \\ SUMMARY}

\subsection{INTRODUCTION}

Although the risk of progressive collapse in most buildings is low, recent terrorist attacks on buildings throughout the world have heightened an awareness of the need to limit the spread of damage in structures subjected to abnormal events, such as explosions and vehicular impacts, so as to avoid progressive collapse. In the U.S., model codes and national design standards do not provide explicit provisions for designing to resist progressive collapse. There are, however, general provisions for "structural integrity" to provide a minimum level of structural continuity and load redistribution capability. Thus an owner's decision to proceed with explicit consideration of progressive collapse for a particular structure has to be made on a case-by-case basis after a rational analysis of risk, as discussed in Chapter 2.

Designing for reducing the risk of progressive collapse requires a different way of thinking compared with traditional design to resist prescribed vertical and lateral loads. The design process must focus on what may go wrong and must identify the performance requirements to be met. The design scenario may be threat-specific or non threat-specific. The design team must determine which abnormal load events and damage scenarios should be considered and what are the acceptable levels of risk.

The purpose of this report is to acquaint owners, engineers, and building officials with best practices for designing buildings to reduce the likelihood of progressive collapse in the event of local damage from an abnormal load. Guidance is provided on the basis of existing knowledge. This chapter summarizes the main points associated with design to prevent progressive collapse that are covered in the report.

\subsection{DEFINITION}

The professional community needs to adopt a common definition of the term "progressive collapse" in order to reduce misunderstandings among design professionals and with the public. The following definition is recommended:

progressive collapse - the spread of local damage, from an initiating event, from element to element resulting, eventually, in the collapse of an entire structure or a disproportionately large part of it; also known as disproportionate collapse.

\subsection{REDUCING RISK}

Chapter 2 provides a comprehensive discussion of a risk basis approach to progressive collapse. The probability of structural collapse, $\mathrm{P}(\mathrm{C})$, as a result of potentially damaging abnormal load, $\mathrm{H}$, was presented as Eq. 2.6, and is reproduced here: 


$$
\mathrm{P}(\mathrm{C})=\mathrm{P}(\mathrm{C} \mid \mathrm{LD}) \mathrm{P}(\mathrm{LD} \mid \mathrm{H}) \lambda_{\mathrm{H}}
$$

where

$\lambda_{\mathrm{H}}=$ rate of occurrence of the abnormal load or hazard,

$\mathrm{P}(\mathrm{LD} \mid \mathrm{H})=$ probability of local damage given that the abnormal load occurs, and

$\mathrm{P}(\mathrm{C} \mid \mathrm{LD})=$ probability of collapse given that local damage occurs.

This equation provides a convenient means of understanding the basic strategies for reducing the likelihood of progressive collapse. These strategies are:

- Event control;

- $\quad$ Specific local resistance; and

- Alternate load path.

Event control - This involves taking actions to minimize the effects of (or reduce the likelihood of) the hazards. This approach requires that the hazard or spectrum of hazards be identified. Such actions might include changes in the building site or access to it, use of perimeter barriers, or controlling hazardous materials. Event control is often the most cost-effective means of risk reduction, and Chapter 3 provides a comprehensive discussion of this topic.

Specific local resistance-This involves designing key structural elements to reduce the likelihood of local damage during an abnormal load event. This is a threat-specific approach and is often the most rational approach for retrofitting existing buildings. Chapter 4 discusses this approach.

Alternate load path-This involves designing the structure so that it can "bridge over" the local damage caused by an abnormal load event and thereby reduce the likelihood of progressive collapse. The design might be for a specific threat or it might be threat independent. This approach is discussed in Chapter 4 .

\subsection{DESIGN METHODS}

As discussed in Chapters 2, 3, and 4, the design team can use an indirect method or one of two direct methods to provide resistance to progressive collapse. The indirect method is a prescriptive approach of providing a minimum level of connectivity between the various structural components. The designer is not required to analyze the structure for the effects of abnormal loads. The indirect method was used first in the U.K., and been adopted by the DOD in UFC 4-023 for use in buildings characterized as requiring a very low level of protection. Chapter 4 gives general guidance on the indirect method and Appendix A gives specific tie strength requirements from various design standards.

The direct methods include the method of specific load resistance and the alternate load path method. These methods require the designer to perform an explicit analysis of the effects of abnormal load events on the structure. The analyses may be threat specific or threat independent as discussed in Chapter 4. Various analysis techniques may be used ranging from a linear elastic, static load method to an inelastic dynamic load method. Required computational resources, fidelity of structural modeling, and experience 
of the analysis are factors to be considered in selecting the appropriate analytical method for a specific project.

Accompanying any analytical method is the criteria for acceptable performance under the abnormal load event. Appendix A provides examples of acceptable performance criteria stipulated in different design guidelines.

\subsection{GENERAL GUIDELINES}

Good structural design integrates the gravity-load resisting system, including the system for resisting progressive collapse, with the lateral-force resisting system. Chapter 5 provides cost-effective guidelines for improving the progressive collapse resistance of buildings incorporating different construction materials or construction methods. In general, the design should provide a combination of strength, ductility, and continuity to permit the structure to absorb the effects of local damage. The design should avoid those features that will make it more difficult to provide progressive collapse resistance, such as large transfer structures and discontinuities in the structural system.

\subsection{EXISTING BUILDINGS}

Existing buildings pose challenges in developing cost-effective solutions for upgrading the resistance to progressive collapse. As discussed in Chapter 5, potential engineering solutions might include local strengthening to prevent initial failure or enhancing the redundancy of the existing structural system to limit the spread of a local failure. Any upgrade program begins with an evaluation of potential threats and an evaluation of the existing structural system. Early in the process, however, the engineer needs to establish whether the constraints established by the existing conditions pose technical of economic obstacles to viable upgrade options.

\subsection{DESIGN GUIDES}

The document is not intended to provide step-by-step guidance on designing buildings for resistance to progressive collapse. Such guidance is available in national standards and design guidelines developed worldwide. In the U.S., the prominent documents are: Progressive Collapse Analysis and Design Guidelines developed by the General Services Administration (GSA 2003) and Design of Buildings to Resist Progressive Collapse developed by the Department of Defense (DOD 2005). Appendix A provides excerpts from these design documents as well as other design standards. 
This page intentionally left blank 


\section{Chapter 7 \\ REFERENCES}

ACI Standard ACI 318-05, (2005), Building Code Requirements for Structural Concrete, American Concrete Institute, Farmington Hills, Michigan.

AISC Standard ANSI/AISC 360-05, (2005a), Specification for Structural Steel Buildings, American Institute of Steel Construction, Chicago, Il., 198 p.

AISC Standard ANSI/AISC 341-05 (341s1-05), (2005b), Seismic Provisions for Structural Steel Buildings Including Supplement No. 1, American Institute of Steel Construction, Chicago, Il., $333 \mathrm{p}$

AISC Standard ANSI/AISC 358-05, (2005c), Prequalified Connections for Special and Intermediate Steel Moment Frames for Seismic Applications, American Institute of Steel Construction, Chicago, Il., $91 \mathrm{p}$.

Allen, D. and W.R. Schriever, (1973), "Progressive Collapse, Abnormal Loads and Building Codes," in Structural Failures: Modes, Causes, Responsibilities, American Society of Civil Engineers, New York, NY, pp. 21-48.

ASCE/SEI/SFPE Standard 29-05, (2007), Standard Calculation Methods for Structural Fire Protection, American Society of Civil Engineers, Reston, Virginia, 80p.

ASCE Standard ASCE/SEI 7-05, (2005), Minimum Design Loads for Buildings and Other Structures, American Society of Civil Engineers, Reston, Virginia.

ASTM Test Method E119-02, (2002), "Standard Methods of Fire Tests of Building Construction and Materials," ASTM International, West Conshohocken, PA

Bailey C.G. and Moore D.B., (2000a), "The Structural Behaviour of Steel Frames with Composite Floor Slabs Subject to Fire-Part 1 Theory,” The Structural Engineer Vol. 78, No.11; June 2000.

Bailey C.G. and Moore D.B., (2000b); "The Structural Behaviour of Steel Frames with Composite Floor Slabs Subject to Fire-Part 2 Design,” The Structural Engineer Vol. 78, No.11; June 2000.

Bennetts, I.D. and I.R. Thomas, (2002), "Design of Steel Structures Under Fire Conditions," Progress in Structural Engineering and Materials, 4(1), pp. 6-17.

Breen, J.E. and C.P. Siess, (1979), "Progressive Collapse-Symposium Summary," ACI Journal 76(9), pp. 997-1004.

Breen, J.E., Editor, (1975), "Summary Report, Research Workshop on Progressive Collapse of Building Structures," The University of Texas at Austin, November. 
Burnett, E.F.P., (1975a), “Abnormal Loading and Building Safety,” SP-48, American Concrete Institute, Farmington Hills, MI, 1975.

Burnett, E.F.P., (1975b), "The Avoidance of Progressive Collapse: Regulatory Approaches to the Problem," Report No. NBS-GCR-75-48, National Bureau of Standards, Washington, DC.

Canadian Standards Association (CSA), (2000), Limit States Design of Steel Structures, CSA S16.1, Rexdale, Ontario, Canada.

CEN, (1994), "Eurocode 1-Actions on Structures, Part 1 - Basis of Design," European Pre-standard ENV 1991-1," Comité Européen de Normalization 250, Brussels, Belgium.

Chalk, P. and Corotis, R.B., (1980), "Probability Model for Design Live Loads," J. Struct. Div. ASCE 106(10), pp. 2017-2033.

CIB W14, (1983), “A Conceptual Approach Towards a Probability-Based Design Guide on Structural Fire Safety,” Fire Safety Journal 6(1), pp. 1-79.

Citipitioglu, A.M., Haj-Ali, R.M., White, D.W., (2002), "Refined 3D Finite Element Modeling of Partially-Restrained Connections Including Slip," Journal of Constructional Steel Research, Vol. 58, No. 5-8, pp. 995-1013.

Conrath, E.J., et al., (1999), "Structural Design for Physical Security-State of the Practice,” Task Committee Report, American Society of Civil Engineers/SEI, Reston, VA.

Corley, W. Gene; Sozen, Mete A.; Thornton, Charles H.; and Mlakar, Paul F., "The Oklahoma City Bombing: Improving Building Performance Through Multi-Hazard Mitigation,” FEMA-277, Mitigation Directorate, August 1996, U.S. Government Printing Office, Washington, DC, 90 pp.

Corley, W.G., P.F. Mlakar, M.A. Sozen and C.H. Thornton, (1998), "The Oklahoma City Bombing: Summary and Recommendations for Multihazard Mitigation," J. Perform. Constr. Fac. ASCE 12(3), pp. 100-112.

Crawford, J. E., (2002), "Retrofit Measures to Mitigate Progressive Collapse," NIST/NIBS Multihazard Mitigation Council National Workshop on Prevention of Progressive Collapse, Chicago, Ill. July. http://www.nibs.org/MMC/ProgCollapse presentations/Crawfords_paper.pdf.

Department of Defense (DOD), (2001), "Interim Antiterrorism/Force Protection Construction Standards, Guidance on Structural Requirements," Draft, March.

Department of Defense (DOD), (2003), "Minimum Antiterrorism Standards for Buildings," Unified Facilities Criteria (UFC) 4-010-01, 8 October, 2003.

Department of Defense, (DOD), (2005), "Design of Buildings to Resist Progressive Collapse," Unified Facilities Criteria (UFC) 4-023-03, 25 January, 2005.

Ellingwood, B. and E.V. Leyendecker, (1978), "Approaches for Design Against Progressive Collapse.” $J$. Struct. Div. ASCE, 104(3), pp. 413-423. 
Ellingwood, B., et al., (1982), "Probability-Based Load Criteria: Load Factors and Load Combinations." J. Struct. Div. ASCE, 108(5), pp. 978-997.

Ellingwood, B., (1987), "Design and Construction Error Effects on Structural Reliability," J. Struct. Div. ASCE, 113(2), pp. 409-422.

Ellingwood, B. and Corotis, R. B., (1991), "Load Combinations for Buildings Exposed to Fires," Engineering Journal, AISC 28(1), pp. 37-44.

Ellingwood, B., (1994), "Probability-Based Codified Design: Past Accomplishments and Future Challenges," Structural Safety 13(3), pp. 159-176.

Ellingwood, B., (2001), “Acceptable Risk Bases for Design of Structures,” Progress in Struct. Engrg. and Mat. 3(2), pp. 170-179.

Elms, D. G. (1992), “Risk Assessment,” in Engineering Safety, D. Blockley, Ed., McGraw-Hill International, Berkshire, UK, pp. 28-46.

Engelhardt, M. D. and Sabol, T. A., (1998), "Reinforcing of Steel Moment Connections with Cover Plates: Benefits and Limitations," Engineering Structures, Vol. 20, Nos. 4-6, pp. 510-520.

Ettouney, M., (2004), "Development of a Progressive Collapse Analysis Method and the PROCAT Computer Program," Counter Terrorism Technology Support Office Technical Support Working Group (CTTSO/TSWG).

Ettouney, M., Hansen, E., Hapij, A., Lawver, D., Tang, M., Tennant, D., Vaughan, D., and Xie, M., (2004), "Development of a Progressive Collapse Tool," Prepared for Combating Terrorism Technology Support Office/Technical Support Working Group (CTTSO/TSWG), Arlington, VA. Report WA-0403.

Federal Bureau of Investigation, (1998), 1997 Bomb Summary, FBI Bomb Data Center General Information Bulletin 97-1, Washington, DC.

Federal Emergency Management Agency (FEMA), (2003), "Primer for Design of Commercial Buildings to Mitigate Terrorist Attacks," FEMA 427, Dec.

Federal Emergency Management Agency (FEMA), (2000a), "Prestandard and Commentary for the Seismic Rehabilitation of Buildings," FEMA 356, Nov.

Federal Emergency Management Agency (FEMA), (2000b), "Recommended Seismic Evaluation and Upgrade Criteria for Existing Welded Steel Moment-Frame Buildings," FEMA 351, June.

Federal Emergency Management Agency (FEMA), (1997), "NEHRP Guidelines for the Seismic Rehabilitation of Buildings," FEMA 273, Oct.

Galambos, T.V., et al., (1982), "Probability-Based Load Criteria: Assessment of Current Design Practice.” J. Struct. Div. ASCE, 108(5), pp. 959-977. 
General Services Administration (GSA), (2003), "Progressive Collapse Analysis and Design Guidelines for New Federal Office Buildings and Major Modernization Projects," June.

Geng, Z.-J., Chajes, M.J., Chou, T.-W., and Pan D. Y.-C., (1998), “The Retrofitting of Reinforced Column-to-Beam Connections, "Composites Science and Technology, Vol. 58, No. 8, pp. 1297-1305.

Green, M. and Wong, Y., (2001), "Value of the Full Scale Cardington Fires Tests to the Structural Engineer," Proceedings of the 2001 Structures Congress \& Exposition, P. C. Chang, Ed., ASCE Reston, VA.

Karter, M. J., (2002), "Fire Loss in the United States During 2001,” NFPA, Quincy, MA, 21 p. www.nfpa.org/assets/files/pdf/2001FireLoss.PDF

Kasai, K., Hodgon, I., and Bleiman, D., (1998), "Rigid-Bolted Repair Methods for Damaged Moment Connections," Engineering Structures, Vol. 20, No. 4-6, pp. 521-532.

Kruppa, J., (2000), "Recent Developments in Fire Design," Progress in Struct. Engrg. and Mat. 2(1), pp. 6-15.

Lawver, D., Daddazio, R., Vaughan, D., Stanley, M. and Levine, H., (2003), "Response of AISC Steel Column Sections to Blast Loading," ASME PVP Conference on Problems Involving ThermalHydraulics, Liquid Sloshing, and Extreme Loads on Structures, PVP, Vol. 454, ASME, New York, July 2003.

Leyendecker, E.V. and Burnett, E., (1976), "The Incidence of Abnormal Loading in Residential Buildings," Building Science Series No. 89, National Bureau of Standards, Washington, DC.

Leyendecker, E.V. and Ellingwood, B.R., (1976), "Design Methods for Reducing the Risk of Progressive Collapse in Buildings," Building Science Series No.98, National Bureau of Standards, Washington, DC.

Li, J., Bakoss, S.L., Samali, B., and Ye, L. (1999), "Reinforcement of Concrete Beam-Column C0nnections with Hybrid FRP Sheet," Composite Structures, Vol. 47, No. 1, December, pp. 805-812.

Mainstone, R.J., (1974), “The hazards of Explosion, Impact and Other Random Loadings on Tall Buildings,” Current Paper 64/74, Building Research Establishment, Garston, United Kingdom.

Marchand, K.A. and Alfawakhiri, F., (2004), Blast and Progressive Collapse, Facts for Steel Buildings Number 2, American Institute of Steel Construction, Chicago, Il., 67 p.

Marjanishvili, S.M., (2004), "Progressive Analysis Procedure for Progressive Collapse," J. of Performance of Constructed Facilities, Vol. 18, No. 2, May.

Matousek, M., (1981), “A System for a Detailed Analysis of Structural Failures,” Structural Safety and Reliability, Elsevier, Amsterdam, pp. 535-544.

McGuire, W., 1974, "Prevention of Progressive Collapse," Proceedings of the Regional Conference on Tall Buildings, Bangkok, Asian Institute of Technology, Bangkok, Thailand. 
Melchers, R.E., (1999), Structural Reliability - Analysis and Prediction, John Wiley.

Moore, D. B., (2002), “The U.K. and European Regulations for Accidental Actions,” NIST/NIBS Multihazard Mitigation Council National Workshop on Prevention of Progressive Collapse, Chicago, Ill. July. http://www.nibs.org/MMC/ProgCollapse presentations/Moore paper.pdf

Mosallam, A.S., (2000), "Strength and Ductility of Reinforced Concrete Moment Frame Connections Strengthened with Quasi-Isotropic Laminates," Composites Part B: Engineering, Vol. 31, No. 6-7. October, pp. 481-497.

National Building Code of Canada (NBCC), (1985), Part 4 and Commentary C, National Research Council of Canada, Ottawa, Ontario.

National Research Council (NRC), (2001), Protecting People and Buildings from Terrorism: Technology Transfer for Blast-effects Mitigation, Committee for Oversight and Assessment of Blast-effects and Related Research, National Research Council, National Academy Press, Washington, DC.

National Research Council (NRC), (2000), Blast Mitigation for Structures: 1999 Status Report on the DTRA/TSWG Program, Committee for Oversight and Assessment of Blast Effects and Related Research, BICE, National Academy Press, Washington, DC.

Pate-Cornell, E., (1994), “Quantitative Safety Goals for Risk Management of Industrial Facilities,” Structural Safety 13(3), pp. 145-157.

PCI Committee on Precast Concrete Bearing Wall Buildings, (1976), "Considerations for the Design of Precast Concrete Bearing Wall Buildings to Withstand Abnormal Loads," PCI Journal, Vol. 21, No. 2, March-April, pp. 18-51.

Priestley, M. J. N. and Seible, F., (1995), "Design of Seismic Retrofit Measures for Concrete and Masonry Structures," Construction and Building Materials, Vol. 9, No. 6, pp. 365-377.

SFPE, (2002), Guide to Performance-Based Fire Protection Analysis and Design of Buildings, Society of Fire Protection Engineers, Washington, DC.

Somes, N. F., (1973), “Abnormal Loading on Buildings and Progressive Collapse,” in Building Practices for Disaster Mitigation (Wright, Kramer and Culver, eds.), Building Science Series No. 46, National Bureau of Standards, Washington, DC.

Starr, C., (1969), “Social Benefits Versus Technological Risk,” Science, Vol. 168, pp. 1232-1238.

Statistical Abstract of the United States, (2001), Department of Commerce, Washington, DC.

Stewart, M.G. and Melchers, R.E., (1997), Probabilistic Risk Assessment of Engineering Systems, Chapman \& Hall, London.

Structural Stability Research Council (SSRC), (1998), Guide to Stability Design Criteria for Metal Structures, $5^{\text {th }}$ Edition, T.V. Galambos, ed., John Wiley, New York. 
Taghdi, M, Bruneau, M., and Saatcioglu, (2000), "Seismic Retrofitting of Low-Rise Masonry and Concrete Walls Using Steel Strips, J. of Structural Engineering (ASCE), Vol. 126, No. 9, Septemebre, pp. 1017-1025.

U.S. Army, (1990), Structures to Resist the Effects of Accidental Explosions," Technical Manual 5-1300, Department of the Army, Washington, DC

van Mier, J. G. M., (1997), Fracture Processes of Concrete, CRC Press, Boca Raton, Fla., pp. 114-131. 


\section{Appendix A \\ COMPARISON OF DESIGN STANDARDS}

\section{A.1 GENESIS OF PROGRESSIVE COLLAPSE PROVISIONS}

\section{A.1.1 Ronan Point}

The failure of an apartment building at Ronan Point, London, U.K., on May 16, 1968, brought the phenomenon of progressive collapse to the attention of the structural engineering community. A domestic gas explosion - estimated later to be between $14 \mathrm{kPa}(2 \mathrm{psi})$ and $83 \mathrm{kPa}(12 \mathrm{psi})$ - blew out a load-bearing flank wall (as well as a non-load bearing front wall) at a corner of an 18th floor apartment of this 24-story precast concrete building. The loss of support caused the floors above to collapse, and the impact and weight of the falling debris caused the floors below to collapse as well.

An inquiry found that there was no violation of any applicable building standards, nor any defect in workmanship in the design and construction of Ronan Point. It was revealed that the building standards, typically, gave detailed requirements for the design of individual members but provided little guidance for the stability design of the entire structural system. The walls in the Ronan Point building were unreinforced, and joint forces were resisted solely by bond, friction and gravity. The explosion reduced considerably, or reversed the gravity load, thus eliminating the friction force and bond between panels. Under these conditions, an estimated pressure of $21 \mathrm{kPa}$ ( $3 \mathrm{psi}$ ) would have sufficed to blow out the panels clear of the building, which was designed for a wind pressure of $570 \mathrm{~Pa}$ or $12 \mathrm{psf}$ (Firnkas, 1969). Upon removal of the walls, the connections above, which were designed for compression only, could not redistribute the loads nor provide alternate load paths, thus causing a chain reaction.

\section{A.1.2 1968 U.K. Standards}

On November 15, 1968, as a direct result of the inquiry of the disaster, the U.K. Ministry of Housing and Local Government issued "Standards To Avoid Progressive Collapse - Large Panel Construction", which listed two methods: "A) Provide alternate paths of support to carry the load, assuming the removal of a critical section of the loadbearing walls; and B) provide a form of construction of such stiffness and continuity as to ensure the stability of the building against forces liable to damage the load supporting members." The standards also specified an accidental static pressure of $34 \mathrm{kPa}$ (or $5 \mathrm{psi}$, a town-gas explosion of "average intensity"), and derived minimum tie forces. These standards became part of the Fifth Amendment that the British Parliament approved in April 1970 as part of mandatory Building Regulations that required consideration of progressive collapse for buildings taller than five stories. Provisions for structural ties entered the British Standards in 1974.

These provisions, with certain modifications that put less emphasis on explosions and more on ductile performance, are still in force today in the U.K., namely, the notional removal of an essential structural element should cause only local collapse $\left(70 \mathrm{~m}^{2}\right.$ or $750 \mathrm{ft}^{2}$ or $15 \%$ of the plan area of the story), and buildings should be designed for an accidental pressure of $34 \mathrm{kPa}$ or 5 psi acting simultaneously with dead and imposed loads. 
Similar provisions have been adopted in the Eurocode. The 2002 revision would allow more flexibility in the definition of the explosive pressure to be designed for, and the class of buildings where such considerations are required, based on the gravity of the consequences of failure. The City of New York has similar provisions on progressive collapse in its building standards since 1973, and is considering the adoption of provisions on ties similar to the British Standards (NYC-WTC 2003).

\section{A.1.3 Initial Approach for Design Criteria:}

Design provisions against progressive collapse are, by no means, universal. Structural engineers on the European mainland have pointed out that the collapse at Ronan Point might have been avoided, had the building been designed to the CEB 1967 Standards for the Design and Construction of Large Panel Structures, which warn of the "necessity of effectively joining the various components together to avoid the tendency for it to behave like a house of cards". In particular, Section R14 states:

"Horizontal joints and ties: Within the thickness of each floor, or close to it, continuous steel ties shall be provided in two directions; these ties shall interconnect the walls or façades on opposite sides of the building, shall include all the vertical panels, and shall be connected to all panels.

Peripheral ties: The total cross sectional area of the longitudinal reinforcement provided over a story height in a peripheral wall shall not be less than $2 \mathrm{~cm}^{2}\left(0.3 \mathrm{in.}^{2}\right)$ irrespective of the grade (strength or class) of steel employed.

Internal ties: The total cross sectional area of the tie reinforcement interconnecting two opposite external walls shall be able to carry a tensile force equal to $1 \%$ of the direct force acting at the level considered on the external wall in question, but not less than $500 \mathrm{~kg} / \mathrm{m}$ $(4.9 \mathrm{kN} / \mathrm{m}$ or $340 \mathrm{lb} / \mathrm{ft})$ of external wall. This cross sectional area may be concentrated at the cross walls or distributed in the floors."

In defense, Short and Miles (1969) pointed out, however, that similar general warnings were contained in British Code of Practice CP 116:1965, and had been made by engineers in the U.K. and elsewhere.

Building standards in force in France before the Ronan Point disaster prohibited the use of cooking gas in buildings higher than $50 \mathrm{~m}$ (164 ft). If gas was used, ventilation requirements were more stringent than the British ones. Furthermore, structural continuity requirements were more demanding because design should be checked under normal and abnormal winds (Ferahian, 1972).

Good engineering judgment, design and construction practices should ensure redundancy, ductility and continuity, which are requisites for structural robustness and integrity. This view is adopted in a number of standards, for example, the ACI Code, which has recommendations for reinforcement continuity and connection details under the heading of "structural integrity," but makes no mention of progressive collapse. 


\section{A.1.4 Operation Breakthrough}

In the U.S., much thought and research went into mitigating the problem of progressive collapse in the 1970s. "Operation Breakthrough" was launched on May 8, 1969, by the Department of Housing and Urban Development (HUD) to encourage industrialized housing concepts in the U.S. Proposals were requested for A) design, testing and evaluation of complete housing systems ready for production, or B) research and development of advanced concepts, materials and components not yet ready for production. To evaluate these innovative concepts, HUD consulted with the National Academies of Science and Engineering and commissioned the National Bureau of Standards (NBS) to develop performance criteria. Progressive collapse was of the utmost concern for the evaluation of concrete panel systems, and the criteria adopted by HUD were similar to the British Fifth Amendment:

"Explosions or other catastrophic loads on any one story level should not cause progressive structural collapse at other levels. The criterion applies to buildings four stories or higher. At a load level of 1.0 dead +0.5 live, the accidental removal of any one of the following (load) supporting structural elements at one level should not cause collapse of the structure on another level:

a) two adjacent wall panels forming an exterior corner;

b) one wall panel in a location other than an exterior corner;

c) one column or other element of the primary structural support system.

This criterion is waived if the above-mentioned structural element or elements are capable of resisting a pressure of $5 \mathrm{psi}(34.5 \mathrm{kPa})$, applied in the most critical manner within one story level to one face of the element and of all space dividers supported by the element or attached to it." (Building Research, 1970).

Other "Breakthrough" criteria found in the 1971 HUD-FHA (Federal Housing Authority) "Provisions to Prevent Progressive Collapse" included:

"Joints between prefabricated structural elements used as columns, beams, bearing walls, or slabs should develop continuity similar to that provided by conventional cast-in-place concrete or structural steel framing systems. In regions not subject to severe seismic or wind action, connections should not be designed solely as gravity-type relying only on compression and friction. Where severe seismic forces are highly probable (Seismic Zones 2 and 1), connections, in particular should be examined. Their response to dynamic forces must be evaluated, e.g., vertical castellated and grouted joints may be completely satisfactory for quasi-static earthquake design loads, but could shake apart under actual dynamic, oscillatory earthquake forces.

Joints between floor elements should develop adequate diaphragm action in order that the entire floor system may transmit lateral forces to the vertical elements. Peripheral ties completely encircling the building are 
also considered necessary to develop this diaphragm action. Vertical and horizontal joints between vertical structural elements must develop necessary continuity and deformability to transmit the lateral forces to the foundations." (Fuller, 1975).

The 1971 HUD-FHA criteria further stated that, if abnormal loading occurred, damage must be limited to $93 \mathrm{~m}^{2}\left(1000 \mathrm{ft}^{2}\right)$ or $20 \%$ of horizontal floor area, whichever was less, and to three stories vertically. These criteria were similar to the British Standard Code of Practice 116, Addendum No. 1 for the Design of Large Concrete Panels (1970). Excerpts of the 1971 HUD-FHA "Provisions to Prevent Progressive Collapse" can be found in Popoff (1972), for example.

These criteria were much more detailed and helpful to designers than the only other reference to progressive collapse that could be found at the time in U.S. building standards, namely, the 1972 American National Standards Institute A58, Minimum Design Loads in Buildings and Other Structures, which contained the following general recommendation: "Progressive collapse: Buildings and structural systems shall provide such structural integrity that the hazards associated with progressive collapse such as that due to local failure caused by severe overloads or abnormal loads not specifically covered herein are reduced to a level consistent with good engineering practice." (Somes, 1973).

As part of "Operation Breakthrough", Yokel, Pielert and Schwab (1975) examined five housing systems and concluded:

1. "The systems with clear spans between transverse bearing walls greater than $5.8 \mathrm{~m}(19 \mathrm{ft})$ had to use "strong" transverse bearing walls at least for the end walls and the transverse walls next to the end walls. In all cases, special provisions had to be made to provide lateral support to the end walls.

2. The systems with clear spans of $3.7 \mathrm{~m}(12 \mathrm{ft})$ or less relied principally on alternate paths of load support.

3. In short-span systems using an alternate path of load support the following joint reinforcement ties were the most critical: horizontal ties in the vertical joints between adjacent or intersecting bearing walls; continuous vertical ties throughout the building in the same joints; transverse horizontal ties between corridor floor panels and adjoining floor panels; and ties between transverse walls and corridor walls and between transverse walls and corridor floor panels. The alternate mode of load support was also assisted by longitudinal horizontal ties between adjoining floor panels on either side of transverse bearing walls, ties between transverse walls and connecting floor panels, and vertical ties between successive transverse bearing wall panels.

Thus depending on the span length, the systems used either the alternate path approach or a combination of the alternate path with strong points provided by specific local resistance." 


\section{A.1.5 U.S. Approach}

Further U.S. efforts in the 1970s focused on quantifying the risk of various accidental loads, including a more rational determination of the pressures engendered by gas explosions, and the vulnerability of large panel, precast concrete structures. The results agreed in general with similar studies performed in Canada, the U.K., and the Netherlands. For buildings susceptible to progressive collapse in the U.S., the risk of fatality is comparable with that for fire (40 per million persons per year, Somes, 1973).

In the mid 1970s, HUD also commissioned the Portland Cement Association to develop standards for large panel structures. Particular attention was paid to internal floor and wall ties [Popoff (1975), PCI Committee on Precast Concrete Bearing Wall Buildings (1976)]. These studies indicated that U.S. building practices differed from European industrialized construction, for example joint details used in Ronan Point, which relied heavily on friction between elements, would be unacceptable in North America. U.S. large panel buildings are often connected by dry joints using bolting or welding, so construction can proceed more rapidly than if a masonry or concrete joint was used. Residential building layout is also different between European and American practices, as American buildings tend to have fewer intermediate walls and supports, and thus fewer alternate load paths. European walls are typically spaced at $4.6 \mathrm{~m}$ to $6.1 \mathrm{~m}$ ( $15 \mathrm{ft}$ to $20 \mathrm{ft}$ ), compared with typical American spans of $6.7 \mathrm{~m}$ to $12.2 \mathrm{~m} \mathrm{(22 \textrm {ft }}$ to $40 \mathrm{ft}$ ). Whereas European rooms tend to be surrounded by loadbearing walls, American living space tends to be defined by non-loadbearing partitions. The proportion of walls to slabs in U.S. construction is frequently as low as $1 / 3$ of that of European buildings. Furthermore, the use of long, precast hollow-core slabs cut to length at U.S. job sites precludes protruding reinforcement used to develop continuity (Breen, 1980, Fintel and Schultz, 1976).

Mitigation of progressive collapse in U.S. buildings should therefore consider these differences rather than adopt European recommendations wholesale. Fewer vertical loadbearing elements in U.S. construction probably make the problem of stability of damaged buildings more severe than in Europe. Some U.S. engineers argue for the adoption of design principles regarding joints and continuity similar to those used for earthquake design as an approach to mitigate progressive collapse. Building standards would recommend minimum detailing requirements to ensure general structural integrity, and engineers would not have to directly consider abnormal loads or progressive collapse.

It is worth noting that $85 \%$ of participants of the "Workshop on Progressive Collapse of Building Structures" held in Austin, Texas, in November of 1975, thought that "satisfactory control over progressive collapse can be provided by embodying in ACI 318 requirements for horizontal and vertical ties; and no reference need be made to "progressive collapse" either in the Code or Commentary." (Breen, 1980). Even though the workshop participants agreed that substantial effort still needed to be made to justify tie forces, interest on the subject has not been strong in the U.S.

\section{A.1.6 Other Early Studies}

As one might expect, considerable testing was performed in the U.K. in the 1970s by the Building Research Establishment and Imperial College on alternate load paths in concrete panel structures (Wilford and Yu, 1973, Regan, 1975). Elsewhere in Europe, Hanson and Olesen (1969) studied keyed shear joints of prefabricated concrete wall panels in Denmark. In Sweden, Granstrom (1970) performed model tests of precast concrete buildings that had sustained local damage. 
Progressive collapse has also been studied in Canada (Ferahian, 1972). Canadian researchers noted the rarity of progressive collapse. "As an analysis of newspaper articles shows, 75 incidents were reported in Canada in ten years from 1962 to 1972, of which almost 50 \% occurred during construction. A wellknown case occurred in February 1959 in Listowel, Ontario, where the local arena collapsed under high snow loads during a hockey game, and resulted in eight deaths and many injuries. Fracture of one of the laminated timber roof trusses led to a lateral progressive collapse of the whole roof and side walls." (The National Research Council of Canada, National Building Code of Canada, Commentary C4.1.1.8, 1975).

A review of research on progressive collapse over the last 25 years is beyond the scope of this document.

\section{A.1.7 Present Interest}

The risk of terrorist bombing has revived interest in the mitigation of progressive collapse. Studies of the Alfred Murrah building in Oklahoma and the Khobar Towers in Saudi Arabia (see Appendix C), both subjected to truck bombing, indicate that the kind of structural detailing recommended for seismic zones could be effective in reducing the risk of progressive collapse. Corley et al. (1998) recommended that compartmentalized construction, special moment frames, and dual systems be considered where a significant risk of seismic and/or blast damage exists. [A special moment frame is a frame in which members and joints are capable of resisting forces by flexure as well as along the axis of the members. A dual frame system is a structural system with an essentially complete space frame providing support for vertical loads. Seismic force resistance is provided by moment resisting frames and shear walls or braced frames (ASCE 7-05)].

Full scale tests of walls and columns subjected to explosions have been conducted by U.S. government civilian and military agencies and their contractors, to provide baseline behavior and measure the effectiveness of protective measures. Advanced computational methods have been applied to predict the behavior of individual structural members under blast, as well as that of entire buildings subjected to the sudden removal of a supporting column. Recent workshops have been held to map the direction of future research (July 10-12, 2002 [http://www.nibs.org/MMC/mmcactiv9.html] and September 10, 2001 (Carino and Lew, 2001)). This best practices report is one of the outgrowths of these workshops.

\section{A.1. 8 Scope}

This appendix provides a survey and comparison of existing building standards and standards for the mitigation of progressive collapse. Section A.2 is a general discussion of current approaches for new or existing buildings. Section A.3 compares provisions on progressive collapse from major international building standards. After a summary comparison, Section A.3.2.1 compares definitions of progressive collapse, also called disproportionate collapse, as opposed to local collapse. Section A.3.2.2 covers the threshold beyond which progressive collapse needs to be considered, usually having to do with the height of the building and the consequences of its failure. Section A.3.2.3 deals with various strategies against progressive collapse, namely mitigation of the hazard, direct design, and indirect design. Section A.3.2.4 presents load combinations recommended for consideration with accidental loads or local damage. Section A.3.2.5 covers the design of structural ties to ensure structural continuity and development of alternate load paths. Section A.3.2.6 covers the design of key elements, whose integrity is recognized to be crucial for the survival of the structure. Section A.3.2.7 deals with structural detailing to ensure continuity, ductility, and redundancy. Finally, Section A3.2.8 covers retrofitting of existing structures to 
improve their resistance to progressive collapse. In this document, standards provisions are sometimes summarized and sometimes they are quoted verbatim.

\section{A.2. APPROACHES TO MITIGATING PROGRESSIVE COLLAPSE}

\section{A.2.1 Requirements for New Buildings}

This survey shows that a number of building standards around the world contain specific provisions for design against progressive collapse, whereas other standards rely on more general provisions dealing with structural integrity and robustness. They all emphasize the need for good structural layout, redundancy, ductility, and continuity.

\section{A.2.1.1 Direct and indirect approaches}

General approaches for mitigation of progressive collapse include minimizing exposure to hazards by preventive measures largely outside the scope of structural engineering; direct design methods, which include the alternate path method (bridging over local damage zones) and the specific local resistance method (hardening structural elements against specific hazards); and the indirect design method (provide strength, redundancy, continuity and ductility). Standards that address progressive collapse, whether by a direct or an indirect approach, usually contain specific requirements for tying together various structural elements within a building, as well as checking building stability under load combinations that take into account structural damage or accidental loads.

\section{A.2.2 Requirements for Existing Buildings}

For existing buildings, recent reports contracted by the U.S. government recommend that retrofit to improve resistance to progressive collapse should wait for other major renovation (such as seismic upgrade); or the decision should be based on the risk of exposure and consequences of failure, and the structural analysis would be similar to that of new buildings.

\section{A.3 SUMMARY OF STANDARDS ON PROGRESSIVE COLLAPSE}

The design standards that were included in the review are listed below. A brief description of each standard is provided here. More details are given in the Section A.4.

\section{A.3.1 British Standards}

Since shortly after the Ronan Point collapse, British Standards have taken the lead in stating explicit design provisions against progressive collapse. British Standards emphasize general tying of various structural elements of a building together, to provide continuity and redundancy. Ties enhance the resistance of wall panels to being blown away in the event of an explosion, and also the ability of a structure to bridge over a lost support. In designing for this possibility, various structural elements are considered lost one at a time. In addition, structural elements deemed vital to a building stability should be designed as key elements, able to withstand accidental loads, e.g., a pressure of $34 \mathrm{kPa}$ (5 psi). 


\section{A.3.2 Eurocode}

Eurocode is a model code adopted by many European countries that may also supplement it with national standards (such as British Standards). In addition to providing general design guidelines to avoid progressive collapse, such as selection of a good structural layout, Eurocode also recommends tying the building together and defines values for tie forces. Buildings can be assigned to one of four safety classes, with only the two highest classes requiring consideration of progressive collapse.

\section{A.3.3 National Building Code of Canada}

The National Building Code of Canada contains a general statement about the need for structural integrity, but its Commentary provides an extensive discussion on means to achieve that goal. The extent of the discussion reflects the importance accorded to the topic at the time, e.g., the 1975 version is much longer than the 1995 version. The Commentary covers recommendation for good structural layout, continuity of reinforcement, and structural mechanisms that would mitigate progressive collapse after local loss of support. No specific values are given for tie forces or accidental loads for key structural elements.

\section{A.3.4 Swedish Design Regulations}

The Swedish Design Regulations BKR contains guidelines on the three safety classes of various buildings. Normally, requirements relating to accidental loads and progressive collapse only apply to Safety Class 3. These requirements are detailed in a separate handbook and consist of: a) checking the stability of a damaged building under dead and live loads, and b) checking that falling debris do not cause successive failure of floors by ensuring load transfer capability within floor structure and between floor and bearing walls (tension and shear forces of $20 \mathrm{kN} / \mathrm{m}$ or about $1400 \mathrm{lb} / \mathrm{ft}$ ).

\section{A.3.5 ASCE 7}

The commentary of ASCE 7-05 contains extensive discussion on general structural integrity. It lists the direct design approaches (alternate path method and specific load resistance method) and the indirect design approach. It provides design guidelines for general structural integrity, such as good plan layout and use of structural ties. As well, it recommends load combinations including extraordinary loads, and explains the underlying probabilities.

\section{A.3.6 $\quad \mathrm{ACl} 318$}

The ACI 31-05 standard is an example of indirect design. It defines requirements for structural integrity such as continuity of reinforcement and use or ties in precast concrete construction.

\section{A.3.7 New York City Building Code}

The 1998 New York City Building Code is an example of direct design. It only mentions the alternate load path and the specific local resistance ( $34 \mathrm{kPa}$ or $5 \mathrm{psi}$ ) methods. 


\section{A.3.8 Department of Defense Unified Facilities Criteria}

Design for resistance to progressive collapse depends on the "level of protection" assigned to the building. For lower levels of protection the indirect design method is used by providing minimum tie forces. For higher levels of protection, the alternate load path method is used if sufficient ties cannot be provided.

\section{A.3.9 Interagency Security Committee}

The Interagency Security Committee (ISC) emphasizes the direct design methods (alternate load paths and specific local resistance) and makes no mention of the indirect method or structural ties.

\section{A.3.10 General Services Administration}

The General Services Administration (GSA) guidelines are based on the alternate load path method and removal of vertical load carrying members.

\section{A.4 COMPARISON OF PROGRESSIVE COLLAPSE PROVISIONS}

\section{A.4.1 Provisions Compared}

Following is a detailed comparison of provisions regarding progressive collapse from major international building standards. The comparison is organized by the following topics:

- Definition of progressive collapse, local collapse, and structural integrity

- Threshold for consideration of progressive collapse

- General strategy

- Loads

- Ties

- Key elements

- Continuity, ductility, and details

- Existing structures

\section{A.4.2 Definition of Progressive Collapse, Local Collapse, and Structural Integrity}

Most definitions of progressive collapse encompass the "house of cards" effect, whereby damage spreads beyond a local region, to an extent disproportionate to the initial cause (some unanticipated load). Damage is assumed local if it is limited to $15 \%$ or $20 \%$ of floor or roof area, or $100 \mathrm{~m}^{2}$ (or about $1000 \mathrm{ft}^{2}$ ), depending on the standards; or to one structural bay or the floors immediately adjacent to the initial damage.

Breen (1980) defines progressive collapse as an incremental type of failure, where the total damage is out of proportion to the initial cause. The word incremental eliminates from consideration the total collapse of 
statically determinate structures upon loss of a single member. This wording has not caught on, probably because the word incremental requires an explanation, just as the word progressive does.

In classifying structural collapses as progressive or not, Allen and Schriever (1973) found it convenient to use the "rule of three": a collapse is progressive if it involves members that are three or more members away from the original failure or if three or more spans collapse. They concluded their survey by saying that, "only a few of the reported incidents should definitely be considered structurally from the point of view of progressive collapse."

Because what constitutes local collapse has consequences on the number of casualties and the load of debris that must be resisted by the damaged structure to stop the progress of collapse, social and technical justifications for such definitions need to be developed further. For example, Leyendecker and Ellingwood (1977) proposed limiting damage in any story to $70 \mathrm{~m}^{2}\left(750 \mathrm{ft}^{2}\right)$ or $15 \%$ of the floor area. This would limit the total average annual fatalities to less than the mortality associated with fires, and two orders of magnitude less than that associated with automobile accidents.

Following are the definitions of progressive collapse, local collapse, and structural integrity used in various building standards:

British Standards BS 5950-1:2000, Structural Use of Steelwork in Building, Section 2.4.5.3-The British Standards do not use the words progressive collapse but rather structural collapse disproportionate to the initial cause. This contrasts with local collapse, which is limited to $15 \%$ of floor or roof area or $100 \mathrm{~m}^{2}$ (about $1000 \mathrm{ft}^{2}$ ), whichever is less, at the relevant level and at one immediately adjacent level, either above or below it.

National Research Council of Canada, National Building Code of Canada (NBCC) - The level of detail about progressive collapse contained in the Commentary of the National Building Code of Canada has evolved over time. In 1975, Commentary C4.1.1.8 contained the following:

"Progressive collapse is the phenomenon in which the spread of an initial local failure from element to element eventually results in the collapse of a whole building or disproportionately large parts of it."

In the 1977 version of Commentary C4.1.1.8, there was the following discussion:

"Progressive collapse is the spread of an initial local failure from element to element eventually resulting in structural collapse disproportionate to the initial cause or to the initial local damage."

In an attempt to define "disproportionate," it was added that:

“collapse should probably be limited

a) where the progression might be vertical, to the story where the abnormal event occurred and the story immediately above and below, and

b) where the progression might be horizontal, 
- to the truss, beam or precast strip floor or roof panel initially damaged and perhaps to one on either side,

- to one bay of a full bay-sized floor or roof slab, except that where the principal support at one end of a slab is removed, two bay-sized slabs may hang together as a catenary."

In 1990, Commentary C4.1.1.3 introduced the term "structural integrity" with the following definition:

"Structural integrity is defined as the ability of the structure to absorb local failure without widespread collapse."

American Society of Civil Engineers (2005), ASCE 7-05-Section 1.4 on General Structural Integrity contains the following statement:

"Buildings and other structures shall be designed to sustain local damage with the structural system as a whole remaining stable and not being damaged to an extent disproportionate to the original local damage."

Commentary $\mathrm{C} 1.4$ provides the following definition:

"Progressive collapse is defined as the spread of an initial local failure from element to element resulting, eventually, in the collapse of an entire structure or a disproportionately large part of it."

New York City Building Code (1998) - Chapter 18 on Resistance to Progressive Collapse Under Extreme Local Loads contains the following description of what constitutes a disproportionate spread of the initial local failure:

“...progressive collapse is interpreted as structural failure extending vertically over more than three stories, and horizontally over an area more than $1000 \mathrm{ft}^{2}\left[100 \mathrm{~m}^{2}\right]$ or 20 percent of the horizontal area of the building, whichever is less."

New York City Department of Buildings, World Trade Center Building Code Task Force - The February 2003 report on the findings and recommendations of the task force contained the following definition:

"Progressive collapse is the propagation of collapse to an extent disproportionate to the initiating zone of damage and is interpreted as structural failure beyond the point of initial damage extending vertically over more than three stories, and horizontally over an area more than one structural bay or 20 percent of the horizontal area of the building, whichever is less."

\section{Department of Defense (2005) Unified Facilities Criteria (UFC) 4-023-03, Design of Buildings to} Resist Progressive Collapse-The definition of progressive collapse given in ASCE 7 is adopted. The following describe the permitted "damage limits" for the spread of damage, as determined by structural analysis, resulting from the notional removal of a vertical load-bearing element (DOD 2005): 


\section{“3-2.6.1 Damage Limits for Removal of External Column or Load- Bearing Wall}

For the removal of a wall or column on the external envelope of a building, the Damage Limits require that the collapsed area of the floor directly above the removed element must be less than the smaller of $70 \mathrm{~m}^{2}\left(750 \mathrm{ft}^{2}\right)$ or $15 \%$ of the total area of that floor and the floor directly beneath the removed element should not fail. In addition, any collapse must not extend beyond the structure tributary to the removed element."

\section{“3-2.6.2 Damage Limits for Removal of Internal Column or Load- Bearing Wall}

For the removal of an internal wall or column of a building, the Damage Limits require that the collapsed area of the floor directly above the removed element must be less than the smaller of $140 \mathrm{~m}^{2}\left(1500 \mathrm{ft}^{2}\right)$ or $30 \%$ of the total area of that floor, and the floor directly beneath the removed element should not fail. In addition, any collapse must not extend beyond the bays immediately adjacent to the removed element."

GSA Progressive Collapse Analysis and Design Guidelines for New Federal Office Buildings and Major Modernization Projects (June 2003) - Section 2 on Definitions provides the following:

"Progressive collapse is a situation where local failure of a primary structural component leads to the collapse of adjoining members which, in turn, leads to additional collapse. Hence, the total damage is disproportionate to the original cause."

Table A1 compares the above information related to extent of permitted spread of initial local damage. 
Table A1: Definition of local collapse

\begin{tabular}{|c|c|c|c|c|}
\hline $\begin{array}{l}\text { BS 5950-1: } \\
2000\end{array}$ & Canada -NBCC 1977 & $\begin{array}{c}\text { NYC 1998, } \\
2003\end{array}$ & $\begin{array}{c}\text { DOD UFC 4-023-03 } \\
2005\end{array}$ & GSA 2003 \\
\hline \multicolumn{5}{|c|}{ Horizontal Spread } \\
\hline $\begin{array}{l}\text { Lesser of } 15 \% \\
\text { of floor or roof } \\
\text { area or } 100 \mathrm{~m}^{2} \\
\left(1000 \mathrm{ft}^{2}\right) .\end{array}$ & $\begin{array}{l}\text { Truss, beam, floor strip } \\
\text { or floor panel of initial } \\
\text { damage plus one same } \\
\text { on either side; one bay; } \\
\text { two bay-sized slabs } \\
\text { may hang together as a } \\
\text { catenary if support at } \\
\text { one end of slab is } \\
\text { removed. }\end{array}$ & $\begin{array}{l}\text { Lesser of } 20 \% \\
\text { of floor or roof } \\
\text { area or } \\
1000 \mathrm{ft}^{2} \\
\left(100 \mathrm{~m}^{2}\right) .\end{array}$ & $\begin{array}{l}\text { Exterior: Damage to } \\
\text { floor above lost } \\
\text { member shall be lesser } \\
\text { of } 70 \mathrm{~m}^{2}\left(750 \mathrm{ft}^{2}\right) \text { or } 15 \\
\% \text { of total floor area; } \\
\text { Interior: Lesser of } \\
140 \mathrm{~m}^{2}\left(1500 \mathrm{ft}^{2}\right) \text { or } 30 \\
\% \text { of total floor area. } \\
\text { Damage must not } \\
\text { spread beyond structure } \\
\text { tributary to failed } \\
\text { element (exterior) or } \\
\text { beyond the bays } \\
\text { adjacent to removed } \\
\text { element (interior). }\end{array}$ & $\begin{array}{l}\text { The structural bay } \\
\text { associated with the } \\
\text { removed member. }\end{array}$ \\
\hline \multicolumn{5}{|c|}{ Vertical Spread } \\
\hline $\begin{array}{l}\text { Level of initial } \\
\text { damage, plus } \\
\text { one adjacent } \\
\text { level, either } \\
\text { above or below. }\end{array}$ & $\begin{array}{l}\text { Level of initial damage, } \\
\text { plus one adjacent level, } \\
\text { either above or below. }\end{array}$ & $\leq 3$ stories & $\begin{array}{l}\text { Floor directly beneath } \\
\text { failed element should } \\
\text { not fail }\end{array}$ & $\begin{array}{l}1800 \mathrm{ft}^{2}\left(170 \mathrm{~m}^{2}\right) \text { at } \\
\text { the floor directly above } \\
\text { a removed exterior } \\
\text { column; or } 3600 \mathrm{ft}^{2} \\
\left(330 \mathrm{~m}^{2}\right) \text { at the floor } \\
\text { directly above a } \\
\text { removed interior } \\
\text { column. }\end{array}$ \\
\hline
\end{tabular}

\section{A.4.3 Threshold}

Of the building standards that contain provisions for structural integrity, some make no mention of thresholds, and by default, apply these provisions to all buildings. Other standards recommend that progressive collapse only needs to be considered for buildings that are above a certain height ( 3 stories to 5 stories), or whose failure could cause severe loss of human life (consequence class).

BS 5950-1:2000, Structural Use of Steelwork in Building, Section 2.4.5 Structural Integrity and BS 8110-1:1997, Structural Use of Concrete, Section 2.2.2.2 Robustness-All buildings

BS 5628-1:1992, Code of Practice for Use of Masonry, Section 37.1 General ConsiderationsCategory 2 buildings (five or more stories) require consideration of notional removal of a load-bearing element or provision of ties or both.

BS 5268-2:2002, Structural Use of Timber, Section 1.6.3 Accidental Damage-No special robustness requirements for buildings not exceeding four stories.

Department of Defense Unified Facilities Criteria (UFC) 4-010-01 Minimum Antiterrorism Standards for Buildings (2003) — Standard 6 on progressive collapse avoidance states that buildings of 
three stories or more require consideration against progressive collapse in the context of terrorist threats. Basements are considered stories if they have one or more exposed walls.

Eurocode 1 - Section 2 - Actions on Structures, Part 1 - Basis of Design (CEN 250 1994) (pre EN 2002)-Four consequence classes are given::

1. Low: No consideration required for accidents.

2. Medium: No consideration beyond robustness and stability rules given in Eurocode 1 to 9 .

3. High: Simplified analysis by static equivalent actions, or prescriptive design/detailing rules applicable.

4. Severe: Dynamic, non-linear analysis, load-structure interaction may be applicable.

A table shows the types of buildings associated with each consequence class:

1. Houses of three stories or less.

2. Houses between three and six stories. Offices of less than four stories.

3. Buildings of ten stories or less, public buildings of less than $200 \mathrm{~m}^{2}\left(2200 \mathrm{ft}^{2}\right)$.

4. Buildings of more than ten stories, public buildings of more than $200 \mathrm{~m}^{2}\left(2200 \mathrm{ft}^{2}\right)$.

Swedish Board of Housing, Building and Planning (Boverket, June 2000); Design Regulations BKR: Mandatory Provisions and General Recommendations, BFS 1993:58 with amendments up to BFS 1998:39, BFS 1999:7 and BFS 1999:46—The Swedish provisions recommend consideration against progressive collapse for all buildings in Safety Class 3, defined as those whose collapse would cause great risk of serious injury to humans; and for floors of multi-story buildings assigned to Safety Class 2, defined as those whose collapse would cause some risk of serious injury to humans. Structural elements in multi-story buildings are assigned to Safety Class 3 if their failure would cause collapse of a floor area greater than $150 \mathrm{~m}^{2}$. Following are relevant excerpts from the Boverket 2000 recommendations:

"Special measures need not be taken in buildings in which the risk of serious accidents due to progressive collapse is slight, or in buildings which are so small that primary damage causes total destruction."

"The requirement relating to accidental actions and progressive collapse normally applies only to elements of structure assigned to Safety Class 3." [Safety Class 3 means great risk of serious injury to persons]

"In addition to the safety class requirement, which relates only to injury to persons, the building owner may stipulate more stringent requirements, for instance with respect to property damage."

"In selecting the safety class, the following principles shall be applied."

"Elements of structure shall be assigned to Safety Class 3 if the following conditions simultaneously apply: 
- the design and use of the building are such that many persons are often present in or in the vicinity of the building,

- the element of structure is of such nature that collapse involves a high risk of injury to persons,

- and the element of structure has properties such that failure causes immediate collapse."

"The classification of other elements of structure shall be not lower than Safety Class 2."

"Examples of the choice of safety class.

"A. Buildings of two and more storeys, of the type residential building (with the exception of single-dwelling houses), office buildings, department stores, hospitals and schools."

"The following elements of structure should be assigned to Safety Class 3:

- The main structural system of the building inclusive of those elements of structure which are of essential importance for the stability of the system.

- Other structural elements such as columns, beams, shear panels, whose failure causes the collapse of a floor area $>150 \mathrm{~m}^{2}$.

- Stairs, balconies, access balconies and other elements of structure which form part of the escape routes of the building."

"The following elements of structure should be assigned to Safety Class 2:

- Floor beams not assigned to Safety Class 3.

- Floor slabs.

- Roof construction with the exception of lightweight stressed skin elements of non-brittle materials.

- Those parts of heavy external wall constructions (mass $>50$ $\mathrm{kg} / \mathrm{m}^{2}$ ) which are situated higher than $3.5 \mathrm{~m}$ above ground level and which do not form part of the main structural system of the building.

- The fixings of external wall constructions which are situated higher than $3.5 \mathrm{~m}$ above ground level and which do not form part of the main structural system of the building.

- Heavy partitions (mass $>250 \mathrm{~kg} / \mathrm{m}^{2}$ ) which do not form part of the main structural system of the building.

- The fixings of heavy ceilings (mass $>20 \mathrm{~kg} / \mathrm{m}^{2}$ ).

- Stairs which are not assigned to Safety Class 3." 
" $B$. Single storey buildings of the open plan type whose roofs are of large span (>15 m) and which are used as sports halls, exhibition halls, places of assembly, department stores, schools and industrial premises in which many people are present. (BFS 1998:39)"

"The following elements of structure should be assigned to Safety Class 3:

- The main structural system of the building inclusive of wind bracing and the stabilizing system.

- The barriers of stands etc. erected where there are large differences in level and where a large number of people may be present.

- Structures which carry large overhead cranes (>15 m span and > 20 tonnes lifting capacity)."

Swedish Board of Housing, Building and Planning - Boverket, 1994, Handbook on Vibrations, Induced Deformations and Accidental Loads-Section 4.4 on Dimensioning states the following:

"For buildings with several stories, however, progressive collapse of floor structures within Safety Class 2 (some risk of serious injury to persons) must be considered. This is required to avoid the collapse of a floor structure onto the lower floor structures, which might bring about progressive collapse."

PCI Committee on Precast Concrete Bearing Wall Buildings (1976)—The Precast Concrete Institute (PCI) recommends the use of horizontal ties in all buildings and, in structures over two stories in height, vertical ties also.

Table A2 compares the threshold for consideration of progressive collapse specified in various building standards. Besides the information discussed above, Table A2 also includes the criteria adopted by GSA in 2000, in which buildings may be exempted from having to consider progressive collapse if certain conditions are satisfied. 
Table A2 Threshold for consideration of progressive collapse

\begin{tabular}{|c|c|}
\hline $\begin{array}{l}\text { British Standards } \\
\text { Steel } \\
\text { Concrete } \\
\text { Masonry } \\
\text { Timber }\end{array}$ & $\begin{array}{l}\text { All buildings } \\
\text { All Buildings } \\
\text { Buildings } \geq 5 \text { stories } \\
\text { Buildings } \geq 5 \text { stories }\end{array}$ \\
\hline Department of Defense - UFC 4-010-01 & Buildings $\geq 3$ stories \\
\hline Eurocode 2002 & $\begin{array}{l}\text { Consequence Classes } 1 \text { to 4: } \\
\text { 1) Low: } 1 \text { to } 3 \text { stories. No consideration. } \\
\text { 2) Medium: } 3 \text { to stories, offices }<4 \text { stories: Eurocode robustness and } \\
\text { stability rules. } \\
\text { 3) High: } 7 \text { to } 10 \text { stories, public buildings }<200 \mathrm{~m}^{2} \text { : Simplified static } \\
\text { analysis, prescriptive detailing rules. } \\
\text { 4) Severe: }>10 \text { stories, public buildings }>200 \mathrm{~m}^{2} \text { : Dynamic, } \\
\text { nonlinear analysis, load-structure interaction. }\end{array}$ \\
\hline Swedish Regulations & $\begin{array}{l}\text { Safety Classes } 1 \text { to 3: } \\
\text { 1) Little risk of serious injury. No consideration. } \\
\text { 2) Some risk of serious injury. Consider only in multi-story } \\
\text { buildings } \\
\text { 3) Great risk of serious injury. Mandatory consideration. }\end{array}$ \\
\hline GSA Guidelines (2003) & $\begin{array}{l}\text { Exemption flowcharts regarding use, occupancy, building type, } \\
\text { proximity of moving or parked vehicles, seismic design, and others. }\end{array}$ \\
\hline Precast Concrete Institute (1976) & $\begin{array}{l}\text { Horizontal ties in all buildings. } \\
\text { Vertical ties in buildings over two stories }\end{array}$ \\
\hline
\end{tabular}

\section{A.4.4 General strategy}

With varying emphasis, most standards refer to three methods of mitigating progressive collapse. The first is to reduce exposure to hazards, for example, by erecting protective barriers against vehicular impact or increasing standoff distance against terrorist bombs, or forbidding the use of cooking gas in high-rise buildings. The other two methods are more under the control of structural engineers. The second method explicitly considers resistance to progressive collapse during the design process and is therefore called the direct design method. It can itself be subdivided into two methods:

- The specific local resistance method, which designs against specific accidents or misuse by providing sufficient strength to resist failure, and

- The alternate path method ${ }^{4}$, which accounts for the possibility of local failure, and provides, by design, redundant, alternate load paths that bridge over the failed members and prevent collapse

${ }^{4}$ A good description of the alternate path method is given by James E. Eads at the 1874 inauguration of his St. Louis Bridge: "The peculiar construction of the superstructure is such that any piece of it can be easily taken out and examined, and replaced or renewed, without interrupting the traffic of the bridge... In completing the western span, two of the lower tubes of the inside ribs near the middle of the span were injured during erection, and were actually uncoupled and taken out without any difficulty whatever, after the span was completed, and two new ones put in 
from progressing. In this method, ultimate strength analysis that accounts for plastic or large deformations, as well as catenary or membrane action may be an appropriate tool.

Finally, the third method, called the indirect design method, considers implicitly resistance to progressive collapse by providing minimum levels of strength, continuity, and ductility. It also includes built-in planes of weakness to control the spread of collapse.

It is generally agreed that the following approaches mitigate progressive collapse:

- select a good floor layout; consider structural isolation of various building parts;

- use ductile connections;

- tie the building together, with peripheral, internal and vertical ties; and

- design for load reversal (uplift), change of span direction, and membrane action in floor slabs.

Following are discussions on the strategy advocated by various building standards to resist progressive collapse.

British Standards-The general strategy conforms with the methods and approaches mentioned above. For concrete structures, the standards specify the "length considered lost" for the purpose of notional removal of walls. Furthermore, buildings must be designed for horizontal loads also (the wind load for which Ronan Point was designed was judged too small). For masonry structures taller than five stories, the standards offer three options, 1) alternate load path, 2) horizontal ties only, and 3) horizontal and vertical ties.

BS 5950-1:2000, Structural Use of Steelwork in Building, Section 2.4.5 Structural Integrity-The standards recommend the following approaches to mitigate progressive collapse:

- Tie building together.

- Remove notionally, one at a time, columns and horizontal force resisting elements, and investigate structural stability.

- Design structural members as key elements where necessary.

BS 8110-1:1997, Structural Use of Concrete, Section 2.2.2.2 Robustness-The standards recommend the following approaches to mitigate progressive collapse:

- Design layout of building to avoid weaknesses.

- Design for notional horizontal ultimate load applied at each floor or roof level simultaneously.

- Provide effective horizontal ties around the periphery, internally, and to columns and walls.

- Identify key structural elements and design them as such, or change structural layout if necessary.

their place in a few hours." (Morgan, 1971, quoted in Allen and Shriever, 1972). Allen and Shriever (1972) reported that the claim was further validated in 1969, when a tugboat knocked out a portion of the lower chord of one of the arches and did not cause progressive collapse. 
- Detail buildings so that removal of any vertical load-bearing element other than a key element will not cause more than local collapse. Generally, vertical ties will achieve this. When this cannot be done, notionally remove such vertical element in turn, and design the member normally supported by the element in question to bridge the gap.

- Provide protection against vehicular impact (bollards, earth banks, etc.)

BS 8110-2:1985, Structural Use of Concrete (Special Circumstances), Section 2.6 Robustness, 2.6.3.2 Walls-The standards specify the following for load bearing walls:

"length considered lost: The length of wall considered to be a single load-bearing element should be taken as the length between adjacent lateral supports or between a lateral support and a free edge."

"A lateral support may be considered to occur at:

a) a stiffened section of the wall (not exceeding $1.0 \mathrm{~m}$ in length) capable of resisting a horizontal force of $1.5 F_{t}$ (in $\mathrm{kN} / \mathrm{m}$ wall height); or

b) a partition of mass not less than $100 \mathrm{~kg} / \mathrm{m}^{2}$ at right angles to the wall and so tied to it as to be able to resist a horizontal force of $0.5 F_{t}$, where $F_{t}$ is the lesser of $\left(20+4 \mathrm{n}_{0}\right)$ or 60 , where $\mathrm{n}_{0}$ is the number of storeys in the structure."

BS 5628-1:1992, Code of Practice for Use of Masonry, Sections 20.1 and 37.5-For all buildings, the standards recommend that designers consider a layout that promotes robustness: "returns at the ends of walls, interaction between intersecting walls and between masonry and other parts of the structure." For Category 2 buildings (five or more stories), three options are available:

- Option 1: Buildings should not collapse following removal, one at a time, of vertical and horizontal elements, unless these are protected elements.

- Option 2: Provide horizontal ties, but no vertical ties. Vertical elements, unless protected, are proved removable, one at a time, without causing collapse.

- Option 3: Provide horizontal and vertical ties.

Eurocode 1- Basis of design ENV 1991-1:1994 E, Section 2.1 Fundamental Requirements-In its Basis of Design, Eurocode makes the following general recommendations:

- Avoid, eliminate, or reduce hazards.

- Select structural form with low sensitivity to hazards considered.

- Select structural form that can survive accidental removal of an individual element, a limited part of the structure, or the occurrence of acceptable localized damage.

- Avoid structural systems that may collapse without warning.

- Tie structure together.

These fundamental requirements make no mention of the local resistance method. 
DD ENV 1992-1-5: 1996 External Prestress, Section 5.5.2 Proportioning of ties-The following requirement is provided for slabs reinforced with unbonded tendons:

"Continuous slabs should be checked to ensure that simultaneous failure of any two adjacent unbonded tendons will not cause collapse."

National Research Council of Canada, National Building Code of Canada (NBCC) - The Commentary of the National Building Code of Canada has discussed means to mitigate progressive collapse to various levels of detail over the years. The recommendations follow the methods and approaches mentioned at the beginning of this section.

Commentary C4.1.1.8 of the 1975 NBCC provides the following guidance:

- Lower the risk of accidents: Prevent storage of gas or other explosive materials. Provide fenders against vehicles.

- Ductility: Design connections to be "ductile and capable of large deformations and energy absorption under the effects of abnormal conditions." Avoid joints that rely on friction due to gravity only.

- Design for abnormal loads: "Key elements," whose failure by a foreseeable abnormal event would initiate progressive collapse, "should be designed to remain just functional under that condition."

- Alternate paths: "Usually, the safest and most economical method of coping with progressive collapse is to design the structure in such a way that it can bridge the gap left when a structural component is removed." Ways to do this include:

o Good floor plan: "Probably, the most important is the proper plan layout of walls and of columns." Decrease wall lengths by adding perpendicular spine walls.

o Allow for possible change of span direction of floor slab: Reinforce floor slab so "it can, with a safety factor of 1.05, span in another direction if a load-bearing wall is removed."

o Load-bearing internal partitions: "To achieve the change in span in the floor slab, the internal walls must be capable of carrying enough load to support the edge of the slab."

o Catenary action of floor slab: If an intermediate support is removed, and the slab cannot change its span direction, the slab may still be able to carry loads by catenary action if there is enough reinforcing throughout the slab and enough continuity and end restraint.

o Beam action of walls: If there is sufficient tying steel at the top and bottom, walls may be able to span over openings as the web of a beam, with the slab above and below as flanges.

Commentary C4.1.1.8 of the 1977 NBCC states that, in general, the designer should "provide continuous ductile load-resisting elements and connections with inherent ductility as well as strength."

The following guidance is provided:

"There are four general considerations that can be used in designing to avoid progressive collapse: 
1. reduce the probability of occurrence of an abnormal event,

2. design using ductile connections,

3. design to resist abnormal loads and

4. design for alternate paths."

"The latter two alternatives can usefully be combined in some buildings."

"A procedure based on the alternate path method, which is tending to be favored because it is easier to apply and administer, is the provision of continuous ductile longitudinal and transverse ties and ties around or very near the periphery of the floors or roof and around the periphery of significant openings in them and in addition, where necessary, continuous ductile vertical ties in load bearing walls. The tie forces are obtained by envisaging typical damage caused by abnormal events and finding alternate paths around the damaged areas. The horizontal forces induced in the tie system should be resisted by frame action, walls or the undamaged parts of the structure, so that the tie forces do not in themselves cause the failure to spread."

Discussion of strategy is similar to the 1975 edition with this addition:

"Bracing of trusses in groups: In some cases the bracing or diaphragm connection of trusses into groups may be possible and may be used with lines of weakness between groups to limit the collapse to one "group" when a single truss collapses."

Commentary C4.1.1.3 of the 1990 version of the NBCC states that the design team should identify accidents with a significant probability of occurrence (approximately $10^{-4}$ per year or more) and ensure adequate structural safety against such accidents with measures that include:

- "Control of accidental events. Such measures include protective devices (curbs, guards) against vehicle impact, inspection of key elements or ground conditions for deterioration during use, and blow-out panels to reduce explosion pressures."

- "Local resistance." Identify and design key components to resist accidents.

- "Design of tie forces. Structural integrity can often be achieved indirectly by providing certain minimum vertical, horizontal and peripheral ties in buildings." "Any building system should be considered as a whole, and effectively tied together in such a way as not to be sensitive to local accidental failure."

- "Alternate paths of support. Here it is assumed that the key member has failed, and the damaged building is checked to ensure that it can support the dead load plus a portion of the live load and wind load." 
- "Control of widespread collapse. This measure consists of dividing the structure into areas separated by planes of weakness which prevent a collapse in one area from propagating into adjacent areas."

American Society of Civil Engineers (1998), ASCE 7-98 - Commentary Section C1.4 in ASCE 7-98 has a short discussion on mitigation of progressive collapse. It provides guidance on the minimum tie force and the probability of accidental loads to design for. Its recommendations follow the methods and approaches mentioned at the beginning of this section:

- Provide sufficient continuity, redundancy, or energy dissipating capacity (ductility), or a combination thereof, in the members of the structure.

- Identify extraordinary events with a probability of occurrence in the range of $10^{-6} / \mathrm{yr}$ to $10^{-4} / \mathrm{yr}$ or greater, and ensure key load-bearing elements can withstand such events.

- Minimum tie force between structural elements should be $20 \mathrm{kN} / \mathrm{m}(1400 \mathrm{lb} / \mathrm{ft})$.

- "Design limit states include loss of equilibrium as a rigid body, large deformations leading to significant second order effects, yielding or rupture of members, of connections, formation of a mechanism, instability of members or the structure as a whole."..."In a damaged structure, additional load-carrying mechanisms, such as membrane or catenary action, may be included."

- As elastic analysis may vastly underestimate the capacity of the structure, non-linear or plastic analysis may be used.

American Society of Civil Engineers (2002), ASCE 7-02 - Commentary C1.4 on Design Alternatives is expanded considerably over the 1998 version and provides guidance on various structural actions that may be relied on to prevent local damage from progressing to total collapse. The methods and approaches summarized at the opening of this section are defined and detailed. Interestingly, the Commentary no longer provides guidance on the minimum tie force or the probability of accidental loads to design for. The Commentary is quoted verbatim here:

"There are a number of ways to obtain resistance to progressive collapse. A distinction is made between direct and indirect design, and the following approaches are defined:

Direct Design. Explicit consideration of resistance to progressive collapse during the design process through either:

- Alternate Path Method. A method that allows local failure to occur, but seeks to provide alternate load paths so that the damage is absorbed and major collapse is averted, or

- Specific Local Resistance Method. A method that seeks to provide sufficient strength to resist failure from accidents or misuse.

Indirect Design. Implicit consideration of resistance to progressive collapse during the design process through the provision of minimum levels of strength, continuity, and ductility. 
The general structural integrity of a structure may be tested by analysis to ascertain whether alternate paths exist around hypothetically collapsed regions. Alternatively, alternate path studies may be used as guides for developing rules for the minimum levels of continuity and ductility needed to apply the indirect design approach to enhance general structural integrity. Specific local resistance may be provided in regions of high risk, since it may be necessary for some element to have sufficient strength to resist abnormal loads in order for the structure as a whole to develop alternate paths.

Guidelines for the Provision of General Structural Integrity. Generally, connections between structural components should be ductile and have a capacity for relatively large deformations and energy absorption under the effect of abnormal conditions. These criteria are met in many different ways, depending on the structural system used. Details that are appropriate for resistance to moderate wind loads and seismic loads often provide sufficient ductility. In 1999, ASCE issued a state of practice report that is a s good introduction to the complex field of blast-resistant design (Mlakar, 1999).

Work with large precast panel structures provides an example of how to cope with the problem of general structural integrity in a building system that is inherently discontinuous. The provisions of ties combined with careful detailing of connections can overcome difficulties associated with such a system. The same kind of methodology and design philosophy can be applied to other systems. The ACI Building Code Requirements for Structural Concrete includes such requirements in Section 7-13.

There are a number of ways of designing for the required integrity to carry loads around severely damaged walls, trusses, beams, columns, and floors. A few examples of design concepts and details follow:

1. Good plan layout. An important factor in achieving integrity is the proper plan layout of walls and columns. In bearing-wall structures there should be an arrangement of interior longitudinal walls to support and reduce the span of long sections of crosswall, thus enhancing the stability of individual walls and of the structure as a whole. In the case of local failure, this will also decrease the length of wall likely to be affected.

2. Provide an integrated system of ties among the principal elements of the structural system. These ties may be designed specifically as components of secondary load-carrying systems, which often must sustain very large deformations during catastrophic events.

3. Returns on walls. Returns on interior and exterior walls will make them more stable.

4. Changing directions of span of floor slab. Where a floor slab is reinforced in order that it can, with a low safety factor, span in another direction if a load-bearing wall is removed, the collapse of the slab will be prevented and the debris loading of other parts 
of the structure will be minimized. Often, shrinkage and temperature steel will be enough to enable the slab to span in a new direction.

5. Load-bearing interior partitions. The interior walls must be capable of carrying enough load to achieve the change of span direction in the floor slabs.

6. Catenary action of floor slab. Where the slab cannot change span direction, the span will increase if an intermediate supporting wall is removed. In this case, if there is enough reinforcement throughout the slab and enough continuity and restraint, the slab may be capable of carrying the loads by catenary action, though very large deflections will result.

7. Beam action of walls. Walls may be assumed to be capable of spanning an opening if sufficient tying steel at the top and bottom of the walls allows them to act as the web of a beam with the slabs above and below acting as flanges.

8. Redundant structural systems. Provide a secondary load path (e.g., an upper-level truss or transfer girder system that allows the lower floors of a multistory building to hang from the upper floors in an emergency) that allows framing to survive removal of key support elements.

9. Ductile detailing. Avoid low ductility detailing in elements that might be subject to dynamic loads or very large distortions during localized failures (e.g., consider the implications of shear failures in beams or supported slabs under the influence of building weights falling from above).

10. Provide additional reinforcement to resist blast and load reversal when blast loads are considered in design.

11. Consider the use of compartmentalized construction in combination with special moment-resisting frames in the design of new buildings when considering blast protection.

While not directly adding structural integrity for the prevention of progressive collapse, the use of special nonfrangible glass for fenestration can greatly reduce risk to occupants during exterior blasts. To the extent that nonfrangible glass isolates a building's interior from blast shock waves, it can also reduce damage to interior framing elements (e.g., supported floor slabs could be made to be less likely to fail due to uplift forces) for exterior blasts."

American Society of Civil Engineers (2005), ASCE 7-05-There are only small editorial differences compared with the 2002 version.

Department of Defense (2003) Unified Facilities Criteria (UFC) 4-010-01: Minimum Antiterrorism Standards for Buildings - The DOD 2003 Minimum Antiterrorism Standards for Buildings refer to ASCE 7, and give additional guidance on ways to reduce the risk of progressive collapse. Of note are the prohibition of the use of unreinforced masonry exterior walls in new buildings, and the addition of one 
story height of unsupported length in the design of exterior load bearing walls and columns. The following is a summary of the recommendations:

- Maximize standoff distance (to minimize terrorist threats);

- Design all additions to existing buildings to be structurally independent (structural isolation);

- Areas that do not meet criteria for inhabited buildings should be structurally independent from the inhabited areas;

- Avoid building overhangs with inhabited space above them;

- Unreinforced masonry walls are prohibited for the exterior walls of new buildings. Provide at least $0.05 \%$ vertical reinforcement with spacing less than $1.2 \mathrm{~m}(4 \mathrm{ft})$;

- Prevent building collapse, using the following guidance:

o Apply ASCE 7 except that exterior member removal also applies to interior vertical or horizontal load carrying elements;

o Use highly redundant structural system such as moment resisting frame;

o Provide continuity across joints equal to the capacity of the connected members;

o Detail members to accommodate large displacements without loss of strength;

o Design all exterior vertical load-carrying columns and walls to sustain a loss of lateral support at any floor level by adding one story height to the nominal unsupported length;

o This provision also applies to internal vertical load-carrying columns and walls where parking beneath building is unavoidable;

o Buildings should be able to withstand removal of one primary exterior vertical or horizontal load-carrying element without collapse.

\section{Department of Defense (2005) Unified Facilities Criteria (UFC) 4-023-03, Design of Buildings to}

Resist Progressive Collapse - The progressive collapse design requirements use two approaches: 1) tie forces and 2) alternate load path (referred to the "alternate path" method).

"In the Tie Force approach, the building is mechanically tied together, enhancing continuity, ductility, and development of alternate load paths. Tie forces are typically provided by the existing structural elements and connections that are designed using conventional design procedures to carry the standard loads imposed upon the structure.

Depending upon the construction type, there are several horizontal ties that must be provided: internal, peripheral, and ties to edge columns, corner columns, and walls. Vertical ties are required in columns and load-bearing walls. Figure 3-1 illustrates these ties for frame construction...."

"If all of the structural elements and connections can be shown to provide the required tie strength, then the tie force requirement has been met. If the vertical design tie strength of any structural element or connection is less than the vertical required tie strength, the designer 
must either: 1) revise the design to meet the tie force requirements or 2) use the Alternate Path method to prove that the structure is capable of bridging over this deficient element...."

"The Alternate Path [AP] method is used in two situations: 1) when a vertical structural element cannot provide the required tie strength, the designer may use the AP method to determine if the structure can bridge over the deficient element after it has been notionally removed, and 2) for structures that require Medium or High Levels of Protection [MLOP or HLOP], the AP method must be applied for the removal of specific vertical load-bearing elements which are prescribed in Section 3-2.3.

For MLOP and HLOP structures, perform and document a peer review for all Alternate Path analyses. The peer reviewers must be independent and qualified organizations who are approved beforehand by the building owner."

The levels of protection (LOP) are defined in UFC 4-010-01 (DOD 2003) in terms of potential structural damage, potential door and glazing hazards, and potential injuries due to an explosive event. The four levels of protection and corresponding potential structural damage are defined as follows:

- Very low level of protection (VLLOP) - heavily damaged and onset of collapse.

- Low level of protection (LLOP) — damaged and unrepairable.

- Medium level of protection (MLOP) — damaged but repairable.

- High level of protection (HLOP) — superficially damaged.

The following requirements are given for structures having these levels of protection:

"A structure with Very Low Level of Protection must provide adequate horizontal tie force capacity. The magnitudes of the horizontal tie forces vary with construction type and with location in the structure, as specified in Chapters 4 through 8 . The designer cannot use the Alternate Path method to verify that the structure can bridge over an element with inadequate capacity. If a structural element does not provide the required horizontal tie force capacity, it must be re-designed in the case of new construction or retrofitted in the case of existing construction."

"The design of a structure with a Low Level of Protection must incorporate both horizontal and vertical tie force capacities. However, if a vertical structural member cannot provide the required vertical tie force capacity, the designer must either re-design the member or use the AP method to prove that the structure can bridge over the element when it is removed. For elements with inadequate horizontal tie force capacity, the Alternate Path method cannot be used. In this case, the designer must redesign the element in the case of new construction or retrofit the element in the case of existing construction. ... The magnitudes and locations of each tie force vary with construction type, as shown in Chapters 4 through 8." 
"For MLOP and HLOP structures, the designer must provide adequate horizontal and vertical tie force capacities. However, if a structural member cannot provide the required vertical tie force capacity, the designer must either re-design the member or use the Alternate Path method to prove that the structure can bridge over the element when it is removed. For elements with inadequate horizontal tie force capacity, the Alternate Path method cannot be used. In this case, the designer must redesign the element in the case of new construction or retrofit the element for existing construction."

The requirements for alternate load paths in structures designated as MLOP and HLOP are as follows:

"The structure must be able to bridge over specific vertical load-bearing elements that are notionally removed from the structure. The plan locations of the removed vertical load-bearing elements include, as a minimum, the center of the short side, the center of the long side, and the building corner, as discussed in Section 3-2.3. In addition, vertical loadbearing elements are removed wherever there is a significant variation or discontinuity in the structural geometry, such as re-entrant corners and abrupt changes in bay sizes."

"For each plan location of a removed element, an Alternate Path analysis is performed for every floor, one at a time; thus, if there are three plan locations and eight stories, twenty four AP analyses must be performed. If bridging cannot be demonstrated for one of the removed load-bearing elements, the structure must be re-designed or retrofitted to increase the bridging capacity. Note that the structural re-design or retrofit is not applied to just the deficient element, i.e., if a structure cannot be shown to bridge over a removed typical column at the center of the long side, the engineer must develop suitable or similar re-designs or retrofits for that column and other similar columns. For instance, a re-design might consist of additional positive moment rebar at a reinforced concrete beam-column joint; this new design must be applied to other columns on that external column line."

"For MLOP and HLOP structures, the designer must perform and document a peer review for all Alternate Path analyses. The reviewer must be an independent organization with demonstrated experience performing progressive collapse design."

In addition, structures designated as MLOP and HLOP have additional deformation and ductility requirements for the perimeter load bearing elements. These requirements are material specific, and the following materials are addressed:

- Reinforced concrete (Chapter 4);

- Structural steel (Chapter 5);

- $\quad$ Masonry (Chapter 6);

- Wood (Chapter 7); and 
- Cold-formed steel (Chapter 8).

Each of the above chapters contains the tie requirements and acceptance criteria for alternate load path analyses for each class of materials. For alternate load path analyses, the acceptance criteria include the following:

- Strength limits of members are not exceeded;

- Deformation limits are not exceeded; and

- Spread of damaged members is limited, as summarized in Table A1.

The following describes the procedures used in alternate load path analyses when member exceed their corresponding strength of deformation limits:

“3-2.7.1 Flexure. When the internal moment (flexural required strength) determined by the AP model exceeds the flexural design strength of an element, the element is either removed or modified. For Linear Static models, structural elements that can sustain a constant moment while undergoing continued deformation must be modified through insertion of an effective plastic hinge. Place a discrete hinge in the model at the location of yielding and apply two constant moments, one at each side of the discrete hinge, in the appropriate direction for the acting moment; see Figure 3-9. Determine the location of the effective plastic hinge through engineering analysis and judgment or with the guidance provided for the particular construction type. In Nonlinear Static and Dynamic models, the software must have the ability to adequately represent the nonlinear flexural response, after the internal moment reaches the flexural design strength of the element."

"For structural elements that fail when the peak moment is reached and in all three model types (Linear Static, Nonlinear Static and Nonlinear Dynamic), remove the element when the internal moment exceeds the flexural design strength. Redistribute the loads associated with the failed element per Section 3-2.4.3, before the analysis continues."

“3-2.7.2 Combined Axial and Flexure. The acceptability criteria for elements undergoing combined axial loads and flexural loads is based on the provisions given in the material-specific design code. For elements that are controlled by flexure, follow the procedure outlined in Section 32.7.1. For elements controlled by buckling, remove the failed element from the model and redistribute the loads per Section 3-2.4.3.”

“3-2.7.3 Shear. If the shear design strength is exceeded for any construction type, remove the member and redistribute the loads from that element per Section 3-2.4.3, before the analysis continues."

“3-2.7.4 Connections. If the design strength for any connection failure mode is exceeded, remove the connection. If the connections at both ends of an element have failed, remove the element and redistribute the 
loads from that element per Section 3-2.4.3, before the analysis continues."

"Use the guidance provided in the material-specific design codes or other sources to develop connection details that can provide the required strength while undergoing potentially large deformations. In a number of the material-specific design codes, provisions for seismic design are presented, including connection details; incorporate this information, as appropriate, in designing connections."

“3-2.7.5 Deformation Limits. Deformation limits are defined in terms of the deflections and rotations in the structural elements, connections and frame. Excessive deflections or rotations imply that the element or portion of the frame has deformed to the point that it can no longer carry load. Calculation of rotations for members, connections, and frames is illustrated in Figures 3-10 and 3-11."

"If an element or connection exceeds a deformation limit, remove it from the model. The values for the deformation limits are specific to each type of construction and are listed in the appropriate sections (Chapters 4 to 8)."

\section{Interagency Security Committee Design Criteria for New Federal Office Buildings and Major Reorganization Projects (2001) - These criteria follow the methods and approaches summarized at the beginning of this section. At a minimum, new facilities should be designed to withstand the loss of a column for one floor above grade at the building perimeter without collapse (alternate path). The designer must either show that the building will not collapse due to the loss of one primary column, or the proposed design precludes such a loss (local resistance). The following good engineering practice guidelines are offered:}

- To design economically against blast, use inelastic or post-elastic design. Dynamic analysis may also be required;

- Due to blast, structural components may act in directions for which they are not designed. Use symmetrical reinforcements;

- Ductile detailing should be used for all connections, especially primary structural member connections;

- Shear reinforcement should allow large deformation, post-elastic behavior;

- Minimize column spacing. A practical upper limit is $30 \mathrm{ft}(9 \mathrm{~m})$;

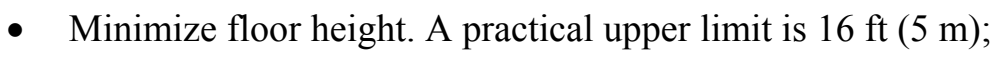

- When concrete masonry units (CMU) are selected, use fully grouted and reinforced CMU.

- Ductile seismic detailing and alternate load paths for progressive collapse design usually assist in blast protection. 
General Services Administration (GSA) Progressive Collapse Analysis and Design Guidelines For New Federal Office Buildings and Major Modernization Projects (2003) - A series of flowcharts guides the designer through an exemption process that takes into account the use, occupancy, type of the building, proximity of moving or parked vehicles, as well as structural features such as seismic design, to help him decide if the building needs to be designed against progressive collapse or not. In case it does, the following general guidance for design is offered:

- Use redundant lateral and vertical elements and detailing;

- Design against shear failure;

- Design for an additional story of unsupported length, columns along the perimeter of the facility, between the first and the third floor above grade, and all columns in public areas or uncontrolled parking areas;

- Design to resist load reversals in the following locations:

o For facilities with uncontrolled parking areas or public areas: at least one structural bay deep around the perimeter from ground level to roof level, and for all interior structural bays for at least three floors above grade;

o For other facilities, at least one structural bay deep around the perimeter from ground to roof level;

- Account for 3-D effects.

The overall recommended design strategy is to notionally remove a primary vertical support, such as one

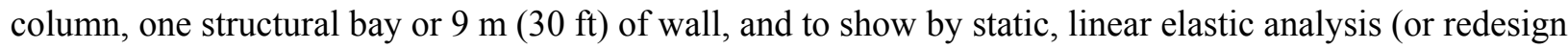
if necessary) that damage is limited to:

- The structural bay directly associated with the removed member, or

- $170 \mathrm{~m}^{2}\left(1800 \mathrm{ft}^{2}\right)$ at the floor directly above (exterior column), or

- $330 \mathrm{~m}^{2}\left(3600 \mathrm{ft}^{2}\right)$ at the floor directly above (interior column).

Notice that structural ties and strengthening of selected members (local resistance method) are not mentioned as alternative methods. These approaches may be used if analysis shows they are required to develop alternate load paths.

To allow the use of simplified analysis, the Design Guidelines make use of the demand-capacity ratio $(D C R)$ defined as

$$
D C R=\frac{Q_{U D}}{Q_{C E}}
$$

where

$Q_{U D}=$ acting force on structural member or joint, and

$Q_{C E}=$ expected ultimate, unfactored capacity. 
Using static, linear-elastic analysis, the designer identifies the magnitude and distribution of potential, inelastic demands on primary and secondary structural elements. The Design Guidelines limit the $D C R$ to 2 or less for typical structural configurations, and to 1.5 or less for atypical structural configurations. If the $D C R$ cannot be limited to these values, then the structural member or connection in question is considered to have failed. These criteria are based on FEMA 274 (1997) and FEMA 356 (2000), Guidelines for the Seismic Rehabilitation of Buildings and the Department of Defense Interim Antiterrorism/Force Protection Construction Standards (March 2001).

The GSA Design Guidelines allow material strength to be increased in this static, linear-elastic analysis: steel structural members by $5 \%$ to $10 \%$, concrete and reinforcing steel by $25 \%$.

For the analysis of atypical construction, the Design Guidelines rely upon engineering judgment for particular cases, such as structures:

- That combine frame and wall systems for primary support;

- With vertical discontinuities;

- With variations in bay size or extreme bay size $(>9 \mathrm{~m}$ or $30 \mathrm{ft})$;

- With irregularities in plan; and

- With closely spaced columns. Simultaneous loss of two adjacent columns may have to be designed for when distance between columns is less than $30 \%$ of the largest dimension of the associated bay.

The GSA Design Guidelines also consider the dynamic effects due to instantaneous removal. If dynamic analysis is performed, member removal should take place in less than 1/10 of the period associated with the structural response mode for the removal. Also, removal is of the vertical element only, not of the connection to any horizontal member.

More sophisticated analyses that account for material and geometric nonlinearities (i.e., large deformations) are alternatives to simplified analysis. The ductility and rotation limits provided by the Department of Defense Interim Antiterrorism/Force Protection Construction Standards (March 2001) are recommended as acceptance criteria.

The Guidelines initially released in 2000 focused primarily on reinforced concrete structures. The 2003 Guidelines were expanded by adding parallel guidance for steel structures.

New York City Building Code (1998), Chapter 18, Resistance to Progressive Collapse Under Extreme Local Loads-The 1998 New York City Building Code follows closely the British approach and recommends checking resistance to progressive collapse using:

a) The alternate path method, or

b) The specific local resistance method if a) is not feasible.

The analysis may use plastic design or ultimate strength method. Further details on the two methods include: 
a) Notionally remove structural elements at any one story and check for progressive collapse:

o One column;

o One wall panel or nominal wall length (typically 2.25 times clear wall height);

o Two adjacent wall panels or nominal wall lengths forming an exterior corner;

o Nominal extent of flooring;

0 Any other one element judged vital to the building stability.

b) Check any single element essential to the stability of the structure, together with its structural connections for a distributed load of $34 \mathrm{kPa}(5 \mathrm{psi})$.

New York City Department of Buildings, World Trade Center Building Code Task Force (2003)The 2003 draft provisions of the World Trade Center Building Code Task Force, "which take much of their substance and methodology from the British Standard," refer to ASCE 7 and also lists three design methods against progressive collapse.

1) Indirect design: The principal feature of this method consists of tying the building together.

2) Direct design: The alternate path method allows local failure to occur but provides alternate load paths to bridge over the damage and avert collapse. The method consists in notionally removing key members one at a time and assessing structural stability for under a load equal to Dead Load +0.25 Live Load + 0.2 Wind Load.

3) Direct design: The specific local resistance method consists in hardening locally key elements against unanticipated loads without failing the connections, or supporting members framing it. The structure shall be detailed to permit load reversals.

The preferred method is the indirect design method (\#1). The alternate path method (\#2) should only be used if method \#1 cannot be accommodated. Likewise the specific local resistance method (\#3) should only be used if methods \#1 and \#2 cannot be accommodated.

Swedish Board of Housing, Building and Planning (Boverket, June 2000): Design Regulations BKR: Mandatory Provisions and General Recommendations, BFS 1993:58 with amendments up to BFS 1998:39, BFS 1999:7 and BFS 1999:46

Section 2:113 Accidental actions and progressive collapse

"Buildings shall be designed so that the risk of progressive collapse is slight. This may be accomplished by designing and detailing buildings either in such a way that they can withstand accidental actions or in such a way that primary damage is limited. Such damage shall not give rise to progressive collapse and severe destruction in any part of the structure other than the region of primary damage and the region adjoining this. (BFS 1995:18)"

Swedish Board of Housing, Building and Planning (Boverket, 1994): Handbook on Vibrations, Induced Deformations and Accidental Loads

Section 4.4 Dimensioning-Boverket recommends the following guidelines for design against accidental loads, or for design of repair after primary damage: 
- Only risk to humans needs to be considered. Risk of structural damage is considered only if it causes further risk to humans;

- Neglect long term damage, as the damaged structure will be either demolished or repaired;

- Design for large deformations, which could activate membrane action, for example. Use plasticity and ultimate strength theories where applicable;

- Consider bridging over local damage by alternate load paths.

Section 4.5 Simplified conditions for normal residential houses and office buildings-Both requirements (a) and (b) must be met in order to design against progressive collapse:

Requirement a-For buildings of 4 stories, the stability of structure after primary damage must be checked under the following load combination:

$$
1.0 G_{\mathrm{k}}+1.0 \Psi Q_{\mathrm{k}}
$$

where $G_{\mathrm{k}}, Q_{\mathrm{k}}$ are the characteristic values of permanent and variable action, respectively. Characteristic values have $98 \%$ probability of not being exceeded at any time during one year. The frequent value of a variable action $\Psi Q_{\mathrm{k}}$ depends on the variation of the action in time and the coefficient of variation of the action.

For buildings of 5 stories to 16 stories, in addition to meeting the same requirements as for 4 story buildings, engineers must also prove the existence of alternate load paths to bridge over damage zones.

Buildings of more than 16 stories should be considered on a case by case basis for progressive collapse.

Requirement $\boldsymbol{b}$-To avoid progressive collapse brought about by successive failure of concrete floor structures loaded by falling debris, the various parts of the floor structure, the various parts of the bearing walls, and the support between floor structure and wall should be able to transfer a tensile force of $20 \mathrm{kN} / \mathrm{m}(1400 \mathrm{lb} / \mathrm{ft})$ and a shear force of $20 \mathrm{kN} / \mathrm{m}$.

Similar conditions also apply between slabs and girders of floor systems and also between girders and columns or walls. The tie force between a girder and a column can, however, be limited to $150 \mathrm{kN}$ (33.7 kips).

Swedish tests of precast floors exposed to the sudden removal of an exterior support showed that if the intermediate floor connection is ductile enough, it is possible to achieve alternate load path by cantilever action and to predict the behavior accurately (Engstrom, 1988).

Summary - Table A-3 compares the strategies advocated by various building standards to resist progressive collapse. 
Table A-3. Strategies to resist progressive collapse

\begin{tabular}{|c|c|c|c|c|}
\hline & BS Steel 2000 & BS Concrete 97, 85 & BS Masonry 1992 & Eurocode 1-1994 \\
\hline Risk & & $\begin{array}{l}\text { Provide protection } \\
\text { against impact. }\end{array}$ & & $\begin{array}{l}\text { Avoid, eliminate, or } \\
\text { reduce hazards. }\end{array}$ \\
\hline Layout & & $\begin{array}{l}\text { Avoid weakness in } \\
\text { building layout. }\end{array}$ & & $\begin{array}{l}\text { Select structural form } \\
\text { with low sensitivity to } \\
\text { hazards considered. } \\
\text { Avoid structural } \\
\text { systems that may } \\
\text { collapse without } \\
\text { warning. }\end{array}$ \\
\hline $\begin{array}{l}\text { Direct } \\
\text { Design: } \\
\text { Alternate } \\
\text { Load Path }\end{array}$ & $\begin{array}{l}\text { Design building to } \\
\text { resist notional } \\
\text { removal of structural } \\
\text { member, one at a } \\
\text { time. }\end{array}$ & $\begin{array}{l}\text { Design building to } \\
\text { resist notional } \\
\text { removal of structural } \\
\text { member, one at a } \\
\text { time. Length of wall } \\
\text { considered lost is } \\
\text { single load-bearing } \\
\text { element taken as } \\
\text { length between } \\
\text { adjacent lateral } \\
\text { supports or between } \\
\text { lateral support and } \\
\text { free edge. }\end{array}$ & $\begin{array}{l}\text { Option 1: Building } \\
\text { should not collapse } \\
\text { following removal, } \\
\text { one at a time, of } \\
\text { vertical and horizontal } \\
\text { elements, unless } \\
\text { protected. }\end{array}$ & $\begin{array}{l}\text { Select structural form } \\
\text { that can survive } \\
\text { accidental removal of } \\
\text { an individual element, } \\
\text { a limited part of the } \\
\text { structure, or the } \\
\text { occurrence of } \\
\text { acceptable localized } \\
\text { damage. }\end{array}$ \\
\hline $\begin{array}{l}\text { Direct } \\
\text { Design: Key } \\
\text { Elements }\end{array}$ & $\begin{array}{l}\text { Design selected } \\
\text { members as key } \\
\text { elements. }\end{array}$ & $\begin{array}{l}\text { Design selected } \\
\text { members as key } \\
\text { elements. }\end{array}$ & & No recommendation \\
\hline $\begin{array}{l}\text { Indirect } \\
\text { Design: Ties }\end{array}$ & Tie building together. & $\begin{array}{l}\text { Provide horizontal ties } \\
\text { around periphery, } \\
\text { internally, to columns } \\
\text { and walls. Provide } \\
\text { vertical ties. }\end{array}$ & $\begin{array}{l}\text { Option 2: Provide } \\
\text { horizontal ties, but no } \\
\text { vertical ties. } \\
\text { Option 3: Provide } \\
\text { horizontal and vertical } \\
\text { ties. }\end{array}$ & Tie structure together. \\
\hline
\end{tabular}


Table A-3 (Continued) Strategies to resist progressive collapse

\begin{tabular}{|c|c|c|c|c|}
\hline & Canada 1975 & Canada 1977 & Canada 1990 & ASCE 7-98 \\
\hline Risk & $\begin{array}{l}\text { Prevent storage of gas } \\
\text { or explosives. Provide } \\
\text { fenders against } \\
\text { vehicles. }\end{array}$ & $\begin{array}{l}\text { Reduce probability of } \\
\text { occurrence of an } \\
\text { abnormal event. }\end{array}$ & $\begin{array}{l}\text { Control accidental } \\
\text { events. }\end{array}$ & $\begin{array}{l}\text { Design for } \\
\text { extraordinary events } \\
\left(10^{-6} \text { to } 10^{-4} \text { per year }\right. \\
\text { or greater }) \text {. }\end{array}$ \\
\hline Layout & $\begin{array}{l}\text { Proper layout of walls } \\
\text { and columns. Add } \\
\text { spine walls. }\end{array}$ & & $\begin{array}{l}\text { Build in planes of } \\
\text { weakness to arrest } \\
\text { collapse propagation. }\end{array}$ & \\
\hline $\begin{array}{l}\text { Direct } \\
\text { Design: } \\
\text { Alternate } \\
\text { Load Path }\end{array}$ & $\begin{array}{l}\text { Design for possible } \\
\text { change of direction of } \\
\text { span of floor slabs; } \\
\text { Strengthen internal } \\
\text { partitions; } \\
\text { Design slabs for } \\
\text { catenary action; } \\
\text { Reinforce walls to act } \\
\text { as webs of beams. }\end{array}$ & $\begin{array}{l}\text { Design for alternate } \\
\text { paths, and possible } \\
\text { change of direction of } \\
\text { span of floor slabs; } \\
\text { Strengthen internal } \\
\text { partitions; } \\
\text { Design slabs for } \\
\text { catenary action; } \\
\text { Reinforce walls to act } \\
\text { as webs of beams. }\end{array}$ & $\begin{array}{l}\text { Design building to } \\
\text { resist notional } \\
\text { removal of structural } \\
\text { member. }\end{array}$ & \\
\hline $\begin{array}{l}\text { Direct } \\
\text { Design: Key } \\
\text { Elements } \\
\end{array}$ & $\begin{array}{l}\text { Design key elements } \\
\text { for abnormal loads. }\end{array}$ & $\begin{array}{l}\text { Design key elements } \\
\text { for abnormal loads. }\end{array}$ & $\begin{array}{l}\text { Identify and design } \\
\text { key components to } \\
\text { resist accidents. }\end{array}$ & \\
\hline $\begin{array}{l}\text { Indirect } \\
\text { Design: Ties }\end{array}$ & $\begin{array}{l}\text { Use energy-absorbing } \\
\text { connections. Avoid } \\
\text { joints that rely on } \\
\text { friction due to gravity } \\
\text { only. }\end{array}$ & $\begin{array}{l}\text { Provide horizontal ties } \\
\text { around periphery, } \\
\text { internally, to columns, } \\
\text { walls and around } \\
\text { openings. } \\
\text { Provide vertical ties. } \\
\text { Use ductile } \\
\text { connections. } \\
\text { Brace trusses or } \\
\text { connect them by } \\
\text { diaphragms into } \\
\text { groups. }\end{array}$ & $\begin{array}{l}\text { Tie building together } \\
\text { with horizontal, } \\
\text { vertical and peripheral } \\
\text { ties. }\end{array}$ & $\begin{array}{l}\text { Provide continuity, } \\
\text { redundancy and } \\
\text { ductility in structure. } \\
\text { Design ties for } \\
20 \mathrm{kN} / \mathrm{m}(1400 \mathrm{lb} / \mathrm{ft}) \text {. } \\
\text { Use non-linear, plastic } \\
\text { analysis. Allow } \\
\text { catenary or membrane } \\
\text { action. }\end{array}$ \\
\hline
\end{tabular}


Table A-3 (Continued) Strategies to resist progressive collapse

\begin{tabular}{|c|c|c|c|c|}
\hline & ASCE 7-02 and 05 & $\begin{array}{c}\text { DOD UFC 4-010-01 } \\
2003\end{array}$ & $\begin{array}{c}\text { DOD UFC 4-023-03 } \\
2005\end{array}$ & ISC 2001 \\
\hline Risk & $\begin{array}{l}\text { Design for } \\
\text { extraordinary events } \\
\left(10^{-6} \text { to } 10^{-4} \text { per year }\right. \\
\text { or greater }) \text {. }\end{array}$ & $\begin{array}{l}\text { Maximize standoff } \\
\text { distance. }\end{array}$ & $\begin{array}{l}\text { Refers to UFC 4-010- } \\
01\end{array}$ & \\
\hline Layout & $\begin{array}{l}\text { Reduce span of long } \\
\text { sections of crosswalls. }\end{array}$ & $\begin{array}{l}\text { Structurally isolate } \\
\text { additions to existing } \\
\text { buildings, or inhabited } \\
\text { from uninhabited } \\
\text { buildings. Avoid } \\
\text { building overhangs } \\
\text { with inhabited spaces } \\
\text { above them. }\end{array}$ & $\begin{array}{l}\text { Refers to UFC 4-010- } \\
01\end{array}$ & \\
\hline $\begin{array}{l}\text { Direct } \\
\text { Design: } \\
\text { Alternate } \\
\text { Load Path }\end{array}$ & $\begin{array}{l}\text { Allow local failure, } \\
\text { but provide alternate } \\
\text { load paths. Reinforce } \\
\text { floor slabs for } \\
\text { possible catenary } \\
\text { action and change of } \\
\text { span direction. } \\
\text { Provide load-bearing } \\
\text { interior partitions. } \\
\text { Consider beam action } \\
\text { of walls. }\end{array}$ & $\begin{array}{l}\text { Refer to ASCE } 7 . \\
\text { Buildings should be } \\
\text { able to withstand } \\
\text { removal of one } \\
\text { primary exterior or } \\
\text { interior vertical or } \\
\text { horizontal load- } \\
\text { carrying element } \\
\text { without collapse. }\end{array}$ & $\begin{array}{l}\text { Applied to facilities } \\
\text { designated as MLOP } \\
\text { and HLOP as } \\
\text { alternative to ties; } \\
\text { withstand removal of } \\
\text { vertical load-bearing } \\
\text { element. Applied to } \\
\text { facilities designated as } \\
\text { LLOP when vertical } \\
\text { tie requirements } \\
\text { cannot be met. }\end{array}$ & $\begin{array}{l}\text { Design new buildings } \\
\text { to withstand loss of an } \\
\text { exterior column for } \\
\text { one floor above grade } \\
\text { without collapse. } \\
\text { Use symmetrical } \\
\text { reinforcement. }\end{array}$ \\
\hline $\begin{array}{l}\text { Direct } \\
\text { Design: Key } \\
\text { Elements }\end{array}$ & $\begin{array}{l}\text { Provide sufficient } \\
\text { strength to resist } \\
\text { failure from accidents } \\
\text { or misuse. Resist load } \\
\text { reversal. }\end{array}$ & $\begin{array}{l}\text { Design all exterior } \\
\text { (interior also if there } \\
\text { is parking underneath) } \\
\text { load-carrying columns } \\
\text { and walls for an } \\
\text { additional story height } \\
\text { of unsupported length. }\end{array}$ & $\begin{array}{l}\text { Apply UFCs for } \\
\text { design to resist } \\
\text { explosive effects; } \\
\text { must still meet } \\
\text { progressive collapse } \\
\text { requirements. }\end{array}$ & \\
\hline $\begin{array}{l}\text { Indirect } \\
\text { Design: Ties }\end{array}$ & $\begin{array}{l}\text { Provide minimum } \\
\text { levels of strength, } \\
\text { continuity, and } \\
\text { ductility. Tie principal } \\
\text { elements of structural } \\
\text { system. Provide } \\
\text { returns* on walls. Use } \\
\text { redundant structural } \\
\text { systems, ductile } \\
\text { detailing, and } \\
\text { compartmentalized } \\
\text { construction. }\end{array}$ & $\begin{array}{l}\text { Provide continuity, } \\
\text { redundancy and } \\
\text { ductility in structure. } \\
\text { Detail members to } \\
\text { accommodate large } \\
\text { displacements without } \\
\text { loss of strength. Do } \\
\text { not use URM as } \\
\text { external walls. }\end{array}$ & $\begin{array}{l}\text { For facilities } \\
\text { designated as VLLOP } \\
\text { provide horizontal } \\
\text { ties; for LLOP } \\
\text { provide horizontal and } \\
\text { vertical ties. For } \\
\text { MLOP and HLOP, } \\
\text { provide horizontal and } \\
\text { vertical ties or use } \\
\text { alternate path method. }\end{array}$ & $\begin{array}{l}\text { Use seismic, ductile } \\
\text { detailing, and inelastic } \\
\text { or post-elastic design. } \\
\text { Dynamic analysis may } \\
\text { be required. Shear } \\
\text { reinforcement to allow } \\
\text { large deformation. } \\
\text { Grout or reinforce } \\
\text { CMU. Minimize } \\
\text { column spacing ( }<30 \\
\text { ft or } 9 \mathrm{~m}) \text { and floor } \\
\text { height }(<16 \mathrm{ft} \text { or } 5 \\
\mathrm{m}) .\end{array}$ \\
\hline
\end{tabular}

* A return is a short length of wall usually at right angle to another wall. 
Table A-3 (Continued) Strategies to resist progressive collapse

\begin{tabular}{|c|c|c|c|c|}
\hline & GSA 2003 & NYCBC 1998 & NYC-WTCTF 2003 & Sweden 1994 \\
\hline Risk & & & & $\begin{array}{l}\text { Accept severe damage } \\
\text { to structure, but } \\
\text { design to minimize } \\
\text { risk to humans. }\end{array}$ \\
\hline \multicolumn{5}{|l|}{ Layout } \\
\hline $\begin{array}{l}\text { Direct } \\
\text { Design: } \\
\text { Alternate } \\
\text { Load Path }\end{array}$ & $\begin{array}{l}\text { Notionally remove } \\
\text { one column, one } \\
\text { structural bay or } 30 \mathrm{ft} \\
(9 \mathrm{~m}) \text { of wall and } \\
\text { analyze structure. } \\
\text { For static, linear } \\
\text { elastic analysis, limit } \\
\text { DCR to } 2 \text { (typical } \\
\text { construction) or } 1.5 \\
\text { (atypical } \\
\text { construction.) For } \\
\text { nonlinear analysis, use } \\
\text { ductility and rotation } \\
\text { acceptance criteria. } \\
\text { For dynamic analysis, } \\
\text { remove member in } \\
\text { less than } 1 / 10 \text { of } \\
\text { period of } \\
\text { corresponding } \\
\text { structural response. }\end{array}$ & $\begin{array}{l}\text { Notionally remove } \\
\text { structural element: } \\
\text {-one column; } \\
\text {-one wall panel; } \\
\text {-two adjacent wall } \\
\text { panels; } \\
\text {-any vital one element } \\
\text { and check for } \\
\text { progressive collapse. }\end{array}$ & $\begin{array}{l}\text { Refer to ASCE } 7 . \\
\text { Notionally remove } \\
\text { key members one at a } \\
\text { time and assess } \\
\text { stability of structure } \\
\text { under D + } 0.25 \mathrm{~L}+ \\
0.2 \mathrm{~W}_{\mathrm{n}} \text {. }\end{array}$ & $\begin{array}{l}\text { Bridge local damage. } \\
\text { Allow large } \\
\text { deformations and } \\
\text { membrane effect. } \\
\text { Apply plasticity and } \\
\text { ultimate strength } \\
\text { theory. }\end{array}$ \\
\hline $\begin{array}{l}\text { Direct } \\
\text { Design: Key } \\
\text { Elements }\end{array}$ & $\begin{array}{l}\text { Design all exterior } \\
\text { columns between } 1 \text { st } \\
\text { and } 3 \text { rd floors, and all } \\
\text { columns in public } \\
\text { spaces, for an } \\
\text { additional story height } \\
\text { of unsupported length. }\end{array}$ & $\begin{array}{l}\text { Check key members } \\
\text { and connections for a } \\
\text { pressure of } 5 \text { psi } \\
(34 \mathrm{kPa}) .\end{array}$ & $\begin{array}{l}\text { Harden locally key } \\
\text { elements, transfer } \\
\text { structures, and column } \\
\text { connections that } \\
\text { support transfer } \\
\text { structures. Detail to } \\
\text { resist load reversals. }\end{array}$ & \\
\hline $\begin{array}{l}\text { Indirect } \\
\text { Design: Ties }\end{array}$ & $\begin{array}{l}\text { Use redundant lateral } \\
\text { and vertical elements } \\
\text { and detail for } \\
\text { continuity and } \\
\text { ductility. Design } \\
\text { against load reversal } \\
\text { and shear failure. }\end{array}$ & & $\begin{array}{l}\text { Tie building together. } \\
\text { Transfer structures } \\
\text { shall be continuous } \\
\text { over several supports. } \\
\text { Column connections } \\
\text { that support transfer } \\
\text { structures shall be full } \\
\text { moment connections } \\
\text { capable of providing } \\
\text { sustained strength } \\
\text { despite inelastic } \\
\text { deformations. }\end{array}$ & $\begin{array}{l}\text { Design floors to resist } \\
\text { falling debris; floors } \\
\text { and bearing walls } \\
\text { shall be able to } \\
\text { transfer a tension of } \\
20 \mathrm{kN} / \mathrm{m}(1400 \mathrm{lb} / \mathrm{ft}) \\
\text { and a shear of } \\
20 \mathrm{kN} / \mathrm{m} \text {. }\end{array}$ \\
\hline
\end{tabular}




\section{A.4.5 Loads for Design to Resist Progressive Collapse}

Of particular relevance to the mitigation of progressive collapse are provisions for accidental loads, lateral loads in zones where seismic and wind forces do not govern the design, and combinations of loads for which the building stability should be checked.

Accidental loads - The pressure due to the 1968 gas explosion at Ronan Point was estimated to be between $14 \mathrm{kPa}(2 \mathrm{psi})$ and $83 \mathrm{kPa}(12 \mathrm{psi})$. An accidental pressure of $34 \mathrm{kPa}$ (5 psi) has been adopted by the British Standards since 1970. In practice, it is used to determine a notional load applied to key elements, resulting in more robust construction against gas explosions and other loads as well.

Research has shown, however, that this pressure may be too high. Ellingwood (1981) reports that, for a typical residential apartment and venting, the mean maximum pressure generated by a gas explosion is about $13.2 \mathrm{kPa}(1.9 \mathrm{psi})$, with a standard deviation of $3 \mathrm{kPa}(0.44 \mathrm{psi})$. The 90 percentile pressure is $17.3 \mathrm{kPa}$ (2.5 psi). Similarly, Ellis and Currie (1998) state that, "for appraisal of structures specifically for the event of a gas explosion, $17 \mathrm{kPa}$ is considered to be an overpressure that will act on all surfaces of the room simultaneously." This statement is based on tests in housing units, where a maximum pressure of 13 $\mathrm{kPa}$ has been measured in gas explosions in a single room. Multi-room, cascading explosions, usually due to piped gas, can produce pressures up to $90 \mathrm{kPa}$ (13 psi), whereas the smallest canister of aerosol exploding in a single room has recorded a pressure of $9 \mathrm{kPa}(1.3 \mathrm{psi})$. The draft Eurocode 2003 allows a smaller accidental pressure, $20 \mathrm{kPa}(3 \mathrm{psi})$, or a value based on calculations that account for room volume, the presence of vents, the strength of windows, and less importantly, the properties of the gas mixture (Alexander and Hambly, 1970).

Where the provision of natural gas is impossible, an unspecified reduced value of equivalent static pressure is permitted. (Ellis and Currie, 1998). The 1996 version of the Institute of Structural Engineers, London, "Appraisal of Existing Structures" recommends that, for large panel system dwellings, "if it is certain that such a building will remain without piped gas supply, the loading for the assessment of key elements ... may be taken as $17 \mathrm{kPa}$."

Gas explosions tend to be slow, with the duration of the initial overpressure of the order of $0.1 \mathrm{~s}$, much slower than the natural periods of structural elements. Thus, a static equivalent pressure is justified. In contrast, high explosives can cause much faster explosions, of the order of $0.001 \mathrm{~s}$, where dynamic, impulsive, and strain rate effects may be important. British tests of $2.4 \mathrm{~m}(8 \mathrm{ft})$ square, reinforced concrete panels under gas explosion or static loading showed similar failure mechanisms, but with the static tests producing significantly lower stiffness and strength (Ellis and Currie, 1998).

Many standards, however, do not define values for accidental loads, but leave them to the designer. After all, the inquiry on the Ronan Point disaster stated that there was only a risk of $3.5 \times 10^{-6} / \mathrm{yr}$ of structural damage due to an urban gas explosion (Ferahian, 1972).

Information is available on the relationships between charge mass, distance, and blast pressure. Technical Manual TM- 5-1300 (Army 1990) contains curves that provide air blast parameters (pressure and duration) as a function of distance for elevated (air burst) charges and ground (surface burst) charges. The Center for Chemical Process Safety provides guidelines on pressures resulting from vapor cloud explosions, flash fires, and boiling liquid expanding vapor explosions (CCPS 1994). The SEI/ASCE Blast Protection of Buildings Standards Committee is developing a standard on blast protection of buildings. 
Lateral loads: The PCI Committee on Precast Concrete Bearing Wall Buildings (1976) recommended a minimum total design force equal to $2 \%$ of the service dead load (weight of superstructure plus superimposed dead load) applied as a lateral load at each floor over the height of structure. The structure should be analyzed for strength and stability for this horizontal load combined with the service dead (vertical) load. The current British Standards on concrete (BS 8110-1:1997) and masonry (BS 56281:1992) recommend that buildings should be designed to resist a uniformly distributed load equal to $1.5 \%$ of the characteristic dead weight of the structure. (For comparison, Ronan Point was designed for a substandard wind pressure of 570 Pa or 12 psf [Firnkas, 1969]).

Load combinations: The loads to be combined reflect the small probability of a joint occurrence of the accidental load and the design live, snow, or wind loads. Table A-4 compares load combinations from various standards.

Table A-4. Load combinations for progressive collapse analysis

\begin{tabular}{|c|c|c|}
\hline Standards & Load combinations after notional member removal & Accidental load \\
\hline BS & $(1 \pm 0.5) D+L / 3+W_{n} / 3$ & $34 \mathrm{kPa}(5 \mathrm{psi})$ \\
\hline Eurocode $2003 \mathrm{draft}$ & & $20 \mathrm{kPa}(3 \mathrm{psi})$ \\
\hline Canada 1977 & $D+L / 3+W_{n} / 3$ & \\
\hline ASCE 7-98, 02, 05 & $\begin{array}{l}(0.9 \text { or } 1.2) D+(0.5 L \text { or } 0.2 S)+0.2 W_{n} \text { (with member removal) } \\
1.2 D+A_{k}+(0.5 L \text { or } 0.2 S) \quad \text { (specific local resistance method) } \\
(0.9 \text { or } 1.2) D+A_{k}+0.2 W_{n} \quad \text { (specific local resistance method) }\end{array}$ & $A_{\mathrm{k}}$ \\
\hline DOD UFC 4-010-01 & $D+0.5 \mathrm{~L} \quad$ net floor uplift & \\
\hline DOD UFC 4-023-03 & $\begin{array}{l}D+0.5 L \quad \text { net floor uplift } \\
(0.9 \text { or } 1.2) D+(0.5 L \text { or } 0.2 S)+0.2 W_{n} \text { (nonlinear dynamic analysis) } \\
2.0[(0.9 \text { or } 1.2) D+(0.5 L \text { or } 0.2 S)]+0.2 \mathrm{~W} \text { (static analysis) }\end{array}$ & \\
\hline NYC 1998, 2003 & $2 D+0.25 L+0.2 W_{n}$ & \\
\hline GSA & $\begin{array}{ll}2(D+0.25 L) & \text { static analysis } \\
D+0.25 L & \text { dynamic analysis }\end{array}$ & \\
\hline Sweden & $G_{\mathrm{k}}+\Psi Q_{\mathrm{k}}$ & $Q_{\mathrm{ak}}$ \\
\hline
\end{tabular}

$D, L, W_{n}, S=$ dead, live, wind and snow loads;

$Q_{\mathrm{ak}}=$ characteristic value of accidental action;

$G_{k}, Q_{k}=$ characteristic dead, imposed loads per unit area of the floor or roof; $\Psi$ is a load reduction factor which, when multiplied with $Q_{\mathrm{k}}$, gives the frequent value of a variable action.

$A_{\mathrm{k}}=$ extraordinary load.

Debris falling from a damaged floor above justifies doubling the dead load " $2 \mathrm{D}$ " in some of the load combinations above. The ability to resist debris loading, including an impact factor, is crucial to limiting the propagation of damage. ${ }^{5}$ In this respect, careful consideration must be given to the shear strength at the supports of large panel buildings.

${ }^{5}$ Risk of airplane impact: In light of the unique and unforeseen collapse of the World Trade Center towers on 9/11/2001, it is worth recalling that the risk of airplane impact on buildings located more than three miles from the end of a runway was estimated to be negligible $\left(10^{-8}\right.$ per year, Somes, 1973). The following exchange on The Stability of Modern Buildings (The Structural Engineer, London, v. 50, no. 7, July 1972, p. 286) is also of interest: "Rowe: If in this context one considers a jumbo jet or other large aircraft then the consequences of the impact on the building are outweighed by those associated with the loss of the aircraft and its passengers and for which insurance 
Following are detailed load provisions from various building standards:

BS 6399-1:1996, Loading for Buildings; Section 12. Accidental Load on Key or Protected Elements

"When an accidental load is required for a key or protected element approach to design, that load shall be taken as $34 \mathrm{kN} / \mathrm{m}^{2}$ (5 psi)."

BS 5950-1:2000, Structural Use of Steelwork in Building, Section 2.4.5 Structural IntegrityFollowing notional member removal, the standard recommends checking building stability for:

$$
D+\frac{L}{3}+\frac{W_{n}}{3}
$$

where

$D=$ dead load,

$L=$ live or imposed load, and

$W_{n}=$ wind load,

except for storage buildings, where $1.0 \mathrm{~L}$ should be used.

A load factor of 1.05 should be applied, except when $D$ provides restoring moments, in which case a load factor of 0.9 should be applied.

BS 8110-1:1997, Structural Use of Concrete, Sections 2.4.3.2 and 3.1.4.2-The provisions are similar to those of BS 5950-1 for steel. In addition, for the purpose of checking structural integrity, at each floor or roof level, the standards recommend to simultaneously apply a horizontal load equal to $1.5 \%$ of the characteristic dead weight of the structure between mid-height of the story below and mid-height of the story above or roof level.

BS 5628-1:1992, Code of Practice for Use of Masonry, Section 22 -For structural integrity, the standard recommends that buildings should be designed to resist a uniformly distributed load equal to $1.5 \%$ of the total characteristic dead load above any level. For checking the strength of a damaged structure, the following loads should be combined:

- $\quad$ Design dead load $=0.95 D$ or $1.05 D$,

- Design imposed load $=0.35 \mathrm{~L}$, except for storage buildings, where $1.05 \mathrm{~L}$ should be used,

- $\quad$ Design wind load $=0.35 W_{n}$.

Eurocode 1 - Section 2 - Actions on Structures, Part 1 - Basis of Design (CEN 250 1994) (pre EN 2002)-For Category 2 buildings, the standard recommends the use of an accidental equivalent static

cover, of some type, will be available. Would Mr. Creasy agree, therefore, that in this, and other instances, society at large should be informed of the risks and also that the structural engineer can do little to reduce them?"

"Creasy: With regard to the crash of a jumbo jet, the community appears to accept that an accident to a critical component of an aeroplane often leads to the total destruction of that aeroplane. It would probably accept the destruction of the building provided the whole building was enveloped by the crashed plane. I would not think it reasonable that quite local damage to a building caused by the impact of a falling component from an aeroplane should lead to the total collapse of the whole structure." 
pressure of $20 \mathrm{kPa}$ ( $3 \mathrm{psi}$ ), or calculated by a formula. Where the provision of natural gas is impossible, an unspecified reduced value is permissible. For Category 3 buildings, some guidance is given, but much is left to the experience of the designer.

National Research Council of Canada, National Building Code of Canada 1977, C4.1.1.8 - The standard recommends applying $D+L / 3+W_{n} / 3$ to the damaged structure to check its structural integrity.

American Society of Civil Engineers (1998), ASCE 7-98, Section C2.5-The standard recommends checking the capacity of the structure after notional removal of load-bearing element for

$$
(0.9 \text { or } 1.2) D+(0.5 L \text { or } 0.2 S)+0.2 W_{n}
$$

where $S$ is the snow load. It is also recommended to check the capacity of the structure or element to withstand extraordinary load $A_{k}$ under

$$
1.2 D+A_{k}+(0.5 L \text { or } 0.2 S) \text { and }(0.9 \text { or } 1.2) D+A_{k}+0.2 W_{n} \text {. }
$$

\section{American Society of Civil Engineers (2002), ASCE 7-02, Commentary Section C2.5, Load Combinations for Extraordinary Events - The following is excerpted directly from the document.}

"Commentary C2.5 explains the basis for the load combinations that the designer should use if the "Direct Design" alternative in Commentary $\mathrm{C} 1.4$ is selected. If the authority having jurisdiction requires the "Indirect Design" alternative, that authority may use these load requirements as one basis for determining minimum required levels of strength, continuity, and ductility. Generally, extraordinary events with a probability of occurrence in the range $10^{-6}$ to $10^{-4} / \mathrm{yr}$ or greater should be identified, and measures should be taken to ensure that the performance of key load-bearing structural systems and components is sufficient to withstand such events."

"Extraordinary events arise from extraordinary service or environmental conditions that traditionally are not considered explicitly in design of ordinary buildings and structures. Such events are characterized by a low probability of occurrence and usually a short duration. Few buildings are ever exposed to such events and statistical data to describe their magnitude and structural effects are rarely available. Included in the category of extraordinary events would be fire, explosions of volatile liquids or natural gas in building service systems, sabotage, vehicular impact, misuse by building occupants, subsidence (not settlement) of subsoil, and tornadoes. The occurrence of any of these events is likely to lead to structural damage or failure. If the structure is not properly designed and detailed, this local failure may initiate a chain reaction of failures that propagates throughout a major portion of the structure and leads to a potentially catastrophic collapse. Approximately $15 \%$ to $20 \%$ of building collapses occur in this way (Allen and Schriever 1973). Although all buildings are susceptible to progressive failures in varying degrees, types of construction that lack inherent continuity and ductility are particularly vulnerable (Breen and Siess 1979; Taylor 1975)." 
"Specific design provisions to control the effect of extraordinary loads and risk of progressive failure can be developed with a probabilistic basis (Ellingwood and Leyendecker 1978; Ellingwood and Corotis 1991). One can either attempt to reduce the likelihood of the extraordinary event or design the structure to withstand or absorb damage from the event if it occurs. Let $\mathrm{F}$ be the event of failure and $\mathrm{A}$ be the event that a structurally damaging event occurs. The probability of failure due to event $\mathrm{A}$ is

$$
P_{f}=P(F \mid A) P(A)
$$

in which $P(F \mid A)$ is the conditional probability of failure of a damaged structure and $P(A)$ is the probability of occurrence of event $A$. The separation of $P(F \mid A)$ and $P(A)$ allows one to focus on strategies for reducing risk. $P(A)$ depends on siting, controlling the use of hazardous substances, limiting access, and other actions that are essentially independent of structural design. In contrast, $P(F \mid A)$ depends on structural design measures ranging from minimum provisions for continuity to a complete post-damage structural evaluation."

"The probability, $P(A)$, depends on the specific hazard. Limited data for severe fires, gas explosions, bomb explosions, and vehicular collisions indicate that the event probability depends on building size, measured in dwelling units or square footage, and ranges from about $0.23 \times 10^{-6}$ /dwelling unit/year to about $7.8 \times 10^{-6} /$ dwelling unit/year (CIB 1983; Ellingwood and Leyendecker 1978). Thus, the probability that a building structure is affected may depend on the number of dwelling units (or square footage) in the building. If one were to set the conditional limit state probability $P(F \mid A)=0.1 / \mathrm{yr}-0.2 / \mathrm{yr}$, however, the annual probability of structural failure from Eq. C2.5-1 would be on the order of $10^{-7}$ to $10^{-6}$, placing the risk in the low-magnitude background along with risks from rare accidents (Wilson and Crouch 1987)."

"Design requirements corresponding to this desired $P(F \mid A)=0.1-0.2$ can be developed using first-order reliability analysis if the limit state function describing structural behavior is available (Ellingwood et al. 1982; Galambos et al. 1982). As an alternative, one can leave material and structural behavior considerations to the responsible material specifications and consider only the load combination aspect of the safety check, which is more straightforward."

"For checking a structure to determine its residual load-carrying capacity following occurrence of a damaging extraordinary event, selected loadbearing elements should be notionally removed and the capacity of the remaining structure evaluated using the following load combination:

$$
(0.9 \text { or } 1.2) D+(0.5 L \text { or } 0.2 S)+0.2 W
$$

For checking the capacity of a structure or structural element to withstand the effect of an extraordinary event, the following load combinations should be used: 


$$
\begin{array}{ll}
1.2 D+A_{k}+(0.5 L \text { or } 0.2 S) & \text { (Eq. C2-3) } \\
(0.9 \text { or } 1.2) D+A_{k}+0.2 W & \text { (Eq. C2-4)" }
\end{array}
$$

"The value of the load effect resulting from extraordinary event $A$ used in design is denoted as $A_{k}$. Only limited data are available to define the frequency distribution of the load, and $A_{k}$ must be specified by the authority having jurisdiction (Burnett 1975). The uncertainty in the load due to the extraordinary event is encompassed in the selection of a conservative $A_{k}$ and thus the load factor $A_{k}$ is set equal to 1.0 , as is done in the earthquake load combinations in Section 2.3. Load factors less than 1.0 on the companion actions reflect the small probability of a joint occurrence of the extraordinary load and the design live, snow, or wind load. The companion action $0.5 \mathrm{~L}$ corresponds, approximately, to the mean of the yearly maximum load (Chalk and Corotis 1980). Companion actions $0.2 S$ and $0.2 \mathrm{~W}$ are interpreted similarly. A similar set of load combinations for extraordinary events appears in (Eurocode 1990)."

\section{American Society of Civil Engineers (2005), ASCE 7-05, Commentary C2.5, Load Combinations for Extraordinary Events-The discussion is essentially the same as the 2002 version, however, the following sentences were added to explain the purpose of including a lateral load of " $0.2 \mathrm{~W}$ " in an alternate load path analysis.}

"The term $0.2 \mathrm{~W}$ in these combinations is intended to ensure that the lateral stability of the structure is checked. Some recent standards require the stability of the structure to be checked by imposing a small notional lateral load equal in magnitude to $0.002 \Sigma P$ at each floor level, in which $\Sigma P$ is the cumulative gravity force due to the summation of dead and live loads acting on the story above that level. If such a stability check is performed, $0.2 \mathrm{~W}$ need not be considered in combinations $\mathrm{C} 2.5-2$ and C2.5-4."

Department of Defense (2002) Unified Facilities Criteria (UFC) 4-010-01, Minimum Antiterrorism Standards for Buildings - According to these criteria, floors are to be designed to withstand a net uplift equal to Dead Load + 0.5 Live Load.

\section{Department of Defense (2005) Unified Facilities Criteria (UFC) 4-023-03, Design of Buildings to} Resist Progressive Collapse - In addition to the uplift requirements of UFC 4-010-01, load combinations are specified for alternate load path analyses. The specific load combination depends on the analytical method that is used:

- For linear and nonlinear static analysis: $2.0[(0.9$ or 1.2$) D+(0.5 L$ or $0.2 S)]+0.2 W_{n}$

- For nonlinear dynamic analysis: $(0.9$ or 1.2$) D+(0.5 L$ or $0.2 S)+0.2 W_{n}$

The following procedures are given for the loads to be applied when members are shown to have failed in the course of an alternate load path analysis:

“3-2.4.3 Loads Associated with Failed Elements. As discussed later, the internal forces or deformation in a structural element or connection 
may be shown to exceed the acceptability criteria. If so, the element is considered to be failed and is removed from the model."

"For a Nonlinear Dynamic analysis, double the loads from the failed element to account for impact and apply them instantaneously to the section of the structure directly below the failed element, before the analysis continues. Apply the loads from the area supported by the failed element to an area equal to or smaller than the area from which they originated."

"For a Linear or Nonlinear Static analysis, if the loads on the failed element are already doubled as shown in Section 3-2.4.2, then the loads from the failed element are applied to the section of the structure directly below the failed element, before the analysis is re-run or continued. If the loads on the failed element are not doubled, then double them and apply them to the section of the structure directly below the failed element, before the analysis is re-run or continued. In both cases, apply the loads from the area supported by the failed element to an area equal to or smaller than the area from which they originated."

New York City Building Code (1998), Chapter 18, Resistance to Progressive Collapse Under Extreme Local Loads-The New York City Building Code specifies checking a building for progressive collapse under the load combination $2 D+0.25 L+0.2 W_{n}$.

New York City Department of Buildings, World Trade Center Building Code Task Force (2003) The draft progressive collapse guidelines recommend that, after removal of key members one at a time, structural stability should be assessed under the load combination $2 D+0.25 L+0.2 W_{n}$.

General Services Administration (GSA), Progressive Collapse Analysis and Design Guidelines for New Federal Office Buildings and Major Modernization Projects (2003) - To assess the potential for progressive collapse, the GSA guidelines stipulate the use of the following downward, vertical loads:

- For static analysis: $\quad 2(D+0.25 L)$

- For dynamic analysis: $\quad \mathrm{D}+0.25 \mathrm{~L}$

Swedish Board of Housing, Building and Planning (Boverket), Handbook on Vibrations, Induced Deformations and Accidental Loads (2004); Section 4.5 Simplified conditions for normal residential houses and office buildings - This Swedish standard recommends checking the stability of the building for certain load combinations, and ensuring that specified normal and shear forces can be transferred between various parts of the structure.

"If both conditions (a) and (b) described below are fulfilled, one may consider that the building has been designed and dimensioned such that primary damage does not lead to progressive collapse."

\section{“Condition a}

Buildings of 4 stories: The stability of the building is checked after primary damage for the actual load combination (BKR 94, 2:321, load combination 6)." 
"In Table b, the characteristic value $G_{\mathrm{k}}$ of a permanent action shall be the value that has a probability of $50 \%$ of not being exceeded. The characteristic value $Q_{\mathrm{k}}$ of a variable action shall be the value that has a probability of $98 \%$ of not being exceeded at any time during one year. The frequent value of a variable action $\Psi Q_{\mathrm{k}}$ shall be determined in view of the variation of the action in time and the coefficient of variation of the action. The characteristic value $Q_{\mathrm{ak}}$ of an accidental action shall be determined in view of the nature of the action. The design value of an action is:

$$
F_{\mathrm{d}}=\gamma_{\mathrm{f}} F_{\mathrm{k}} \quad \text { or } \quad F_{\mathrm{d}}=\gamma_{\mathrm{f}} \Psi F_{\mathrm{k}}
$$

where $F_{\mathrm{k}}$ is the characteristic value of an action, $\Psi$ is a load reduction factor which, when multiplied with $F_{\mathrm{k}}$, gives the frequent value of an action, and $\gamma_{\mathrm{f}}$ is a partial factor according to subsection 2:321. The product $\Psi F_{\mathrm{k}}$ appears in the combination of actions."

"Table b. Prescribed combinations of actions 5-7 associated with the partial factor $\gamma_{\mathrm{f}}$ and with the values of actions for the ultimate limit state in conjunction with accidental action, progressive collapse or fire.

\begin{tabular}{|l|c|c|c|}
\hline \multirow{2}{*}{ Action } & \multicolumn{3}{|c|}{ Combination of actions } \\
\cline { 2 - 4 } & $\mathbf{5}$ & $\mathbf{6}$ & $\mathbf{7}$ \\
\hline $\begin{array}{l}\text { Permanent action } \\
\text { Weight of elements of structure, soil } \\
\text { and water below mean water level, } G_{\mathrm{k}}\end{array}$ & $1.0 G_{\mathrm{k}}$ & $1.0 G_{\mathrm{k}}$ & $1.0 G_{\mathrm{k}}$ \\
\hline $\begin{array}{l}\text { Variable action: All variable loads } \mathrm{P} Q_{\mathrm{k}} \\
\text { for which } \Psi \geq 0.5\end{array}$ & $1.0 \mathrm{P} Q_{\mathrm{k}}$ & $!$ & $1.0 \mathrm{P} Q_{\mathrm{k}}$ \\
for which $\Psi \geq 0.25$ & & $1.0 \mathrm{P} Q_{\mathrm{k}}$ & $!$ \\
\hline $\begin{array}{l}\text { Accidental action } \\
\text { One accidental action } Q_{\mathrm{ak}}\end{array}$ & $1.0 Q_{\mathrm{ak}}$ & $!$ & $!$ \\
Action in consequence of fire $Q_{\mathrm{ak}}$ & $!$ & $!$ & $1.0 Q_{\mathrm{ak}}$ \\
\hline
\end{tabular}

(BFS 1998:39)"

"General recommendation: Combination of actions 5 should normally be applied only for elements of structure in Safety Class 3. Combination of actions 6 shall be applied, after local damage, for the other part of the structure. The local damage can also occur as a consequence of fire. Combination of actions 7 which applies in case of fire comprises a thermal action $Q_{\mathrm{ak}}$ which is determined either in accordance with the standard fire curve in Swedish Standard SIS 024820 or on the basis of the energy balance method and the fire load density concerned."

"Buildings of 5 to 16 stories: The condition required for 4-story buildings has to be fulfilled. Furthermore, one should prove that the zone of primary damage could be bridged over by alternate load paths, see last paragraph of Section 4.4." 
"Buildings of more than 16 stories: Necessary measures are to be determined based the actual conditions. There are reasons to assume that the primary damage is more extensive than assumed in Section 4.2.2."

\section{“Condition b}

To avoid progressive collapse brought about by successive failure of concrete floor structures loaded by falling debris:

- The different parts of the floor structure-e.g., prefabricated elements and their joints - should be able to transfer two forces, a tensile force $\mathrm{N}=20 \mathrm{kN} / \mathrm{m}(1400 \mathrm{lb} / \mathrm{ft})$ and a shear force $\mathrm{T}=20 \mathrm{kN} / \mathrm{m}$. These forces are normal to each other and lie on the floor plane, see Figure (e).

- The different parts of the bearing walls should be able to transfer two forces, a tensile force $\mathrm{N}=20 \mathrm{kN} / \mathrm{m}$ and a shear force $\mathrm{T}=$ $20 \mathrm{kN} / \mathrm{m}$. These forces are normal to each other and lie on the wall plane, see Figure (e).

- The support between floor structure and wall should be able to transfer a tensile force $\mathrm{N}=20 \mathrm{kN} / \mathrm{m}$ and a shear force $\mathrm{T}=20$ $\mathrm{kN} / \mathrm{m}$, see Figure (e).

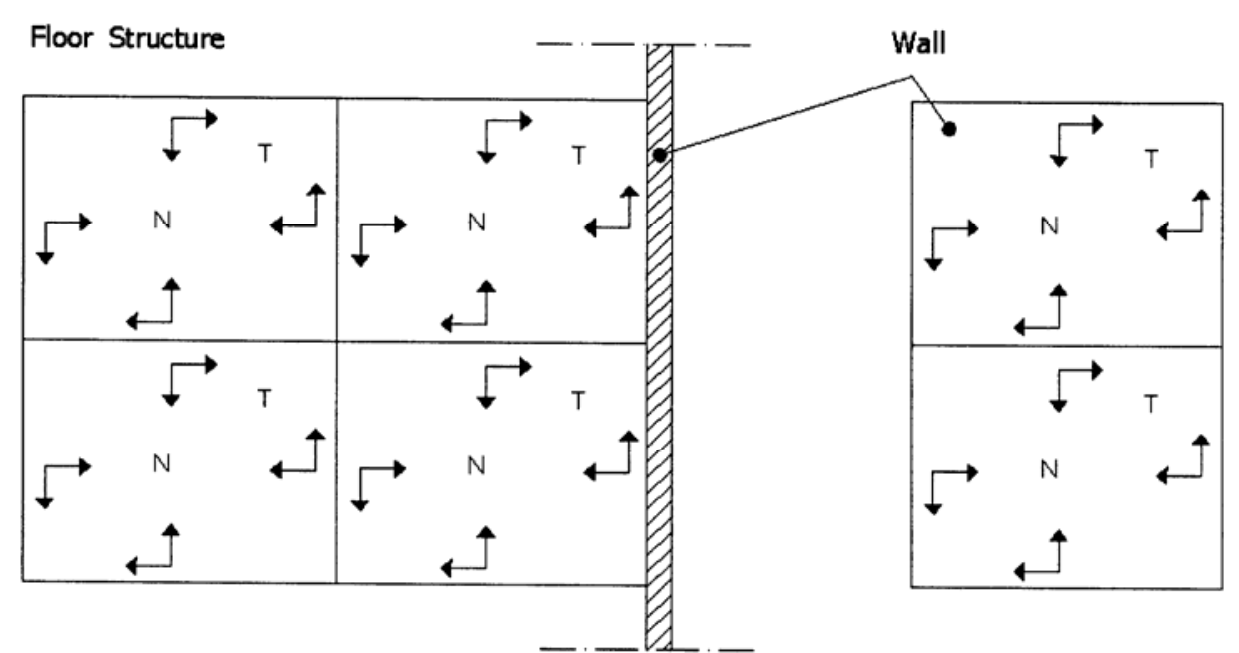

Figure (e). Shear and normal forces in floor structure and wall”

"For other types of (i.e., non-concrete) floor structures the forces $\mathrm{N}=\mathrm{T}=$ $20 \mathrm{kN} / \mathrm{m}$ can be proportioned to (dead weight of floor structure + usual live load). In this respect, the dead weight of a concrete floor structure can be set to $4 \mathrm{kN} / \mathrm{m}^{2}$ (about $85 \mathrm{psf}$ )."

"Conditions similar to the above three conditions should also apply to the interaction between slabs and girders of floor systems and also to the interaction between girders and columns or walls. The tie force between a girder and a column can, however, be limited to $150 \mathrm{kN}$ (34 kips)." 


\section{“4.6 Example}

Figure (f) shows a floor structure consisting of prefabricated concrete elements. The tying forces required according to Section 4.5 are sketched in the figure and their magnitudes are given in Table (a)."

"Notice that the force F6 that couples a saddlebeam to a column shall be able to be transferred to the column, but the column need not be dimensioned for that force."
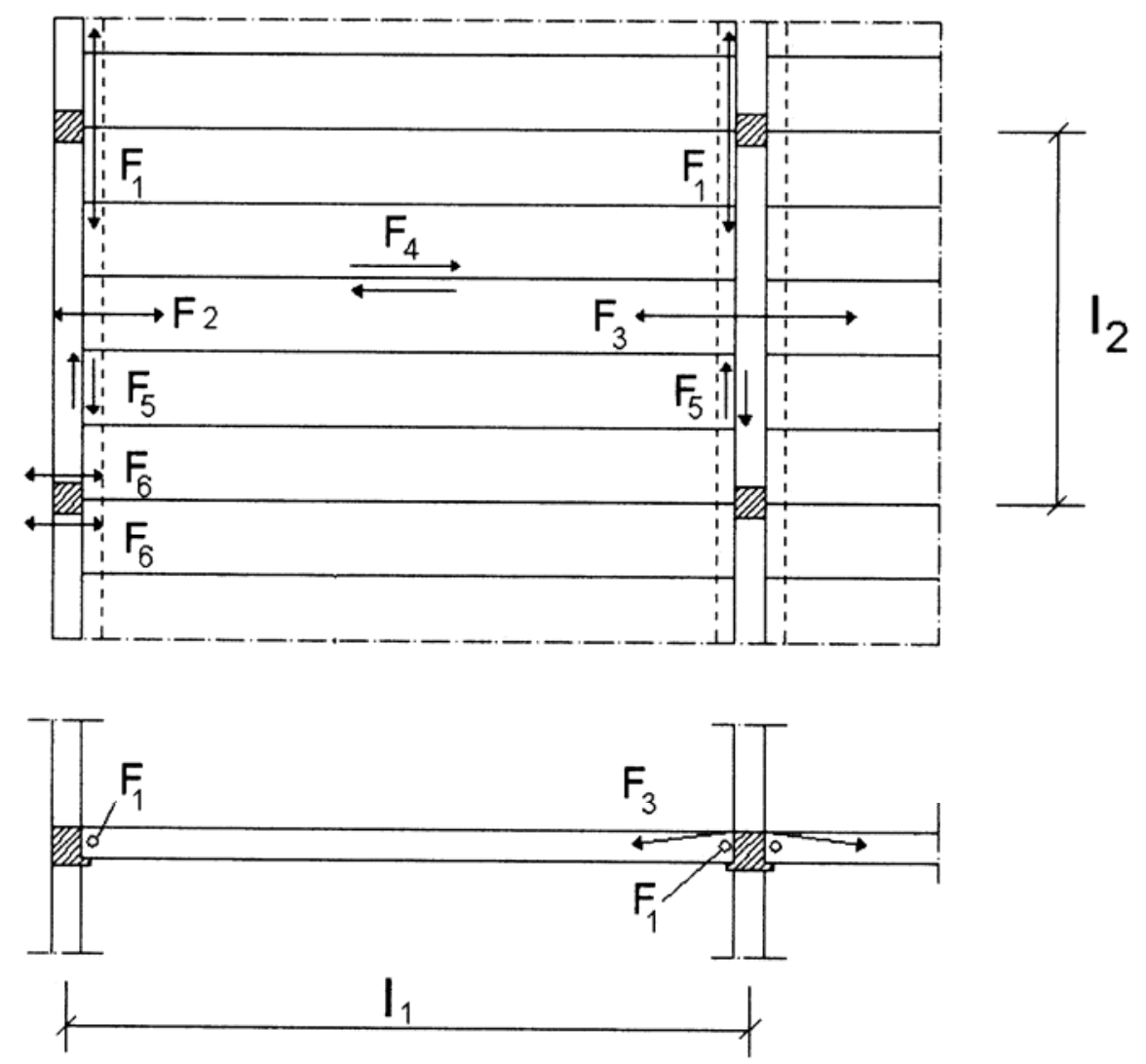

"Figure (f) Connection forces in floor structure of prefabricated concrete elements according to $\S 4.5$ ” 
Table a. Summary and explanations of forces in Figure (f)

\begin{tabular}{|l|l|l|}
\hline Forces & Magnitude & Comments \\
\hline $\begin{array}{l}\text { Tensile force normal to } \\
\text { floor slabs }\end{array}$ & $\mathrm{F}_{1}=20 l_{1} / 2 \mathrm{kN}$ & $\begin{array}{l}\text { Can be concentrated as tensile bands along the } \\
\text { slab supports, consisting of reinforcement in } \\
\text { concrete joints cast in place or in the floor } \\
\text { beams (Note 1). }\end{array}$ \\
\hline $\begin{array}{l}\text { Connection between } \\
\text { slabs and façade beam }\end{array}$ & $\mathrm{F}_{2}=20 \mathrm{kN} / \mathrm{m}$ & $\begin{array}{l}\text { Corresponding force within slabs are carried by } \\
\text { existing longitudinal reinforcement }\end{array}$ \\
\hline $\begin{array}{l}\text { Connection of slabs } \\
\text { over a middle support }\end{array}$ & $\mathrm{F}_{3}=20 \mathrm{kN} / \mathrm{m}$ & $\begin{array}{l}\text { In a hollow core floor system the reinforcement } \\
\text { can be placed in the longitudinal joints between } \\
\text { the slabs. }\end{array}$ \\
\hline $\begin{array}{l}\text { Shear forces in } \\
\text { longitudinal joints } \\
\text { between slabs }\end{array}$ & $\mathrm{F}_{4}=20 \mathrm{kN} / \mathrm{m}$ & $\begin{array}{l}\text { This force is normally transferred through } \\
\text { friction with } F_{1} \text { as a "clamping force" (Notes } 2, \\
\text { 3) }\end{array}$ \\
\hline $\begin{array}{l}\text { Shear force in joints } \\
\text { between slabs and beam }\end{array}$ & $\mathrm{F}_{5}=20 \mathrm{kN} / \mathrm{m}$ & $\begin{array}{l}\text { This force is normally transferred through } \\
\text { friction. } F_{2} \text { or } F_{3} \text { act as a "clamping forces" } \\
\text { (Note 2) }\end{array}$ \\
\hline $\begin{array}{l}\text { Connection between } \\
\text { façade beam and } \\
\text { column }\end{array}$ & $\begin{array}{l}\mathrm{F}_{6}=20 l_{2} / 2 \\
\leq 150 \mathrm{kN}\end{array}$ & $\begin{array}{l}\text { Force at of each beam end perpendicular to the } \\
\text { façade. }\end{array}$ \\
\hline
\end{tabular}

Notes:

1. Beams on either side of a column are required to be tied together with force $F_{1}$.

2. If the joint surface is smooth, the corresponding "clamp forces" shall be at least equal to the values given in the table divided by 0.7 (cf. BBK 94, Equation 3.11.3a).

3. For hollow core slabs, it is usual to set an upper limit to the shear forces in the longitudinal joints. This is $0.10 \mathrm{MPa}$ to $0.15 \mathrm{MPa}$, depending on the properties of the joint surfaces, and calculated over the joint height. Example: Joint height $=200 \mathrm{~mm}$, upper limit $=0.10 \mathrm{MPa}, F_{4}=20 \mathrm{~N} / \mathrm{mm}=20 \mathrm{kN} / \mathrm{m}$."

\section{A.4.6 Ties}

To limit structural damage due to accidental loads, and to ensure continuity and development of alternate load paths, some building standards recommend that buildings susceptible to progressive collapse should be effectively tied together at each principal floor level. The following should be provided: peripheral ties, internal ties, horizontal column or wall ties, and where required, vertical ties, particularly in panel buildings. Effective ties allow development of the following structural mechanisms, in case they are needed to bridge local failures:

- for wall panels: cantilever action, beam action, and vertical suspension;

- for floors: diaphragm action, and membrane action.

Membrane action: In the alternate path method, a robust structure should be able to bridge (perhaps string is a better verb) over a failed support. This requires continuous reinforcements that can act as ties, 
connections that can withstand the axial forces associated with catenary or membrane action, and slabs that can act in a direction where they are not normally stressed. Creasy (1972) proposed that the sag over the missing support be limited to $20 \%$ of an adjacent single span. The edge restraint of a "hanging" slab of an external bay may be provided by peripheral (fascia) beams to which the slab must be tied. It is important to reinforce a corner slab in two directions, so it can act as a cantilever over a diagonal if a corner column is lost. If the adjacent columns are lost instead, then the outer beams or edges of the slab should be able to transfer load to the corner column. Creasy (1972) proposed that the depth of the edge beams should not be less than $1 / 20$ of the span between adjacent columns. Walls that are as high as one story should be able to cantilever or bridge over a missing support if they are tied together in their plane at each floor level. Additionally, tying walls to floors will provide restraint against lateral buckling of the compression zone of a "hanging" wall.

Fintel and Schultz (1976) did not think that catenary or membrane action is suitable for American large panel construction because of the longer floor spans in the U.S. $(6 \mathrm{~m}$ to more than $12 \mathrm{~m}$, or $20 \mathrm{ft}$ to more than $40 \mathrm{ft}$ ), as opposed to $3 \mathrm{~m}$ to $5.5 \mathrm{~m}$ (10 ft to $18 \mathrm{ft}$ ) in Europe. Furthermore, U.S. large panel systems generally use hollow-core slabs produced in long beds and cut to length on site, thus precluding the protrusion of reinforcement necessary to ensure overlapping and continuity as in Europe. In addition, $12 \mathrm{~m}$ to $24 \mathrm{~m}$ ( $40 \mathrm{ft}$ to $80 \mathrm{ft}$ ) catenary spans would engender deflections of the order of a story height. Fintel and Schultz (1976), however, recognized the usefulness of longitudinal ties in enabling partial membrane action to inhibit progressive collapse from debris loading, should a vertical support become ineffective and undergo a limited displacement, say up to $0.6 \mathrm{~m}$ (24 in). If floor elements are well reinforced, ties need not be continuous over the entire floor span.

Action of ties: Transverse ties allow the development of cantilever action of wall panels above a lost support. If successive stories have sufficient shear strength, the entire wall assembly then acts as a monolithic cantilever; a more likely behavior is that some slip will occur within the vertical tie connections, making the damaged wall assembly less stiff than a monolithic one, but stiffer than the sum of individual panels. Walls can also develop beam action over an ineffective panel if sufficient tensile tie strength exists within the walls or in the transverse horizontal connections.

Ties between walls and floors serve to tie the load-bearing walls to the rest of the structure, and must be provided equally at the top and bottom of a wall panel. Longitudinal ties ensure that floors can develop membrane or catenary action upon the loss of vertical support, and thus minimize debris loading on the floor below. Horizontal ties also promote cantilever membrane action at the corners.

Vertical ties serve as tension tiebacks or suspenders for cantilever action over damaged zones, also make it harder for a wall to be knocked out, and provide clamping and dowel action in horizontal connections for shear friction. Because external walls are more vulnerable to abnormal loading than internal walls, Fintel and Schultz (1976) recommend greater vertical continuity in flank wall assemblies and placement of the flank wall vertical ties inside the peripheral ties. Ties and their connections must be designed to resist impact and load reversals.

Peripheral ties anchor internal ties and counteract the inherent weakness of corners by allowing membrane action in corner slabs. Peripheral and internal ties stiffen floor and roof membranes, thus making them more monolithic and enabling diaphragm action to resist torsion and non- uniform load distribution on the structure. Regarding peripheral tie forces, Breen (1980) remarked that "there is no clear rationale for determination of the appropriate level of force in the general case." Attendees of a 
major national workshop in Austin, Texas, on progressive collapse in 1975 recognized that substantial effort was still required to provide values for tie forces (Breen, 1980).

The PCI Committee on Precast Concrete Bearing Wall Buildings (1976) recommends the use of horizontal ties and, in structures over two stories in height, vertical ties also. Peripheral horizontal ties at each floor and roof level should be strong enough to develop diaphragm action, but not less than $71 \mathrm{kN}$ $(16000 \mathrm{lb})$. Longitudinal ties (in the direction of the floor span) should be capable of developing $2.5 \%$ of the service load on the wall, but not less than $22 \mathrm{kN} / \mathrm{m}(1500 \mathrm{lb} / \mathrm{ft})$ width measured perpendicular to the span. Similarly, transverse ties (perpendicular to the floor span) should be capable of resisting not less than $22 \mathrm{kN} / \mathrm{m}(1500 \mathrm{lb} / \mathrm{ft})$ width measured parallel to the span. Part of the tie strength may be provided by reinforcement designed primarily for flexure or temperature. For buildings over two stories in height, the Committee recommends the use of continuous vertical ties in all loadbearing and shear walls, from foundation to roof. These ties (two or more per wall) should be capable of resisting uplift, shear- friction forces, but not less than $44 \mathrm{kN} / \mathrm{m}(3000 \mathrm{lb} / \mathrm{ft})$ of wall. Breen (1980) notes that the level of tie forces is roughly equivalent to then current construction practice.

Table 5 compares the tie strength recommended by various standards. The Swedish Standards is similar to the Eurocode, and the New York City 2003 Draft is similar to the British Standards, but needs to be finalized. Interestingly, the GSA 2003 Guidelines make no mention of ties. 
Table A.5 Strength of ties

\begin{tabular}{|c|c|c|c|c|}
\hline BS Steel 2000 & BS Concrete 1997 & BS Masonry 1992 & Eurocode 2-2002 & PCI 1976 \\
\hline $\begin{array}{l}\text { Interior } \\
0.5\left(1.4 g_{k}+\right. \\
\left.1.6 q_{k}\right) s_{t} L \geq 75 \mathrm{kN}\end{array}$ & $\begin{array}{l}\text { Greater of } \\
\frac{g_{k}+q_{k}}{7.5} \frac{l_{r}}{5} F_{t} \\
\text { or } 1.0 F_{t}, \text { where } F_{t}= \\
\text { the lesser of }(20+4 \\
\left.n_{0}\right) \text { or } 60 \mathrm{kN}\end{array}$ & $\begin{array}{l}\text { Greater of } F_{t} \text { or } \\
\frac{G_{k}+Q_{k}}{7.5} \frac{L_{a}}{5} F_{t} \mathrm{kN} / \mathrm{m}\end{array}$ & $\begin{array}{l}F_{\text {tie, int }}=20 \mathrm{kN} / \mathrm{m} . \\
\text { For ties grouped at } \\
\text { beam lines: } \\
f_{\text {tie }}=\left(l_{1}+l_{2}\right) q_{4} / 2 \\
\leq q_{5} \text { where } \\
q_{4}=20 \mathrm{kN} / \mathrm{m} \text { and } q_{5} \\
=70 \mathrm{kN}\end{array}$ & $\begin{array}{l}\text { Horizontal } \\
\geq 22 \mathrm{kN} / \mathrm{m} \\
(1500 \mathrm{lb} / \mathrm{ft})\end{array}$ \\
\hline $\begin{array}{l}\text { Peripheral } \\
0.25\left(1.4 g_{k}+\right. \\
\left.1.6 q_{k}\right) s_{t} L \geq 75 \mathrm{kN}\end{array}$ & $1.0 F_{t}$ & $F_{t} \mathrm{kN}$ & $\begin{array}{l}F_{\text {tie, per }}=l_{i} q_{3} \leq q_{4} \\
\text { where } \\
q_{3}=10 \mathrm{kN} / \mathrm{m} \text { and } q_{4} \\
=70 \mathrm{kN}\end{array}$ & $\begin{array}{l}\geq 71 \mathrm{kN} \\
(16000 \mathrm{lb})\end{array}$ \\
\hline $\begin{array}{l}\text { Edge Columns } \\
1 \% \text { of the maximum } \\
\text { factored vertical dead } \\
\text { and imposed load in } \\
\text { the column adjacent to } \\
\text { that level or same as } \\
\text { for interior ties, } \\
\text { whichever is more. }\end{array}$ & $\begin{array}{l}\text { Greater of } \\
{\left[2.0 F_{t} \text { or }\right.} \\
\left(l_{s} / 2.5\right) F_{t} \text { if less], or } 3 \\
\% \text { of total ultimate } \\
\text { vertical load carried } \\
\text { by column at that level }\end{array}$ & $\begin{array}{l}\text { Lesser of } 2 F_{t} \text { or } \\
(h / 2.5) F_{t} \mathrm{kN}\end{array}$ & $F_{\text {tie, } \text { col }}=150 \mathrm{kN}$ & \\
\hline Corner Columns & $\begin{array}{l}\text { Same as for edge } \\
\text { columns, but in } 2 \\
\text { perpendicular } \\
\text { directions }\end{array}$ & & $\begin{array}{l}\text { Corner columns } \\
\text { should be tied in two } \\
\text { directions. }\end{array}$ & \\
\hline Walls & $\begin{array}{l}\text { Greater of } \\
{\left[2.0 F_{t} \text { or }\right.} \\
\left(l_{s} / 2.5\right) F_{t} \text { per meter if } \\
\text { less], or } \\
3 \% \text { of the total } \\
\text { ultimate vertical load } \\
\text { carried by the wall at } \\
\text { that level }\end{array}$ & $\begin{array}{l}\text { Lesser of } 2 F_{t} \text { or }(h \\
/ 2.5) F_{t} \mathrm{kN} / \mathrm{m}\end{array}$ & $\begin{array}{l}F_{\text {tie, façade }}= \\
20 \mathrm{kN} / \mathrm{m}\end{array}$ & $\begin{array}{l}2.5 \% \text { of service } \\
\text { load } \\
\text { on wall, but } \\
\geq 22 \mathrm{kN} / \mathrm{m} \\
(1500 \mathrm{lb} / \mathrm{ft})\end{array}$ \\
\hline $\begin{array}{l}\text { Vertical } \\
\text { Largest factored } \\
\text { vertical dead and } \\
\text { imposed load reaction } \\
\text { applied to the column } \\
\text { at a single floor level }\end{array}$ & $\begin{array}{l}\text { Maximum design } \\
\text { ultimate dead and } \\
\text { imposed load received } \\
\text { by the column from } \\
\text { any one story }\end{array}$ & $\begin{array}{l}\text { Greater of } \\
\frac{34 A}{8000}\left(\frac{h_{a}}{t}\right)^{2} \mathrm{~N} \text { per } \\
\text { column or } \\
100 \mathrm{kN} / \mathrm{m} \text { of wall } \\
\text { length }\end{array}$ & & $\begin{array}{l}\geq 44 \mathrm{kN} / \mathrm{m} \\
(3000 \mathrm{lb} / \mathrm{ft}) \\
\text { of wall }\end{array}$ \\
\hline
\end{tabular}

$A=$ horizontal cross sectional area of column or wall;

$g_{k}, G_{k}$, characteristic dead load per unit area of the floor or roof;

$h=$ clear story height;

$h_{a}=$ clear height of a column or wall between restraining surfaces;

$L=$ span;

$L_{a}=$ the lesser of: $5 h$, or the greatest distance in the direction of the tie, between the centers of columns or other vertical

loadbearing members, whether this distance is spanned by a single slab or by a system of beams and slabs;

$l_{i}=$ length of end span;

$l_{1}, l_{2}=$ span length of floor slabs on either side of the beam;

$n_{0}, N_{s}=$ number of stories including ground and basement;

$q_{k}, Q_{k}=$ characteristic imposed floor or roof load per unit area;

$s_{t}=$ mean transverse spacing of the ties adjacent to that being checked;

$t=$ thickness of column or wall. 
Following are detailed provisions from various building standards:

\section{BS 5950-1:2000, Structural Use of Steelwork in Building, Section 2.4.5 Structural Integrity-}

"All buildings should be effectively tied together at each principal floor level. Each column should be effectively held in position by means of horizontal ties in two directions, approximately at right angles, at each principal floor level supported by that column. Horizontal ties should similarly be provided at roof level."

"Unless the steel frame is fully continuous in at least one direction, all columns should be carried through at each beam-to-column connection."

Braced bays or other systems for resisting horizontal forces should be distributed throughout the building.

\section{Strength of ties:}

a) "General tying. Steel members acting as horizontal ties, and their end connections, should be capable of resisting the following factored tensile loads, which need not be considered as additive to other loads:

- for internal ties: $0.5\left(1.4 g_{k}+1.6 q_{k}\right) s_{t} L$ but not less than $75 \mathrm{kN}$ (17 kips);

- for edge ties: $0.25\left(1.4 g_{k}+1.6 q_{k}\right) s_{t} L$ but not less than $75 \mathrm{kN}$ (17 kips);

where $g_{k}$ is the specified dead load per unit area of the floor or roof; $L$ is the span; $q_{k}$ is the specified floor or roof load per unit area; and $s_{t}$ is the mean transverse spacing of the ties adjacent to that being checked.

b) Tying of edge columns: The horizontal ties anchoring the column nearest to the edges of a floor or roof should be capable of resisting a factored tensile load, acting perpendicular to the edge, equal to the greater of the load specified in a) or $1 \%$ of the maximum factored vertical dead and imposed load in the column adjacent to that level."

c) Continuity of columns: "All column splices should be capable of resisting a tensile force equal to the largest factored vertical dead and imposed load reaction applied to the column at a single floor level located between that column splice and the next column splice down."

The form of the tie strength formula can be derived in the following simplistic manner: due to failure of an interior column, a slab now bridges a double span $2 L$. Under the circumstances, the slab hangs as a catenary, with a maximum midspan deflection of $a$. Besides the usual vertical reaction, a horizontal reaction force $F$ must be provided to the slab at its ends, and equilibrium of moments at midspan gives:

$$
F a=\frac{w(2 L)^{2}}{8}
$$


where $w$ is the load per unit length. If the horizontal reaction is provided by ties, placed at a transverse spacing of $s$, then $w=q s$, where $q$ is the floor load. The moment equilibrium equation becomes:

$$
F=\frac{q s L}{2(a / L)}
$$

Creasy (1972) proposed that the sag over the missing support be limited to $a / L=0.20$, but Breen (1980) thought that the British calculations were based on $a / L=0.15$. If two-way action is available, then the tie

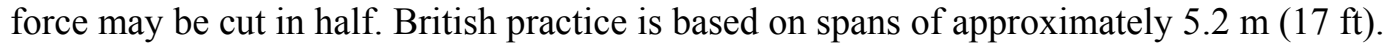

BS 8110-1:1997, Structural Use of Concrete, Section 3.12.3-The British standards recommend that:

- Peripheral, internal, vertical, and horizontal ties to columns and walls should be used.

- Reinforcement provided for other purposes may be regarded as forming part of, or the whole of these ties.

- Bar ties should be lapped, welded or mechanically joined. Ties intersecting at right angles should have an effective anchorage length beyond the other tie.

- "Ties should be distributed at each floor and roof level in two directions approximately at right angles. They should be effectively continuous and anchored to peripheral ties at each end. Generally, they should be spaced at less than $1.5 l_{r}$, where $l_{r}$ is the greater of the distances between the centers of the columns, frames or walls supporting any two adjacent floor spaces in the direction of the tie under consideration. In walls, they should be within $0.5 \mathrm{~m}$ (1.6 $\mathrm{ft}$ ) of the top or bottom of floor slabs."

- "Each column and each wall carrying vertical load should be tied continuously from the lowest to the highest level."

Strength of ties: Ties should be designed to resist a tension (in $\mathrm{kN} / \mathrm{m}$ width) equal to the greater of:
a) $\frac{g_{k}+q_{k}}{7.5} \frac{l_{r}}{5} F_{t}$
or b) $1.0 F_{t}$

where $g_{k}, q_{k}=$ characteristic dead load and imposed floor load, respectively $\left(\mathrm{kN} / \mathrm{m}^{2}\right)$,

$F_{t}=$ the lesser of $\left(20+4 n_{0}\right)$ or 60 , where $n_{0}=$ number of stories.

In inch-pound units: Ties should be designed to resist a tension (in $\mathrm{lb} / \mathrm{ft}$ width) equal to the greater of:

a) $\frac{g_{k}+q_{k}}{160} \frac{l_{r}}{16} F_{t} \quad$ or b) $1.0 F_{t}$

where $g_{k}, q_{k}=$ characteristic dead load and imposed floor load, respectively $\left(\mathrm{lb} / \mathrm{ft}^{2}\right)$,

$F_{t}=$ the lesser of $68.5\left(20+4 n_{0}\right)$ or 4100 , where $n_{0}=$ number of stories. 
Peripheral ties should be designed for a tension of $1.0 F_{t}$ in $\mathrm{kN}\left(3.3 F_{t}\right.$ in $\left.\mathrm{lb}\right)$ and located within $1.2 \mathrm{~m}$ $(4 \mathrm{ft})$ of building edge or within perimeter wall.

Horizontal ties to columns and walls: "Each external column and, if the peripheral tie is not located within the wall, every meter length of external wall carrying vertical load should be anchored or tied horizontally into the structure at each floor and roof level with a capacity of developing a force (in $\mathrm{kN}$ ) equal to the greater of:

a) $2.0 F_{t}$ [or $\left(l_{s} / 2.5\right) F_{t}$ if less, where $l_{s}$ is the floor to ceiling height in $\mathrm{m}$ ] or

b) $3 \%$ of the total ultimate vertical load carried by the column or wall at that level."

In inch-pound units, each external column and, if the peripheral tie is not located within the wall, every 3.3 feet length of external wall carrying vertical load should be anchored or tied horizontally into the structure at each floor and roof level with a capacity of developing a force (in lb) equal to the greater of:

a) $6.6 F_{t}$ [or $\left(l_{s} / 2.5\right) F_{t}$ if less, where $l_{s}$ is the floor to ceiling height in $\left.\mathrm{ft}\right]$ or

b) $3 \%$ of the total ultimate vertical load carried by the column or wall at that level

(Note that the factor 2.5 in a) is correct for $l_{s}$ in $\mathrm{ft}$ and wall length $=3.3 \mathrm{ft}$ ).

Corner column ties should be in two directions approximately at right angles, and capable of developing a force equal to the greater of a) or b) from the previous paragraph.

Vertical ties should be designed to resist "a tensile force equal to the maximum design ultimate dead and imposed load received by the column or wall from any one story."

In tests performed at Imperial College, London University, it was found that bending action dominates until the flexural capacity of the critical section is reached. If the load is increased beyond this stage, deflection increases, until the concrete in the compression zone crushes, thus reducing flexural resistance and transferring the load to catenary action. This transfer continues until the concrete is completely crushed and the load is carried entirely by catenary action, leading in some cases to rupture of the tensile reinforcement (Wilford and $\mathrm{Yu}, 1973$ ). The shape of the deflected slab can be assumed to be bi-linear (Vshaped) if the applied load is less than the flexural capacity of a single span, or parabolic (U-shaped) for greater loads (Regan, 1975). Tests in the U.K. and by the Portland Cement Association (PCA) in the U.S. also confirmed the assumption of two-way action with half of the load carried in each direction (Breen, 1980).

Some engineers have objected to the British criteria for being "quite arbitrary and empirical." "Absolute numbers are specified without relating these to loads, weight, height, thickness, span or other geometric or physical characteristics" (Popoff, 1972). He was referring in particular to tie forces when he wrote about absolute numbers). Perhaps performance criteria would be more rational, such as, the amount of continuous steel in a slab must be sufficient to carry in tension the slab hanging as a catenary, under its 
own weight and some portion of the applied load. The deflection that can be tolerated in a damaged structure should be limited only by life safety considerations, say $1.8 \mathrm{~m}(6 \mathrm{ft})$ of maximum sag for a $3.6 \mathrm{~m}$ (12 ft) story height.

The slab reinforcement must be detailed accordingly: anchorage and connections must be capable of accommodating large deflections while resisting tension as well as shear. Lewicki and Pauw (1972) stress the importance of tensile continuity and joint ductility, especially in large precast panel buildings. If the slab can hang, this would minimize further debris loading and possibly arrest the collapse.

BS 5628-1:1992, Code of Practice for Use of Masonry, Sections 37.3 - 37.5-Horizontal ties may be provided by "structural members, which may already be fully stressed in serving other purposes."

Horizontal tie strength: The standard defines a basic strength $F_{t}$ defined as follows:

$$
\begin{aligned}
& F_{t}=60 \mathrm{kN} \text { or }\left(20+4 N_{s}\right) \mathrm{kN} \\
& \text { or } \\
& F_{t}=60 \mathrm{kN} / \mathrm{m} \text { or }\left(20+4 N_{s}\right) \mathrm{kN} / \mathrm{m}
\end{aligned}
$$

In inch-pound units:

$$
\begin{aligned}
& F_{t}=13500 \mathrm{lb} \text { or } 225\left(20+4 N_{s}\right) \mathrm{lb} \\
& \text { or } \\
& F_{t}=4100 \mathrm{lb} / \mathrm{ft} \text { or } 68.5\left(20+4 N_{s}\right) \mathrm{lb} / \mathrm{ft}
\end{aligned}
$$

where $N_{s}=$ number of stories including ground and basement.

The standard specifies the following tie strengths:

Peripheral tie strength: $F_{t} \mathrm{kN}$ or $\mathrm{lb}$.

Internal tie strength: $F_{t} \mathrm{kN} / \mathrm{m}$ width or $\frac{G_{k}+Q_{k}}{7.5} \frac{L_{a}}{5} F_{t} \mathrm{kN} / \mathrm{m}$, whichever is greater.

In inch-pound. units: $F_{t} \mathrm{lb} / \mathrm{ft}$ width or $\frac{G_{k}+Q_{k}}{160} \frac{L_{a}}{16} F_{t} \mathrm{lb} / \mathrm{ft}$, whichever is greater.

where $G_{k}, Q_{k}=$ characteristic dead, imposed floor loads $\left(\mathrm{kN} / \mathrm{m}^{2}\right.$ or $\left.\mathrm{lb} / \mathrm{ft}^{2}\right)$, and $L_{a}$ is the lesser of: five times the clear story height $h$; or the greatest distance in meters in the direction of the tie, between the centers of columns or other vertical load bearing members, whether this distance is spanned by a single slab or by a system of beams and slabs.

External column tie strength: $\quad 2 F_{t} \mathrm{kN}$ or $(h / 2.5) F_{t} \mathrm{kN}$ whichever is less $(h$ in $\mathrm{m})$

$$
\text { (Inch-pound units) } \quad 2 F_{t} \mathrm{lb} \text { or }(h / 8) F_{t} \mathrm{lb} \text { whichever is less }(h \text { in } \mathrm{ft})
$$

External wall tie strength: $\quad 2 F_{t} \mathrm{kN} / \mathrm{m}$ or $(h / 2.5) F_{t} \mathrm{kN} / \mathrm{m}$ whichever is less $(h$ in $\mathrm{m})$

(Inch-pound units) $\quad 2 F_{t} \mathrm{lb} / \mathrm{ft}$ or $(h / 8) F_{t} \mathrm{lb} / \mathrm{ft}$ whichever is less $(h \mathrm{in} \mathrm{ft})$ 
Vertical tie strength should be:

$$
\frac{34 A}{8000}\left(\frac{h_{a}}{t}\right)^{2} \mathrm{~N} \text { or } 100 \mathrm{kN} / \mathrm{m} \text { length of wall or per column, whichever is greater, }
$$

(Inch-pound units) $\quad \frac{5 A}{8}\left(\frac{h_{a}}{t}\right)^{2} \mathrm{lb}$ or $6850 \mathrm{lb} / \mathrm{ft}$ length of wall or per column, whichever is greater,

where $h_{a}=$ clear height of a column or wall between restraining surfaces,

$t=$ thickness of column or wall,

$A=$ horizontal cross sectional area of column or wall $\left(\mathrm{mm}^{2}\right.$ or $\left.\mathrm{in}^{2}\right)$.

Eurocode 2 - Design of concrete structures, Part 1, (prEN 1992-1-1: July 2002): General rules and rules for buildings, Section 9.10

"The following ties should be provided:

- peripheral ties,

- internal ties,

- horizontal column or wall ties,

- $\quad$ where required, vertical ties, particularly in panel buildings.

Where a building is divided by expansion joints into structurally independent sections, each section should have an independent tying system."

Strength of ties:

Peripheral ties should be designed to resist: $\quad F_{\text {tie, per }}=l_{i} q_{3} \leq q_{4}$

where $l_{i}=$ length of end span ( $\mathrm{m}$ or $\left.\mathrm{ft}\right)$

$$
\begin{aligned}
& q_{3}=10 \mathrm{kN} / \mathrm{m}(700 \mathrm{lb} / \mathrm{ft}) \\
& q_{4}=70 \mathrm{kN}(16000 \mathrm{lb})
\end{aligned}
$$

Internal ties: In each direction, internal ties should be designed to resist: $F_{\text {tie, int }}=20 \mathrm{kN} / \mathrm{m}$ $(1400 \mathrm{lb} / \mathrm{ft})$ width. Where transverse internal ties are grouped along beam lines, the minimum forces on an internal beam line is:

$$
f_{\text {tie }}=\frac{l_{1}+l_{2}}{2} q_{4} \leq q_{5}
$$

where $l_{1}, l_{2}=$ span length ( $\mathrm{m}$ or $\mathrm{ft}$ ) of floor slabs on either side of the beam, and 


$$
\begin{aligned}
& q_{4}=20 \mathrm{kN} / \mathrm{m}(1400 \mathrm{lb} / \mathrm{ft}) \\
& q_{5}=70 \mathrm{kN}(16000 \mathrm{lb}) .(\text { Notation is from Eurocode } 2) .
\end{aligned}
$$

Internal ties should be connected to peripheral ties.

Horizontal ties to columns and lor walls:

"Edge columns and walls should be tied horizontally to the structure at each floor and roof level."

They must resist at least:

$F_{\text {tie, } c o l}=150 \mathrm{kN}(34000 \mathrm{lb})$

$F_{\text {tie, façade }}=20 \mathrm{kN} / \mathrm{m}(1400 \mathrm{lb} / \mathrm{ft})$.

"Corner columns should be tied in two directions."

Vertical ties: The standard recommends no specific value of strength.

"In panel buildings of 5 storeys or more, vertical ties should be provided in columns and/or walls to limit the damage or collapse of a floor in the case of accidental loss of the columns or wall below." ... Continuous vertical ties should be provided from the lowest to the highest level, capable of carrying the load in an accidental situation, acting on the floor above the column wall accidentally lost. Other solutions, e.g., based on the diaphragm action of remaining wall elements and/or membrane action on floors, may be used if equilibrium and sufficient deformation capacity can be verified."

\section{New York City Department of Buildings, World Trade Center Building Code Task Force (2003)—}

\section{Indirect design, General:}

Tie strength should be the lesser of $4.1 \mathrm{kips} / \mathrm{ft}$ or $F_{t}=\left(1.4+0.27 N_{s}\right) \mathrm{kips} / \mathrm{ft}$ of width,

where $N_{s}=$ number of stories.

In SI units: Tie strength should be the lesser of $60 \mathrm{kN} / \mathrm{m}$ or $F_{t}=\left(20+4 N_{s}\right) \mathrm{kN} / \mathrm{m}$ of width.

\section{Indirect Design - Reinforced Concrete Structures:}

Horizontal ties: Internal ties should be at each floor and roof level in two perpendicular directions and should be anchored to the peripheral ties at each end.

"The spacing of the ties should not be greater than $1.5 L_{r}$, where $L_{r}$ is the spacing of the columns, frames or walls supporting any two adjacent floor spans in the direction of the tie." 
Tie strength should be the greater of $F_{t}$ or $2 F_{t}\left(L_{a} / 5\right)(D L+L L)$ per unit width, where $D L\left(\mathrm{kips} / \mathrm{ft}^{2}\right)$ is the dead load, $L L\left(\mathrm{kips} / \mathrm{ft}^{2}\right)$ the live load, and $L_{a}(\mathrm{ft})$ is the lesser of the largest span between columns in the tie direction or $5 h$, and $h(\mathrm{ft})$ is the clear story height.

In SI units: Tie strength should be the greater of $F_{t}$ or $F_{t}\left(L_{a} / 5\right)(D L+L L) / 7.5$ per unit width, where $D L$ $\left(\mathrm{kN} / \mathrm{m}^{2}\right)$ is the dead load, $L L\left(\mathrm{kN} / \mathrm{m}^{2}\right)$ the live load, and $L_{a}(\mathrm{~m})$ is the lesser of the largest span between columns in the tie direction or $5 h$, and $h(\mathrm{~m})$ is the clear story height.

Peripheral ties: "At each floor and roof level, an effectively continuous tie should be provided, capable of resisting a tensile force of $3.3 F_{t}$ in kips $\left[1.0 F_{t}\right.$ in $\left.\mathrm{kN}\right]$ located within $4 \mathrm{ft}[1.2 \mathrm{~m}]$ of the edge of the building or within the perimeter wall."

Column and wall ties: "Each external column and if the peripheral tie is not located within the walls, the load-bearing external wall should be anchored or tied horizontally into the structure at each floor or roof level with a tie capable of resisting a force equal to the greater of $6.6 F_{t}$ [in kips] (or $\mathbf{0 . 8} h F_{t}$ if less) and $3 \%$ of the total design ultimate vertical load carried by the column or wall at that level, where $h$ is the floor to ceiling height in feet."

In SI units: ... a force equal to the greater of $2.0 F_{t}$ in $\mathrm{kN}$ (or $\mathbf{0 . 8} h F_{t}$ if less) and $3 \%$ of the total design ultimate vertical load carried by the column or wall at that level, where $h=$ floor to ceiling height in meter.

Note: The NYCDOB-WTC task force guidelines deviate from British Standard, which is equivalent to:... a force equal to the greater of $2.0 F_{t}$ in $\mathrm{kN}$ (or $0.4 h F_{t}$ if less) and $3 \%$ of the total design ultimate vertical load carried by the column or wall at that level, where $h$ is the floor to ceiling height in meter. The BS values are consistent, the WTC task force value appears to be incorrect; 0.4 should be used for both SI and inch-pound units. Also, the tie force should be per $3.3 \mathrm{ft}$ of wall.

Corner columns should be tied in two perpendicular directions with ties that can develop the same strength as above.

Vertical ties: "Each column and each wall carrying vertical load should be tied continuously from the lowest to the highest level. The tie should be capable of developing a tensile force equal to the maximum ultimate dead and live load received by the column or wall from any one story."

\section{Indirect Design - Steel Structures:}

"Every steel member should act as a horizontal tie, and their connections should be capable of resisting a tensile force equal to its end reactions under factored loads, which need not be considered additive to other loads."

"The horizontal tie anchoring all columns should be capable of resisting a factored tensile load, acting horizontally in any direction, equal to the greater of the end reactions under factored loads or $2 \%$ of the maximum factored vertical dead and live load in the column adjacent to that level. 
When multiple members frame in one direction, no connection strength should be less than $1 \%$ of the column load."

"If columns are not continuous then the frame should be detailed to provide full continuity to the column."

"Each column splice should be capable of resisting a tensile force equal to the largest factored vertical dead and live load reaction applied to the column at ten floor levels located immediately below that column splice, or $2 / 3$ of the column capacity, whichever is smaller."

"Braced bays or other systems for resisting lateral loads should be distributed throughout the building."

Indirect Design, Masonry Structures:

"Peripheral horizontal ties should be provided along the whole perimeter, within $4 \mathrm{ft}(1.2 \mathrm{~m})$ of slab edge, and anchored at re-entrant corners. The design capacity is $3.3 F_{t}$ " [in kips (or $1.0 F_{t}$ in $\mathrm{kN}$ )].

"Interior horizontal ties should be provided both ways either uniformly or in strips no further apart then 20 -feet $[6 \mathrm{~m}]$ or in walls no further than 1.6-feet $[0.5 \mathrm{~m}]$ from floor or roof. The design strength along the width is the greater of $F_{t}$ or $\left(2 F_{t}\right)(D L+L L)\left(L_{a} / 5\right)$ per unit width, where $D L$ and $\mathrm{LL}$ are the dead and live load expressed in ksf, and $L_{a}(\mathrm{ft})$ is lesser of the largest span between columns in the tie direction or $5 h$, and $h$ is the clear story height expressed in feet."

In SI units: The design strength along the width is the greater of $F_{t}$ or $F_{t}$ $\left(L_{a} / 5\right)(D L+L L) / 7.5$ per unit width, where $D L\left(\mathrm{kN} / \mathrm{m}^{2}\right)$ is the dead load, $L L\left(\mathrm{kN} / \mathrm{m}^{2}\right)$ the live load, and $L_{a}(\mathrm{~m})$ is the lesser of the largest span between columns in the tie direction or $5 h$, and $h(\mathrm{~m})$ is the clear story height.

"Exterior horizontal ties should be provided from perimeter columns and walls to floor slabs. Tie corner columns both ways. Tie walls uniformly, or not farther than 18-feet apart, or within 9-feet of wall ends. Design strength should be at least the lesser of $6.6 F_{t}$ (or $0.8 h F_{t}$ if less) in units of kips at columns and $2 F_{t}$ (or $0.12 h F_{t}$ if less) kips/foot at walls, where $h$ is the story height expressed in feet."

In SI units: Tie walls uniformly, or not farther than $5.5 \mathrm{~m}$ apart, or within $2.7 \mathrm{~m}$ of wall ends. Design strength should be at least the lesser of $2.0 F_{t}$ (or $0.8 h F_{t}$ if less) in $\mathrm{kN}$ at columns and $2.0 F_{t}$ (or $4 h F_{t}$ if less) in $\mathrm{kN} / \mathrm{m}$ at walls, where $h(\mathrm{~m})$ is the story height.

Note: This deviates from BS Masonry, which is equivalent to:... Design strength shall be at least the lower of $2.0 F_{t}$ (or $0.4 h F_{t}$ if less) in $\mathrm{kN}$ at columns and $2.0 F_{t}$ (or $0.4 h F_{t}$ if less) in $\mathrm{kN} / \mathrm{m}$ at walls, where $h$ is the story height in $\mathrm{m}$. In the previous sentence, $F_{t}$ is only defined in $\mathrm{kN} / \mathrm{m}$, in keeping with this proposed NYC Masonry guideline. The BS values are consistent; the NYC value appears to be incorrect; 
0.4 should be used for both SI units and inch-pound units. See conversion in BS sections. The confusion is due to $F_{t}$ having the same numerical value but two different possible units, $\mathrm{kN}$ or $\mathrm{kN} / \mathrm{m}$.

"Vertical ties should be provided floor to floor at load bearing walls 6inch minimum thickness, masonry strength 725-psi and maximum slenderness (clear height/thickness) of 20. Tie every 16-feet maximum and 8-feet $(2.5 \mathrm{~m})$ from unrestrained end of wall. Design tie capacity for the larger of $12.7 A\left(h_{a} / t\right)^{2}$ kips or $6.85-\mathrm{kip} / \mathrm{ft}$ of wall or per column, where $A$ is the horizontal cross-sectional area in square inches of the column or load-bearing wall including piers, $h_{a}$ is the clear wall height and $t$ is the thickness of column or wall."

Note: Again, $12.7 A\left(h_{a} / t\right)^{2}$ kips is wrong by a large amount (by $20000=4.448^{2} \mathrm{H} 1000$, where $1 \mathrm{lb}=$ $4.448 \mathrm{~N}$ and $1 \mathrm{kN}=1000 \mathrm{~N}$. Tie would be 20 times bigger than column). Formula should be $\frac{5 A}{8}\left(\frac{h_{a}}{t}\right)^{2} \mathrm{lb}$, where $A$ is in in ${ }^{2}$.

Department of Defense (2005) Unified Facilities Criteria (UFC) 4-023-03, Design of Buildings to Resist Progressive Collapse-The following are general requirements for tie strength:

“3-1.2 Required Tie Strength. The required tie strength for horizontal and vertical ties is defined for each material type in Chapters 4 through 8 . The structural elements used as ties must not only provide sufficient tie strength, but they must also be adequately connected so that the tie forces can be distributed throughout the rest of the building."

"The design tie strengths are considered separately from the forces that are typically carried by each structural element due to live load, dead load, wind load, etc.; in other words, the design tie strength of the element or connection with no other loads acting must be greater than or equal to the required tie strength."

"Some of the tie forces are based on the dead and live loads. In some cases, a structure may have different loads, such as a corridor load or office load, on the same floor. In such cases, use an averaged dead or live load, by computing the total force acting on the floor and dividing by the total plan area. When tie forces are based on a span $\mathrm{L}$ that varies along the length of a tie, the largest span in a continuous tie should be used for the tie force calculation."

Appendix B explains that the tie force requirements are based on those provided in the British Standards for reinforced concrete, structural steel, and masonry "and have been marginally modified to make clearer some of the connection and continuity issues." The following excerpts explain the rationale in the use of the British Standards:

"The British Tie Force requirements were developed in response to the Ronan Point accident in 1968. The steel and reinforced concrete requirements are different in form and magnitude and appear to have been developed by separate code writing bodies (as with ACI and ASCE 
in the United States). The masonry requirements are almost identical to reinforced concrete, with the exception of the additional requirements for developing full vertical ties (Table 7-1). Attempts to uncover the processes and logic by which these requirements were developed were partially successful and, in discussions with British engineers, it has been noted that engineering judgment was used for some of the requirements. The results of the background research are presented in the following sections."

"It is noted that the British Tie Force requirements are adopted almost verbatim in this UFC and it has been assumed that they are directly applicable to US construction, i.e., that there is sufficient similarity between current British and US construction practices that the Tie Force requirements can be applied to US construction. Additional research and analysis are needed to determine if a new or modified set of Tie Force requirements should be developed. However, the Tie Force requirements presented in this UFC have been effective for the British over the last 3 decades and are the most prescriptive procedure available for Indirect Design. In lieu of additional research and analysis, they are deemed to be sufficient for DoD construction."

The following discussion is provided in the Commentary with regard to the tie force requirements for wood-frame structures (Chapter 7) and cold-formed steel structures (Chapter 8):

"In this UFC, Tie Force requirements for wood frame (and cold-formed steel) are specified in a similar manner to those for reinforced concrete and masonry, since all four types of structures rely on load-bearing walls, posts, and columns and share a number of similar connection and floor configurations. The differences are in the values for the upper limit of $F_{t}$ (the "Basic Strength"), the constants in the equation defining $F_{t}$ as a function of the number of stories, and the scaling values for the internal tie strength in Section 7-2.4.2. These are based on a similar analysis as shown in Section B-3.1.1.1 and Figure B-1. In this case, typical values for American light frame wood construction were used: Dead Load = $0.72 \mathrm{kN} / \mathrm{m}^{2}$ (15 psf), Live Load $=2.39 \mathrm{kN} / \mathrm{m}^{2}$ (50 psf), and span A = $4.6 \mathrm{~m}(15 \mathrm{ft})$, resulting in an upper limit of $\mathrm{F}_{\mathrm{t}}=21.9$ in SI units and 4.92 in English units. Note that the constants in the equation for the Basic Strength as a function of the number of stories have been scaled from that for concrete and masonry, to give the correct upper limit."

\section{Swedish Board of Housing, Building and Planning (Boverket, 1994): Handbook on Vibrations, Induced Deformations and Accidental Loads. Section 4.5 Simplified conditions for normal residential houses and office buildings-}

\section{"Condition b}

"To avoid progressive collapse brought about by successive failure of concrete floor structures loaded by falling debris: 
- The different parts of the floor structure - e.g., prefabricated elements and their joints- should be able to transfer two forces, a tensile force $\mathrm{N}=20 \mathrm{kN} / \mathrm{m}$ and a shear force $\mathrm{T}=20 \mathrm{kN} / \mathrm{m}$. These forces are normal to each other and lie on the floor plane, see Figure (e).

- The different parts of the bearing walls should be able to transfer two forces, a tensile force $\mathrm{N}=20 \mathrm{kN} / \mathrm{m}$ and a shear force $\mathrm{T}=20$ $\mathrm{kN} / \mathrm{m}$. These forces are normal to each other and lie on the wall plane, see Figure (e).

- The support between floor structure and wall should be able to transfer a tensile force $\mathrm{N}=20 \mathrm{kN} / \mathrm{m}$ and a shear force $\mathrm{T}=20$ $\mathrm{kN} / \mathrm{m}$, see Figure (e).

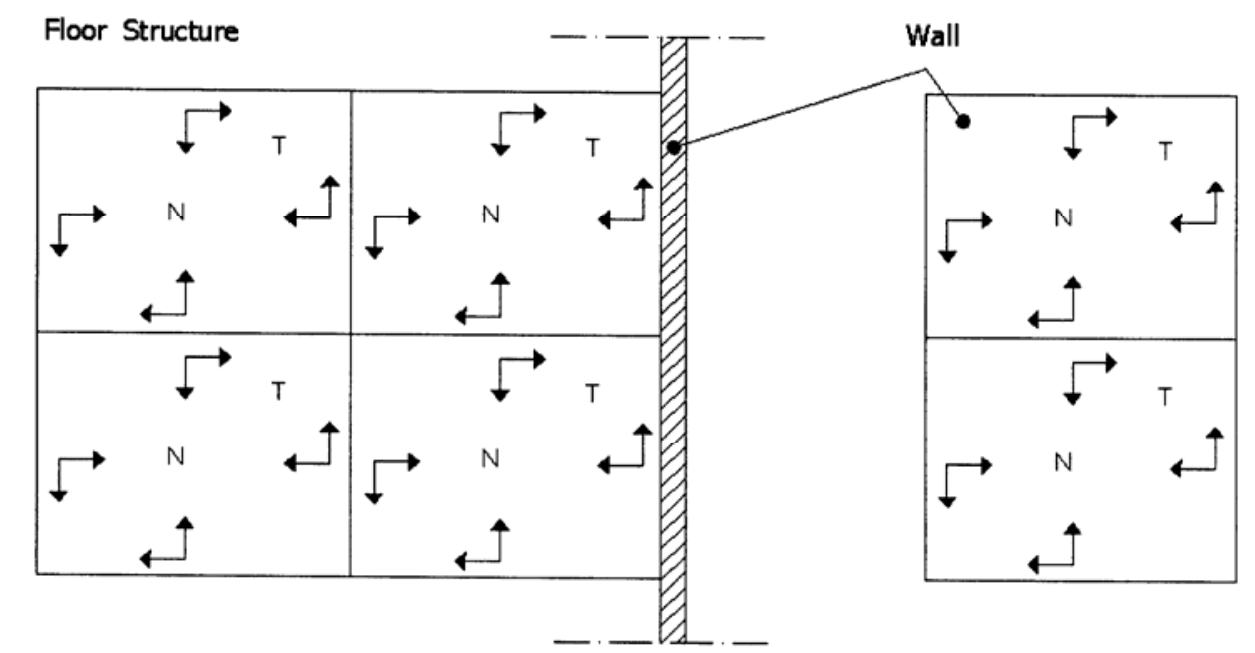

Figure e. Shear and normal forces in floor structure and wall"

\section{A.4.7 Key Elements}

Key elements are defined as structural elements whose notional removal would cause collapse of an unacceptable extent. They should therefore be designed for accidental loads, which are specified in several standards as $34 \mathrm{kPa}$ or 5 psi. The origin of this value was discussed in Section A.3.2.4: Loads.

The difficulty with strengthening key elements is that it must be done with a specific threat in mind. In this context, it is instructive to learn from controlled demolition experts, who report, for example, using only $150 \mathrm{~kg}$ of explosives judiciously placed to bring down a 22-story building (Anonymous, 1985). Typically the structure to be demolished has to be pre-weakened by removing many redundancies, such as internal partition walls, stairwell or elevator walls (Williams, 1990).

Following are details of various building standards: 


\section{BS 5950-1:2000, Structural Use of Steelwork in Building, Section 2.4.5 Structural Integrity}

"If the notional removal of a column, or of an element of a system providing resistance to horizontal forces, would risk the collapse of a greater area, that column or element should be designed as a key element... Any other steel member or other structural elements that provide lateral restraint vital to the stability of a key element should itself also be designed as a key element for the same accidental loading."

\section{BS 8110-2:1985, Structural Use of Concrete, Sections 2.6.2.2-3}

"In all cases, a key element and its connections should be capable of resisting a design ultimate load of $34 \mathrm{kN} / \mathrm{m}^{2}$ (5 psi), to which no partial factor of safety should be applied, from any direction."

\section{BS 5628-1:1992, Code of Practice for Use of Masonry, Section 37.1.1}

"Protected members or key elements shall be designed to resist reduced design load and an accidental load of $34 \mathrm{kN} / \mathrm{m}^{2}$ (5 psi) applied from any direction."

\section{New York City Building Code (1998), Chapter 18, Resistance to Progressive Collapse Under Extreme Local Loads-}

"Specific load resistance methods.

Any single element essential to the stability of the structure, together with its structural connections, shall not fail under the loads stipulated in this criterion after being subjected to a load equivalent to that caused by a uniform pressure of 720 psf [ 5 psi or $34 \mathrm{kPa}]$."

\section{New York City Department of Buildings World Trade Center Building Code Task Force (2003)_}

Under the heading of "The Specific Local Resistance Method," the draft progressive collapse guidelines recommend that key elements should be hardened locally against unanticipated loads without failing the connections or supporting members framing it. The structure should be detailed to permit load reversals.

Special attention is given to transfer structures, which, by definition, concentrate the load bearing system onto fewer structural elements.

"Transfer structures should be continuous over several supports with substantial structure framing into these members to create a two-way redundancy that provides an alternate load path in the event of a localized failure. The column connections, which support the transfer structures should provide sustained strength despite inelastic deformations and designed as full moment connections. Transfer structures and the columns that support the transfer members should be hardened to the requirements of the specific local resistance." 
Department of Defense (2005) Unified Facilities Criteria (UFC) 4-023-03, Design of Buildings to

Resist Progressive Collapse - The following guidance is provided for designing to resist a specific threat:

"As the initiating event is unknown, the requirements in this UFC are not intended to directly limit or eliminate the initial damage. This is consistent with UFC 4-010-01, which applies where there is a known risk of terrorist attack, but no specific terrorist threat is defined; in this case, the goal is to reduce the risk of mass casualties in the event of an attack. For cases where specific explosive threats against a building have been identified, design guidelines for specific blast hardening can be found in UFC 4-013-01 Structural Design to Resist Explosives Effects for New Buildings and UFC 4-013-02 Structural Design to Resist Explosives Effects for Existing Buildings. Even if a structure is designed to resist an identified or assumed threat, the progressive collapse requirements of this UFC will still apply."

\section{A.4.8 Continuity, Ductility, and Other Details}

Continuity of reinforcement, anchorage and joint requirements are specified in various standards to promote catenary action, resistance to uplift forces, and general structural integrity. Good details between structural elements are particularly important for prefabricated elements.

A question that needs further study is to what extent structural details designed to resist earthquakes also help resist progressive collapse. Ferahian (1972) showed that structural elements designed to withstand an El-Centro earthquake should be capable of resisting a gas explosion also. The GSA (2000) design guidelines against progressive collapse rely heavily on seismic criteria.

Following are details from various building standards:

\section{BS 5950-1:2000, Structural Use of Steelwork in Building, Section 2.4.5 Structural Integrity-}

"Where precast concrete or other heavy floor or roof units are used, they should be effectively anchored in the direction of their span, either to each other or over a support, or directly to their supports as recommended in BS 8110."

BS 8110-1:1985, Structural Use of Concrete, Section 2.6.3.1-

"At each story in turn, each vertical load-bearing element other than a key element is considered lost in turn... If catenary action is assumed, allowance should be made for the horizontal reaction necessary for equilibrium."

BS 8110-1:1997, Structural Use of Concrete, Section 5.1.8.4, 3.12.3.2-

"In buildings of five or more storeys where precast floor or roof members are not used to provide the ties required by 3.12.3, they should nevertheless be effectively anchored, such anchorage being capable of 
carrying the dead weight of the member, to that part of the structure which contains the ties."

Ties connecting floor and roof members should be arranged to minimize out of balance effects, i.e., minimize eccentricity. Proper anchorage and lapping of ties are required.

"Bars should be lapped, welded or mechanically joined in accordance with 3.12.8.9. A tie may be considered anchored to another tie at right angles if the bars of the former tie extend:

a) 12 diameters or an equivalent anchorage beyond all the bars of the other tie; or

b) an effective anchorage length (based on the force in the bars) beyond the centre-line of the bars of the other tie.

At re-entrant corners or at substantial changes in construction, care should be taken to ensure that the ties are adequately anchored or otherwise made effective."

Eurocode 2 - Design of concrete structures, Part 1, (prEN 1992-1-1: July 2002). General rules and rules for buildings, Section 9.10.3-

"Ties in two horizontal directions shall be effectively continuous and anchored at the perimeter of the structure. They may be provided wholly within the in-situ concrete or at connections. Where ties are not continuous in one plane, the bending effects resulting from the eccentricities should be considered. Ties should not normally be lapped in narrow joints between precast units. Mechanical anchorage should be used in these cases."

\section{American Concrete Institute International, Building Code Requirements for Structural Concrete and Commentary ACI 318-05 and 318R-05 (2005)-}

\subsection{Requirements for Structural Integrity, and R7.13 Commentary}

"7.13.1 - In the detailing of reinforcement and connections, members of a structure shall be effectively tied together to improve integrity of the overall structure."

"7.13.2.2 - Beams along the perimeter of the structure shall have continuous reinforcement consisting of:

a) at least one-sixth of the tension reinforcement required for negative moment at the support, but not less than two bars; and

b) at least one-quarter of the tension reinforcement required for positive moment at midspan, but not less than two bars."

"7.13.2.4 - In other than perimeter beams, when stirrups as defined in 17.13.2.3 are not provided, at least one-quarter of the positive moment 
reinforcement required at midspan, but not less than two bars, shall be continuous or shall be spliced over or near the support with a Class A tension splice or a mechanical or welded splice satisfying 12.14.3, and at noncontinuous supports shall be terminated with a standard hook."

"R7.13.3 - ...Connection details that rely solely on friction caused by gravity forces are not permitted."

\section{A.4.9 Existing Buildings}

\section{Interagency Security Committee (ISC), Design Criteria for New Federal Office Buildings and Major Reorganization Projects (2001 Draft)}

\section{Section 4.C Existing Construction Modernization, 4.C.2 Progressive Collapse}

"Existing buildings will not be retrofitted to prevent progressive collapse unless they are undergoing a structural renovation, such as a seismic upgrade. Prior to the submission for funding, all structures shall be analyzed according to requirements for new construction, and a written report shall clearly state the potential vulnerability of the building to progressive collapse."

\section{General Services Administration (GSA), Progressive Collapse Analysis and Design Guidelines For New Federal Office Buildings and Major Modernization Projects (2003)}

The GSA guidelines incorporate an exemption process that takes into account the use, occupancy, and type of the facility, proximity of moving or parked vehicles, as well as structural features such as seismic design, to help the user decide whether the potential for progressive collapse needs to be considered. The following statement is provided for existing construction:

"For existing construction, if the facility is determined no to be exempt from further consideration for progressive collapse, the methodology for existing construction outlined in Section 4.2 or 5.2, as applicable, shall be executed. The potential for progressive collapse determine $3 \mathrm{~d}$ in this process (whether low or high) must be quantified and analysis procedure and results documented."

Section 4.2 is for reinforced concrete structures and section 5.2 is for steel structures. The following guidance is provided for existing reinforced concrete facilities:

\section{“4.2 Existing Construction}

Existing facilities undergoing modernization should be upgraded to new construction requirements when required by the project specific facility security risk assessment and where feasible. In addition, facilities undergoing modernization should, as a minimum, assess the potential for progressive collapse as the result of an abnormal loading event. The flowchart, shown in Figure 4.8, outlines the process for assessing the potential for progressive collapse in existing facilities. Findings of this 
analysis should be incorporated into the project-specific risk assessment, and shall be documented in accordance with the provisions in Section 1.5. The 'analysis' provisions contained in Section 4.1.2 concerning analysis techniques, procedure, analysis considerations and loading criteria, analysis criteria, material properties, and modeling guidance, shall also apply to existing construction."

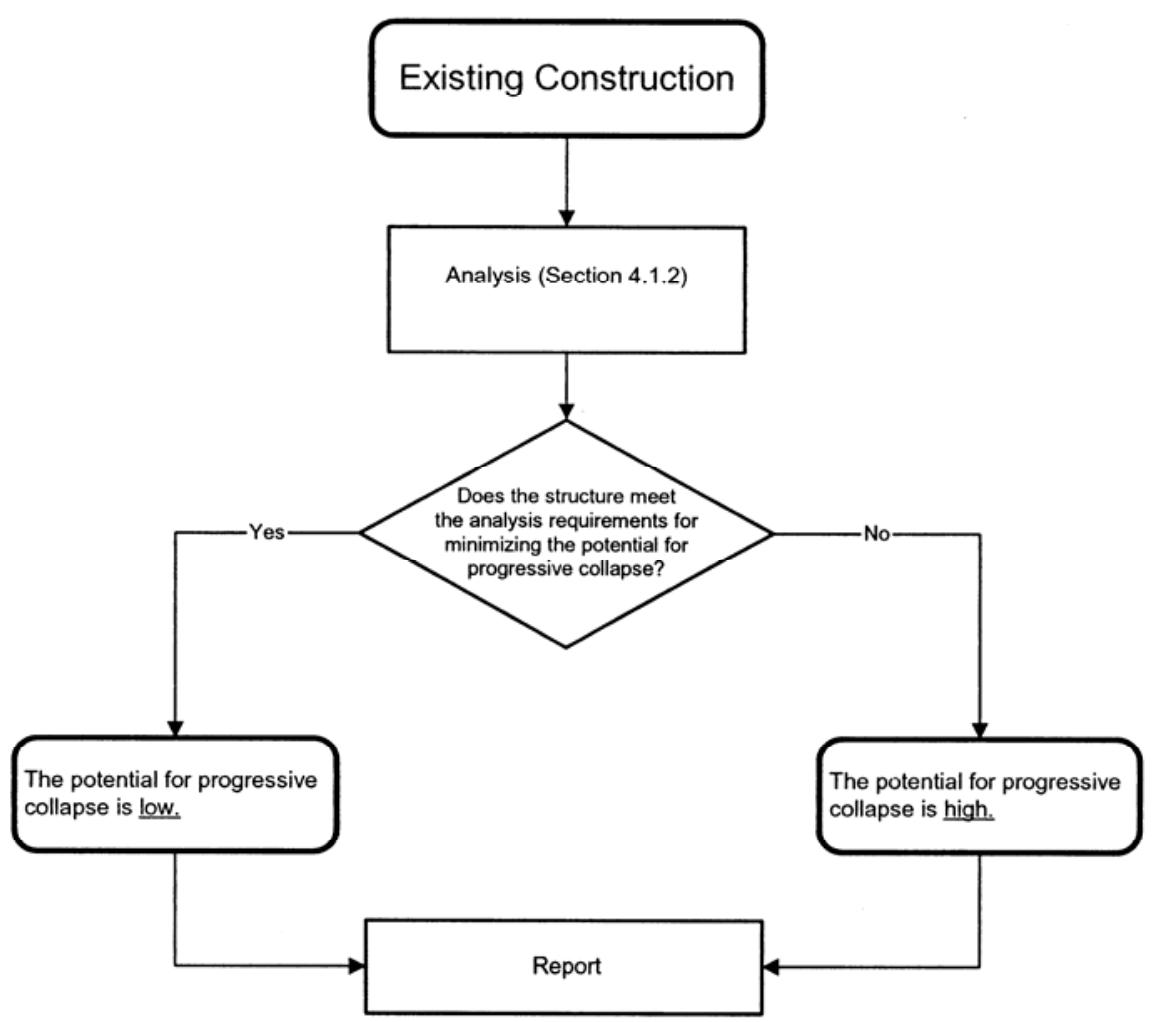

"Figure 4.8 Process for assessing the potential for progressive collapse in existing construction."

Section 5.2 provides a similar statement for steel structures. Refer to A.2.3 for a summary of the analysis procedures regarding notional removal of supporting members and calculating extent of damage.

\section{Department of Defense (2005) Unified Facilities Criteria (UFC) 4-023-03, Design of Buildings to}

Resist Progressive Collapse-The UFC for design to resist progressive collapse are applicable equally to new and existing facilities. The following actions are specified for different levels of protection:

Very Low Level of Protection-"If a structural element does not provide the required horizontal tie force capacity, it must be re-designed in the case of new construction or retrofitted in the case of existing construction." 
Low Level of Protection-“For elements with inadequate horizontal tie force capacity, the Alternate Path method cannot be used. In this case, the designer must re-design the element in the case of new construction or retrofit the element in the case of existing construction."

Medium and High Level of Protection - "For elements with inadequate horizontal tie force capacity, the Alternate Path method cannot be used. In this case, the designer must re-design the element in the case of new construction or retrofit the element for existing construction."

\section{A.5 SUMMARY}

This survey shows that a number of building standards around the world contain specific provisions for design against progressive collapse, whereas other standards rely on more general provisions dealing with structural integrity and robustness. They all emphasize the need for good structural layout, redundancy, ductility, and continuity.

General approaches for mitigation of progressive collapse include minimizing exposure to hazards by preventive measures largely outside the scope of structural engineering; direct design methods, which include the alternate path method (bridging over local damage zones) and the specific local resistance method (hardening structural elements against specific hazards); and the indirect design method (provide strength, redundancy, continuity and ductility). Specific provisions also address requirements for tying together various structural elements within a building, constructing planes of weakness to limit the spread of damage, as well as checking building stability under load combinations that take into account damage or accidental loads.

When remaining structural elements must bridge over damaged ones, they oftentimes must perform very close to their ultimate strength. For masonry structures in the U.S., the advent of strength methods with the 2002 Building Code Requirements for Masonry Structures (ACI 530-02/ASCE 5-02/TMS 402-02) should make it easier to consider provisions against progressive collapse. This may be more challenging than for concrete structures, because masonry wall panels themselves, and not just the joints, may fail.

Catenary or membrane behavior of slabs with ties has been tested in the U.K., with a maximum deflection of $15 \%$ of span. For U.S. practice, it is desirable to test longer spans, under larger deflections, up to $50 \%$ of story height. It is also necessary to ensure that connections and splices can withstand such high level of deflection and rotation. Tests at PCA of large panel construction confirm the importance of proper details and analysis for the shear capacity of horizontal joints (Breen 1980). More research, that takes into account the possible shifting of load application points, for example, is needed in this area.

For existing buildings, recent reports contracted by the U.S. government recommend that retrofit to improve resistance to progressive collapse should wait for other major renovation (such as seismic upgrade); or the decision should be based on the risk of exposure and consequences of failure, and the analysis would be similar to that of new buildings. Analytical methods that account for nonlinear geometric and material properties, and various member failure criteria can be very challenging (see, for example, Blandford, 1997). 


\section{A.5 REFERENCES}

\section{Building Standards}

American Concrete Institute, (2005), "Building Code Requirements for Structural Concrete and Commentary," ACI 318-05 and 318R-05, Section 7.13.

American Institute for Steel Construction, (2001), "Manual of Steel Construction: Load and Resistance Factor Design," 3rd Ed.

American Society of Civil Engineers (ASCE), (2005), "Minimum Design Loads for Buildings and Other Structures," SEI/ASCE 7-05, Reston, Va.

Australian Building Code Board, (1996), "Building Code of Australia."

Australian/New Zealand Standard, (2002), "Structural Design Actions, Part 0: General Principles," AS/NZS 1170.0:2002.

Australian/New Zealand Standard, (2002), "Structural Design Actions: General Principles Commentary," AS/NZS 1170.0 Supplement 1:2002.

Boverket (Swedish Board of Housing, Building and Planning) BFS 1993:58 with Amendments up to BFS 1998:39, BFS 1999:7, BFS 1999:46, "Design Regulations BKR-Mandatory Provisions and General Recommendations."

Boverket (Swedish Board of Housing, Building and Planning), 1994 Handbook on Vibrations, Induced Deformations and Accidental Loads

British Standards Institute, (2000), "Structural Use of Steelwork in Building, Part 1: Code of Practice for Design - Rolled and Welded Sections,” BS 5950-1:2000.

British Standards Institute, (2002), "Structural Use of Timber, Part 2: Code of Practice for permissible stress design, materials and workmanship," BS 5268-2:2002.

British Standards Institute (1992), "Code of Practice for Use of Masonry Part 1: Structural Use of Unreinforced Masonry,” BS 5628-1:1992.

British Standards Institute, (1997), "Structural Use of Concrete, Part 1: Code of Practice for Design and Construction," BS 8110-1:1997.

British Standards Institute (1985), "Structural Use of Concrete, Part 2: Code of Practice for Special Circumstances,” BS 8110-2:1985.

British Standards Institute, (1996), "Loading for Buildings, Part 1: Code of Practice for Dead and Imposed Loads," BS 6399-1:1996.

British Standards Organization, (1998), European Prestandard ENV 1991-2-7:1998 Eurocode 1: 'Basis of design and actions on structures, Part 2-7: Accidental actions due to impact and explosion', London. 
CAN/CSA-S16-01, "Limit States Design of Steel Structures," Section 6.1.2, Structural Integrity.

Comité Européen de Normalisation, (2002), Draft prEN 1991-1-7: March 2002, Eurocode 1 - Actions on structures. Part 1.7: General Actions - Accidental actions due to impact and explosions. First Project Team (Stage 32) draft, Amended version 8, Brussels.

Comité Européen de Normalisation, (2002), Draft prEN 1992-1-1: July 2002, Eurocode 2 - Design of concrete structures, Part 1: General rules and rules for buildings, Brussels.

ComitéEuropéen de Normalisation, (1994), ENV 1992-1-3:1994 E, Eurocode 2 - Design of concrete structures, Part 1.3: General rules - Precast concrete elements and structures, Section 5.5: Limitation of damage due to accidental action

Comité Européen de Normalisation, (1996), DD ENV 1992-1-5: 1996, Eurocode 2 - Design of concrete structures, Part 1.5: General rules - Structures with unbonded and external prestressing tendons.

Comité Européen de Normalisation, (1994), ENV 1991-1:1994 E, Eurocode 1- Basis of design and actions on structures, Part 1: Basis of design.

Comité Européen de Normalisation Du Batiment (General Commission for Building Standards- France) BAEL 91: Regles Techniques De Conception Et De Calcul Des Ouvrages Et Constructions En Beton Arme Suivant La Methode Des Etats Limites (Technical Rules On Limit State Design And Calculation Of Reinforced Concrete Structures And Construction).

Department of Defense (DOD), (2003), “DOD Minimum Antiterrorism Standards for Buildings," Unified Facilities Criteria (UFC) 4-010-01, 8 October, 2003.

Department of Defense, (DOD), (2005), "Design of Buildings to Resist Progressive Collapse," Unified Facilities Criteria (UFC) 4-023-03, 25 January, 2005.

Department of Defense, (DOD), (2001), "Interim Antiterrorism/Force Protection Construction Standards, Guidance on Structural Requirements," Draft, March.

Eurocode No. 1, (1990), "Common Unified Rules for Different Types of Construction and Material," Commission of the European Communities, Brussels.

Federal Emergency Management Agency, (1997), "NEHRP Commentary on the Guidelines for the Seismic Rehabilitation of Buildings," FEMA 274, Oct.

Federal Emergency Management Agency, (2000), "Prestandard and Commentary for the Seismic Rehabilitation of Buildings," FEMA 356, Nov.

General Services Administration (GSA), (2003), "Progressive Collapse Analysis and Design Guidelines for New Federal Office Buildings and Major Modernization Projects," June.

Interagency Security Committee, (2001), "Design Criteria for New Federal Office Buildings and Major Reorganization Projects" 
Japan Ministry of Land, Infrastructure and Transport, (2002), Building Standard Law and Enforcement Order

National Research Council of Canada, (1975, 1977, 1980, 1990, 1995), "National Building Code of Canada," Ottawa, Canada.

New York City Building Code, (1998), "Resistance to Progressive Collapse Under Extreme Local Loads," Chapter 18.

New York City Department of Buildings, World Trade Center Building Code Task Force, (Feb. 2003), "Draft Progressive Collapse Guidelines," Section 5.2 of Findings and Recommendations, http://www.nyc.gov/html/dob/html/publications.html

New Zealand Standard, (1982), Code of Practice and Commentary for the Design of Concrete Structures, Parts 1 and 2. NZS-3101-1982, Standards Association of New Zealand, Wellington.

New Zealand Standard, (1992), Code of Practice for General Structural Design and Design Loadings for Buildings (known as the Loadings Standard): Volumes 1and 2, Code of Practice and Commentary, Standards Association of New Zealand, Wellington.

Norges Byggstandardiseringsrad (Norwegian Council for Building Standardization) NS 3473 E, "Concrete Structures Design Rules", 4th Ed. Nov. 1992.

PCI Committee on Precast Concrete Bearing Wall Buildings, (1976), "Considerations for the Design of Precast Concrete Bearing Wall Buildings to Withstand Abnormal Loads,” PCI Journal Vol. 21, No.2, March-April, pp. 18-51.

Standards Association of Australia, (1989), "Minimum Design Loads on Structures (known as SAA Loading Code)" Part 1: Dead and Live Loads and Load Combinations AS 1170.1-1989.

Standards Association of Australia, (1994), “Concrete Structures” AS 3600-1994.

Standards Association of Australia, (1998), "Masonry Structures” AS 3700-1998.

Standards Association of Australia, (1998), "Steel Structures” AS 4100-1998.

Standards Association of Australia, (1996), "SAA Timber Structures Code: Part 1: Design Methods" AS 1720.1-1996.

Standards Association of Australia, (1992), "National Timber Framing Code" AS 1684-1992.

\section{Other References}

Allen, D.E. and Shriever, W.R., (1973), "Progressive Collapse, Abnormal Loads and Building Codes," ASCE National Meeting on Structural Failures: Modes, Causes, Responsibilities, Cleveland, Ohio, April, pp. 21-47. 
Anonymous, (1985), "Demolition of Concrete Structures - A Fine Art", The Civil Engineer in South Africa, V. 27, No. 10, Oct., pp. 523-524.

Alexander, S.J. and Hambly, E.C., (1970), "The Design of Structures to Withstand Gaseous Explosions," Concrete, Feb. pp. 62-65, Mar. pp.107-116.

U.S. Army, (1990), "Structures to Resist the Effects of Accidental Explosions," TM 5-1300, Department of the Army, Washington DC.

Blandford, G.E., (1997), "Review of progressive Failure Analysis for Truss Structures," ASCE Journal of Structural Engineering, V. 123, No. 2, Feb. pp. 122-129.

Building Research Division Team, (1970), "Guide Criteria for the Evaluation of Operation Breakthrough Housing System,” PB-212055, 212056, 212058, NTIS, Springfield, VA.

Breen, J., (1976), "Progressive Collapse of Building Structures," Proceedings of a Research Workshop held at the University of Texas at Austin, 18-20 Nov. 1975.

Breen, J., (1980), "Developing Structural Integrity in Bearing Wall Buildings," PCI Journal, V. 25, No.1, Jan-Feb. pp. 42-73.

Breen, J.E. and C.P. Siess, (1979), "Progressive Collapse - Symposium Summary.” ACI Journal 76(9):, pp. 997-1004.

Burnett, E.F.P., (1975), "The Avoidance of Progressive Collapse: Regulatory Approaches to the Problem," NBS-GCR 75-48, National Bureau of Standards, Washington, DC.

Carino, N.J. and Lew, H.S., (2001), "Summary of NIST/GSA Workshop on Application of Seismic Rehabilitation Technologies to Mitigate Blast-Induced Progressive Collapse," Proceedings of a Workshop held in Oakland, CA, on 10 Sept. 2001 by NIST, Gaithersburg, MD, NISTIR 6831.

Chalk, P. and Corotis, R.B., (1980), "Probability Model for Design Live Loads." J. Struct. Div. ASCE 106(10), pp. 2017-2033.

Corley, W.G., Mlakar Sr., P.F., Sozen, M.A. and Thornton, C.H., (1998), "The Oklahoma City Bombing: Summary and Recommendations for Multihazardous Mitigation," ASCE J. of Performance of Constructed Facilities, V. 12, No.3, Aug. pp. 100-112.

CCPS, (1994), Guidelines for Evaluating the Characteristics of Vapor Cloud Explosions, Flash Fires, and BLEVEs, Center for Chemical Process Safety, John Wiley \& Sons.

Creasy, L.R., (1972), "Stability of Modern Buildings," The Structural Engineer, London, V. 50, No. 1, January, pp. 3-6, and discussion, V. 50, No. 7, July, pp. 275-288.

Dusenberry, D. and Juneja, G., (2002), "Review of Existing Guidelines and Provisions Relating to Progressive Collapse," Multihazard Mitigation Council National Workshop on Prevention of Progressive Collapse, Chicago, Ill. July. 
Ellingwood, B., (1981), "Treatment of Accidental Loads and Progressive Failures in Design Standards," Proceedings of ICOSSAR '81, The 3rd International Conference on Structural Safety and Reliability, Trondheim, Norway, June, pp. 649-665.

Ellingwood, B. and E.V. Leyendecker, (1978), “Approaches for design against progressive collapse.” $J$. Struct. Div. ASCE 104(3), pp. 413-423.

Ellingwood, B. and R. B. Corotis, (1991), "Load combinations for buildings exposed to fires," Engineering Journal, AISC 28(1), pp. 37-44.

Ellingwood, B., Galambos, T.V., MacGregor, J.G., and Cornell, C.A., (1982), "Probability-based Load Criteria: Load Factors and Load Combinations.” J. Struct. Div. ASCE 108(5), pp. 978-997.

Ellis, B.R.and Currie, D.M., (1998), "Gas Explosions in Buildings in the UK: Regulation and Risk," The Structural Engineer, V. 76, No. 19, 6 October, pp. 373-380.

Engstrom, B., (1988), "Tests of the Dynamic Behavior of Precast Floors at Sudden Removal of an Exterior Support," Nordic Concrete Research, No.7, pp. 52-72.

Ferahian, R.H., (1972),"Buildings: Design for Prevention of Progressive Collapse," Civil Engineering, ASCE, Feb. pp. 66-69.

Fintel, M. and Schultz, D.M., (1976), "A Philosophy for Structural Integrity of Large Panel Buildings," Proceedings, 8th Joint Panel Conf. of US-Japan Coop. Program in Natural Resources: Wind and Seismic Effects, NBS, Gaithersburg, MD. May 18-21, pp. VI.220-VI.251.

Firnkas, S., (1969), "Concrete Panel Buildings Systems: Progressive Collapse Analyzed,” Review of the Report on the Inquiry into the Collapse at Ronan Point, Canning Town, England, by H. Griffiths, A. Pugsley and O. Saunders, 1968, Civil Engineering, ASCE, Nov. p. 96.

Fuller, G.R., (1975), "Industrialized Concrete Construction for HUD," ACI-SP 48, Industrialization in Concrete Building Construction, pp. 7-33.

Galambos, T.V., Ellingwood, B., V., MacGregor, J.G., and Cornell, C.A., (1982), "Probability-based Load Criteria: Assessment of Current Design Practice.” J. Struct. Div. ASCE 108(5), pp. 959 - 977.

Granstrom, S., (1970), "Stability of Buildings after Accidental Damage. Forces in Element Joint - Model Tests,” Swedish Building Research Report R20: 1971, summarized in Concrete (U.K.), V. 4, No.3, March, 1970.

Hanson, K. and Olesen, S.O., (1969), "Failure Load and Failure Mechanism of Keyed Shear Joints," Danish Academy of Engineering, Building Department Report 69/22, Copenhagen, June.

Leggatt, A.J., (1971), "The Economic and Social factors of Design for Accidental Damage," The Structural Engineer, London, V. 49, No. 7, July, pp. 299-305. 
Lewicki, B. and Pauw, A., (1972), “Joints, Precast Panel Buildings,” Proceedings of the International Conference on the Planning and Design of Tall Buildings, Lehigh University, Bethlehem, Pa. Aug. Vol. 3, pp. 171-189.

Leyendecker, E.V. and Ellingwood, B.R., (1977), "Design Methods for Reducing the Risk of Progressive Collapse in Buildings,” NBS Building Science Series 98, Gaithersburg, MD. April.

Moore, D. B., (2002), "The U.K. and European Regulations for Accidental Actions," NIST/NIBS Multihazard Mitigation Council National Workshop on Prevention of Progressive Collapse, Chicago, Ill. July. http://www.nibs.org/MMC/ProgCollapse\%20presentations/Moore\%20paper.pdf

Morgan, A.E., (1971), “Dams and Other Disasters,” Porter Sargent, Boston, p. 119

Mlakar, P.S., (1999), "Structural Design for Physical Security: State of the Practice,” ASCE, Reston, Va.

Popoff, A., (1972), "Stability of Precast Concrete System Buildings," Proceedings of the International Conference on the Planning and Design of Tall Buildings, Lehigh University, Bethlehem, Pa. Aug. Vol. 3, pp. 571-583.

Popoff, A., (1975), “Design Against Progressive Collapse,” PCI Journal, Mar-Apr. pp.45-57.

Regan, P.E., (1975), "Catenary Action in Damaged Concrete Structures,” ACI SP 48-9, American Concrete Institute, Farmington Hills, MI.

Short, A. and Miles, J.R., (1969), "An Introduction to the New Code of Practice for Large Panel Construction," Concrete, London, V. 3, No. 4, Apr. pp. 121-123.

Somes, N.F., (1973), “Abnormal Loadings on Buildings and Progressive Collapse,” NBS Building Science Series 46, Building Practices for Disaster Mitigation, pp. 427-470.

Taylor, D.A., (1975), "Progressive Collapse," Canadian Journal of Civil Engineering, Vol. 2, No. 4, pp. 517-529.

Wilford, M.J.C. and Yu, C.W., (1973), "Catenary Action in Damaged Structures - Tests on RC Beams and Slabs," DOE/CIRIA Seminar on The Stability of Precast Concrete Structures, London, March.

Williams, G.T. (1990), “Explosive Demolition of Tall Buildings in Inner City Areas," Municipal Engineer (Institution of Civil Engineers), V. 7, No. 4, Aug. pp. 163-173.

Wilson, R. and Crouch, E.A., (1987), "Risk Assessment and Comparisons: An Introduction," Science, 236 pp. $262-270$.

Yokel, F.Y., Pielert, J.H. and Schwab, A.R., (1975), “The Implementation of a Provision Against Progressive Collapse,” NBSIR 75-715, National Bureau of Standards, Washington, DC. 


\section{Appendix B \\ RESEARCH NEEDS}

\section{B.1 CONNECTIONS DETAILS}

\section{B.1.1 Analytical Representation-Explicit Modeling}

Ever since the Northridge earthquake, the performance of existing and new steel moment connections has been the subject of considerable research (FEMA 267, FEMA 267-A, FEMA 288, FEMA 289). This work should be evaluated and leveraged into models that can predict the response of the numerous tests and then expanded to progressive collapse type test that have a component of dynamic loading on the system. The key elements to consider in the modeling are whether it is capturing the correct failure modes, whether it can capture local plate or weld failures and whether it be used in the low rate dynamic runs needed for progressive collapse.

There have been many static tests on shear tabs and double angle connections. These have been performed statically to develop moment-rotation curves. For shear tabs, recent research has indicated that the following limit states can occur:

- Shear failure of bolts;

- Yielding of gross area of plate;

- Fracture of net area of plate;

- Fracture of welds; and

- Bearing failure of beam web or plate.

The analytical model should predict these modes from previous test work and be able to handle the dynamic runs needed for progressive collapse.

Reinforced concrete connections have similarly been investigated and the relationships for joint panel failure are currently based on previous test data. Numerical simulation using these relationships needs to be performed to confirm these failure modes predict the results of the static tests and tests using the dynamic progressive collapse loading. The modeling should use explicit reinforcing steel to capture confinement effects and localized detail failures.

\section{B.1.2 Analytical Representation-Simplified Modeling}

Simplified methods that are easy to model and analyze have already been developed for shear tab connections. Using these approaches, the moment curvature properties and failure mechanisms of the simplified models are calibrated with static test results and then used to analyze structures subjected to dynamic loading. Dynamic test results are needed to calibrate these properties and to make sure the calculated failure mechanisms are consistent with observations. Knowing when simple procedures are 
satisfactory or when more sophisticated methods are warranted would help design engineers select the appropriate analysis method for a given structure.

\section{B.1.3 Investigation of Properties of Connections in Existing Buildings}

The accurate representation of connection details depends on the as-built conditions, which may not be accurately represented in the construction documents. In particular, bolt and weld connection details for steel construction and reinforcing bar details for reinforced concrete construction may result from change orders and field conditions that are not represented on the construction documents. Furthermore, degradation of the connection details over time may limit the capacity or increase the flexibility of idealized pristine conditions. A survey of connection details for a variety of construction types and an evaluation of their properties will provide the analyst a range of properties from which the best characterization of the structure may be selected. Following a collection of as-built connection data, advanced analytical models may be developed and the sensitivity of the response to a range of variations observed in actual construction may be determined.

\section{B.1.4 Component Testing-Develop Force-Displacement and Moment-Rotation Properties}

To date, most of this work has been applied to static and earthquake type loading. Research is required to extend this to the strain rates associated with progressive collapse in order to determine any new failure modes that arise and to evaluate which failure modes govern the response. Fracture critical failure modes might be very important.

\section{B.1.5 Evaluate Whether Seismic Connection Requirements Improve Resistance to Progressive Collapse}

Details that were developed for structures in seismic regions have the benefit of over fifty years of construction experience, research and public awareness. Much of the consideration in the development of these details focus on multiple cycles of response and load reversal. Seismic design requirements result in ductile connection details that are capable of resisting multiple cycles of load reversals and inelastic deformation; it is often said without analytical proof that these details will be beneficial in preventing a progression of collapse. While the superior performance of seismic design details relative to conventional connection details is undisputed, the increased effectiveness of these details alone may not be sufficient to arrest the progression of collapse following a localized structural failure. Analytical evaluations of steel frame and concrete frame structures should be conducted using conventional connection details, intermediate moment frame requirements and special moment frame requirements. Any improvements to the performance of structures following the removal of a primary load-bearing element should be noted and the differences investigated. This research may identify relatively simple procedures that are already standard practice in some parts of the country that provide improved resistance to progressive collapse. Alternatively, it may dispel a myth that is perpetuated without a rigorous technical basis. 


\section{B.2 FAILURE CRITERIA}

\section{B.2.1 Acceptance Criteria for Different Analysis Methods}

The evaluation of structural performance in response to an initiating damage state, whether by artificial removal of a critical gravity load bearing element or the application of an extreme loading to a critical gravity load bearing element, may be performed by a variety of approaches ranging from elastic static to inelastic dynamic. The greater the simplification of the analysis in representing the response of the structure, the more difficult it will be to evaluate the performance of the structure from the calculated results. For example, the static methods will ignore inertial effects that will amplify the effect, however, the extent of this amplification will depend on the time over which the critical element is removed and the frequency characteristics of the structure. Because an inelastic analysis is load path dependent, the characteristics of response will depend to a great extent on the extent of this amplification. Similarly, a linear elastic analysis will provide infinite resistance to extreme loading conditions and the calculated response are likely to over predict the member response forces and under-predict the member deformations. The limiting extent of response need to be developed for the range of analytical approximations that may be used to analyze the structure, otherwise the calculated results will be of little use to the design community.

\section{B.2.2 Applicability of Demand Capacity Ratio to Define Failure for Linear Analysis Methods}

Simplified limits on the demand capacity ratios are used by current Guidelines for the evaluation of structural response to column removal, however, these limits are seemingly arbitrary and relatively insensitive to different features of the building construction. These quantities are typically based on a flexural mode and may not be based on shear or axial modes that may be more critical for the prediction of progressive collapse. If these static elastic methods are to be used to determine a structure's performance in response to a zone of localized structural damage, the performance limits need to be better understood and characterized and additional research is required to determine their adequacy and limiting magnitudes.

\section{B.2.3 Applicability of Limiting Ductility or End Rotation to Define Failure}

Steel members will most likely fail at the joints and concrete joints/panel zones will develop rotation limit states. Research is required to define the member failure mechanisms in terms of end-rotation or ductility.

\section{B.3 FLAT SLAB CONSTRUCTION}

Flat slab and flat plate structures are very economical to construct and very popular in many regions of the country. As a result, it is important to determine the extent of resistance these structures have in the event of column removal. Current analytical approaches may not account for the membrane capacity of these structures to redistribute forces. 


\section{B.3.1 Development of Catenary Slab Resistance}

Research previously performed at White Sands Missile Range showed that slabs can redistribute significant forces and prevent the beams from collapsing, particularly for small buildings with short bays. Extensive analytical studies are required to determine the extent slabs assist structural frames in bridging over failed components.

\section{B.3.2 Testing of Full Scale Flat Slab Structure}

Various criteria and guidelines define design procedures to mitigate the possibility of progressive collapse of buildings due to abnormal loading; however, many of these approaches are idealized or prescriptive and there is little direct evidence that these approaches are effective in response to actual events. Because physical tests of test structures are prohibitively expensive, actual buildings that are slated for demolition may be subjected to small satchel explosives that are designed to destroy local load bearing elements. These tests should be instrumented to capture the structure's dynamic response and the results of these tests should be compared with analytical predictions to validate existing modeling approaches.

\section{B.4 FIRE INDUCED PROGRESSIVE COLLAPSE}

\section{B.4.1 Coupling Thermal, Mechanical, and Structural Analysis}

The performance of structures in response to extended exposure to elevated temperatures may be determined through coupled thermal, mechanical and structural analyses. These calculations, based on idealized fire spread and fireproofing conditions, correspond to a sequence of static analyses of the structure using heat specific degraded mechanical properties of the materials. The analyses may then identify the theoretical time to failure of individual structural elements; however, should a localized failure overstress adjacent structural components, thereby precipitating a progression of collapse, the subsequent calculations of the fire weakened structure are necessarily dynamic and inelastic.

\section{B.4.2 Material Behavior at Elevated Temperatures}

Ongoing research is required to evaluate material behavior at elevated temperatures. Material properties that may be used in structural analysis software must be developed for a variety of construction materials including steel frame construction, reinforced concrete frame construction and gravity load-bearing wall construction. Tests of full scale structural elements subjected to simulated dead and live loads must be performed at sustained elevated temperature to determine the effectiveness of fireproofing materials and the rate of degradation of material properties over time.

\section{B.4.3 Fire Exposure}

Realistic design basis events, corresponding to likely fire conditions in modern construction and occupancies, need to be studied and defined. Fire exposures, based on the fuel loads and fire spread, will enable engineers to determine whether the likely extent of exposure will result in a catastrophic collapse. 


\section{B.4.4 Investigation of Case Histories}

Investigations of actual fires within steel frame, concrete frame and load-bearing wall construction are required in order to correlate observed performance with analytical methods. Accurate information regarding the structural system, occupancy, contents and damage state condition of the structure as well as eyewitness accounts of the fire spread are required for these investigations to be meaningful. While this will not necessarily provide comprehensive validation for the analytical methods, it will provide the engineering community confidence that the available methods are predicting performance levels that are consistent with past events. These investigations should be an ongoing process as fire events and fire damage are reported and fire departments should be encouraged to document future events to a degree necessary for meaningful investigations to be performed.

\section{B.5 DEVELOPMENT OF IMPACT FACTORS FOR SLAB "PANCAKE" FAILURE}

Flat slab construction is particularly vulnerable to punching shear failure, particularly prior to complete curing of the concrete or as a result of overloading the floor system. Self-load and live loads are amplified when a slab fails at its supports and impacts the floor below. These impact amplification factors may overwhelm the floor below and cause a cascading failure of floor slab until failure is arrested. Inelastic dynamic analyses of a flat slab punching shear failure and the subsequent impact onto the floor below may be performed to determine the effective amplification factors and response characteristics of the floor below. Different types of flat slab details may be evaluated to determine which are most resistant to the impact loads and able to arrest the progression of collapse.

\section{B.6 QUANTIFICATION OF RISK ASSOCIATED WITH DIFFERENT UPGRADE APPROACHES}

The effectiveness of common candidate measures for upgrading existing buildings to enhance their resistance to local damage or progressive collapse should be evaluated within the general context of the risk assessment described in Chapter 2. The value of alternative risk mitigation measures must be traded off against the required additional investment to provide these measures. Because risk measures are relative rather than absolute, risk benchmarks and costs must be established for common rehabilitation technologies that can be used as a standard for comparing alternatives. Research is required to develop a series of test-beds and databases describing costs and uncertainties that the professional engineering community can draw upon to educate itself and to facilitate communication of risks and benefits to other stakeholders. While the life safety performance goal is paramount, efforts should be made to address other relevant performance goals as well.

\section{B.7 PERFORMANCE OF PRESCRIPTIVE DESIGN REQUIREMENTS}

Prescriptive design requirements were incorporated in the U.K. Building Standards since the 1970s and these provisions are acknowledged to be effective in protecting the occupants in response to extreme loading. Because this implicit approach establishes the acceptable level of protection against progressive collapse for all projects, it is most appropriate for the design of regular building layouts that do not contain significant transfer mechanisms and for structures that do not qualify for a higher importance category. However, the development of these prescriptive requirements is not well documented and their 
evolution over time is not well understood by U.S. reviewers. It would therefore be of great interest to trace the development of the requirements and to subject structures designed with and without these prescriptive requirements to numerical simulation studies. This investigation will demonstrate the effectiveness of the prescriptive design requirements and possibly produce modifications to specific details that will improve their value.

\section{B.8 REFERENCES}

FEMA-267, Interim Guidelines: Evaluation, Repair, Modification, and Design of Welded Steel Moment Frame Structures, (SAC 95-02), Federal Emergency Management Agency, 1995, 215 pp.

FEMA-267A, Interim Guidelines Advisory No. 1 - Supplement to FEMA -267, (SAC 96-03), Federal Emergency Management Agency, 1997; 100 pp.

FEMA 288, Background Reports on Metallurgy, Fracture Mechanics, Welding, Moment Connections and Frame Systems Behavior, (SAC 95-09), Federal Emergency Management Agency, 1996, 365 pp.

FEMA 289, Connection Test Summaries, (SAC 96-02), Federal Emergency Management Agency, 1997; $135 \mathrm{pp}$. 


\section{Appendix C \\ CASE Studies}

\section{C.1 INTRODUCTION}

This appendix includes case studies of a few buildings that offer some insight into the causes for progressive collapses and the means by which such failures can be mitigated. It is divided into three sections: Major Collapses, Structures that Survived Major Damage, and Designs to Prevent Progressive Collapse.

\section{C.2 MAJOR COLLAPSES}

This section describes a few structural collapses that, in many cases, began with isolated damage that led to a progression of failures until a disproportionate portion of the entire structure collapsed. These events offer insight into structural conditions that should be avoided during designs for robustness.

\section{C.2.1 Ronan Point}

\section{C.2.1.1 Introduction}

Ronan Point was a development of apartment buildings in London. It was built between 1966 and 1968. On the morning of May 16, 1968, a gas leak caused an explosion in an apartment of the 18th floor of one of the buildings. The explosion blew out an exterior wall panel. The loss of an exterior wall triggered the collapse of the upper floors followed by the collapse of the floors below due to the impact of the falling upper floors.

\section{C.2.1.2 Description of the structure}

The Ronan Point buildings were $64 \mathrm{~m}$ (210 ft) tall, 22 story apartment buildings. With five apartments per floor, the footprint of the building with the collapse measured $24.4 \mathrm{~m}$ by $18.3 \mathrm{~m}(80 \mathrm{ft}$ by $60 \mathrm{ft})$. Of the 110 apartments in the entire building, 44 were one-bedroom apartments and 66 were two-bedroom apartments. The structural system, including the walls, floors, and staircases was precast concrete. Each floor was supported directly by the walls in the lower stories. The wall and floor system fitted together through slots and were bolted. The connections were filled with dry packed mortar to secure the connection.

The system used in Ronan Point was selected because of ease of construction. The structure was assembled by lifting the precast concrete panels with a crane and then bolting them together. In essence, the structure was like a "house of cards" with no redundancy for load redistribution in the even of a local failure. 


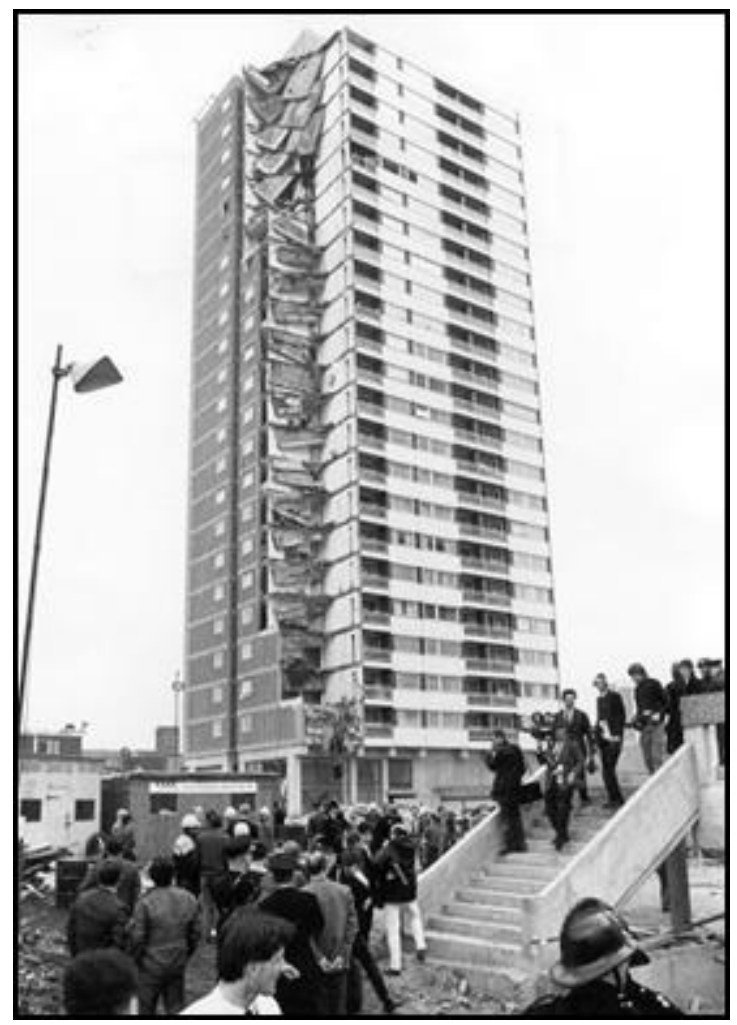

Figure C1. Ronan Point after collapse

(http://www.eng.uab.edu/cee/faculty/ndelatte/case_studies_project/Ronan Point.htm)

\section{C.2.1.3 The event}

On the morning of May 16, 1968 a gas explosion blew out an outer panel of the $18^{\text {th }}$ floor of one the buildings in Ronan Point. The loss of a bearing wall in the $18^{\text {th }}$ floor caused the progressive collapsed of floors nineteen through twenty-two. Then, a second phase of progressive collapse occurred. The dynamic loading imparted by the falling debris triggered the progressive collapse of floors seventeen and below. The southeast corner of the building collapsed to the ground level. The collapse destroyed the living room portions of the apartments, leaving intact the bedrooms, except for floors seventeen through twenty-two.

\section{C.2.1.4 Progressive collapse issues}

The British government formed a team to investigate the causes of the collapse of the Ronan Point Tower. The investigating team concluded that the explosion was small and estimated that a pressure less than 10 psi was originated from the outburst. The primary evidence of a small explosion was that the hearing of the person who lit the match was not damaged. Tests were performed by the Building Research Station and Imperial College to estimate the structural capacity of the as-built Ronan Point tower. The results showed that the kitchen and living room walls would fail at a pressure of about approximately $11.7 \mathrm{kPa}$ (1.7 psi), while the exterior wall would fail at a pressure of approximately $20.7 \mathrm{kPa}(3 \mathrm{psi})$.

The collapse of the Ronan Point building was attributed to its lack of structural integrity. There was no alternate load path for redistribution of forces at the onset of the loss of a bearing wall. Therefore, as the exterior wall of the 18th floor apartment was blown out, the exterior walls of the upper floors immediately 
collapsed. The impact loading of the falling debris on floor seventeen was sufficient to exceed its capacity and to trigger the sequential failure of the lower 16 floors.

The investigation of the Ronan Point collapse showed other interesting aspects of the design. It was determined that strong winds and/or the effects of a fire could also have caused progressive collapse. In addition, it was found that the building had been built with very poor workmanship. Only half of the specified mortar had been placed in the connections and bolts and nuts were not tightened as specified. However, it was concluded that this issue had little impact on the event of May 16, 1968. Although the building was rehabilitated and strengthened, continuing concerns about structural safety led to its demolition in 1986.

\section{C.2.1.5 References}

http://www.lalamy.demon.co.uk/ronanpnt.htm

Pearson, C. and Delatte, N. "Lessons Learned from the Progressive Collapse of the Ronan Point Apartment Tower," Forensic Engineering, Proceedings of the Third Congress, October 19-21, 2003, San Diego, CA.

McGuire, W. "The Why of General Structural Integrity," Engineering Foundation Conference, Structural Failures II. Palm Coast, Florida, December 1987.

\section{C.2.2 Kansas City Hyatt Regency Hotel Skywalks}

\section{C.2.2.1 Introduction}

The Kansas City Hyatt Regency Hotel was constructed with a large atrium area that was used on occasion for large gatherings. On July 17, 1981, a tea dance attended by between 1500 and 2000 people drew spectators and dancers to the atrium floor and the three pedestrian walkways that were suspended overhead. Suddenly, the $2^{\text {nd }}$ and $4^{\text {th }}$ floor walkways collapsed, killing 114 people and injuring over 200 more.

\section{C.2.2.2 Description of structure}

The Kansas City Hyatt Regency Hotel is a 40-story tower, with guest rooms and an atrium, which opened in 1980. Three walkways were suspended from the ceiling level of the atrium. The $2^{\text {nd }}$ and $4^{\text {th }}$ floor walkways shared a common suspension system, with the $2^{\text {nd }}$ floor walkway suspended directly below the $4^{\text {th }}$ floor walkway. The $3^{\text {rd }}$ floor walkway was in a different area and hung separately from the ceiling.

The walkways were constructed of structural steel and hung by steel rods from the roof of the atrium.

The original design of the $2^{\text {nd }}$ and $4^{\text {th }}$ floor walkways called for them to be hung from the "ceiling" using continuous rods to support both walkways. Hence, these two walkways were to be connected independently to the same set of rods.

In the final configuration the contractor elected not to support both walkways from the same steel rods but to hang the $4^{\text {th }}$ floor walkway from a set of rods that extended directly from the roof structure and 
terminated under the channels that were part of the framing system for the 4 th floor walkway. The $2^{\text {nd }}$ floor walkway was suspended, in turn, from separate rods which extended to the 4th floor walkway and connected to the same framing channels there. This meant that the loads from the $2^{\text {nd }}$ floor walkway were transferred to the channels of the $4^{\text {th }}$ floor walkway, and that the forces in the connections from the $4^{\text {th }}$ floor walkway to the rods to the roof were essentially twice as large as in the original design intent.

\section{C.2.2.3 The event}

On July 17, 1981, during a video taped tea dance, people were on all three walkways so that they could better view the event. The $4^{\text {th }}$ floor walkway collapsed onto the $2^{\text {nd }}$ floor walkway, while the $3^{\text {rd }}$ floor walkway remained intact.

\section{C.2.2.4 Progressive collapse issues}

Apparently the original design was barely capable of carrying the loads and the revised design placed significant additional loads on the beams at the $4^{\text {th }}$ floor. Certain elements of the connection details were changed as well. While the original intent was for the loads of both walkways to be carried directly by the steel rods hung from the atrium roof, the fabricator found difficulties in constructing the system as shown on the drawings.

The fabricator altered the detail, and claimed that he telephoned the structural engineer for change approval. The engineer claims that he did not receive such a call.

A lack of communication between the structural engineer and the fabricator is certainly a major contributor to the failure of the walkways. However, evidence shows that the structural engineer did receive revised drawings during construction and that he approved them. The revised design was much less capable of carrying the required loads.

Whether the structure had been constructed as originally designed or as modified during the construction process, it was a statically determinate system with no potential to develop alternate load paths. Once one of the connections failed, it created the potential for both walkways to collapse. Further, the distortions placed on the elements of the walkways in the event of a single failure necessarily were too severe for nearby connections to survive. Total collapse of these walkways was an inevitable outcome of the failure of a single connection, because induced loads and distortions would by necessity fail adjacent hanger connections in succession.

This event drew significant attention to the practice within the structural engineering community for the design of connections. Prior to this event, it was common practice for fabricators to design certain connections in structures. Subsequently, structural engineers now generally assure themselves that the connections are designed either by the engineer of record or a responsible, qualified party.

\section{C.2.3 L'Ambiance Plaza}

\section{C.2.3.1 Introduction}

L'Ambiance Plaza was a 16-story apartment building under construction in Bridgeport, Connecticut. It was being erected using the lift-slab technique, which required the floor slabs to be cast on the ground and 
lifted into place by a jacking operation. In the afternoon of April 23, 1987, shortly after completion of one of the jacking operations, the building collapsed entirely.

\section{C.2.3.2 Description of the structure}

The structure had two wings of post-tensioned concrete flat slabs supported on steel columns. Erection was by the lift-slab process, which involved the casting of all floor slabs at grade level, one on top of the other. Columns were installed in sections that were several stories high, through holes left for this purpose in the stack of slabs. Jacks were installed at the tops of these columns, and then the slabs were jacked up the columns in groups. The lower slabs were connected in succession at their permanent locations on the columns.

Upper-floor slabs could not be lifted to their final positions until the lower floors were in place and the full heights of the columns were installed. Hence, slabs needed to be temporarily "parked" at storage locations on the columns for periods of days while related construction proceeded. Parking was achieved by installing steel wedges under groups of three slabs, with the wedges resting on sloped parking plates that were welded to the flanges of the columns. Wedges allowed for height adjustment, but they needed to be tack welded in place for security.

Lateral resistance in the completed structure was to be provided by shear walls that were constructed in slots left in the slabs for this purpose. Shear wall construction followed the lifting of slabs by several floors. During the interim period when shear walls were not in place, upper stories were stabilized with guy wires. However, interferences prevented guy wires from being installed where slabs were being lifted.

The concrete slabs had very little mild steel reinforcing. The perimeter of the slab of each floor was encircled with two number 4 bars, as were all openings for shear walls and the elevator shafts.

Post-tensioning tendons were designed to create one-way slabs. Bundles of tendons were placed along column lines parallel to the long dimension of the slabs (Figure C2). In the transverse direction, posttensioning tendons were uniformly spaced to carry floor loads from the slab to the column strips reinforced with the bundled tendons. Tendons in both directions were draped.

Elevator shafts in one wing required alterations of the basic patterns of post-tensioning tendons. With the elevator shaft interrupting a column line, the construction called for placement of two columns, one on either side of the opening. In one case, the remaining strip of slab concrete between the elevator shaft opening and the opening around the column was only a few centimeters (inches).

The tendon pattern along the interrupted column line splayed at the last column in the line, with a portion of the bundled tendons sweeping to the column on one side of the elevator shaft, and the remaining tendons sweeping in the other direction to the second column adjacent to the elevator shaft (Figure C2). 


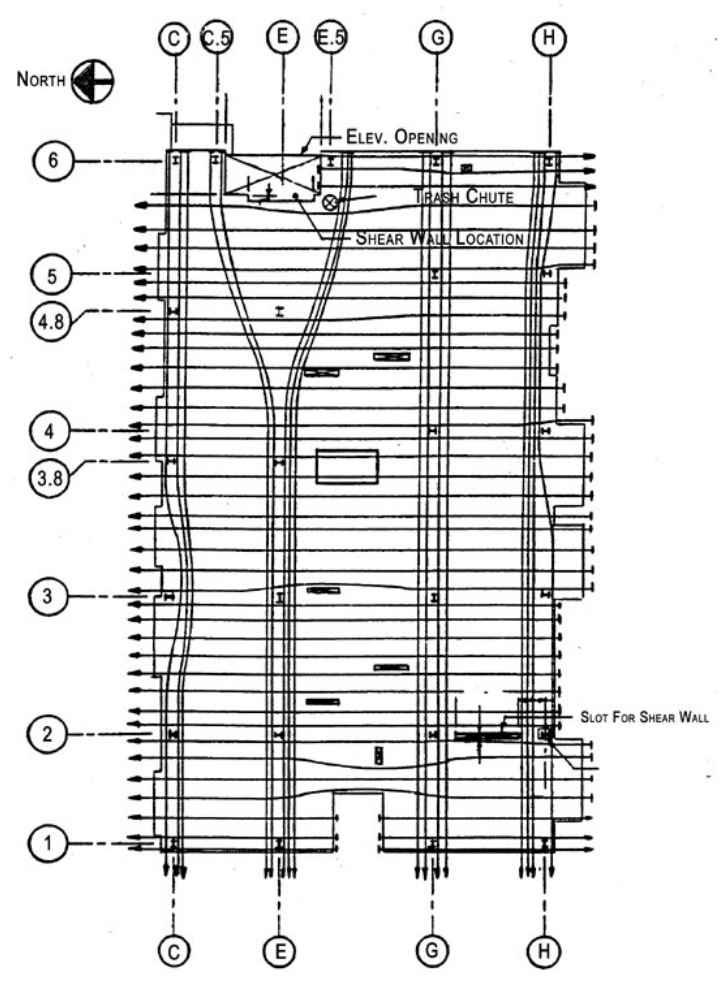

Figure C2. Tendon layout pattern

All openings in the slabs for columns were framed in shear collars composed of steel channel sections welded together at corners (Figure C3). On the insides of two of the channels were welded angles with slots the projected inward toward the columns. The slots in the angles were where jacking rods connected the lifting jacks to the group of slabs to be lifted. The slots were open on the inboard edge of the angles, so that the lifting rods could be slipped in with nuts under the angles to engage the lifting collars.

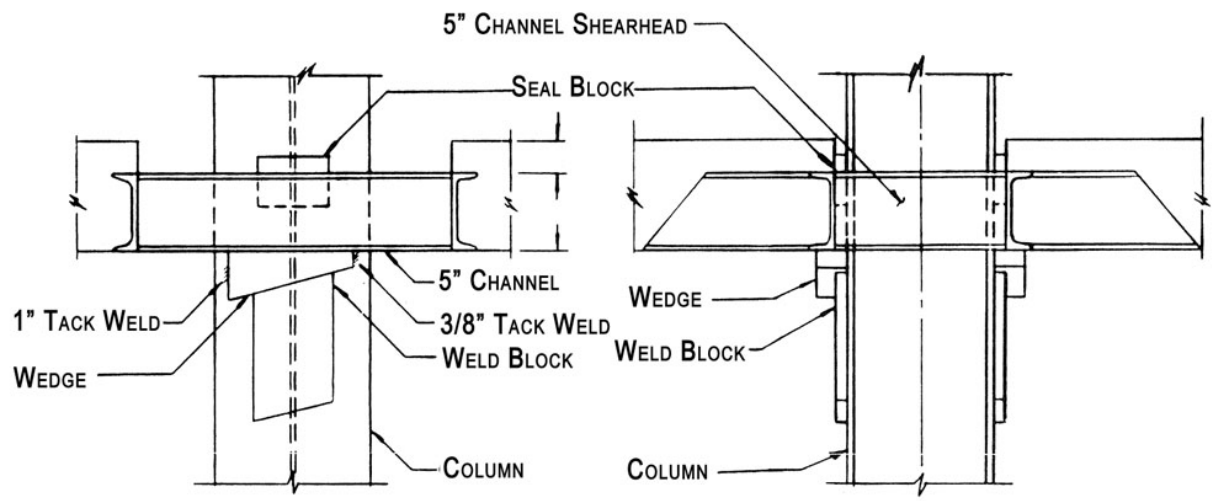

Figure C3. Shear collar configuration

The wedges that supported the slabs rested on the underside of the shear collars. With column dimensions decreasing with height, progressively larger wedges were needed from floor to floor to bridge the gap between the faces of the columns and the shear collars. 


\section{C.2.3.3 The event}

In the morning preceding the failure, a group of slabs had been lifted to a parking position, and work had begun to install wedges so that jacks could be disconnected. Apparently, there had also been attempts to plumb the columns supporting the newly-lifted slabs, by jacking between slabs of that wing and the slabs of the adjacent wing of the building.

Witness to the collapse report that failure began where workers were installing wedges, which also happened to be at the column where bundled tendons splayed to opposite sides of the elevator shaft opening. Apparently, there was sudden loss of support for one or more slabs near that location, leading ultimately to the entire collapse of both wings of the building in a matter of seconds.

The debris from each wing fell into piles that largely did not extend outside the footprint of the building (Figure C4). In general, the center portions of slabs for each wing were near the bottoms of the piles, and the slab corners were turned up or, in some cases, upside down.

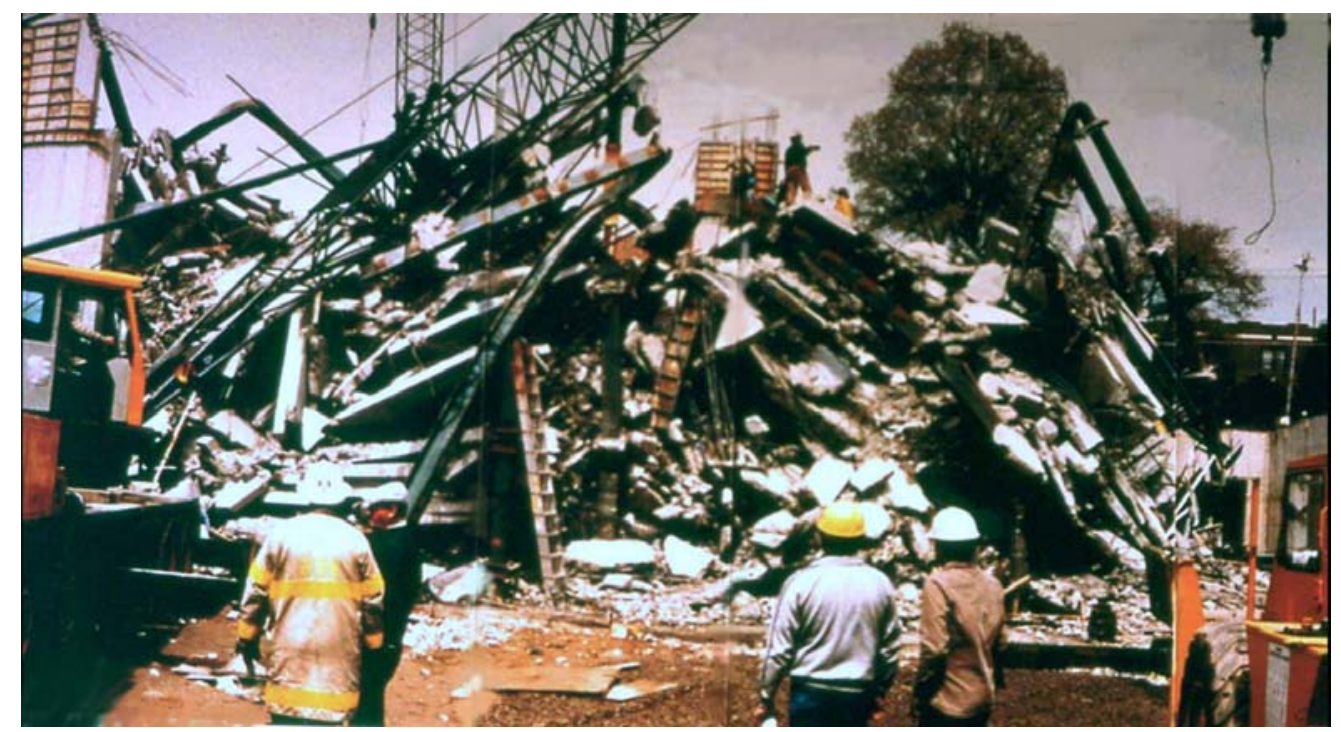

Figure C4. Debris Pile from collapse of L'Ambiance Plaza

Many investigators studied this failure. However, the circumstances under which these investigations were performed generally did not allow for their thorough completion. The Occupational Safety and Health Administration enlisted the National Bureau of Standards (NBS) (now called the National Institute of Standards and Technology) for a study that was mandated by law to be completed within six months. Investigators retained by potential litigants to lawsuits related to the collapse were discharged when the lawsuits were settled before most experts were able to fully evaluate evidence, data, and analyses. Hence, there remain several conflicting opinions about the initiating causes of the collapse. Several of the potential causes include the following.

NBS concluded (Culver et al., 1987) that the failure occurred because a lifting rod was not fully seated in the slot on a lifting collar. In this configuration, the lifting collar would have been overloaded causing the supporting angle to rotate and release the lifting rod. With the lifting rod disconnected, the slab it supported at that location would have dropped, leading to local failure of the slabs. 
A second theory (Cuoco, 1992) is that the wrong size wedges were used to temporarily support the slabs on the parking plates. Documents for the construction apparently show that the specified wedges at the location of the failure were not as thick as they should have been to bridge the gap, leading to the possibility that they could roll off the parking plates. Once that occurred, the supported slab at that location would have dropped.

A third theory (Heger, 1991 and Poston et al., 1991) relates to the configuration of the post-tensioning tendons. At the column where failure is believed to have begun, the tendons diverged horizontally, creating unusual tension stresses in the plane of the slab. At the terminus of these splayed tendons, all tendons were positioned on one side of the last column, and the amount of concrete surrounding that column was minimal. A more damaging detail, however, was that the specified drapes for the slab tendons did not account for the separation of the tendons for a single column line into two bands (Figure C5). The slab tendons were shown to be high in the slab along the extension of the column line (proper position if the tendons had not been separated) and low at the locations of the splayed tendons (locations that might have been at mid-span of the slab if the tendons had not been separated). If constructed this way, the tendons were in the wrong places, causing the post-tensioning operation to induce critically high tensile stresses in slabs that had no effective reinforcing to restrain cracks. If cracks were induced in one of these slabs, it would have broken and dropped.

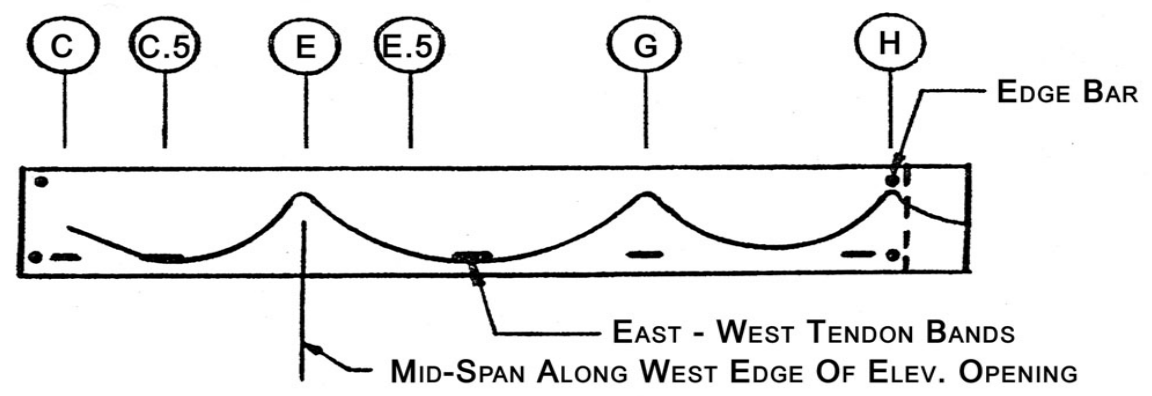

Figure C5. Tendon positions in slabs

\section{C.2.3.4 Progressive collapse issues}

There are several other theories to explain the initiation of the collapse of L'Ambiance Plaza. While there may never be agreement of the trigger for the collapse, it is clear that the failure originated with a localized failure, and progressed through not just the wing where that failure occurred, but also destroyed the adjacent wing.

The primary reasons why the structure was not able to sustain the localized failure include the following.

1) The floor slabs had minimal mild steel reinforcing. Throughout most of the slabs, the cracking strength of the concrete exceeded the strength of the reinforcing steel. Hence, cracks that formed must have been able to grow without significant restraint.

2) The slabs had ungrouted post-tensioning tendons. Once one bay of the structure was damaged sufficiently to rupture tendons, the strengths of all bays through which those damaged tendons passed were compromised. Successive failures of slab bays were inevitable.

3) The stability of the frame during construction did not provide reserve for unusual conditions. Upper floors did not have guy wires, shear walls were not installed to full height, and the 
temporary connections between the columns and the slabs had limited moment transfer capability. The slabs rested on two wedges that were tack welded. Moment continuity existed only to the extent that the gravity loads were balanced between the two wedges, and neither lifted off when the slab rotated. Once one side of the lifting collar tended to lift off, tack welds would have failed and moment restraint would have been lost.

\section{C.2.3.5 References}

Cuoco, Daniel (1992), "Investigation of L'Ambiance Plaza Building Collapse," Journal of Performance of Constructed Facilities, American Society of Civil Engineers, November, 1992.

Culver, Charles G., Scribner, Charles F., Marshall, Richard D., Yokel, Felix Y., Gross, John L., Yancey, Charles W., and Hendrickson, Erik M. (1987), "Investigation of L'Ambiance Plaza Building Collapse in Bridgeport, Connecticut," NBSIR 87-3640, U.S. Department of Commerce, National Bureau of Standards, Gaithersburg, Maryland.

Heger, Frank J. (1991), “Public Safety Issues in Collapse of L'Ambiance Plaza.” Journal of Performance of Constructed Facilities, American Society of Civil Engineers, May, 1991.

Poston, Randall W., Geldmann, Gerard C., and Suarez, Mario G. (1991), "Evaluation of L'Ambiance Plaza Posttensioned Floor Slabs," Journal of Performance of Constructed Facilities, American Society of Civil Engineers, May 1991.

\section{C.2.4 Alfred P. Murrah Federal Building}

\section{C.2.4.1 Introduction}

The Alfred P. Murrah Building (hereafter referred to as the Murrah Building), located in Oklahoma City, Oklahoma, was an office facility for the U.S. government. On the morning of April 19, 1995 the Murrah Building was the target of a terrorist attack in which a truck bomb was detonated in front of its north side. The explosion caused extensive structural damage to the building.

\section{C.2.4.2 Description of the structure}

The Murrah Building was designed and constructed between 1970 and 1976. The structural configuration of the Murrah Building was composed of a nine-story reinforced concrete ordinary moment frame. The overall plan dimensions were approximately $67 \mathrm{~m}(220 \mathrm{ft})$ in the east-west direction and $30.5 \mathrm{~m}(100 \mathrm{ft})$ in the north-south direction. The architectural plan of the building consisted of ten $6.1 \mathrm{~m}(20 \mathrm{ft})$ bays in

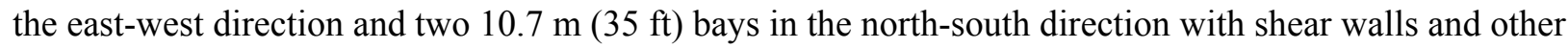
localized columns in the middle of the south side of the building. The typical floor height was $4 \mathrm{~m} \mathrm{(13 \textrm {ft } )}$ from the third to the eighth floor and $4.3 \mathrm{~m}(14 \mathrm{ft})$ for the ninth floor. A picture of the undamaged building is shown in Figure C6.

A key feature of the building was a transfer girder at the third floor level in the north side of the building. The transfer girder had a span of $12.2 \mathrm{~m}(40 \mathrm{ft})$ and supported columns spaced at $6.1 \mathrm{~m}(20 \mathrm{ft})$ in the

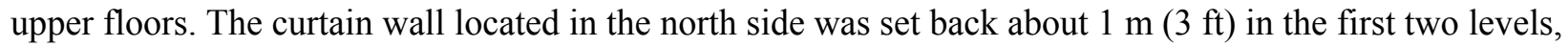
providing an open space below the third level. 
Vertical circular ventilation shafts serve as support to spandrel beams in the east and west ends. The infill walls between spandrels were 75 -mm (3-in) granite panels backed by vertical steel studs and drywall.

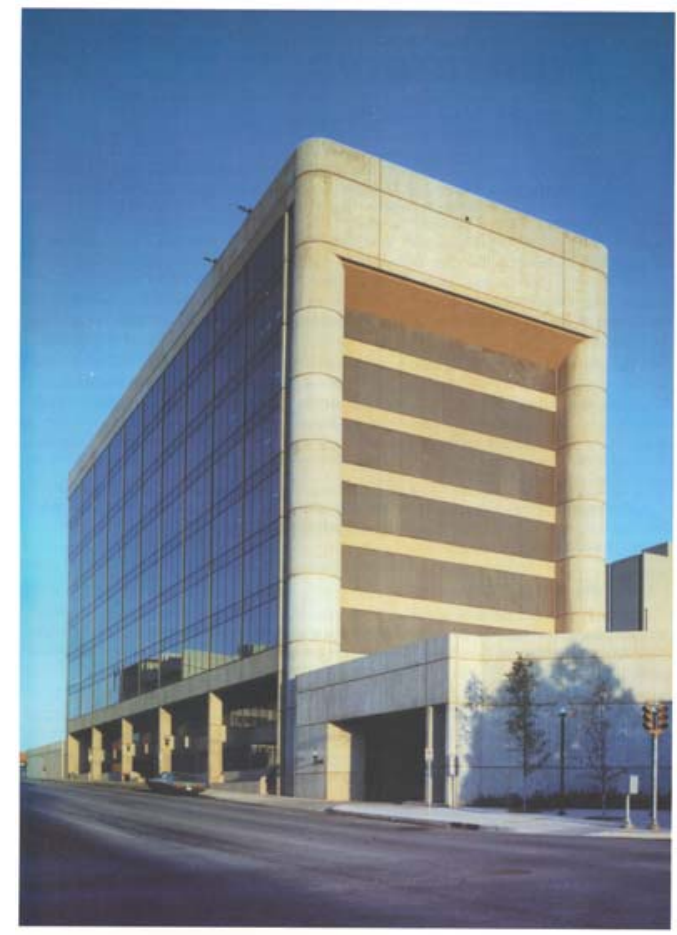

Figure C6. Alfred P. Murrah Building before explosion (FEMA 277)

\section{C.2.4.3 The event}

At approximately 9:00 AM on April 19, 1995 a truck bomb was parked on the street right in front of the north side of the Murrah Building. The bomb was detonated, causing extensive damage to the Murrah Building and various degrees of damage to other buildings in the vicinity of the explosion.

The north side of the Murrah Building, which was exposed directly to the blast, sustained severe structural damage. Most of the north half of the rectangular footprint was destroyed. The damage spread the entire $21.3 \mathrm{~m} \mathrm{(70} \mathrm{ft)} \mathrm{width} \mathrm{of} \mathrm{the} \mathrm{building.} \mathrm{Three} \mathrm{columns} \mathrm{that} \mathrm{supported} \mathrm{the} \mathrm{transfer} \mathrm{girder} \mathrm{in} \mathrm{the}$ third floor were immediately destroyed by the blast, triggering progressive collapse of the upper stories. It was estimated that roughly half of the usable space in the building collapsed. The failure boundaries and a picture of the north side of the building after the explosion are shown in Figure C7.

The east end wall suffered significant damage. The blast removed some of the granite panels of the infill walls from the third through the sixth floor. Some the granite panels in the seventh floor were fractured. Other panels randomly failed in flexure due to inward or outward pressure. All granite panels in the west end wall remained in place but some failed in flexure due to outward or inward pressure from the blast. Damage to the south side of the building was mild and limited to failure of glazing and door frames. 


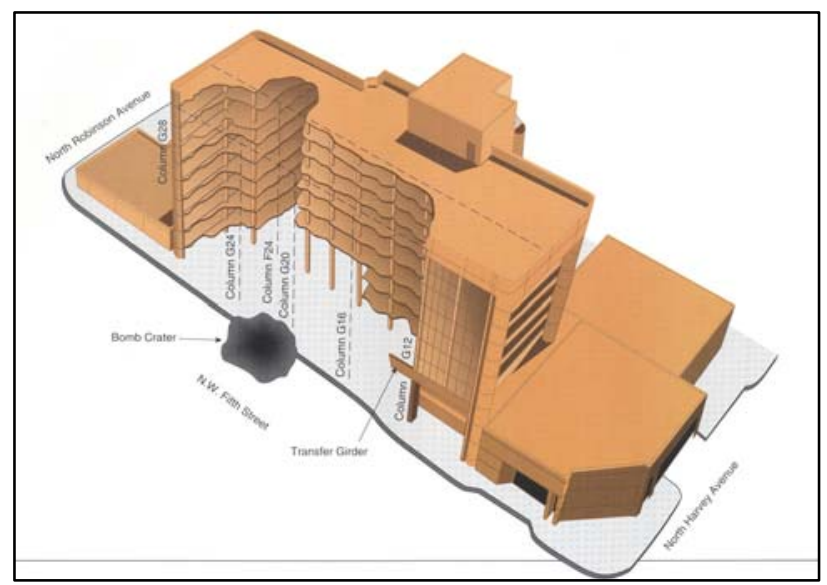

(a)

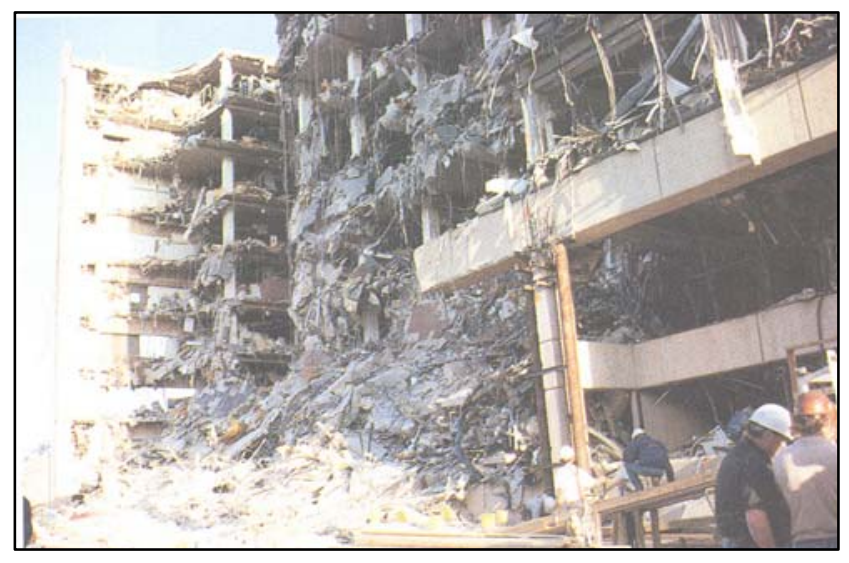

(b)

Figure C7. a) Failure boundaries, b) North side of the building after the explosion (Himman and Hammond, 1997))

\section{C.2.4.4 Progressive collapse issues}

The structure was designed as a reinforced concrete ordinary frame in accordance with ACI 318-71. A building performance evaluation team assembled by the Federal Management Emergency Agency (FEMA) determined that the design was adequately performed following the existing codes at the time and that the building was very well detailed. In agreement with the governing codes, the building was not designed to resist blast, earthquakes, or any other type of extreme loading condition.

It was estimated that the explosion had a yield equivalent to approximately $1.8 \mathrm{Mg}(4,000 \mathrm{lb})$ of TNT and that the bomb was located approximately $4.9 \mathrm{~m}(16 \mathrm{ft})$ from one of the columns in the north side of the building. The blast immediately removed this column, which supported the transfer girder of the third floor. The investigating team determined that an ordinary moment frame could not allow for the redistribution of load that resulted from the removal of a first floor column.

The assessment team found during the investigation that the removal of a column in the first floor would redirect additional loads to the laterally adjacent columns, exceeding their yield moment and shear capacity. The loss of these columns would leave the transfer girder only partly supported. It was concluded that an ordinary moment frame could not sustain the level of ductility required to redistribute the loads with three columns missing in the first story.

The investigating team suggested that if more recently developed detailing, such as those present in special moment frames used in seismic regions had been in place, the collapsed area would have been reduced at least by $50 \%$ and at most by $80 \%$.

\section{C.2.4.5 References}

Corley, W.G., Mlakar, P.F., Sozen, M.A., and Thornton, C.H. "The Oklahoma City Bombing: Summary and Recommendations for Multihazard Mitigation", Journal of Performance of Constructed Facilities, 12(3), 1998, P 100-112. 
Corley, W.G., Mlakar, P.F., Sozen, M.A., and Thornton, C.H. "The Oklahoma City Bombing: Structural Details and Possible Mechanisms for the Murrah Building", Journal of Performance of Constructed Facilities, 12(3), 1998, P 120-136.

FEMA 277 "The Oklahoma City Bombing: Improving Building Performance Through Multi-Hazard Mitigation," Federal Emergency Management Agency and ASCE, August 1996.

Hinman E. E. and Hammond D.J. "Lessons from the Oklahoma City Bombing: Defensive Design Techniques.” 1997 ASCE Press.

\section{C.2.5 Jackson Landing Skating Rink}

\section{C.2.4.1 Introduction}

The Jackson Landing Skating Rink was an unheated, covered skating rink in Durham, New Hampshire. After a heavy snow storm in 1996, the entire roof covering the ice collapsed completely (Figure C8). Fortunately, the sole person in the rink at the time of the failure escaped injury.

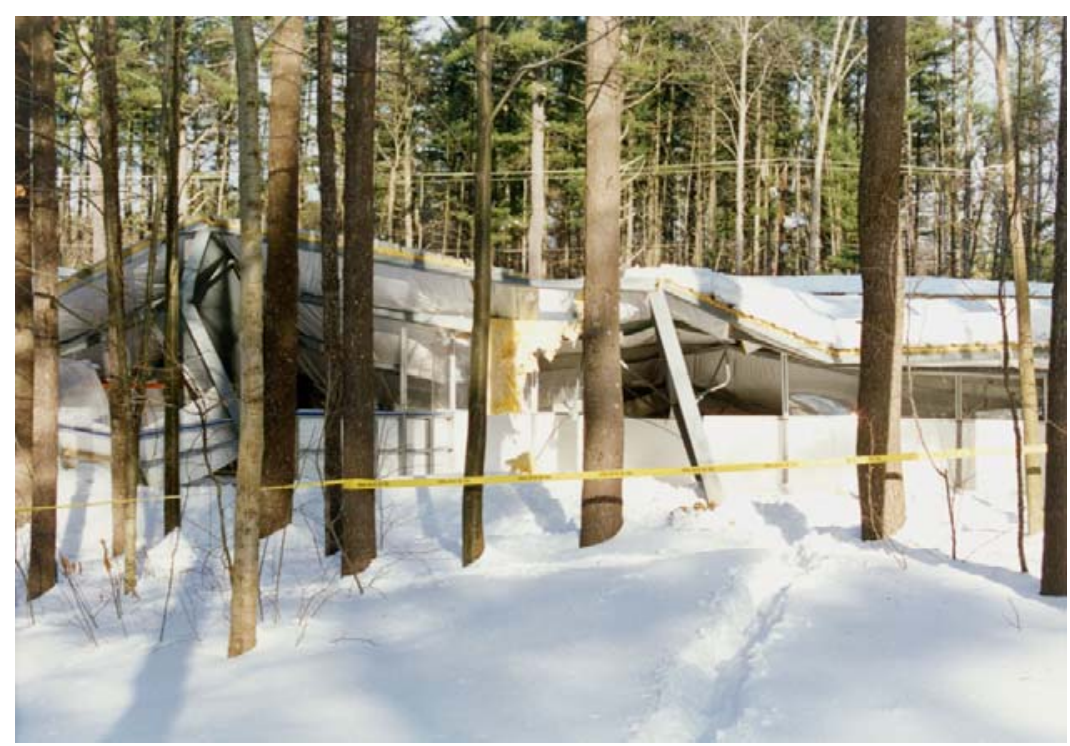

Figure C8. Collapsed Jackson Landing Skating Rink

\section{C.2.4.2 Description of the structure}

The roof structure was a pre-engineered rigid frame structure (Figure C9), approximately $210 \mathrm{ft}$ (64 m) long by $30.5 \mathrm{~m}(100 \mathrm{ft})$ wide. There were 9 bents spaced at $6.4 \mathrm{~m}(21 \mathrm{ft})$, and column-and-beam end walls. The roof structure was metal deck over steel Z-shaped and C-shaped purlins that were bolted to the top flange of the bents. Side and end walls were open. In the long direction, perpendicular to the spans of the bents, lateral loads were carried by cable crossbracing in 3 bays.

The bents rested on cast-in-place circular concrete piers that extended typically approximately $1.5 \mathrm{~m}(5 \mathrm{ft})$ below grade. The thrust at the base of each bent was supported by two steel tie rods that extended under the structure, embedded in concrete-filled trenches below the ice, to connect the concrete piers on opposite sides of the bents. Anchorage for the steel rods was to be through steel plates that were to be cast into the piers, positioned outboard of the anchor bolts for the columns (Figure C9). 


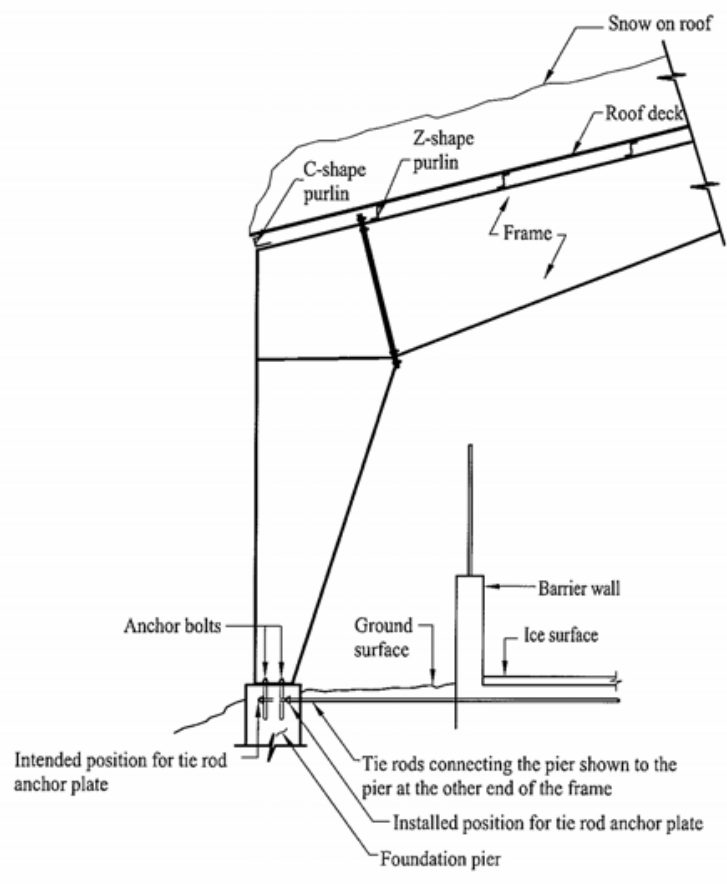

Figure C9. Framing system

\section{C.2.5.3 The event}

Over the days preceding the collapse, snow accumulated to about $750 \mathrm{~mm}$ (30 in) depth in Durham. The unheated, relatively low-slope rink roof structure accumulated all the new snow, loading it to approximately $1.3 \mathrm{kPa}$ (27 psf) at the time of the failure (the design load was approximately $1.9 \mathrm{kPa}$ [40 psf]).

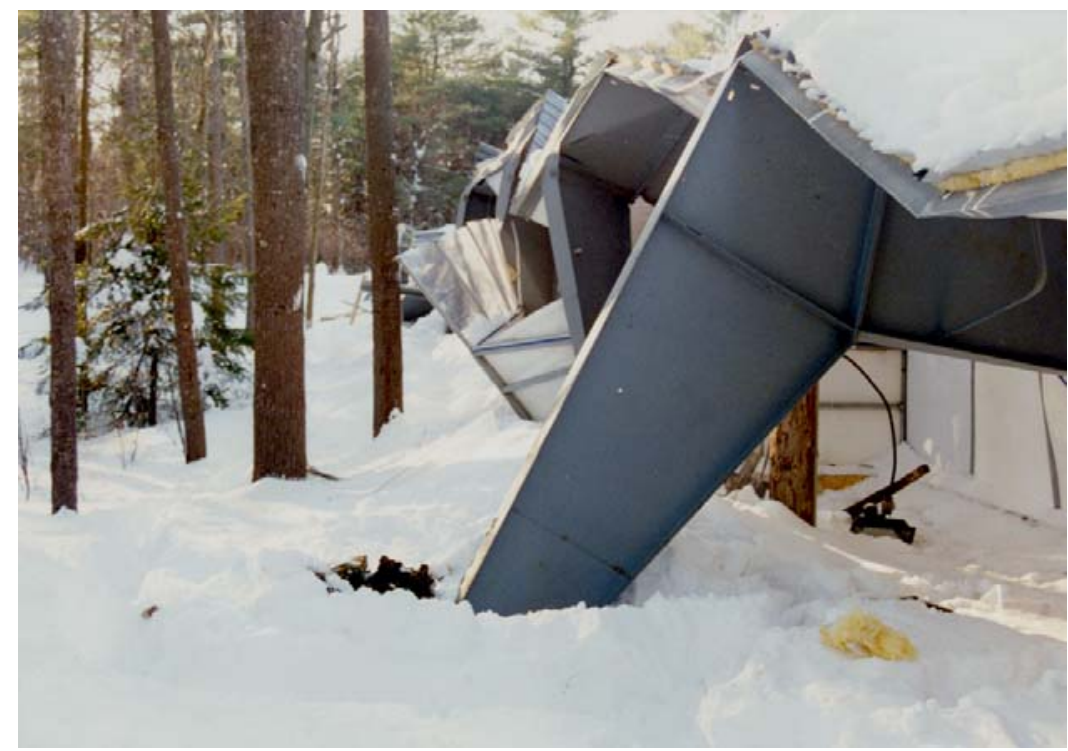

Figure C10. Failed bents looking in direction of progression of collapse

The failure began at one end of the rink (Figure C10) when anchorage for the thrust tie rods for one of the bends failed suddenly. The collapse of one bent caused the anchorage to fail at two adjacent bents. The 
next three bents failed by overload as the collapsing purlins successively pulled down on the roof structure. The last three bents at the far end of the structure from the failure origin point toppled over from lateral load induced by the progressive collapse.

\section{C.2.5.4 Progressive collapse issues}

An investigation of the failure traced the initial failure to misplaced anchor plates. At the first failure location, the anchor plates had been placed inboard of the anchor bolts for the columns. The progressive collapse began when one of the piers with a misplaced anchor plate split vertically due to column thrust, allowing the column base to kick outward (Figure C11).

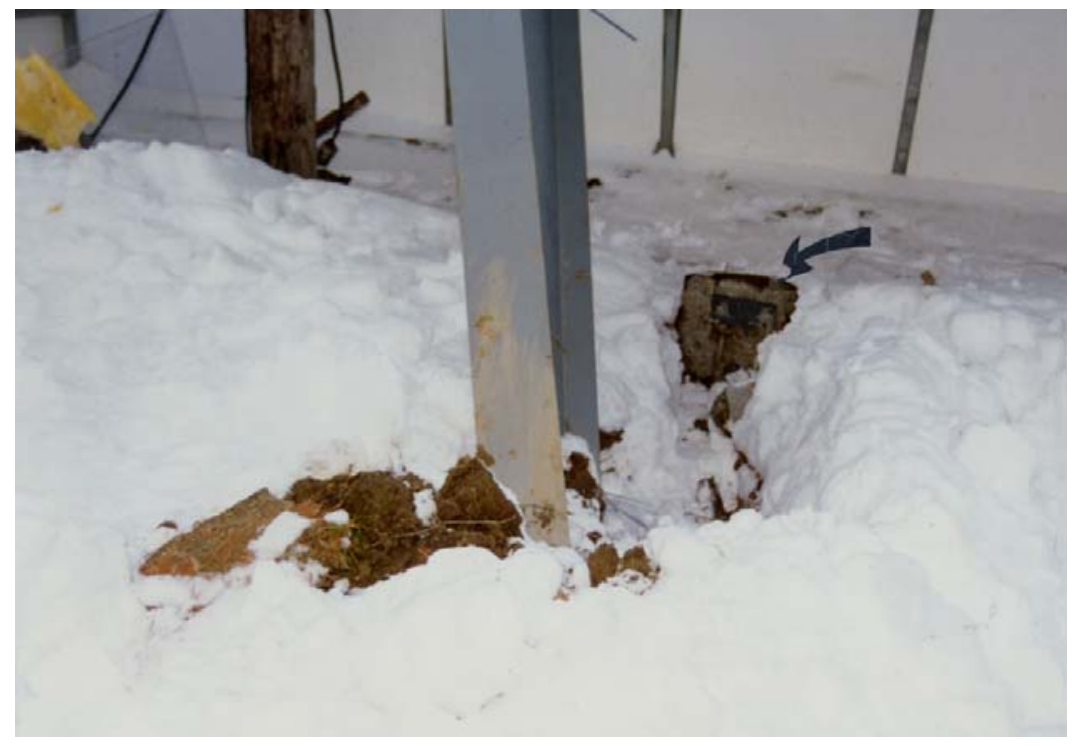

Figure C11. Split pier (arrow) at failure initiation location

Subsequent failures were from either overload as the downward pull on purlins added to stresses caused by roof snow or by lateral instability. Lateral instability was a contributor to this failure in part because the open structure required design for relatively low wind loads. As such, bracing in the direction perpendicular to the bents was relatively light, and insufficient to carry the forces from the collapsing structure.

The Jackson Landing Skating Rink failure is particularly interesting because it was a horizontal progression of failure, rather than the more common vertical progression. It calls attention to the need, when evaluating progressive collapse potential, to consider the ability of horizontal bracing to support extraordinary overloads, or for providing means to limit horizontal progression of failure in otherwise vulnerable structures by detailing connections to avoid transfer of failure loads beyond pre-defined failure-limiting locations in such structures.

\section{C.3 STRUCTURES THAT SURVIVED MAJOR DAMAGE}

This section contains case studies of events that involved very substantial initial damage to structural systems, but with the final result being relatively good performance without general collapse. These circumstances yield insight into structural features that add robustness to structures. 


\section{C.3.1 The Pentagon}

\section{C.3.1.1 Introduction}

On September 11, 2001, terrorists flew a Boeing 757 into the west face of the Pentagon (Figure C12) in Arlington, Virginia. For almost 20 minutes, the building remained standing, even though there was extensive damage from the impact. Ultimately, a relatively small portion of the damaged area collapsed, but only after sufficient time for building occupants above the impact area were able to evacuate.

\section{C.3.1.2 Description of the structure}

The structural system is cast-in-place reinforced concrete using normal-weight aggregate. Most of the structure has a specified concrete strength of 17.2 MPa (2 $500 \mathrm{psi})$ and intermediate-grade reinforcing steel (yield strength of $276 \mathrm{MPa}[40000 \mathrm{psi}]$ ). Interior column spacings typically are $3 \mathrm{~m}, 4.6 \mathrm{~m}$, and 6.1 $\mathrm{m}(10 \mathrm{ft}, 15 \mathrm{ft}$, and $20 \mathrm{ft})$ (Figure C13). At perimeter walls, column spacing typically is $3 \mathrm{~m}(10 \mathrm{ft})$. Girders span circumferentially between columns. Beams, spaced $3 \mathrm{~m}(10 \mathrm{ft})$ apart, typically span $6.1 \mathrm{~m}$ (20 ft). The slab thickness nominally is $140 \mathrm{~mm}$ (5.5 in). Nearly all columns that support more than one level are spirally reinforced. The remaining columns have ties.

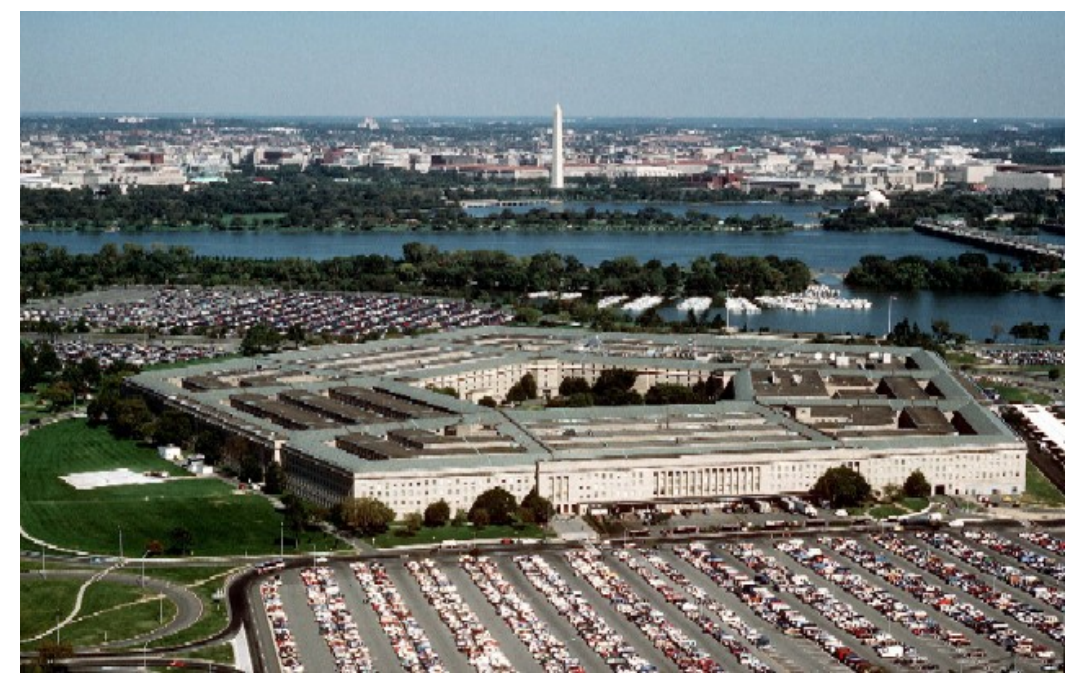

Figure C12. The Pentagon

The perimeter exterior wall of Ring E is faced in limestone and backed with unreinforced brick filled into the concrete frame.

The live load used for the original design was $7.2 \mathrm{kPa}$ (150 psf). Slabs, beams, and girders all make use of straight and trussed bars. Approximately half of the bottom bars are continuous with laps of 30 bar diameters to 40 bar diameters at the supports. Beams and girders typically have open-topped stirrups. The longer spans generally have approximately equal areas of steel at the positive and negative moment critical sections. 


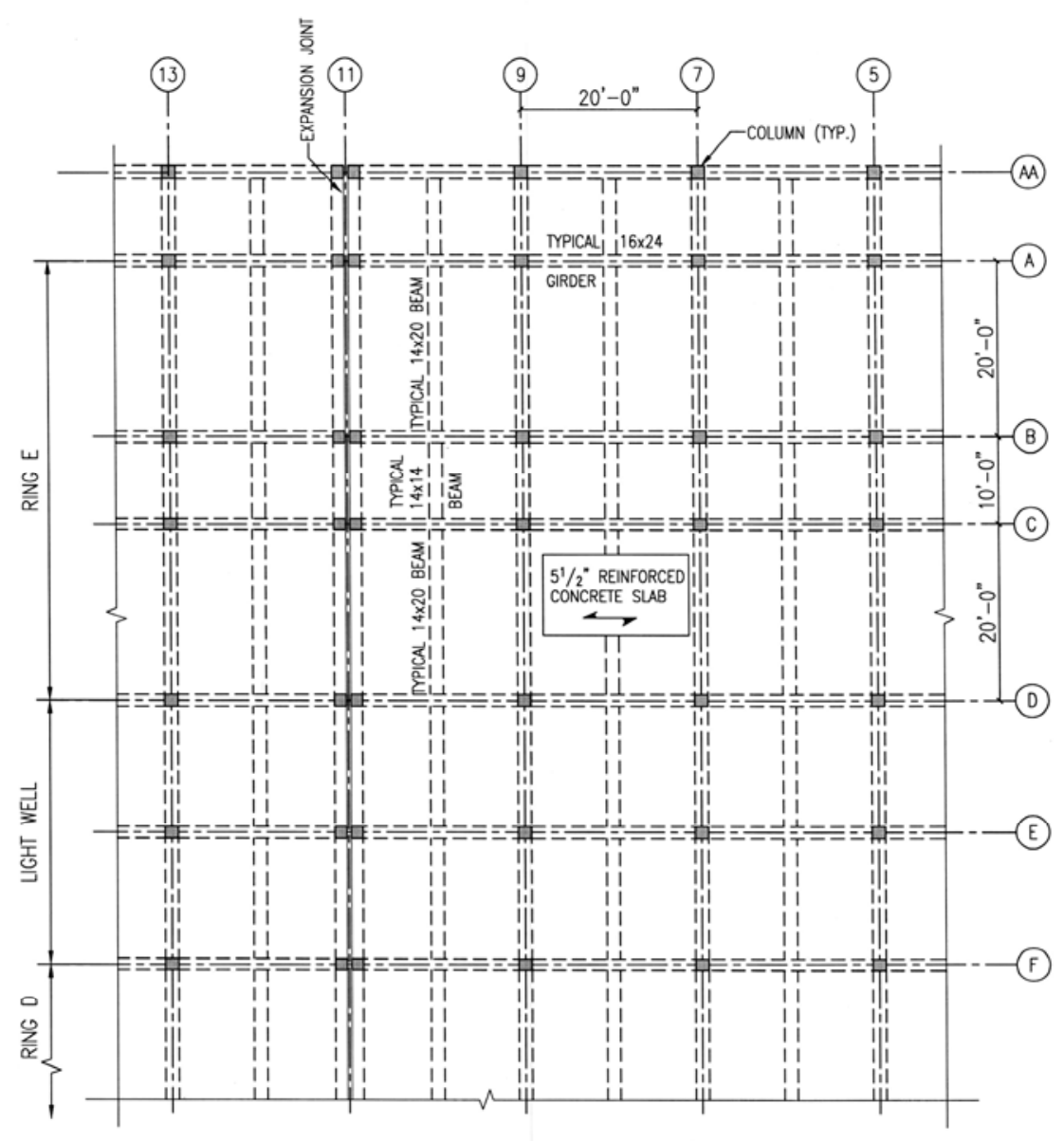

Figure C9. Typical framing arrangement

\section{C.3.1.3 The event}

The aircraft entered the first floor, flying just feet above the ground, traveling at approximately $850 \mathrm{~km} / \mathrm{h}$ (530 $\mathrm{mph}$ ). It sliced through the exterior columns and a portion of the second floor slab, and then proceeded approximately $95 \mathrm{~m}$ (310 ft or about two airplane lengths) into the building beneath the second floor slab.

None of the building collapsed immediately even though nearly 50 columns on the first floor were devastated by the impact. Although a portion of the heavily damage structure collapsed after approximately $20 \mathrm{~min}$ (Figure C14), many lives were spared because there was enough time after the impact for everyone on the third to fifth floors in the building to evacuate, even in the area immediately above the path of the aircraft. The remaining heavily damaged portion of the structure never collapsed, being able to span over areas with numerous destroyed columns.

The aircraft fuselage impacted the building at an angle of approximately 42 degrees to the normal to the face of the building, at or slightly below the second-story slab. The aircraft debris slid below the second floor slab, opening a hole in the west façade that was approximately $36.6 \mathrm{~m}$ (120 ft) wide. 


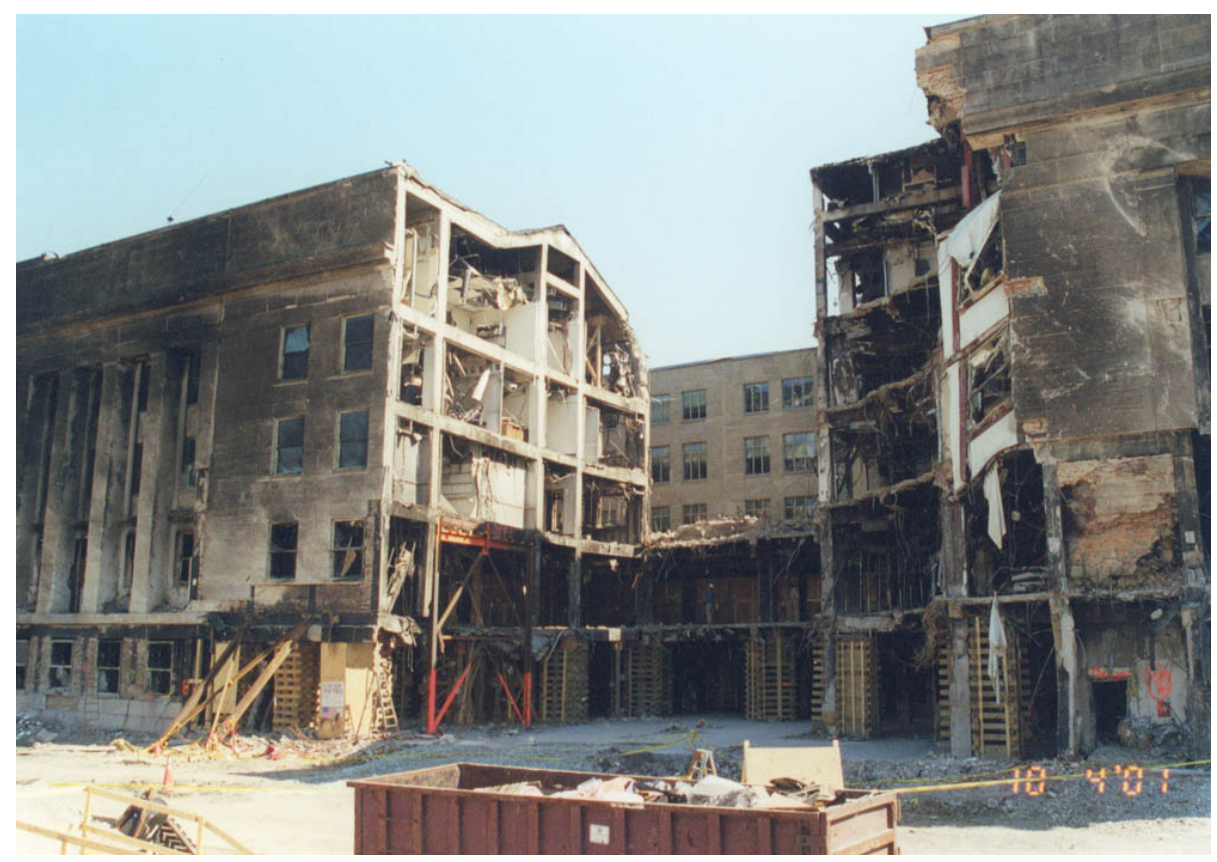

Figure C14. Collapse area after debris removal

As a general characterization of the damage to the first story, Figure C15 shows that most of the serious damage to first-story columns occurred in a trapezoidal region that extended approximately $70.1 \mathrm{~m}$ $(230 \mathrm{ft})$ into the building. Within this region, the worst damage generally was within a region represented approximately by a triangle (Figure $\mathrm{C} 15$ ) centered on the trajectory of the aircraft, with a projected base width at the aircraft entry point of approximately $27.4 \mathrm{~m}(90 \mathrm{ft})$ and a length along the aircraft path of approximately $70.1 \mathrm{~m}(230 \mathrm{ft})$.

Numerous columns were destroyed by impact. Other columns were bent with midheight displacements equal to several column diameters. However, the spirally reinforced first-story columns that remained for inspection after the incident did not fail in shear (spirals did not unravel, even in those columns that were severed at one end or the other), and vertical steel did not pull out of the concrete. In general, where columns where separated from either the slab below or the beams overhead, the vertical steel was necked, indicating that the steel had been pulled until the vertical steel broke in tension.

These two observations and the nature of the reinforcing pattern suggest that the columns responded with ductility. Had the columns been tied columns instead of spirally reinforced columns, many more columns would have been destroyed.

Although a portion of Ring E collapsed after the attack, a large segment of the building survived even though it was exposed to heavy impact and fire. That area extended deeply into the building to the north of the area that collapsed. In one zone within this area, a cluster of at least eight destroyed or heavily damaged columns represented insufficient destruction to cause progressive collapse.

The sections that remained standing, even with severe damage at the first floor level, survived primarily because the floor system was redundant (i.e., framed with two-way construction), reinforcing steel in beams and girders lapped substantially at support points (thereby creating the ability for these members to span over missing columns), and there was excess capacity in the original design. 


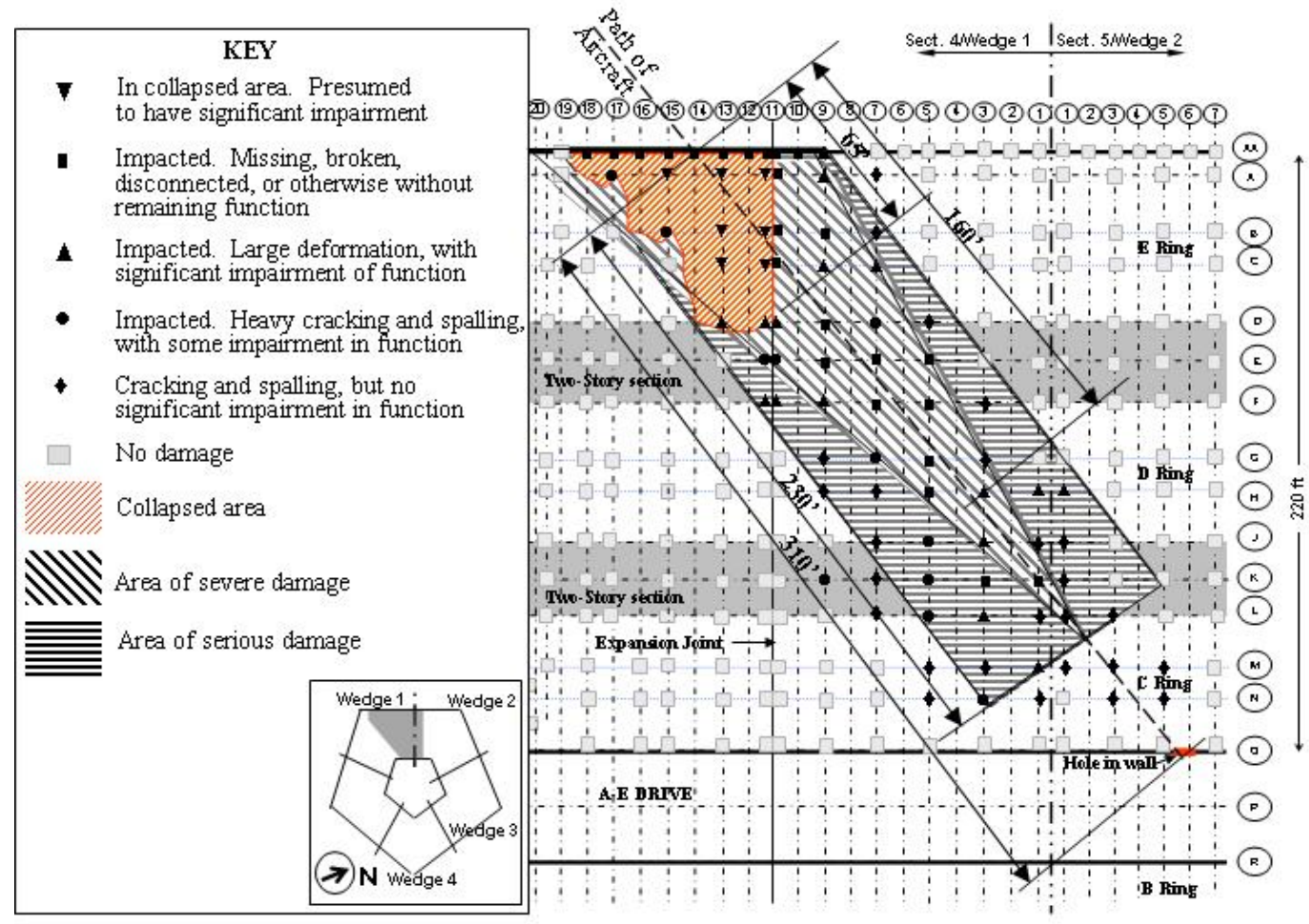

Figure C15. Damage to first story

The area that collapsed ultimately failed because impact damage removed concrete cover that otherwise would have protected reinforcing steel in beams and columns from the intense heat of the fire that followed the impact. The fire caused additional spalling and reduced the strength of the reinforcing steel in critical beams and columns to levels that could no longer sustain the high stresses imposed by the redistributed forces in remaining members near the impact point. Most probably, portions of the building also stood until occupants could vacate the upper floors because infill panels in the exterior walls acted as shear panels, allowing the walls to form multi-story beams that could span above removed columns.

\section{C.3.1.4 Progressive Collapse Issues}

Even though there was extensive column damage on the first story, the collapse of the floors above was extremely limited. This life-saving structural response was created by the following features:

- Redundant and alternate load paths of the beam and girder framing system;

- Short spans between columns;

- Substantial continuity of beam and girder bottom reinforcement through the supports:

- Design for high live load;

- Significant ductility and residual load capacity of damaged spirally reinforced columns; and

- Ability of the exterior walls to act as deep beams. 


\section{C.3.1.5 Reference}

Mlakar, Paul F., Dusenberry, Donald O., Harris, James R., Haynes, Gerald A., Phan, Long T., and Sozen, Meta A. (2003), The Pentagon Building Performance Report, American Society of Civil Engineers, Reston, Virginia.

\section{C.3.2 130 Liberty Street}

\section{C.3.2.1 Introduction}

The building at 130 Liberty Street, also known as The Bankers Trust Building or Deutsche Bank, was constructed in the early 1970s as a steel-framed structure just to the south of the World Trade Center complex in Manhattan, New York. On September 11, 2001, it was in the path of the shower of debris that fell when the twin towers of the World Trade Center collapsed. The building sustained a severe gash that destroyed significant structural framing in its north face. However, collapse did not spread, and the building remained standing.

\section{C.3.2.2 Description of the structure}

At approximately $170 \mathrm{~m}$ (560 ft) tall, 130 Liberty Street has 40 stories above grade and 2 subterranean

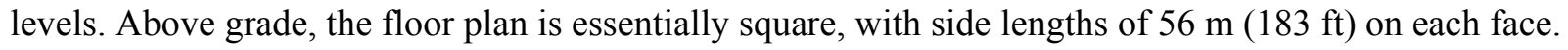
Interior framing has 8 column lines, spaced at approximately $8 \mathrm{~m}(26 \mathrm{ft})$, in each direction.

Columns are wide-flange shapes. Girders and spandrel beams are wide-flange shapes with depths up to

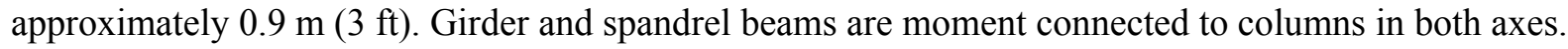

Floor beams typically are non-composite wide-flange sections ranging from W14 to W18 shapes spanning north to south between girders. Typical beam spacing is $2.6 \mathrm{~m} \mathrm{(} 8 \mathrm{ft} 8 \mathrm{in})$. Connections to girders were through end plates welded to the floor beams and bolted to the girders using ASTM A307 bolts. The floors typically are $38 \mathrm{~mm}$ (1.5 in) metal deck supporting $65 \mathrm{~mm}$ (2.5 in) lightweight concrete slabs.

\section{C.3.2.3 The event}

The collapse of the World Trade Center towers caused a vast amount of heavy debris to crash onto buildings surrounding the site. 130 Liberty Street, located just to the southeast of the south tower, was in the path of several parts of the exterior wall of the south tower. One or more of these pieces of debris plunged into the north face of this building at approximately the $23^{\text {rd }}$ floor. The momentum of this falling debris carried it deeper into the building as it sliced through spandrel beams and exterior columns between the $23^{\text {rd }}$ floor and the $9^{\text {th }}$ floor (note that " 13 " was not used for a floor number).

The product of the impact from falling debris was a deep gash that extended at some points more than $9 \mathrm{~m}$ (30 ft) into the building (Figure C16). Within this area of destruction was serious structural damage that included destroyed floor systems, removed spandrel beams over all impacted floors, and a removed exterior column between approximately the $9^{\text {th }}$ floor and the $18^{\text {th }}$ floor. 


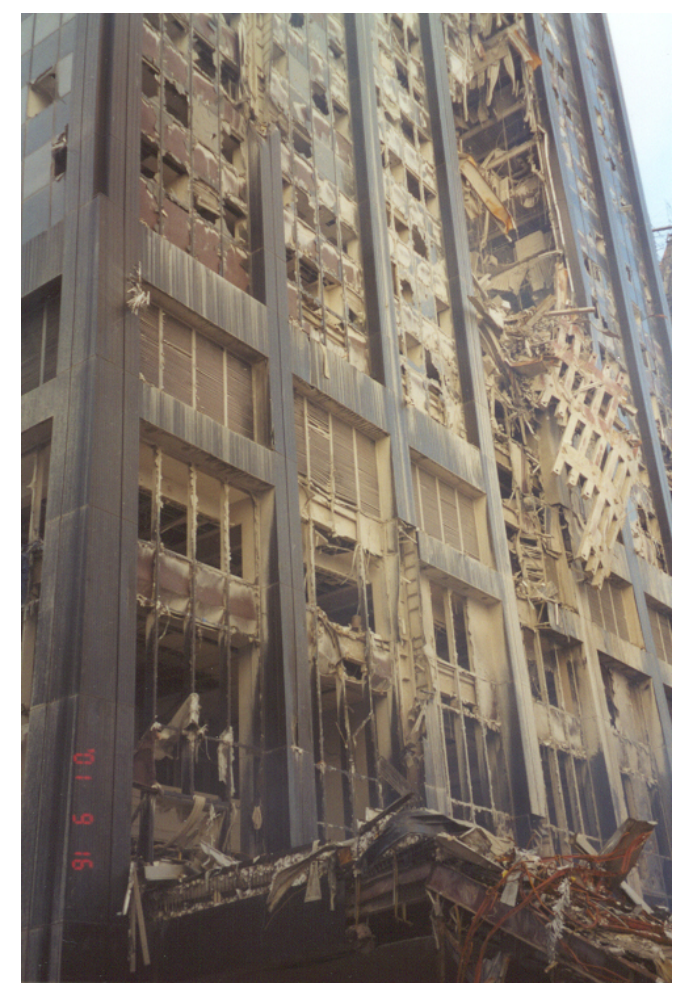

Figure C16. Gash in North Face of 130 Liberty Street

At the $8^{\text {th }}$ floor, the debris from the partial collapse came to rest in a two-story-tall pile on the floor system.

Although no authoritative account has yet been published to fully explain the performance of this building, it is evident that the framing system was able to support and redistribute the loads that originated above the area of extensive damage. Accounts of the condition of the building after the event reveal that the upper floors did not experience serious deformation even though a column had been removed from the north face of the building. Ultimately, the capacity for energy absorption in the floor system was sufficient to bring to rest the impacting parts from the adjacent tower and the accumulated debris from the floor collapses within 130 Liberty Street.

The strength of the moment frame above the damaged area was adequate to support loads from above. The strength of the floor system at the base of the damaged area was adequate to support an accumulation of debris that most probably weighed at least 5 times its dead load.

\section{C.3.2.4 Progressive collapse issues}

The building at 130 Liberty Street sustained serious damage that removed an exterior column and important horizontal framing elements for several floors. Nevertheless, collapse of the structure did not extend outside the immediate damage area, and the structural systems were sufficiently robust to bring the falling debris to rest.

The principal reason for this performance appears to be the ability of the moment frame system to redistribute vertical loads to adjacent columns that had sufficient reserve strength to accommodate the 
added loads. In addition, the floor framing systems were sufficiently robust to be able to dissipate the kinetic energy of the falling debris.

\section{C.3.2.5 Reference}

Federal Emergency Management Agency (2002), World Trade Center Building Performance Study: Data Collection, Preliminary Observations, and Recommendations, Federal Emergency Management Agency, Federal Insurance and Mitigation Administration, Washington, DC.

\section{C.4 DESIGNS TO PREVENT PROGRESSIVE COLLAPSE}

\section{C.4.1 Khobar Towers}

\section{C.4.1.1 Introduction}

Khobar Towers (Figure C17) was a complex of numerous apartment buildings in Al-Khobar near Dhahran, Saudi Arabia. On June 25, 1996, one of the apartment buildings was extensively damaged and others were seriously damaged when a massive bomb was detonated in the roadway that passed in front of the building.

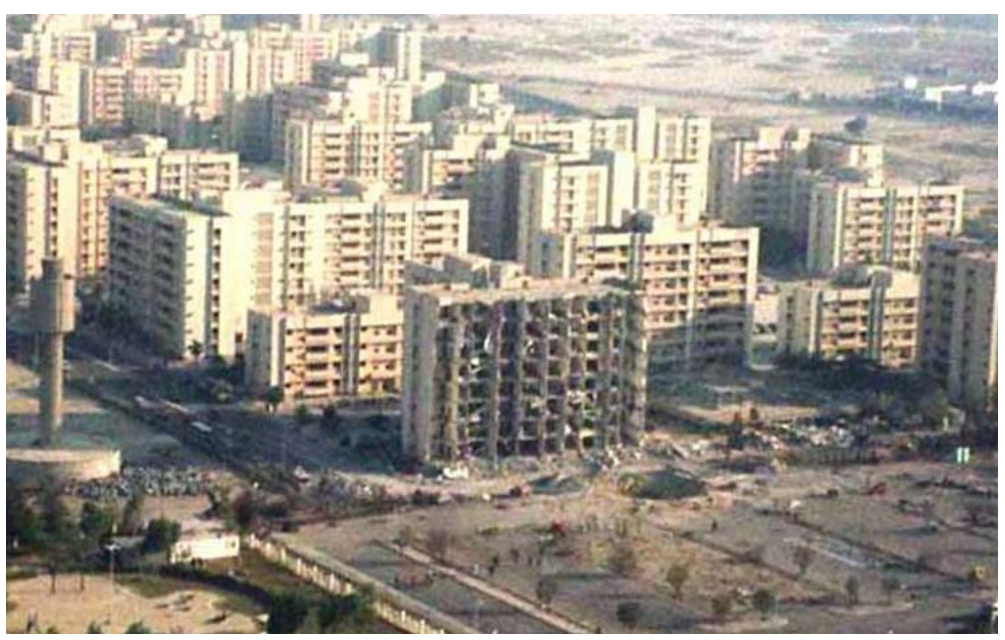

Figure C17. Khobar Towers

\section{C.4.1.2 Description of structure}

The most heavily damaged building was eight stories tall, and T-shaped in plan. It and the other apartment buildings at Khobar Towers were constructed of precast concrete wall and floor components. Hence, vertical and lateral loads were carried by wall systems.

The British concrete design code (CP-110) was used for the structural design and the detailing of connections in the Khobar Towers buildings. This code included a prescriptive approach for collapse prevention, and required ductile detailing and effective ties (indirect method discussed in Chapter 4). In the system as implemented in these buildings, the precast floor planks were cast with castellated edges, with loops of reinforcing steel extending from the plank ends into what would be the gap between adjacent plank ends (Figure C18). When adjacent planks were placed, two $11 \mathrm{~mm}(0.43 \mathrm{in})$ diameter steel 
strand (1.9 GPa [270 ksi] strength) were threaded through the overlapping loops from adjacent plank, effectively interlocking them, and the gaps were grouted. Similarly, joints between wall elements were constructed with protruding loops that were threaded with steel bars. The bars from one level to the next were connected with nuts inside connecting brackets (Figure C19).

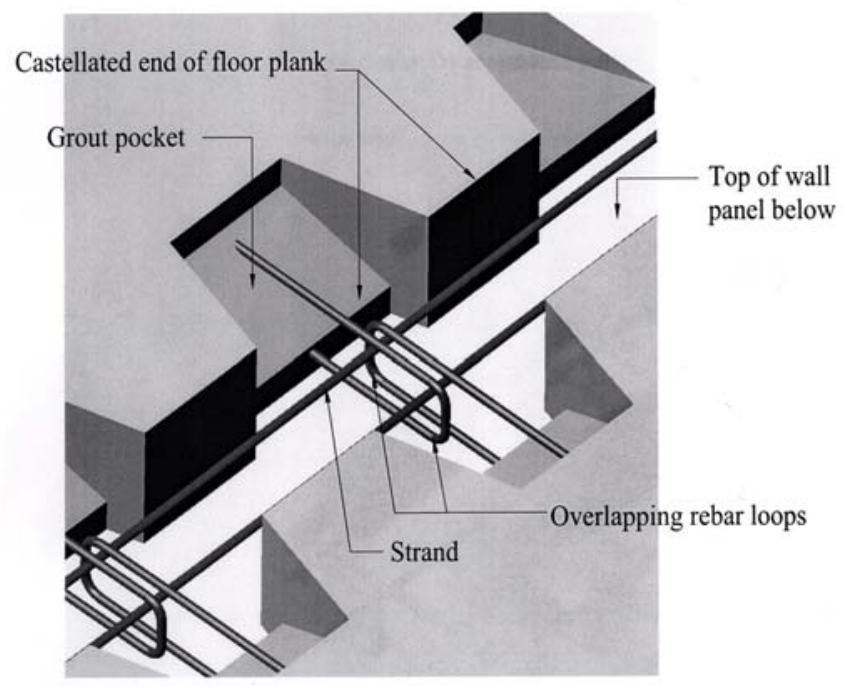

Figure C18. Typical floor plank connection

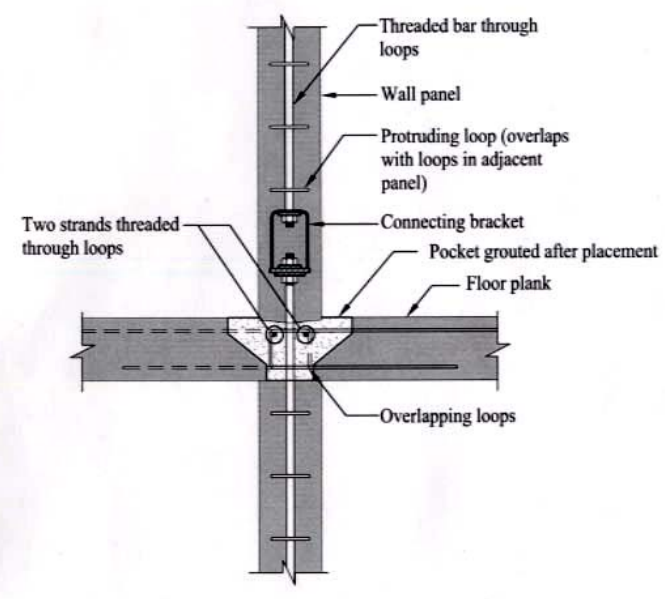

Figure C19. Connection at floor plank and wall intersection

\section{C.4.1.3 The event}

On June 25, 1996, terrorists detonated a bomb estimated at $9 \mathrm{Mg}(20000 \mathrm{lb})$ TNT equivalent, apparently placed in a tank truck parked approximately $24 \mathrm{~m}(80 \mathrm{ft})$ from one of the buildings. The explosion, which created a crater $17 \mathrm{~m}(55 \mathrm{ft})$ in diameter and $5 \mathrm{~m}$ (16 ft) deep (Figure C20), destroyed the facing façade wall of the closest building, and damaged interior floors and wall components (Figure C21). In addition, 
the explosion seriously damaged other nearby buildings, and caused widespread glass damage in the complex.

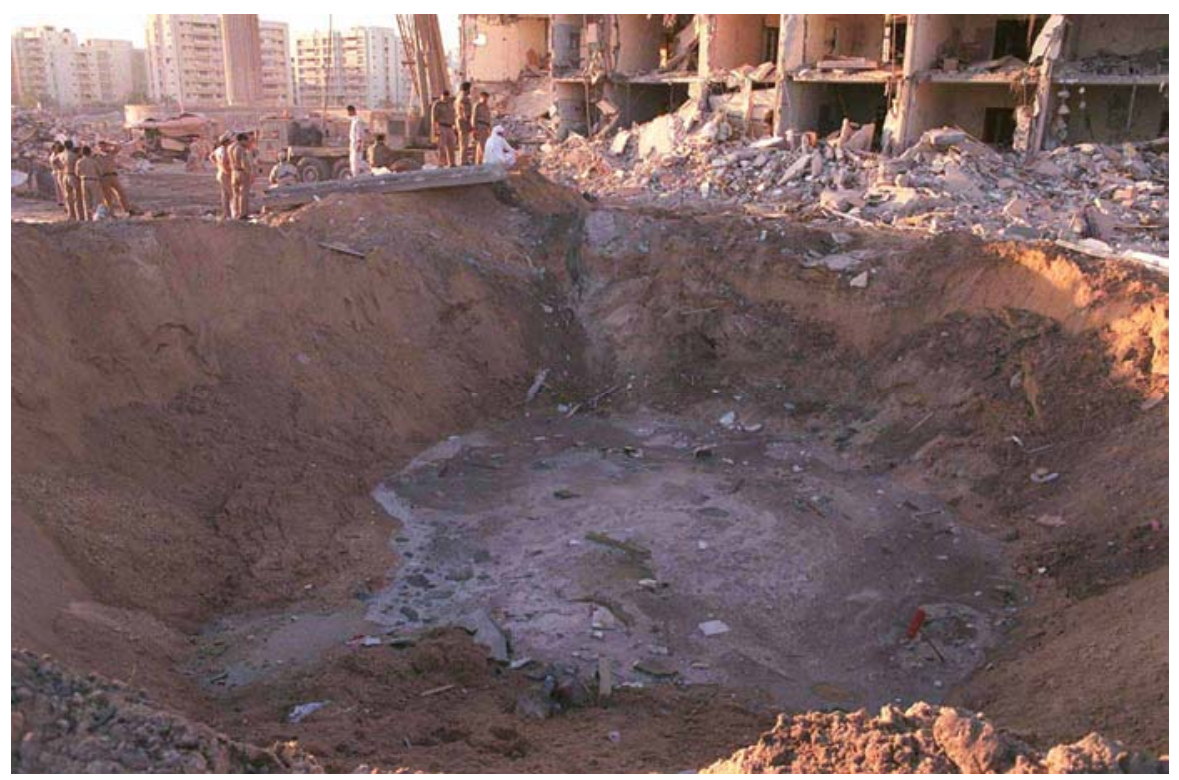

Figure C20. Crater caused by bomb (source: http://en.wikipedia.org/wiki/Khobar_Towers_bombing)

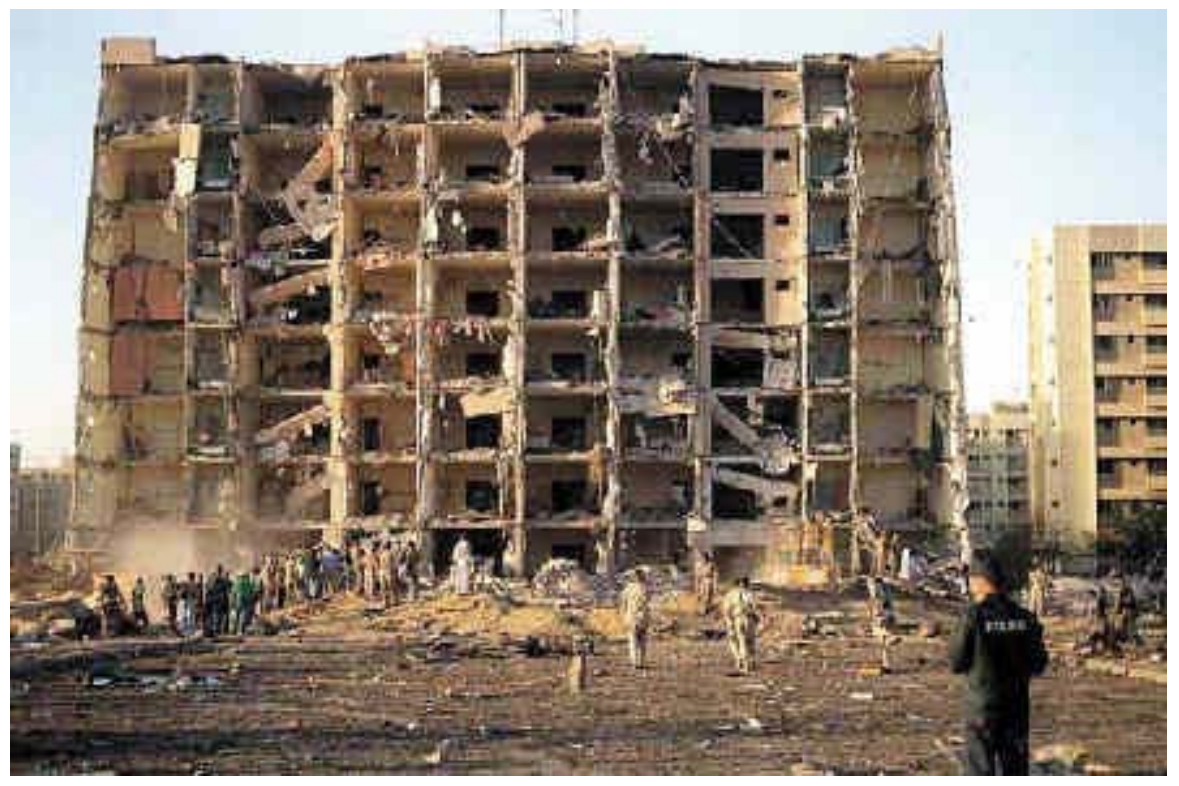

Figure C21. Side of building facing the explosion (source: http://en.wikipedia.org/wiki/Khobar_Towers_bombing)

Collapse was limited to the façade and some planks of the outer bay of the closest building. Even though the exterior shear wall for essentially the full length of the building was removed by the blast, collapse did not progress beyond areas of first damage. 


\section{C4.1.4 Progressive collapse issues}

An investigation of the damage to Khobar Towers revealed that the precast concrete system used for these buildings had sufficient ductility to resist the extraordinary assault on one of the buildings. Floor plank spanned parallel to the shear wall that was removed by the blast, limiting the damage induced by the removal of the façade wall. Even though walls parallel to the blast, and interior walls facing the blast, were extensively damaged (Figure C22 shows yield lines in interior walls), they continued to support vertical load.

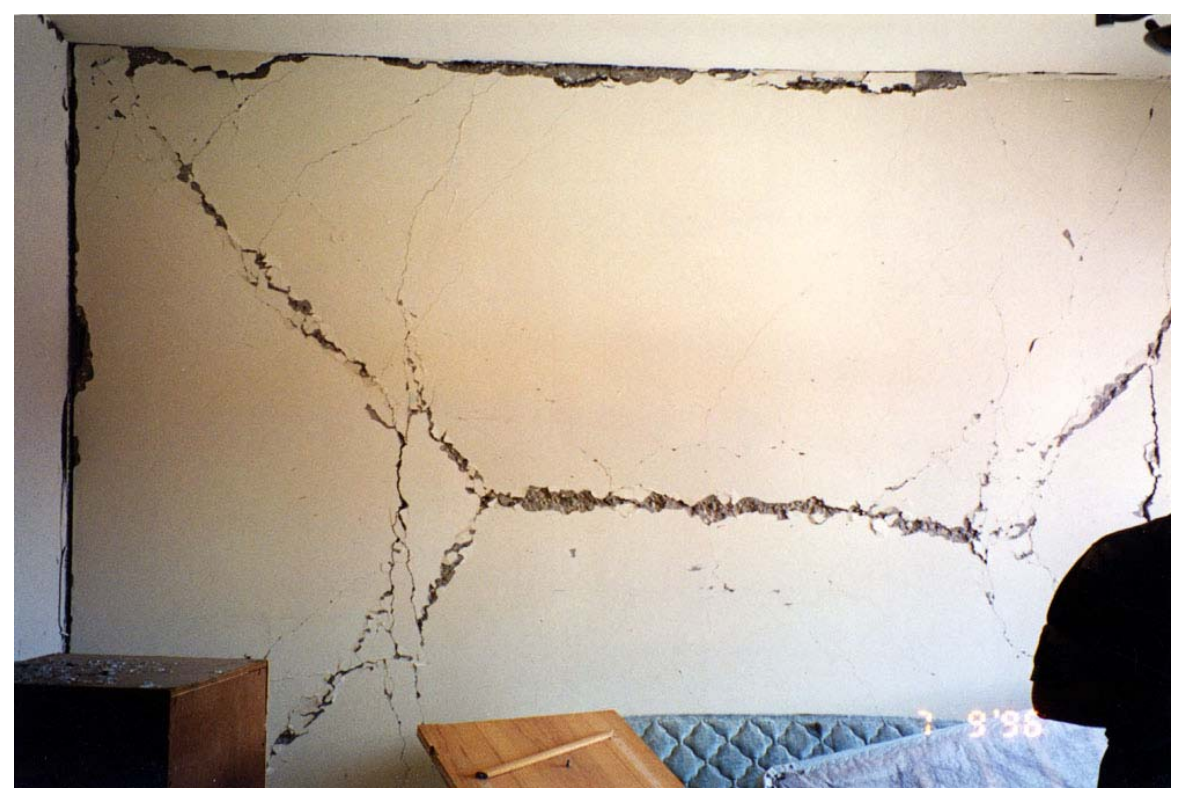

Figure C22. Interior wall exhibiting yield line damage

The precast elements themselves generally were detailed with sufficient ductility to retain integrity even after they were seriously damaged. In addition, the interlocked connections between floor plank in adjacent bays and between plank and wall elements for the most part survived the blast, resisting the potential for the building to collapse as a "house of cards."

\section{C.4.1.5 References}

Cohen, W.S., Secretary of Defense, "Report: Personal Accountability for Force Protection at Khobar Towers," July 31, 1997

Sohn, Y.G. and Park, E., "Design Report for Al-Khobar Housing,” Hyundai Engineering and Construction Co., Seoul Korea, May 1981 